\title{
Studies on the mechanism of zymogen activation in blood coagulation
}

Citation for published version (APA):

Tans, G. M. H. (1980). Studies on the mechanism of zymogen activation in blood coagulation. [Doctoral Thesis, Maastricht University]. Rijksuniversiteit Limburg. https://doi.org/10.26481/dis.19800101gt

Document status and date:

Published: 01/01/1980

DOI:

10.26481/dis.19800101gt

Document Version:

Publisher's PDF, also known as Version of record

\section{Please check the document version of this publication:}

- A submitted manuscript is the version of the article upon submission and before peer-review. There can be important differences between the submitted version and the official published version of record.

People interested in the research are advised to contact the author for the final version of the publication, or visit the DOI to the publisher's website.

- The final author version and the galley proof are versions of the publication after peer review.

- The final published version features the final layout of the paper including the volume, issue and page numbers.

Link to publication

\footnotetext{
General rights rights.

- You may freely distribute the URL identifying the publication in the public portal. please follow below link for the End User Agreement:

www.umlib.nl/taverne-license

Take down policy

If you believe that this document breaches copyright please contact us at:

repository@maastrichtuniversity.nl

providing details and we will investigate your claim.
}

Copyright and moral rights for the publications made accessible in the public portal are retained by the authors and/or other copyright owners and it is a condition of accessing publications that users recognise and abide by the legal requirements associated with these

- Users may download and print one copy of any publication from the public portal for the purpose of private study or research.

- You may not further distribute the material or use it for any profit-making activity or commercial gain

If the publication is distributed under the terms of Article $25 \mathrm{fa}$ of the Dutch Copyright Act, indicated by the "Taverne" license above, 
Mromotor Frof. Dr. H.C. Hemker

Copromator Prof. Dr. R.F.A. Zwaal

Referenten Dr. J.H. Griffin

Prof. Dr. L.L.M. van Deenen

Exof. Dr. H.S.B. Struyker-Boudier

In this thesis work is presented that has been done in close cooperation with: Jan Rosing, Gerbrand van Dieyen, Coen Hemker, Rob Zwaal, Henk van Zutphen, Paul Confurius, Jose Govers-Riemslag and last but certainly not least Truus Janssen-claessen.

The manuscript was typed by Mrs. Helene Vermeer and Mrs. Barbara Geexs. 
Aan Geja en Bram voor

al dile gemiste uren. 

Murphy's Law:

If anything can go wrong it will

Sharon, T.M. (1979) J.I.R. 25, 23

'From now on I"m thinking only of me"

Majox Danby replied indulgently with a

superior smile: "But, Yossarian suppose

everyone felt that way'.

"Then', sald Yossarian, "I'd certainly be a damned fool to feel any other way.

wouldn't I : ?'

J. Heller Catch 22

Sturgeon "s Revelation:

$90 \%$ of everything is crud

Sharon, T.M. (1979) J.I.R. 25, 23 
CONITES

Chapter 1. Introduation T

Chapter 2. witerature 13

2.1 Prothrombtis Atetuation 13

2.2 Fator X Activation 16

2.2 .1 the Intwingic Fator $x$ Activator 17

2.2.2 The Extrute Factor X Aativator 19

2.3 Phopholipid Invotwent in BLood Coagulation 20

Chapter 3. Lipta phase Tansitions and Procoagulant Aativity 29

chapter 4. The Rote of phospholipids and Faotor $V_{a}$ in the 39

Prothombirase Complex

Chapter 5. The Rote of Phospholipid and Factor VII in the 51 Activation of sonine feretor $X$

Chapter 6. The Aotivation of Factor IX by Faotor XI

Active Site Titration and Development of a

Speatrophotometric Ascay

Chapter 7. Determination of the Binding Conetant of Pactor $x$ Binding to thospholipid Vestates

Chapter B. General Disausion

Summary

Samenvatting 
CHAQTER $\mathbb{1}$

INT RODUCTION

Most people take it for granted that bleeding from a wound stops within a few minutes. However, history has provided us with some famous examples, like the Russian czar family, that this canrot be taken for granted at all.

The events responsible for the arrest of bleeding from a wound are called the haemostatic mechanism. Actually, thrombosis which can be regarded as a positive overshoot of the haemostatic mechanism is of much more medical importance than bleeding tendencies are. Bleeding disorders and thrombotic disorders together account for well over half of all deaths in western society. The importance of research on the haemostatic mechanism can therefore hardly be exaggerated.

Haemostasis is the result of a complex series of physlological and chemical events taking place in the blood. The history of research in this field dates back some 150 years. In 1835 Buchanan showed that the formation of the fibrin clot is caused by an enzyme demonstrable in the clot (1). Later work a.o. of Schmidt and Peeckelharing was adequately summarised by Morawitz (1910) in the formulation of the four factor hypothesis of coagulation. He postulated that the formation of a fibrin clot was the result of the interaction of four factors: prothrombin, flbrinogen, calclum lons and thromboplastin (2). It was thought that thromboplastin and calcium ions were necessary for the conversion of prothrombin into thrombin and that thrombin converted fibrinagen into fibrin.

Nowadays, it is known that coagulation is a much more complleated process. Blood coagulation is taken care of by proteins, called clotting factors, which are present in the blood. In a way this is an advantage because they are ready at hand when needed. However, it is clear that some means must exist to avold blood clotting when not necessary. This is achieved by the fact that the clotting factors are present in the blood in a form without emzymatic activity (zymogen form). Coagulation thus results from the activation of these clotting factors.

Based on reactions and interactions between clotting factors known at that time Macfariane (3) and Davie and Ratnoff (4) in 1964 independently put forward the so-called cascade mechanism for blood coagulation. A simplified representation of the blood coagulation 


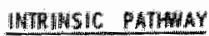

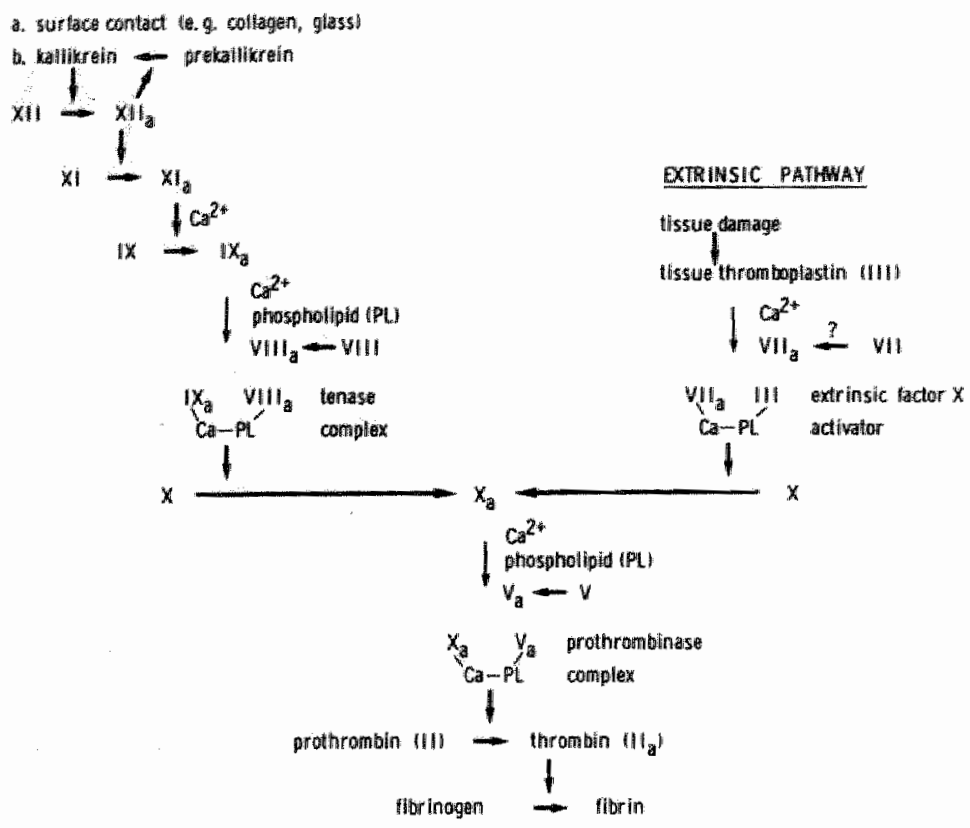

Wig. 1. Simplified representation of the blood coagulation cascade Activated cloteing factors are denoted by the subscript a. Note the simiarity between the complexes in what phospholipid is involved: the lntrinsic factor $x$ activator, the extinsic factor $x$ activator ard the prothrombinase complex. Taken from ref. 12 .

cascade as it is nowadays understood 1 s presented in Fig. 1 .

Coagulation can be inltiated in a number of ways. Depending upon intiation two different chains of evente occur, i.e. the so-called intrinsic and extrinste pathway of coagulation. Both pathways proceed via a series of consecutive actlvations of clotting factors present in the blood. Both the intinsic and extrinsic pathway result in the activation of the zymogen factor $x$ to the active form factor $x$. ractor $x_{\text {a }}$ is the enzyme which together with factor $v$, phospholipid and caleium ions activates prothrombin to thrombin. mhombin converts fibrinogen to fibrin and the fibrin network is formed.

A number of advantages for such an enzyme cascade can be recognised. First, the cascade mechanism has considerable potential for amplification. Only a small trigger signal is requixed to give an explosive burst of thrombin formation. For example a few molecules of 
activated factor XII, resulting from the trigger", can activate hundreds of factor XI zymogens which in turn can activate some ten thousand factor IX zymogens. The plasma concentrations of the coagulation factors increase along the cascade (5) so efficient amplification can be achieved. A second advantage is the abundant number of possibilities for control. There is a number of positive and negative feedback control steps. For example in contact activation there is considerable amplification by the fact that factor XII can activate prekallikrein to kallikrein which in turn can activate the factor XII zymogen (6). A second example of a positive feedback mechanism is the activation of factors $V$ and VIII by trace amounts of thrombin (for reviews see ref. 7,8). The activated clotting factors $V_{a}$ and VIII, which are devoid of enzymatic activity, strongly enhance the rate of activation of respectively prothrombin and factor $X$. A possible negative feedback control mechanism is the inactivation of both factors $v_{a}$ and VIII by larger amounts of thrombin $(7,9)$. Another example of negative control is the inactivation of various activated clotting factors by inhibitors present in the blood, e.g. antithrombin III and $\alpha_{2}$-macroglobulin. Finally, biological control is exerted by the liver which rapidly removes activated clotting factors (rather than zymogens) from the circulation (10).

All enzymes participating in the coagulation cascade belong to the class of serine proteases. Factors $I X_{a}, X_{a}$ and thrombin show constderable homology with the pancreatic serine proteases trypsin and chymotrypsin suggesting a common ancestry and comparable function. Trypsin and chymotrypsin are also enzymes which are normally present in the zymoger form and have to be activated by limited proteolysis. For an excellent book on the relationshlp between enzyme structure. molecular mechanism and kinetics of pancreatic serine proteases the reader is referred to ref. 11. Since clotting factors are homologous to these enzymes it is expected that their structure and the reactions in which they are involved will show a high degree of similarity with the reactions catalysed by trypsin and chymotrypsin (see ref. 9)

Blood coagulation is only a part of the haemostatic mechanism. Over the past 75 years trirough clinical, physiological and blochemical research a picture of this mechanism has emerged which shows that vessel wall, thrombocytes and plasma clotting factors cooperate in a complex way to achleve haemostasis. The haemostatic mechanism as a 
whole is sill not fully understook and at regular intervals new aspects are reported which have to be included in the overall picture.

At the risk of oversimplification it can be outlined as follows. When a leston occurs in the ressel wall, either by injury or by the development of an atherosclerotic plaque, blood platelets adhere a1most Immedately to the subendothelial structure which has become exposed. The achered platelets release substances which stimulate the aggregation of other platelets. At the same tume the blood coagulation cascade is triggered. The thrombin formed has two major functions. It strongly activates platelets resulting in the formation of platelet aggregates and tt converts fibrinogen into fibrin. The fibrin netwoxk resulting from the clotting stabilises the platelet plug. Thls completes the haemostatic process leading to a permanent arrest of bleeding.

The two processes, the formation of the platelet pling and the flbrin clot are closely interrelated at many stages. For example the platelets provide the phospholipid surface necessary in some reactions in the clotting cascade. The work presented in this thesis concerns the interactions of phospholipid and coagulation factors. Its purpose is to study in detall one of the parts of the hamostatic process in the hope that eventually enough of the completeprocess will be known to enable adequate intervention in hyper- and hypocoagulant alseased states

The reactions that we investlgated show a peruliar feature which has not bean discussed yet. It was already mentioned that clotting factors are in mamy aspect similar to the panoreatic serine proteases. Howewer, activation of clotting factors is in general more complex than the activation of the zymogens from the pancreatic system. In many reactions of the coagulation cascade clotting factors are not activated by single enzymes, but by complexes in which the action of the enzyme on the substrate is stimulated by other components (cf. Fig. 1). Phospholipids participate in number of these so-called mult-component enzyme systems. These are prothrombin activation and factor $X$ activation both via the extrinsio and intrinsic pathway. The enzyme complexes in these three reactions have a similar composition. Apart from the enzyme, necessary to activate the substrate, they consist of calcium ions, phospholipid and a protein co-factor. The function of these accessory components in these complexes appears also allke. In prothrombin and factor $\mathrm{x}$ activation the rate of acti- 
wation by the enzyme is enormously stimulated by the presence of calcium ions, phospholipid and the accessory protein. The mechanism via which these rate enhancements occur is still not fully understood. In chapter 2 further background information is given pertinent to the understanding of these reactions.

Phospholipid bilayers must fulfill a number of requirements in ordex to have a stimulatory effect in these reactions. The physical properties rather than the chemical properties of the phospholipid bilayer are important in this aspect. It is well established that the phospholipid bilayer must have a net negative charge in order to stimulate coagulation. Chapter 3 deals with the question whether phospholipld bilayers in the liquid crystalline phase show a different procoagulant activity than phospholipid bilayers in the solid gel phase.

Coagulation is a process which is tured to produce an explosive burst of thrombin formation when needed. Control of this process is provided by a number of positive and negative feedback loops. To be able to appreciate the contribution of the different reactions to the overall reaction it is of vital importance to investigate the kinetics of the reactions involved. When the kinetic parameters of all the reactions of the clotting cascade are known it will be possible to evaluate their relatiwe importance to clot formation in vivo. Quantitative study of these reactions has only become possible in the last few years with the elaboration of purification methods of the proteins involved and has been enormously facilitated by the appearance of a number of good chromogenic substrates for activated clotting factors. Chapter 4 is completely devoted to a kinetic analysis of prothrombin activation by factor $x_{a}$ and to the effect of calcium lons, phospholipia and factor $\mathrm{v}$ on the kinetic parameters of prothrombin activation. Chapter 5 deals with a comparable kinetic analysis of factor $x$ activation by factor $I_{a}$ in the presence and/or absence of calclum lons, phospholipid and factor VIII

In order to be able to quantitate reaction rates it is necessary that the amounts of enzyme, substrate and product can be expressed on a molax basis. For factor $x_{a}$, thrombin, factor $X$ and prothrombin this is readily possible. In chapter 6 it is shown that factor IX a can be quantitated on a molar basis by active site titration of the enzyme with $\mathrm{p}$-nitropheny $1-\mathrm{p}^{\prime}$-guanidinobenzoate ( $\mathrm{P}$-NPGB).

The data presented in chapters 3,4 and 5 ald concern the role of phospholipid in coagulation. The reactions involved are thought to 
take place on the surface provided by the phospholipids. However. exact binding paraneters of the protein-phospholipid complexes under our circumstances are not known. In chapter 7 , a simple and rapid method for the measurement of binding of factor $x$ to the phospholipid surface 13 presented which may help to establish how the phospholipid surface mediates factor $X$ activation.

The effects of accessory components on the kinetic parameters of prothrombin and factor $X$ activation reported in chapters 4 anci 5 have consequences for their mode of action in the zymogen activation. A general discussion on the role of phosphollpid and factor $W_{a}$ and factor VIII in the mechanism of activation of prothrombin and factor $x$ is presented in chapter 8 .

\section{REPEREACES}

1. Buchanan, A. (1835) Med.Gaz, 18, 50

2. Morawitz, P. (1905) Ergebnisse der Physiologie Biologisohen chemie und experimentat pharmakologie 4, 307

3. Macfarlame, R.G. (1964) Hature (London) 202, 498-499

4. Davie, E.D. and RatnofE, O.D. (1964) Soience. $145,11310-1312$

5. Davie, E.W. and Kirby, E.P. (1973) In Current Topics in Cell Regulation (Honecker, B.L. and stadtman, E.R.., Eds.) Vol. 7 . 51-86, Acad.Press, New York

6. Griffin, J.H. and Cochrane, C.G. (1979) In Seminars in Thrombosis and Haemostasis. Wol. $V$, No. 4, p. 254-273

7. Davie, E.W. anc Eujikawa, K. (1975) Ann.Rev. Bloohem. 44,799-829

8. Davie, E.W., Fujtkawa, K., Kurachi, K. and Kisiel, W. (1979) Adv. Ensmot. 48, 277-318

9. Sliverberg, S.A. and Nemeson, $X$. (1975) Biochemistry 14, 26362644

10. Deykin, D., Cochlor, E., De Camp, G. and Lopez, A. (1968) A

11. Fersht, A. (1977) Enzymes, Structure and Mechanism. W.H.Freeman and Company Ltd., Reading and San Franclsco

12. Zwa 1. R.r.A. (1978) Btoohim. Btophys.Acta 515,163-205 
CHAPTER 2

LITERATURE

It is quite a hopeless task to try and give an extensive review of the literature on coagulation. The work presented in this thesis will contribute to the present understanding of pxothrombin activation, factor $x$ activation via the intrinsic pathway and, by extension, extrinsic factor $X$ activation. Therefore, I will restrict myselfy to the literature pertinent to the understanding of these reactions. This chapter is divided into paragraphs dealing with:

2.1: prothrombin activation by the prothrombinase complex (i.e. factor $\mathrm{x}_{\mathrm{a}}$, factor $\mathrm{V}_{\mathrm{a}}$, $\mathrm{Ca}^{2+}$ and phospholipid)

2.2: factor $X$ activation both by the intrinsic factor $X$ activator (i..e. factor IX ${ }$, factor VIII, $\mathrm{Ca}^{2+}$ and phospholipia) and by the extrinsic factor $x$ activator (1.e. factor VII $\mathrm{C} \mathrm{Ca}^{2+}$ and tissue thromboplastin)

2.3: phospholipid involvement in blood coagulation. For reviews on coagulation, the reader is referred to references $1-3$. for a review on phospholipid involvement in coagulation to reference 4, and for reviews on phospholiplds and phospholipid phase transitions to references 5 and 6 .

\subsection{Prothrombin aotivation}

The activation of prothrombin provides the best documented example of zymogen activation in blood coagulation. Bovine prothrombin ( $F i g$. 1) is a giycoprotein of $72,000 \mathrm{M}$.W. containing 11 \% carbohydrate (N.B. human prothrombin alffers from bovine prothrombin only in minor detalls). Bovine prothrombin consists of one single polypeptide backbone of 582 amino acid resldues. It is one of the so-called vitamin K dependent clotting factors (1ike factors $X$, VII, IX, and protejn $C$. These factors possess a number of unusual amino acta residues 1. e. $\gamma$-carboxyglutamic acid, which provides $c a^{2+}-$ binding sites. Prothrombin is the zymogen which can be activated to thrombin through limited proteolysis. Several proteolytic enzymes can bring about this activation but under physiological conditions the serine protease factor $x_{a}$ is the activating enzyme.

In the past 25 years many papers appeared in the l1texature describing the detection and isolation of partial proteolysis products of prothtombin activation (for a review see ref. 3). This finally resulted in a series of excellent papers by the group of Jackson (7-12) which 


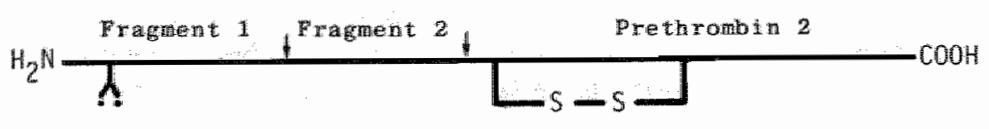

A y-carboxylutamic acid

E.j. 1. Schematic representation of the prothrombin molecule

Fagment 1 th the region which contains the 10 y-carboxyglutamic acid residus. Pragment 2 presumably has bindirg places for factor v. Frethrombin 2 is the fmodiate predursar of thrombin.

completed the description of the sites of peptide-bond splitting and order of bond cleavage during prothrombin activation. The activation of prothrombin into thrombin by factor $x_{a}$ is thought to result from the two-step mechanism as depicted in Fig. 2 .

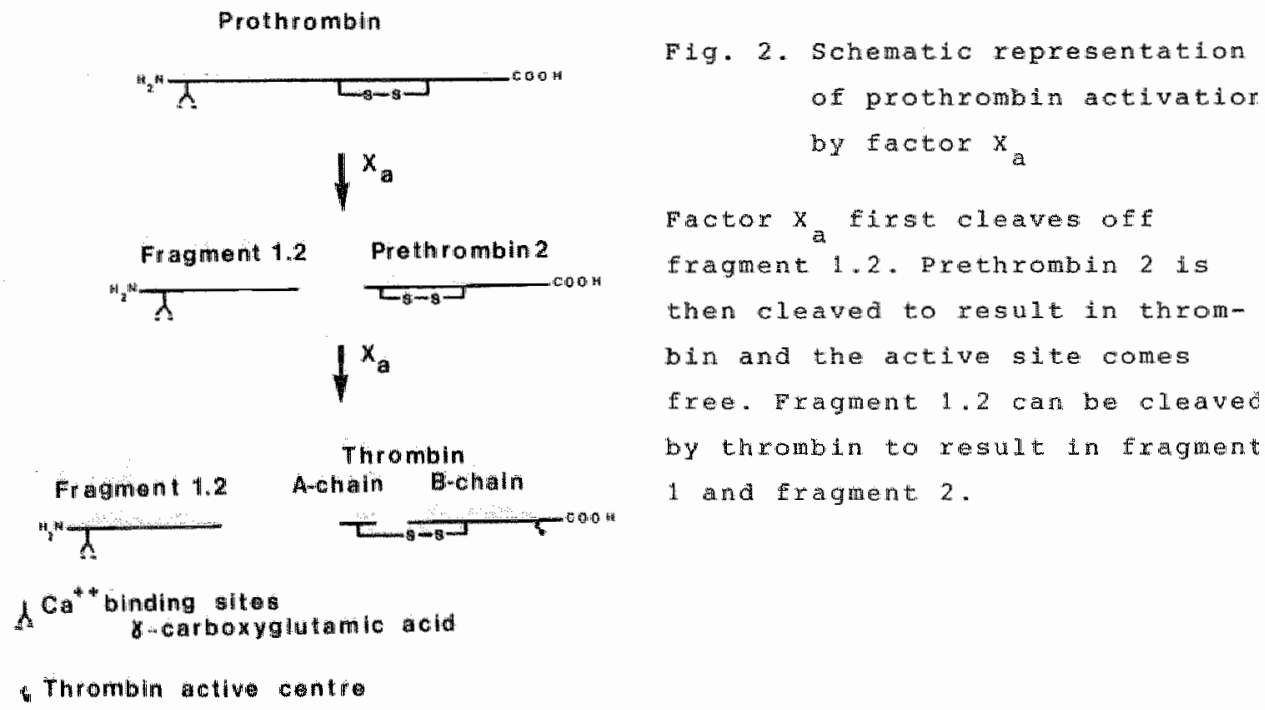

The firgt step is the cleavage of an arginine-threonine peptide bond resulting in an activation peptide (fragment 1.2) and an intermediate (prethrombin 2). Thrombin actirity appears after the cleavage of an arginine-isoleucine bond in this intermediate. Thrombin is a twochain molecule held together by a disulfide bridge. The light chain contains 49 amino acid residues. The active site is located in the 
heavy chain, which contains 259 amino acid residues.

Athough this activation mechanism is the most plausible it must be emphasized that there are examples of other mechanisms. First, prothrombin can be activated by the formation of a one-to-ome complex with staphylocoagulase, an exoprotein produced by certain strains of Staphylococcus aureus (13). Without the occurrence of peptide bond cleavage, staphylocoagulase presumably alters the conformation of prothrombin resulting in the formation of an active centre which is comparable to that of thrombin (13) but for its action on platelets and the factors $V$ and VIII. Secondly, the occurrence of an intermediate (i.e. melzothrombin) has been reported in the activation of an abnormal prothrombin (14). Meizothrombin results from prothrombin by the cleavage of the peptide bond in the prethrombin 2 region and has proteolytic activity. This intermediate also occurs when prothrombin is activated by an enzyme from Echis Carinatus (15). Thus, the order of bond cleavage in prothrombin activation by factor $\mathrm{x}_{\mathrm{a}}$ may not be compulsory.

In vitro, the prothrombin molecule can be cleaved by thrombin resulting in fragment 1 and prethrombin 1 . Thrombin can also split fragment 1.2 into fragments 1 and 2 . The possible regulatory function of this feedback reaction 1 , however, doubtful since it has been reported that this cleavage does not occur in whole blood (16).

It has been show (see ref. 3) that additional components are essential for prothrombin activation during blood coagulation. It is now generally accepted that $\mathrm{Ca}^{2+}$, phospholipid and factor $\mathrm{V}_{\mathrm{a}}$ are required for prothrombin activation undex physiological conditions. The factors $x_{a}$, $V_{a}$ and prothrombin have to be adsorbed on the phospholipid surface in order to acquire efficient interaction see ref. 3). Both prothrombin and factor $x_{a}$ bind to the phosphollpla surface via calcium bridges between the $\gamma$-carboxyglutamic acid residues present in these proteins and polar head groups of the phospholipid molecules $(17,18)$, whlle hydrophobic interactions presumably play an important role in the binding of factor $v_{a}(19,20)$. Thus the complex can be deplcted as shown in Fig. 3 .

It is well established that $\mathrm{Ca}^{2+}$ " phospholipid and factor $V_{\text {a }}$ function as co-factors of the enzyme $x_{a}$ bringing about a considerable enhancement of the relative rates of prothrombin activation $(12,21)$. Not much is known, however, about the mechanism responsible for the enhancement of the rate of prothrombir activation by factor $\mathrm{v}_{a}$ and 
phospholipla. Esmon and Jackson did not find evidence for a change sites and order of bond cleavage when the prothromin molecule is activated by different comblnations of the components of the prothrombinase complex (10).

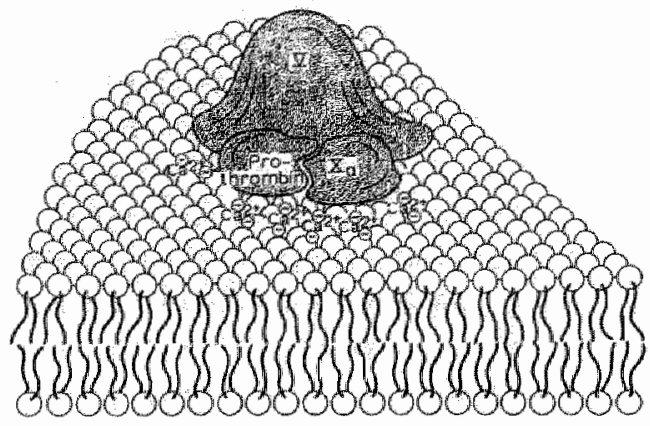

Fig. 3. Schematic model for th prothrombinaseprothrombin complex (Taken from reE.4).

\section{2 Fator Xativation}

Bovine factor $X$ (see Fig. 4) is a glycoprotein of MW 55,000, contai: Ing 10 s carbohydrate, which is composed of a light and a heavy chai held together by a disulfide bridge (again the human material is hardly different). The light chain contains 140 amino acid residues 12 of which are y-carboxyglutamic acid residues (22). The heavy cha consists of 307 amino acid residues and contains the active centre which is exposed upon splitting an arginyl-isoleucine bond, thus releasing an activation peptide containing 51 amino acid residues from the heavy chain $\mathbb{N}$-terminal $(23,24)$.

Upon purtfleation two different forms of factor $x$, called factor $x_{1}$ and factor $x_{2}$, are found which differ 1 in elution patterm on DEAESephadex A-50 (25). Up till today, however, no other differences betwen these two forms have been reported.

Factor $x$ can be activated both via the extrinsic and intrinsic pathway. It can also be activated by a protease from Russell"s viper venom and by trypsin. All these activations occur through the cleavage of the same peptide bond resulting in the so-called afactor $\mathrm{x}_{\mathrm{a}}(26)$. There are several feedback reactions which may hamper a quantrtative study of factor $x$ activation. Jesty et al. $(27,28)$ have shown that factor $x_{a}$ can autocatalytically cleave a small peptlde from the carboxy terminal end of the heavy chain of the zymogen resulting in the so-called Bfactor $X$ (see Fig. 4). 


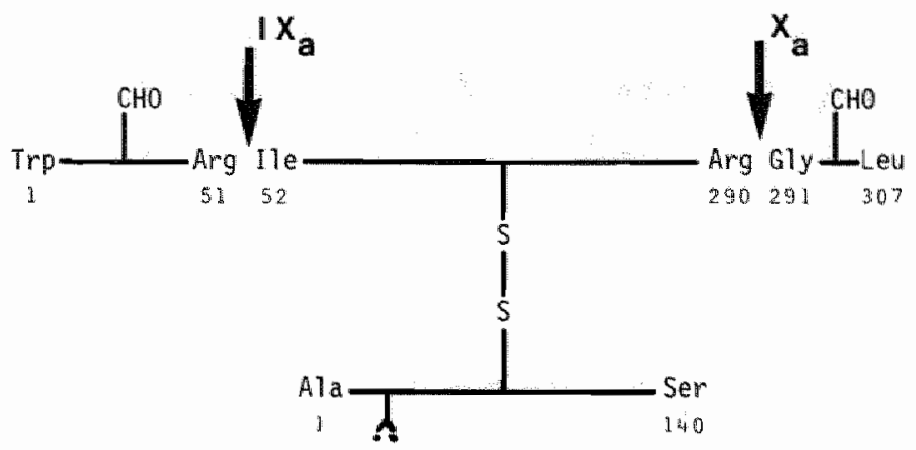

LY-carboxyglutamic acid residues

CHO carbohydrate

Fig. 4. Schematic representation of the bovine factor $x$ molecule The 1 ight chain contains 12 r-carboxyglut mic acid residues. Factor $x$ activation by factor Ix results from the cleavage of the arginineisoleucine bond as indicated. Factor $X$ activation is also achieved by cleavage of this bond by factor VII, RVV-x or trypsin. Factor $x$ can be split by factor $x_{a}$ at the arginine-glycine peptide bond as indicated in the figure to result in $\beta$ factor $x$.

Also factor $x_{a}$ can convert the zymogen into the actlve form by cleavage of the same arginyl-isoleucine bond. These reactions both require $\mathrm{Ca}^{2+}$ and phospholipid in order to result in detectable amounts of sactor $\mathrm{x}$ and Bfactor $\mathrm{x}_{\mathrm{a}}$. 2.2.1 The intrinotic factor $X$ activator

Factor $X$ can be activated via the intrinsic pathway by a complex which consists of factor $\mathrm{IX}_{a}, \mathrm{Ca}^{2+}$, phospholipld and factor VIII. Factor IX, is the activated form of the zymogen factor IX, a glycoprotein of MW 55,000 containing some 26 carbohydrate. It consists of a single polypeptide chain of 416 residues of wich 12 are $\gamma$-carboxyglutamic acid residues (29, see Fig. 5). In vivo, factor IX is activated by factor $X I_{a}$ by the proteolytic cleavage of two peptide bonds. After the cleavage of the first peptide bond, an intermediate results which is inactive in ccagulation and has no detectable esterase activity. Coagulant activity and esterase activity appear upon the cleavage of the second bond liberating an actlvation peptide of 9,000 MW (30). Factor IX can also be activated by RVV-X 


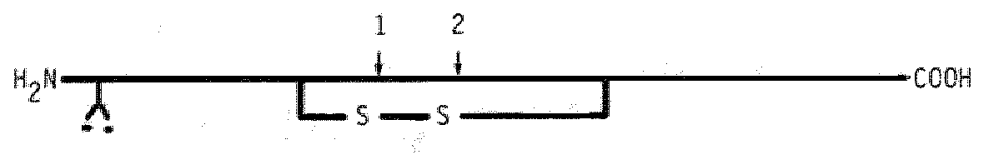

ג. Y-carboxyglutanic acid

Fig. 5. Schematic representation of the bovine factox IX molecule Factor $r$ can be activated by factor XI. Fixst an arginire-alanine peptide bond is clewed (Indicated in the figure with 1), resulting in an labetve intermedate. Esterase activity appears as a result of the cleavage of an arginime-valine bond (indicated by 2). Factor Ix is a two chaln molecule of which the light chain contains 12 $\gamma$-carboxyglutamic acia residues. The active serine is located in the heavy chain.

by cleavage of the second bond resulting in the formation of an activated factor IX or the same MW as the zymogen (31). Recently, evidence has appeared that factor IX can also be activated by facto: VII and tissue thromboplastin (32,33) explaining the earlier reports on interactions between the proteins involved in the extrin. sic pathway with the proteins involved in the intrinsic pathway $(34,35,36)$. This latter finding suggests intriguing possibilities on the regulation of factor $x$ activation during blood clotting. It has been shown that the proteins involved in intrinsic factor $x$ activation have to be adsorbed onto the phospholipid bilayer during the activation reaction $(37-43)$. Not much is known about the roles of the indiwadual components of the intrinstc factor $x$ activator. Pactor IX, since it is highly homologous to other serine proteases (29) wil likely be the enyme which activates factor $x$. up $t i 11$ now, however, it has not been reported that factor $I_{a}$, in the absence of the accessory components, i.e. Factor VIII, phospholipid and $\mathrm{Ca}^{2+}$, is capable of activating factor $x$. Hultin and Nemerson showed that a very low rate of factor $X$ activation can be observed in the presence of $\mathrm{Ca}^{2+}$ and phospholipid (44), which is stimulated about 500 fold by the addition of thrombin activated factor VIII. Brown et al. (45) reported $a K_{m}$ for factor $X$ of 0.2 M when factor $X$ activation was measured in the presence of $a 11$ accessory componen 
The role of factor VIII is still somewhat ambiguous. It has been. reported many times that factor VIII has to be activated by trace amounts of thrombin in order to stimulate factor $x$ activation $(44,46-49)$. There is also evidence that factor VIII nay be activated by factor $x_{a}(47,49)$ and by factor $I x,(49)$. of interest is the finding of Vehar and Davie $(48,49)$ that thrombun activated factor VIII can be inhibited by disopropylphosphorofluoridate (DFP). This may have consequences for the role of factor VIII in the mechanism of factor $\mathrm{X}$ activation.

In conclusion, however, since intrinsic factor $x$ activation is in many respects highly similar to prothrombin activation it seems plausible that factor VIII, $\mathrm{Ca}^{2+}$ and phospholipid act as cofactors of the enzyme factor IX analogous to the roles of factor $\mathrm{v}_{\mathrm{a}}, \mathrm{Ca}^{2+}$ and phospholipid in the prothrombinase complex.

2.2.2 The extrunstic factor $X$ activator

Factor $X$ activation via the extrinsic pathway is accomplished by a complex consisting of factor VIIa, $\mathrm{Ca}^{2+}$ and tissue thromboplastin. Factor VII is the enzyme in this complex and tissue thromboplastin and $\mathrm{Ca}^{2+}$ act as co-factors.

Factor VII is the activated form of the zymogen factor VII. Again this is a vitamin $K$ dependent glycoprotein. It has a $\mathrm{MW}$ of 45,000. It is highly probable that factor VII contalns some 10-12 $\gamma$-carboxyglutamic acid residues (see ref. 1). It has been shown that the zymogen factor VII can activate factor $x$ at a very low rate in the presence of tissue thromboplastin and $\mathrm{Ca}^{2+}(50)$. Factor $\mathrm{x}_{a}$ in its turn can activate factor WII and thus a strong feedback mechanism is provided $(51,52)$. Factor XII and factor $X I_{a}$ as well. have been reported to be capable of the activation of factor VII (53,54). A possible regulatory mechanism can be recognised in the fact that both factor $\mathrm{X}_{\mathrm{a}}$ and thrombin are also capable of 1 nactivating factor VII a. It will be clear that a detalled kinetio analysis of all these reactions is necessary to establish their relative importance.

The co-factor of factor VII in factor $x$ activation, $1 . e$. tisive thromboplastin, consists of phospholipid to which an insoluble membrane protein is bound (tissue factor). This complex strongly interacts with factor VII. Therefore, the roles of factor VII a $\mathrm{Ca}^{2+}$ "phospholipid and protein co-factor (tissue factor) seem completely ldentical to the rolles of factor $x_{a}$, phospholipid and factor $v_{a}$ in the 
prothromblinase complex.

Sllverberg et al. (55) reported a kinetic analysis of factor $X$ activation by the extrinsic complex (see table I). In the absence of the protein cofactor, the catalytic efflciency $\left(\mathrm{k}_{\mathrm{cat}} / \mathrm{K}_{\mathrm{m}}\right)$ of factor $x$ activation 13 rather low. This is, however, dramatically increase by addition of tissue factor. The $\mathrm{K}_{\mathrm{m}}$ is then below the factor $\mathrm{X}$ pla: concentration and $k$ cat has reached a level which is normal among ser. proteases. Therefore, it is easily recognised that whout the prot co-factor bound to phospholipid there will be no physiological signiflcant factor $x_{a}$ formation during in vivo clotting.

Table I. Kinetic data for extrinsic factor x activation Data taken from Silverberg et al: 155 l.

\begin{tabular}{|c|c|c|}
\hline & With tissue factor & $\begin{array}{c}\text { Without tissue } \\
\text { factor }\end{array}$ \\
\hline$k_{\mathrm{m}}(\mu$ mactor $x)$ & 0.45 & 4.87 \\
\hline$v_{\max }\left(\mathrm{pmol} / \mathrm{mLn}^{-1}\right)$ & 64 & 1.09 \\
\hline E (pmol) & 0.93 & 46 \\
\hline $\begin{array}{l}k_{\text {cat }}\left(\mathrm{s}^{-1}\right) \\
\text { coeffictent of proteolytic }\end{array}$ & 1.15 & $3.95 \times 10^{-4}$ \\
\hline eticlency $C_{P, E}\left(\mathrm{k}_{\mathrm{cat}} / \mathrm{K}_{\mathrm{m}}\right)$ & 2.55 & $8.1 \times 10^{-5}$ \\
\hline refect of tissue factor on $C_{P . E}$ & 31,500 & 1 \\
\hline
\end{tabular}

\subsection{Phospholipid involvement in blood coagulation}

Phospholipids represent about 30 of the total mass of most mammali pllasma membranes. The remaining 70 consist of membrane proteins, cholesterol and a small amount of glycolipids.

The general structure of a phospholipid molecule is shown in Fig. 6 The primary building block is a $5 \mathrm{~m}$-glycerol-3-phosphorlc acid molecu which results from esteriflcation of a primary alcohol group of glycerol to phosphorie acid. The two remalning hydroxyl groups are esterified to fatty acids (R1. and R2). Phospholipids are classified according to their head group $(X)$ which results from the esterification of an alcohol compound $(\mathrm{X}-\mathrm{OH})$ to the phosphoric acid group to form a phosphodiester. The three major classes are shown in the figure. Thus a phospholipid molecule consists of a pollar region (the head group) and a nor-polar region represented by the fatty 
GLYCEROPHOSPHOLIPIDS<smiles>[X]OP(=O)([O-])OCC(COC([R2])=O)OC([R2])=O</smiles>

$P E: X=-\mathrm{CH}_{2}-\mathrm{CH}_{2}-\overbrace{}^{-\mathrm{NH}_{3}}$

$\mathrm{PC}: \mathrm{X}=-\mathrm{CH}_{2}-\mathrm{CH}_{2}-\mathrm{N}\left(\mathrm{CH}_{3}\right)_{3}$

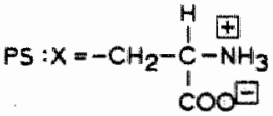

Fig. 6. Structure or a phospholipid molecule

Fhospholipld molecules contain two fatty acyl chains resulting from the esteriflcation of two adjacent alcohol groups of an-glycerol-3-phosphordc acid molecule to fatty acids (RI and R2).

Fhospholipids are classifled according to their head group $(\mathrm{x})$. The thrae major classes are shown. PE, phosphatidylethanolamine, PC, phosphatidylcholine; PS, phosphatidyserine. When the phosphoric acid group is not esterified $(\mathrm{X}=\mathrm{H})$ the resulting molecule is phosphatidic acid.

acid chains.

This is the reason why phospholipids spontaneously form concentric multilamellar structures (11posomes) when suspended in an aqueous environment (56). The head groups are in contact with the solvent and the non-polar region is excluded from the polar environment. undlamellar vestcles can be obtained upon sontcation of the liposome suspension (57, see Flg. 7). The phospholiplds which are of prine

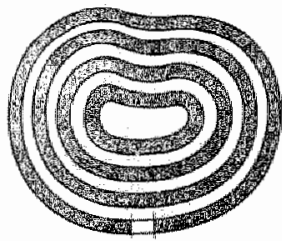

ingosone

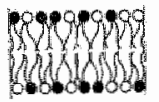

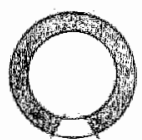

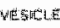

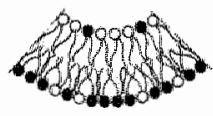

Fig. 7. Schematic representation of rnultiamellar 1iposomes and unidimedita vesteles

bue to the strong curwature, westcles may be asymetric both with respect to the number of PL molecule per monolayer and the distribution of $\mathrm{PL}$ over both layers when more than one PL clase is present. Taken from ref. 4 .

interest to the work presented in this thesis belong to the classes of phosphatidylcholine and phosphatidylserine. When mixtures of these 
phospholiplas axe sonicated, vesicles with a diameter of about 250 are obtained $(58)$.

The lipid bilayer is thought to be the structural framework of the membrane whereas the proteins perform most of the blochemical functions. Therefore, it is not surpxising that a vast amount of literature has appeared concerning the physical characteristics of the lipla bilayer. Research in this field is carried out using sophisticated techniques like K-ray diffraction, N.M.R. and E.S.R., calorimetric stiviles etc. (fox revilews, see $5,6,59-61$ ). Most of this research is carried out using well-defined phospholipids. As a consequence much is known nowadays about the characteristics of the phospholipid bilayer. Much less is known about bilayers containing protein. When proteins which interact with the bilayer are present study of the physical characteristics becomes alfficult. It appears that the physical state of the bilayer can change dramatically upon the introduction of protelins among the phospholipids and consequentiy great cation should be taken in extrapolation from the well defined systems to systems where proteins are present.

Lipld molecules in the bilayer are not confined to their position in the lattice (like atoms in a crystal are). Diffusion rates for phospholipld molecules in a bilayer in the liquid crystaline phase of $10^{-8} \mathrm{~cm}^{2} / \mathrm{s}$ have been reported (62). This diffusion drops about ten-fold upon going to the gel state. Therefore, the lipld bilayer in the liquid crystalline state appears fluid-like whereas fluidity is drastically decreased in the solid gel state. The temperature at which this phase transition accurs is strongly dependent on the length and degree of unsaturation of the fatty acyl chains and on the nature of the head group. For example, 1,2-aimyristoyl-snglyeero-3-phosphoserine $($ di-C $14: 0$-glycerophosphoserine or dimyristoyl. phosphatidylserine) has a phase transition temperature of about $35^{\circ} \mathrm{C}$ (63). 1,2-Dipalmitoy $1-s n-g l y c e r o-3-p h o s p h o s e r i n e ~\left(d i-C_{16: 0}\right.$-glycerophosphoserine ox alpalmitoylphosphatidylserine) melts at $55^{\circ} \mathrm{C}(64)$ whereas 1,2 -dipalmitoyl-sn-glycero-3-phosphocholine (di-C $16: 0$-glycerophosphocholine or aipalmitoylphosphatidylcholine) has its transition temperature at $41^{\circ} \mathrm{C}(65)$. The miscibility properties of bilayers composed of different phospholipid molecules are dependent on the difference in chain length of the fatty acyl chains and on the nature of the head group of the different components. Mixing is close to ideal for two liplds with the same head group and differing only slightly in chain length. However, when the head groups differ, the 
picture becomes more complicated. For example, dimyristoylphosphat $1-$ dylcholine and dipalmitoylphosphatidylethanolamine show only partial miscibility both in the liquid crystaline and the gel phase (66). The nature of the physical state can be strongly influenced upon interaction with calcium ions. It has been reported that addition of calcium ions to bilayers composed of phosphatidylserine molecules results in an increase of the phase transition temperature of more than $100^{\circ} \mathrm{C}$. Calcium ions do not appear to influence the physical state of phosphatidylcholine bilayers. As a consequence addition of calcium ions to bilayers consisting of a mixture of phosphatidylserine and phosphatidylcholine may result in phase separation $(67-71)$.

Much of our present understanding of phospholipid involvement in blood coagulation has come from work on the prothrombinase complex. It is a pity, however, that most of this research is carried out with poorly defined phospholipid preparations such as egg-yolk phosphatidylchollne, beef-brain phosphatidylserine, inosithin and cephalin. These preparations contain a large variety of different molecular species and often contain impurities of other phospholipids as well.

Nevertheless, it is clear that mixtures of different phospholipid. classes provide the best catalytic surface for coagulation. The physical rather than the chemical characteristics of this surface axe important. A number of physical requirements must be met in order to observe procoagulant activity. It is well

established that a correlation exists between net negative charge of the phospholipid bilayer and procoagulant activity. When no net negative charge is provided no procoagulant activity is observed. Thus, phosphatidylcholine vesicles have no clot promoting effect. The magnitude of the charge seems to be less critlcal. By varying the phosphatidylserine content in mixtures of egg-yolk phosphatidylcholine and bovine brain phosphatidylserine, Bull et a1, (72) showed that there is an optimal procoagulant activity at about 30 : phosphatidylserine content in the phospholipid bilayer.

Nowadays, it is accepted that the vitamin $K$ dependent protelns bind to the phospholipid surface through calcium bridging between the $r$-carboxyglutamic acid residues of these protelns and the negatively charged phospholipid head groups. Factors $V$ and VIII interact with the bilayer presunably via more hydrophobic interactions $(19,20$; see ref. 4). The combination of the negatively charged serine head groups of phosphatidylserine together with the neutral head groups 
of phosphatidylcholine is thus thought to be the most ideal phospt 1 lpld bilayer. It has to be mentioned, however, that the interacti of factor $V$ wth the phospholipid bllayer does require the presenc of negatively charged phospholipids too (73).

Binding of the protelns, though being a prerequisite for procoagul activity does not necessarily mean that procoagulant activity appe BuIl et a1. (72) showed that mixtures of phosphatidic acid and pho phatidylcholine bind prothrombin very effectively. However, the pr coagulant activity is much less than for mixtures of phosphatidylserine and phosphatidylcholine.

There appears to be a correlation between procoagulant activity an the physical state of the bilayer. Sterzing and Barton (74) showed that hydrogenation of mixtures of phosphatidylcholine and phosphat dylserine decreases procoagulant activity. Hydrogenation of the fatty acyl chains shifted the phase transition from $-14^{\circ} \mathrm{C}$ to $72^{\circ} \mathrm{C}$. Subsequent addition of cholesterol, which is known to have a liquefylng effect on the phosphollpid bilayer in the gel phase, restored procoagulant activity (74). Therefore, it is likely that the phospholipid bilayer in the liquid crystalline phase shows optimal procoagulant activity.

It was mentioned already that most of this work has been done on the phospholipid involvement in the prothrombinase complex. Much less is known on the phospholipld requlrement of the intrinsic and the extrinsic factor $X$ activator. The requirements appear to be alike with respect to the requirement for negative charge. Wijngaards et al. (75) showed that the extrinsic factor $x$ activator regulres a phospholipid bllayer of moderate negative charge compose of a mixture of different phospholipid molecules. It has been reported that the phospholiptd requirement for the intrinsic factor $y$ activator may be different from the requirement for the prothrombin ase complex (76). Negative charge woula still be needed but the composition of the bilayer showing optimal factor $X$ activation was reported to differ from the optimal composition of the bilayer for prothrombin activation.

\section{RE FERENCES}

1. Davie, E.w., Fujikawa, K., Kurach1, K. and Kisie1, W. (1979) Adv. whymoz. 48, 227-318

2. Davie, E.W., Fujikawa, K. (1975) Ann.Rev.Biochem. 44, 799-829

3. Suttie, J.W. and Jackson, C.M. (1977) Rhysiol.Rev. 57, 1-70 
4. Zwaal, R.F.A. (1978) Broehtm.Brophss.Aota 515. 163-205

5. Lee, A.G. (1977) Bioefim.Btophys.Aata 472, 237-281

6. Lee, A.G. (1977) Biochim.Biophys.Aeta 472, 283-344 7. Owen, W.G. Esmon, C.T. and Jackson, C.M. (1974) J.E2ot.Chem.
$249,594-605$

8. Esmon, C.T., Owen, W.G. and Jackson, C.M. (1974) J.Btot.chem. $249,606-611$

9. Esmon, C.T. and Jackson, C.M. (1974) J.Biot.Chem. 249,7782-7790

10. Esmon, C.T. and Jackson, C.M. (1974) J.Biol.Chem. 249,7791-7797

11. Esmon, C.T., Owen, W.G. and Jackson, C.M. (1974) J.Broz.Chem. $249,7798-78.07$

12. Esmon, C.T., Owen, W.G. and Jackson, C.M. (1974) J.Bzol.chen. $249,8045-8047$

13. Bas, B.M., Muller, A.D. and Hemker, H.C. (1974)Bïochim. Bïophys.Aata $379, \quad 164-171$

14. Guillin, M.C., Bezeaud, A. and Menache, D. (1978) Btoohim. Btophys. Acta $537,160-168$

j5. Rabiet, M.J., Bemaxous, R., Lable, D. and Josso, F" (1978) Abstr. XVIIth Congmess Int.Soe.Haemat. 862

16. Aronson, D.L., Stevan, L., Bull, A.P., Franza Jr, B. R. and Finlayson, J.S. (1977) d.CZin.Invest.60, 1410-1418

17. Papahadjopoulos, D.P., Hougie, C. and Hanahan, D.J. (1962) Proc.Soo. Exp. Btot. Med. 111, 412-416

18. Barton, P.G. and Hanahan, D.J. (1969) Bioohim. Biophys.Aota $187, \quad 319-327$

19. Kandall, C.L., Shohet, S.B., Akinbarni, T.K. and Colman, R.W. (1975) Thrombos.Diathes. hamornth. 34, 256-270

20. Kahn, M.J.P. and Hemker, H.C. (1969) Thrombog.Diathes.haemorith. $22,417-430$

21. Jobin, F. and Esnouf, M.P. (1967) Btoohen. t. 102, 666-674

22. Enfield, D.L., Eicicsson, L.H., Walsh, K.A., Neurath, H. and Titani, R. (1975) Proe. Nat2. Aad. Scz. USA 72, 16-19

23. Titanl, K., Fujikawa, K., Enfield, D.L., Ericsson, I.H., Walsh, K.A. and Neurath, H. (1975) Proe. Nat2. Aodd. SoL. USA 72, 3082-3086

24. Deutsch, E., Irsigler, K. and Lomoschitz, H. (1964) Thrombos. Diathes. Naemorrith.12, $12-34$

25. Jackson, C.M. and Hanahan, D.J. (1968) Biochemietry 7, 4506-4517

26. Fujikawa, K., Coan, M.H., Legaz, M.E. and Davie, E.W. (1974)

Biochemistry 13, $5290-5294$ 
27. Jesty, J. and Nemerson, $Y$. (1974) d.Biol. Chem. 243, 509-515

28. Jesty, J., Spencer, A.K. and Nemerson, Y. (1974) J.Biol. Chem. $249,5614-5622$

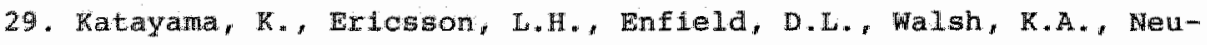
rath, H., Davie, E.W. and Titani, K. (1979) Proc. Nat2. Aoad. Sot. HSA 76, 4990-4994

30. Fujikawa, K., Legaz, M.E., Kato, H. and Davie, E.W. (1974) Biockemistry $13,4508-4516$

31. Lindquist, P.A., Fujikawa, K. and Davie, E.W. (1978) d.8to2.Ch $253,1902-1909$

32. Dsterud, B. and Rapaport, S.I. (1977) Proo. NatL.Alad. Sei. US. $74,5260-5264$

33. Jesty, J. and Silverberg, S.A. (1979) J.Biol. Chem.254, 1233712345

34. Josso, F; and Prou-Wartelle, o. (1965) Thrombos. Diathes haemors Suppt. $17,35-44$

35. Blggs, R. and Nossel, H.L. (1961) Thrombos. Diathes. Faemorn. $6,1-4$

36. Rapaport, S.I., Hjort, P.F., Patch, M.J. and Jeremic, M. (1966) Soand.J.Haematol. 3, 59-75

37. Schiffman, S., Rapaport, S.I. and Chong, M.M.Y. (1966) Proc. SE Exp. Biol. Med.123,736-744

38. Hougle, C., Denson, K.W.E. and Biggs, R. (1967) Thrombas.diathe haemorrh.18, 211-222

39. Barton, P.G. (1967) Nature 215, 1508-1509

40. Hemker,H.C. and Kahn, M.J.P. (1967) Nature 215, 1201-1202

41. Dsterud, B. and Rapaport, S.I. (1970) Bioohem. J. 9, 1844-1861

42. Varad1, K. and Hemker, H.C. (1976) Thrombos. Rea. 8, 303-317

43. Henker,H.C., Kahn, M.J.P. and Devilee, P.P. (1970) Thrombos. Diathes. haemory. 24, 214-223

44. Hultin, M.B. and Nemerson, Y. (1978) Blood 52, 928-940

45. Brown, J.E., Brugh, R.F. and Hougie, C. (1978) Thrombos. Res. $13,893-900$

46. Wsterud, B., Rapaport, S.I., Schiffman, S. and Chong, M.M.Y. (1 IR $x^{2}$. I. Haematol. 21, 643-660

47. Davie, E.W., Fujikawa, K., Legaz, M.E. and Kato, H. (1975) Cold spring Harbox conference on Cetl proliferation 2, 65-77

48. Vehar, G.A. and Davie, E.W. (1977) Seience 197, 374-376

49. Vehar, G.A. and Davie, E.W. (1980) Biochemistry 19, 401-410

50. Nemerson, $Y$. Personal Communication 
51. Radcliffe, R. and Nemerson, Y. (1975) J.Biol.Chem.250, 388-395

52. Radcliffe, R. and Nemerson, $x$. (1976) J.Brol.CRem.251, 4797-4802

53. Kisiel, W., Fujlkawa, K. and Davie, E.W. (1977) Bibohemisty $16,4189-4194$

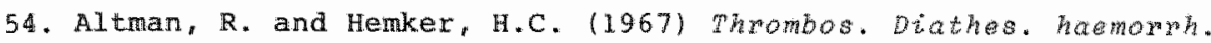
$18,525-531$

55. Silverberg, S.A., Nemerson, Y. and Zur, M. (1977) d.Biot.Cham. $25 \overline{2}, 8481-8488$

56. Bangham, A.D., Standish, M.M. and Watkins, J.C. (1965) J.Mol.Blot. $13,253-264$

57. Huang, C. (1969) Biochemist"y 8, 344-351

58. Berden,J.A.,Barker, R. W. and Radda,G.K. Biochim. Biophys.Aota 375 (1975) $186-208$

59. Azzi, A. (1975) Quart.Rev. Biophys. 8, 237-316

60. Wennerström, H. and Lindblom, G. (1977) Ruam. Rev. Biophys. 10, $67-97$

61. Seelig, J. (1977) quart. Rev. Biophys.10,353-419

62. Cullis, P.R. (1976) EEBS Letters 70, 223-228

63. Comfurius, $\mathbb{P}$. and Zwaal, R.F.A. (1977) Eioohim. Brophys. Aota $488,36-42$

64. Mac Donald, R.C., Simon, S.A. and Bear, E. (1976) Biochemistry $15.885-891$

65. Ladbrooke, B.D. and Chapman, D. (1969) Chem. Phys. Lipids $3,304-367$

66. Blume, A. and Ackerman, T. (1974) FEBS Luetters 43, 71-74

67. Ohrishi, S.I. and Ito, T. (1973) Biochem. Biophys. Res. Commun. $51,132-138$

68. Ohnishi, S.I. and Ito, T. (1974) Bioohemistry 13, 881.-887

69. Ito, I. and ohmishi, S.I. (1974) Btoothow. Btophys. Aota $352,29-37$

70. Papahajopoulos, D., Poste, G., Schaeffer, B.E. and vail, W.J. (1974) Brachim. Btophys. Mata 352, 10-28

71. Lee, A.G. (1975) Btoohim. Biophys. Acta 413, 11-23

72. Bull, R.K., Jevons, S. and Barton, B.G. (1972) d.Btok.Chem. $247,2747-2754$

73. Subbalah, P.V., Bajwa, S.S., Smith, C.M. and Manahan, D.J. (1976) Biochin. Eiophys. Acta $444,131-146$

74. Sterzing, P.R. and Barton, P.G. (1973) Chem. Phys. Liptade 10, $137-148$ 
75. Wijngaards, G., van Deenen, L.L.M. and Hemker, H.C. (1977) Biochim. Blophye. Acta 488, 161-171

76. 䃑1sh, P.N. (1978) Br. Haematol. 40, 311-331. 


\title{
Lipid Phase Transitions and Procoagulant Activity
}

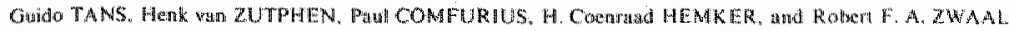

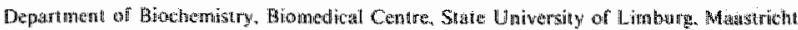

Received Noneratber 30.1978 :

1. The relation between acyl chain fluidity of synthetic phosphatidylserine/phosplatidylutholine mixidures and their activity in the prothrombinase complex has been invescigated using differential scancing calorimetry and a one-slage prothrombinase assay.

2. Mixtures of dioleoylphosphatidylserine und dioleoylphosphatidyldholne which wro liquid crys. talline at physiologicall temperature proved to be comsiderably more ative in cotgatiantion than

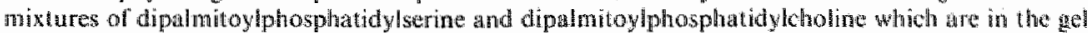
phase, while this diference disappears completely upon addition of cholesterol. Varying ilue proportion of phosphatidylserine from 30 to $70 \mathrm{~mol} / 00 \mathrm{~mol}$ has $\mathrm{no}$ signifiont influence on the conguland behavioun.

3. The procongulant activity of mixtures composed of dimyristoytphosphatidytserine and dipalmitoylohosphalidylcholine was contuated with the plase diagram consuructed from the calor metric data. Going through the phase transition to the liquid state was accompstied by a shap increase of clot-promoting activity.

4. The phospholipid concentration which exhibited maximal coagulant activity appeared to be strongly dependent on the miscibility properties of he lipids. Solid solid inmuscibility was obser wed both with mixtures of the two dinyristoyl compounds and the dipalnitoyl compounds, and a 5-10-fold increase in the lipid concentration required for maximal coagulant activiny was obserwed below the phase transition. This shin was lond to be absent wh mixures of the dioleoyl spectes

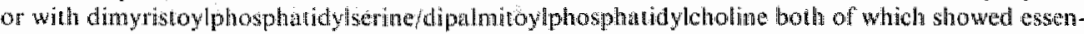
tiatly complete miscibility in both phases.

Phosploflipids play a crucial role in blood coagulation by specifically accelerating some of the reaction steps loading to clot formation [1-4]. The final lipidactitud step in the coagulation cascade is the conversion of polingmbin into lhrombin by the prothrombinase complex. which is composent of factor $X_{2}$, factor $V$. Ca ${ }^{*}$ and phospholipids tse for recent roview [5]). Alhough there is condusive evidence that a negarye surface charge of the phospholiphds is required for codgulanl wotivity $[6-8\}$, neither the magnitude of the charge nor the charge density alone are sufficient to accom tor the abilty of the lipids to form a procosgutant surface. Significantly. it has been shown that the chot-pronoting activity of gymthetic disaturated phosphatidylserines. when mixed with ratural phosphatidylethanolamine, is maximal with dimyristoylphosphatidylserine, whereas the activity decreases using species with longer or shorter hydro carbon chans [9]. Moreover, it has been shown by

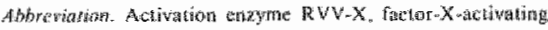
anzyme hrom Rustel's viper venom.
Sterzing and Barton [10] that hydrogenation of mix lures of egeyolk phosphatidylcholine and bef-brath phosphatidylsemine decreases procoagullant activity, but this effect could be reversed upon increasing the degree of unsaturation or by additon of cholestercot

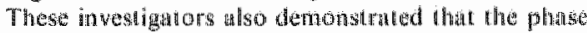

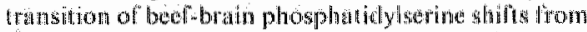

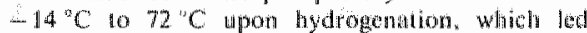
therm to propose that mestoration of procoudentant activity is related to the phitse-transiton temperature of the lipid mixtures. However, a diret relatonship with the lipid phe transition can only be estatblishod

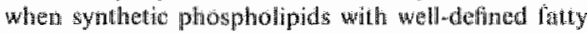
acids are used, having atrangtion lemperature in the range whene cloting assatys can be performed.

It the present siudy, the clot-promotng behatiour in a one-gtage prothorintzinase assity of synthetic mixlures of phosphatidylererine and phosphatidylcholine is compared with their phase inansition and mixting propertics as observed calorimentically. The results demonshate that molting of the lipids is indece acconpaned with a sharp increase in coamulant actiw- 
ity, while phase separations of the lipids thave a profound influence on the lipid concentration required for maximal actuity.

\section{MATERIALS AND METHODS}

Lofipids

1.2-Dideoyl-sin-glyero-3-phosphacholine (dioleoyphosphat dylcholine), 1,2 -dipallmutoyl- $m$-glycero-3m phosphochofine (dipalmitoylphosphatidylcholine), and 1,2-dimyristoyl-swalycero-3-phosphocholine dot myristoylphosphatidylcholine) were prepared by reacylating the caulnim chloride adduct of an-glycero. 3-phosphocholine with the approprate fatty acyl chloride according to the method described by Baer and Buchnea $[11]$. Dry ether was tised instead of dry chloroform to achieve lingher yields (H. M. Verhey, personal com phosphoserime (dioleoylphosphatidylserine), 1,2-dipalmitoyl-sh-glycero-3-phosphoserine (dipalmitoylphosphatidylserine and 1,2-dimytistoyl-sm-glycero-3phosphoserine (dmingrishoylphosphatidlylserine) were prepared from the respective phosplatidylcholines by enzymatic symthesis as described by Comfurius and $Z$ waal [12]. Chotesterol (99\% pure) was oblained from Merck. All other reagents were of analytical givade.

\section{Cogusulation Assay}

$0.1 \mathrm{ml}$ delipidated bovine plasma (diluted five-fold with Michaelis buffer oH 7.4) was incubated for $30 \mathrm{~s}$ with $0.1 \mathrm{ml}$ actiwation enzyme RVV.X (factor $\mathrm{X}$ activating enzyme from Russell's viper venom) sollu. tion in Michaielis buffer (1 $\mu \mathrm{g}$ protein/ml) and $0.1 \mathrm{mll}$ $\mathrm{CaCl}_{2}$ (15 mM) to achieve activation of factor $\mathrm{X}$ [13] $0.1 \mathrm{~m}$ ! phospholipid vesicle suspension was added in concentrations ranging from $1000-1 \mathrm{nmol} / \mathrm{m}$

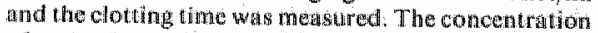
of activition enzyme RVW $\mathrm{X}$ witu tused as adjustable

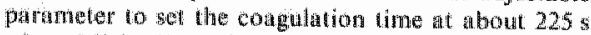
when Michallis buffer was eadded instead of lipid vatuletes

Delipidated bowne phama was obtained from nomal bowne cituted plasma adjusted to a density of $1.21 \mathrm{gml}$ wh $\mathrm{KHr}$, wand a fotation density teonnique [14], Contrifugation whs cartied out at $\$ 50000$ or for $36 \mathrm{~h}$ at $4^{\circ} \mathrm{C}$. The resulting delipidsted plasma was dietyzed agangt solution of $150 \mathrm{~mm}$ NaCl and $10 \mathrm{mM}$ sodiun citrate. Alternatively, plasma was delipidated with butanol id i isopropyl ether 400,60 , vivising the mathod desentibed by Chan and Knowles [15]. Both nothods gatve similar results. Factor $V$ whis deternimed by a onewstage assaty using factor-Vdeficient reagent $[16]$. Aboutl $50 \%$ of the normat value was present in both delapidated plasman. Factor
II and factor $X$ were also determined in a one-stage assay using the respectiwe factor-deficient reagents $[17,18]$. These factors were present in concentrations ranging from $80-100 \%$ of the normal valtes. Actiwitton enzyme $\mathrm{RVV}-\mathrm{X}$, purified according to the method of Schiffman et all: [19], was a gift of Mrs. GowersRiemslag. No phospholipase A activity coud be dettected in this preparation. The lipid vesicle solutions were prepared by drying 5 mmol of lipid under nitrom gen followed by sonication for 10 min above the phase transition temperalure in $5 \mathrm{ml}$ Michatlis buffer using a MSE uttrasanic disintegrator (mark II 150 W) set at 10 um peak to peak amplitude. After sonituation no pH adjustment was needed.

\section{Differential Scaming Calorimetry}

Differential scanning calorimetry was used to detect the phase transitions and also to investigatle the miscibility properties of the mixtures of the lipids used. 5 umoll lipid was dried in the sample pan under nutrogen and drying was completed in wachum for at least three hours $[20]$. After addition of $15 \mu$ bufter the sample pan was sealed. Before the finall scams were macte the samples were scamed through the phase transition at least five thmes and then incubated for ten minutes above the phase transition. Michaelis buffer/ethylene glycol $(1 / 1, v / v)$ was used in samples containing dioleoylphosphatidylcholine or dioleoylphosphatidylserine. In all other samples. only Michaelis buffer was used. Scans were made on a Perkin-Elmer DSC-1 B calorimeter at a rate of $8^{\circ} \mathrm{C} /$ min using heating seans only. For the construction of the phase diagram of the dimyristoyphosphatidytserine/dipalmitoylphosphatidylcholine binary mixture, three heating and three cooling curves were recorded at a rate of $4^{\circ} \mathrm{C} / \mathrm{min}$. The diagram was constructed aceording to the method described by $V$ at Dijok et all. [20]

\section{RESULTS}

The calorimetric behavions of a number of mix nures of synthetic phosphatidylserines and phosphatidyldholnes was compared with their clotpromoting activity in the one-stage prothrombinase assay.

\section{Dholeylphosphatidylserine? Dioleoylphosphandyholine}

These mixtures were irwestigated bectuse the phospholipid bilayers atre in the liquid crystalline phase, well above the phase transition, at physiological temperature. The cttorimetric data indicate complete miscibility for all compositions as is to be expected from the almost identical transition temperature for 


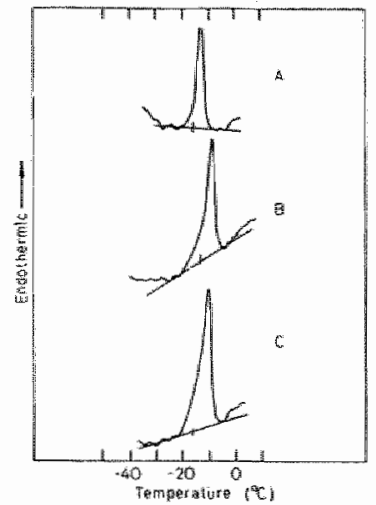

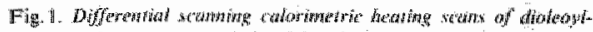

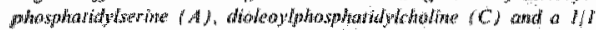

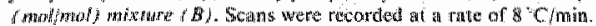

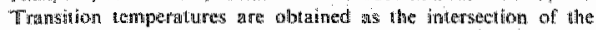

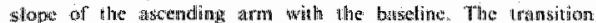

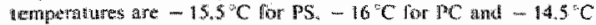
for the mixture

the phosphatidylserine and the phosplatatidycholine $\left(-15.5 \mathrm{C}\right.$ and $-16^{\circ} \mathrm{C}$, respectively). The transition temperature for the pure phosphatidylcholine is slightIy higher than found by De Krayf et al. [21]; who measured in waterfeflaylene glycol $(1 / 1, v / v)$. They found the transition at $-20^{\circ} \mathrm{C}$. Fig. 1 shows the heating curves for the single compounds and the $50 / 50$ (mol/mol) mixhre. All mixtures tested $(80 / 20,60 / 40$. $50 / 50,40 / 60,20 / 80$, mol/mol) had their solidus point at about $-14.5^{\circ} \mathrm{C}$. Under the presert conditions it was not feasible to construct a phase diagnam as in our buffer system the lipids showed considerable hysterasis.

When invesuigating the coagulatit activity of the phosphatidy serine and the mixtures, in all cases the maximal procoagulame activity was found at the sume phospholipid concentration (Fig. 2). Stawting at concentrations of 1 nimolimit of lipid added, the cloting

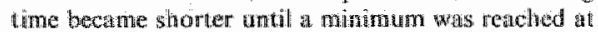
about 75 nmol/hnl added tipid. At higher lipid coneenthathons gradual increase of the clotting time. wats observed. Mixures ranging from 40 min $70 \mathrm{~mol}$ of phosphatidylserine/100 mol showed maximal procoagulant activity (about 27 s cloting time) while mixtures containing 20 or $80 \mathrm{~mol}$ of phosphattidy. serime 100 mol were sightaly lese ouctive (about 31 s\%. The maximal activity for the pure pliosphatidylserine arone $x^{\prime}$ as found to be considerably smaller (about $40 \mathrm{~s}$ cloting time) confming that fipid mixures form a betser catalytic surface in the prothrombinatse complex than the sungle compond. Phosphatidycholime alone

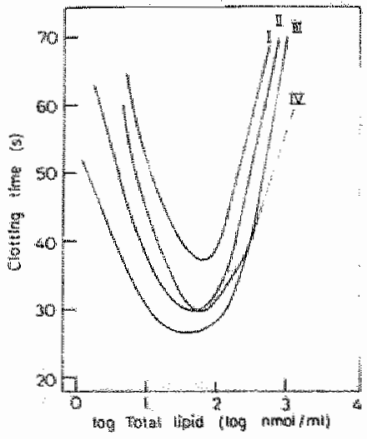

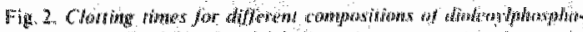

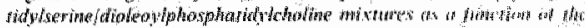

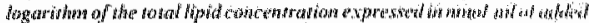

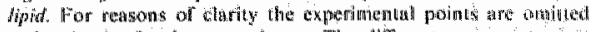

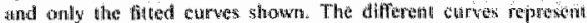

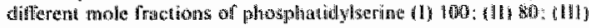

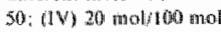

showed almost no activity since coadulation limes in the order of the bufler time were obserwed.

\section{Dipalwiroylphosphatidytserve! Dipalminoplphosphandy/dtoline}

These mixtures were stidied because, in contrast to the mixteres described above, both phospholipids are in the gel phase at ploysiological temperature. In agreement with the laterature $[22.23]$, the transition lemperatures for the pure phosphatidylserine and phosphatidylcholine were found to be $57^{\circ} \mathrm{C}$ and $41.5^{\circ} \mathrm{C}$, respectively. The calorimetric data of the mixtures indicated solid/solid himmischility bectuse they did not give a single trastion peratk (resuts not shown. It the coagulation assay these mixtures also showed naximal proconatant atotivy at defned phospholipid coticentrahors but in contrast to the diolcoyl nixtures described abowe ithe conewntrallions were found to be sighalfiednly lagher, Moreover, the soting times were foumd to be considerably longer (Fig. 3). For the most active mixture $(50 \mathrm{~mol}$ of phosphatidy/3erine/100 mol) a tomimal dolting tine of 58 s wat measured.

It has been shown thint indroducing cholesterol in bilayers of phosphatidytholine twas a conderising effect on bilayers in the likpuid ctyoultihe phase and a liquefying effect on bilyers in the get state [24]. This internediate stat to apears to be almost liquid crystalline. The lateral diffurion rate of the lipid molecules in the bitayer in the butid crystalline phase is redwed 


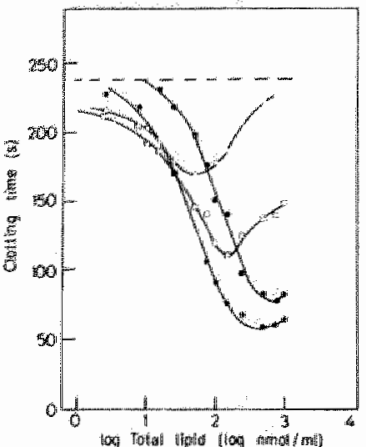

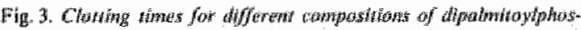

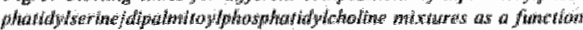

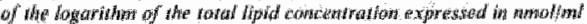

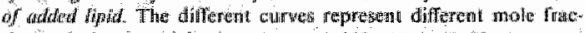

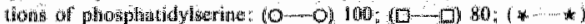

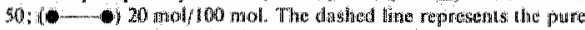

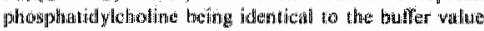

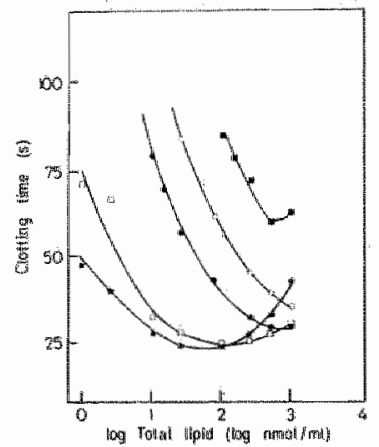

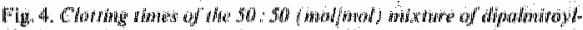

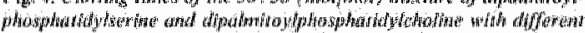

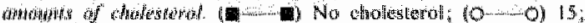

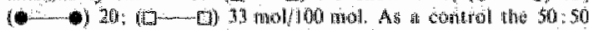

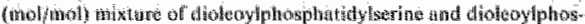
pht (*). + )

two-fold upon wingers with cholesterol, wherens it goes down 10 -times when going from the liquid orystat line to the get phase [25]. The effect was tesiad by introducing cholesterol ap 10 amounts of $33 \mathrm{~mol}$ $100 \mathrm{~mol}$ total lipid since at his ratio the effect on the phasse transition is completed [24]. The addition of cholesterol to a $50 / 50$ (mol/moly mixinte of the dipalmitoyl compounds had a dramatic effect on the procosgulana activity.

Althongh medition of cholestarol to the dioleoyl mixture shows somewhat shorter clotting times rom-

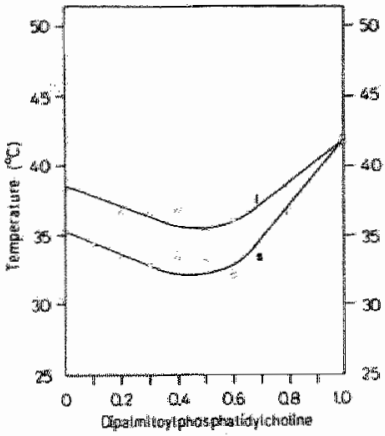

(nimilimall

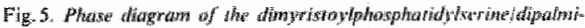

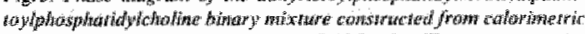

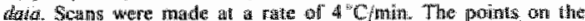

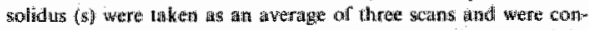

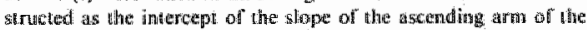

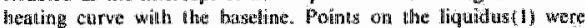

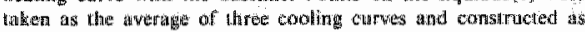

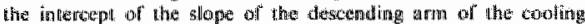

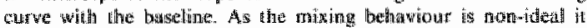

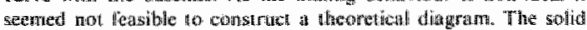
line represents as fil $\$ 0$ the experiment all points

pare Fig. 2) it is difficult to assess whether this is significant since variations of approximately $5^{\circ} \mathrm{may}$ occur from day to day. From fige 4 it is clear that the addition of cholesterol up to $33 \mathrm{~mol} / 100 \mathrm{~mol}$ to a phospholipid bilayer in the gel state reduces the coagrtation thme to becone almost equal to that of a ruixture in the liquid crystalline state. Moreower, the lipid concentration at which maximal procoggulant activity was obserwed, shifted to lower valnes.

\section{Dinturistop/phosphatidylserine, Dipatmitoylphosphatidy/choline}

In onder to establish a direct correlation between melting of the fat $y$ acyl chains and coagunn activity. it was decided lo investiggte the mixture of dimyristoylphosphatidylserine and dipalmitoylphosphathidyleholine because both lipids tat we their phase transition not far trom physiologies lemperature. The phasediagram constrwcted from calorimetric that is stown in Fig. 5 . lin af areement will other investigators. Uhe transirion temperature determined from the heating cutves for the phosphatidytserine and the phosphatidylcholine were found to be $35.0{ }^{\circ} \mathrm{C}$ and $41.5{ }^{\circ} \mathrm{C}$ respectively $[12,23]$. It was observed that the two compounds exhibit aniscibitty in both phases but the mixing behaviour is non-idex. The coagulant activity of mixtures of these two lipids showed marked simnlatily to the bellaviour of the two dioleoyl compounds (Fig. 6). For $100,80,60,50$, and 40 mol of phasplati- 


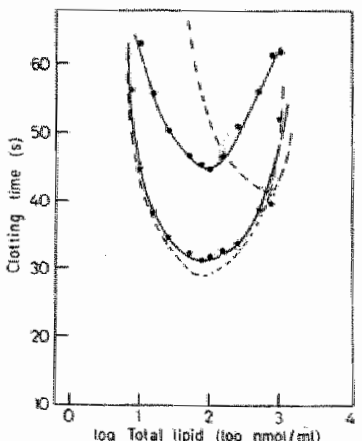

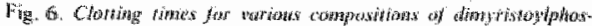

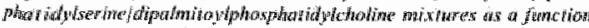

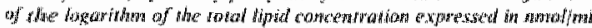

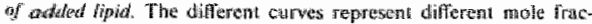

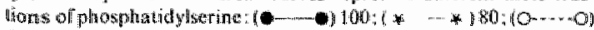
to:

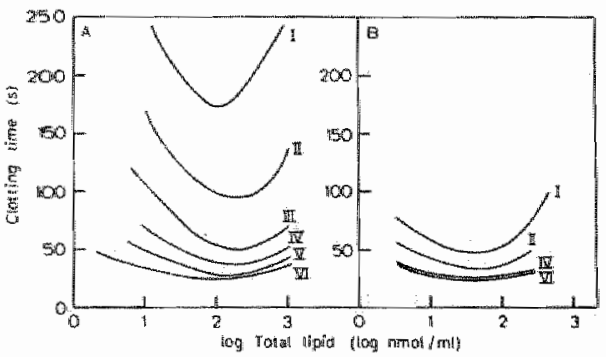

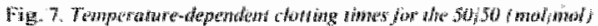

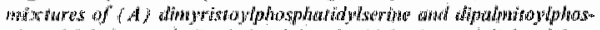

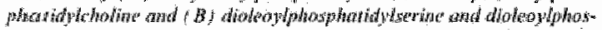

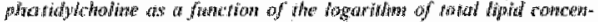

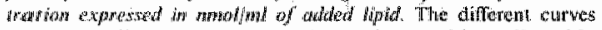

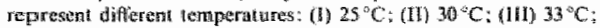

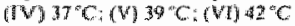

Helserino $100 \mathrm{~mol}$ there is excellent agrement with the phase diagram which predtets hiqud crystalline bethaviour at physiological tamperature. Since the phase dugrum predicts that is $50 / 50$ mol/mol mixhure witl be in the gel state below $33^{\circ} \mathrm{C}$ the procoagulant artivity of this mixture was compared with a mixture of the dioleoyl compounds at tomperatures bethesen $25{ }^{\circ}$ and $430 \mathrm{C}$. The difference butween the wo shixhures vanished almosi completely upon going through the phase transtion (Fig. 7). As it has been shown that the clofting time is inversely proportionat to the welowity of congeldation [37] an Arrisenius plot or the data obtained with the optimal lipid concentrafion (100 nomolml added hipid) was constructed. This औhowed sharp increase in coagulant activity at $0.00324 \mathrm{~K}^{-1}\left(35.9^{\circ} \mathrm{C}\right)$ which corresponds closely

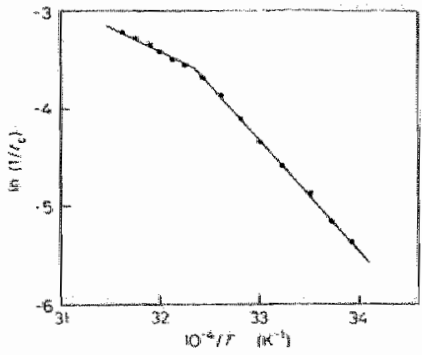

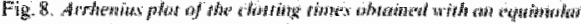

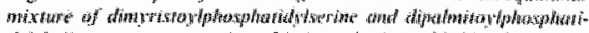

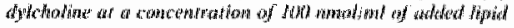

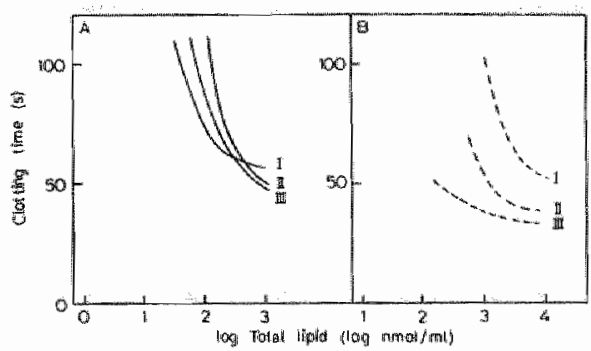

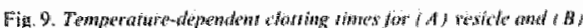

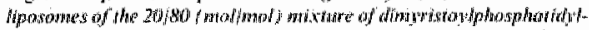

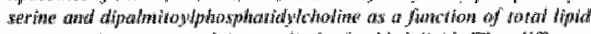

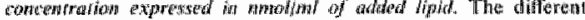

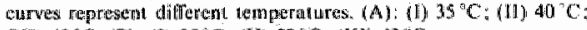

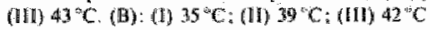

to the phase transition temperrature of the lipid mixture (Fig. 8).

The behaviout of the $20 / 80$ (molnoly mixture containing $20 \mathrm{~mol}$ of phosplasidylserine/100 mol proved lo be of spectul interest. As expected from the phase diagram, this moxture is in the gel phase at physiological temperature, which may be responsilble for its weker codgulant activity. However, no sharp

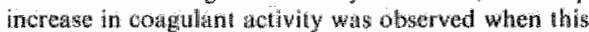
mixture was heared above ins plase lrationion tempera. ture (Fig, 9 A). On the olhen hand, the expected jump in corgulation the did occur irded when handshaken liposones ware tosed ( $\mathrm{F}$ ig 9 B). Since less lipid is available at the surface of liposomes as compared to vesicles [26], the optimal lipid concentrations shit lo higher values. 


\section{Dinyristoyphowphatidylserine Dimyristoylphosphatidyloholine}

Althowh the optimal lipid concentration where maximal procoagulant aetwity was found is the same with lipid mixtures the hand crystalline state (50-100 nmol/mil added lipid), marked difference was obserwed betwen lipids in the gel state. The mixiure of the dipalmitoyl compounds exhibited miximal procoagulant aivivity at $500-750 \mathrm{nmol} / \mathrm{mol}$ added lipich, whereas the equimolar mixture of dimyristoylphosphatidylserine and dipalmitoylphos phatidyllholine had its optimum at about 100 nmol mildod lipid both betow and above the phase transjlion. Therefore, iat mixture of the lwo dimyristoy? compounds was investigated since the coagulant bethaviout of this mixture could also be metusured above and below the phase transition.

The miscibility properties of dimyristoylphosphatidylserine and dimyristoylphosphatidylcholine were found to be similat to the mixtures of the dipalmitoyl compoundsi Melting started at the transition temperature of the dimyristoylphosphatidyloholime $\left(23^{\circ} \mathrm{C}\right)$ and was completed at about $30^{\circ} \mathrm{C}$, indicating solidif solid immigcibility. When the coagulant behaviour of an equimolar mixture was tested as a function of iemperature, a sharp increase in the coagulant activity whs observed on going through the phase transition (Fig. 10). However, in contrast to the mixture of dimyristoylphosphatidylserine and dimyristoylphos phatidylcholine, the optimal lipid concentration for maximal procoagulant activity shifted from aboul 500 momol $/ \mathrm{ml}$ added lipid at $23^{\circ} \mathrm{Ct}$. $50-100 \mathrm{nmol} / \mathrm{ml}$ uclded lipid at $37^{\circ} \mathrm{C}$

\section{DISCUSSION}

The influence of phospholipids on the clotting Hine of phasma in the presence of activation enzyme RVVX prowides dinet information of the lipid requirements of the prothrombinase complex. Since ractor $x$ is activated by incubation with the anctivation endyme $\mathbb{R}$ VV-X and CaCl, prior to addition of lipids, no contributions of the accelerating efreet of phospholipids on the intritasic and extrinsic factor $X$ atctivator are to be oxpected $[5]$.

the pesults show excellent correlation between linutitisy of the phospholipid bilayer as deterted with diflowenthat scanning calorimetry and the procoagulart activity measured in the coagulation assay. The minnat clothing times for phospholipids in the liquid crystalline phase are significantly shorter than those observed for lipids in the gel platse. For example: equmolar mixtures of dioleoylphosphattidylserine and dioleoylphosphalldytcholine (l:iquid crystalline) at thout $2 \%$ of their optimal concentration exhibit cloting times of 60 shich are comparable with the

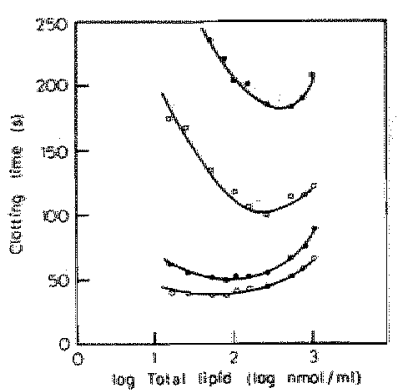

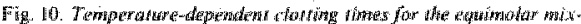

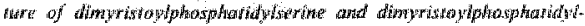

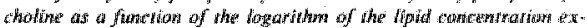

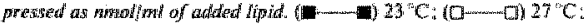

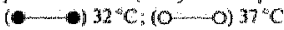

minimal cllotting limes of equimolar mixtures of di. palmitoylphosphatidylserine and dipalmitoylphosphatidylcholine. Assuming that the prothrombinase complex will: be equally active with a solid and at liquid crystalline lipid surface, it cam be tentatively concluded that the maximal number of active pro thrombinase complexes formed in the presence of phospholipids in the gel phase is some 50 inmes smaller than with phospholipids in the liquid crystalline phase, provided that prothrombin is in excess in both cases. If can be ruled out that the observed lower coagulant activity of lipids in the gel phase is caused by a minor contamination of lower melting lipids, because addition of the dioleoyl mixture to the dipalmitoyl mixture in a ratio of $2 \mathrm{~mol} / 100 \mathrm{~mol}$ prior to sonication has no significant infuence on the coagulant belliaviour.

The relation between acyl chan fluidity of the phospholipids and their procoagulant activity is further supported by the experiments using cholesterol. The disappeatance of the difference between the $50 / 50$ (mol/mol) mixure of the dipatmitoyl compounds and the $50 / 50$ (molmol) mimture of the dioleoyl compounds upon introducing cholesterol into the bilayer is consistent with the observations of Sterzimg and Barton [10]. These authors carried oul experiments with bowne brain phosphatidylserine and wilh mixtures of this lipid with agg-yolk lecithin. From the increase in coagulant actiwity upon introducing cholesterol into bilayers of hydrogenated phospholipids and from the increase in activity when the degree of unsaturation of the acyl chans was increased these authors concluded that the restoration of activity was related to the transition temperatures of the lipid mixures. It should be mentioned, however, that this was not demonstrated in a direet experiment showing that the lipids acquire procoagulant activity when scaned through the phase transition temperature. 
Derect evidence is provided by the results obtained wh the mixture of dimyristoylphosphatidylserine and dipalmitoylphosphatidylcholine, showing a srriking correlation between the coagulant activity and the phase diagram. Furthermone, an Arrhenius plot for the $50 / 50$ (molimol) mixture indicates a sharp increase in coagulant activity when going through the phase transition, thus allowing the condlusion that melting of the fatty acyl chains (and not for axamplea pretransition of phosphatidylcholine occurriag some $10 \mathrm{C}$ below the actual phase transition! is inded the determining parameter

The apparent exception formed by the $20 / 80$ mollmoly dimgristoylphosphatidylarine/dipalmitoyl phos phaidy/choline mixiture may be of further interest. It has been shown that with vesicles, phosphatidylserime has preference for the in ner hat of the bilayer [27]. It can be expected that the asymmetric distribum tion is enhaned when the hydrocarbon chains of phosphatidylserine ate shorter than the duains of phosphatidylcholine, as is the case with these mixtures. Therelore, it is reasonable to suppose that in this mix ture the anoum of phosphatidylserine at the outer surfuce will be lower than the critical value of phosphatidytserine required to show procodgulant activity, which is presumbily not the catse when liposomes of the same composition are used. In the olher mixures this effect was only observed when the phosphatidylserine content became less that 10 mol/100 mol which is in agreement with the lindings of Bull and Burton [28]. Also, the lipid concentration at which the maximat procougulant ativity is reached shifs to values about elght rimes higher when liposomes are used instead of vesicles, which is in agrement with the obserwation that the avallable surface diminishes about eight-fold in liposome suspensions [26].

In order to be active in coagulation, the phospholippid/water interface musi provide binding sites for the vitmin-K-dependert clotting factors $X_{0}$ and 11 , us well as for factor $V$. Ir has tween suggesled by subbatah et al. [29] ghat a negatue lipid surface is atro regund to bind factor $V$. Preliminary investigations catrited ou in our lahoratory by Dr Rosing show that factor Whits 10 bind lo pure egg-yolk lecithin whereas binding is observed when bratn phosphatulalserine is present in the bilayer. Moreover, ti was found that the binding decreases about fiwe-fold when the phospholipids are in the gel phase thus supporting the notion that the interaction with lactor $\mathrm{V}$ is also Wydrophobic. On the other hand, the intarations with the vitamin-K-dependent clotting factors are though to be sheerly electrostatic. These clotling fatcors presumably bind to negat ively dhened lipids though $\mathrm{Ca}$ fon bridging. In agreement with the literature il was forand that the bilayer must have a net negative surface charge [6-8]. However, in cond as to the general wiew the magnitude of this charge can vary consider- ably whoult intuencing the congullan behavour. Although a negative charge sems 10 be requirod, the amount of avallable lipid surtice as well as the physical state of the liphds appeas to be mone arition.

The appearance of an optimal hipat concentration is thought to result from the balancing effect of the density of botnd proteins on the phasphohipid sunfuce and the hateral difusion rates of these proteins over the surface. Al low concentrations the densiy will be maximal. The more phospholipid strface is prosided the more prothrombinase complexes will be formed and the cloting line bocomes shorter. However, in higher concentrations the densily of the bound proteins will decresse and their collision chano will therefore decrease also. This affee tends to protong the clotting times. Thus. the concentration at which maxnal artivity is reached is expeted to be a mestsurt of the amount of notive phospholipid surface involved as wetl as of the number of prothrombinase complexes formed. This is of course also influenced by the concentrations of the cloting Iactors in the plasmat The binary mixtures which show complete miscibility in botil phases (the dioldeyl mixures and the miximites of dimyristoylphosphatidyserine and dipalmitoylphosphatidyleholine) have an optimal concontration of about $100 \mathrm{nmol} / \mathrm{ml}$ added lipid. The dipalmitoylphosphatidy/serine also has a optimand concentlution of about $400 \mathrm{nmol} / \mathrm{ml}$ added lipid whereas the binary mixtures of dipalmiloylphosphatidylserine and di palmitoylphosphatidylichotine as well as the mixtures of the wo dimyristoyl compounds at lemperatures below their phase transitions hatwe optumat concentradous at significandy higher walues. These latter mixtures show only partial miscibility in the solid state because the calorimetric heating scans show two peaks of which ore can be ideribied as the pera of the phosphatidylcholine. The second peak is presumbly produced by the transition of a mixure of both lipids, since the transition temperature lies between those of the pure substanees. Since phospinatidyloholine atone has no procoagulant activity it ou be assimed that only part of the available lipid surfase of mixtures showing plase separtion contributes to the formation of prouhrombinase. "This may explatin why highor amouns of lipids are reded to reach maximal coaguland activity wath those mixtures. Assuming that with the two dimytrotoyl compounds, complete mixing Docurs abowe the phase Iransition it may be cond uded that the shin in optimat concentrution which is observed on measuring congulant activity between 23 and $37^{\circ} \mathrm{C}$ is at reflection of the simount of mixed surfiace. Since tho shift accurs with the mixture of dimyristoylphosphat tidyserine and dipalmioyphosphatidycholine, it is unlikely that he total surface area awalable for catalysis is the determining param eter, also because all lipid vesuctes have been prepared by sonication above the phase transition. Although 
it is mot ned out that small variations of vesile size among the warous preparations may occur, it car be calculated from $[38$ | that the amount of lipid present on visicles with a dimetar of $25 \mathrm{~nm}$ is about $65 \%$ while this value derreases to $57 \%$ when the vestcle

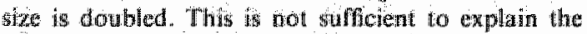
matmitude of the shifle describud abowe.

If is generally known that $\mathrm{Ca}^{2+}$ is an essential component of the prathrombime complex. It is also known that Cat" can have wery drastic effects on the physteal state of a phospholinte bilsyer $[30-32]$. In mixtures of phosphatdylserine and phosphatudyl. choline $\mathrm{Ca}^{2}$ can induce a phase separation of the two phospholipids [33] which is thought to be caused by the clustering of the serine heat groups bridged logether by the Ca jons thus rreezing out the phosphatidyserine from the liquid orystalline phosphafadyctioline matrix. These phase separathons are expected to occur rapidly [34,35]. However the reults. presented above do not show a correlation between coagulart actity and the physucal state of the billayers when the effect of $\mathrm{Ca}$ ions is taken anth account. This is markedly illusirated by a control experiment using $50 / 50(\mathrm{moll} / \mathrm{mol}) \mathrm{min}$ (ure of dimyristoylphosphatiolylsertine and dipalmitoylphosphatidylcholine. Prior to addition in the congulation assay, the vesicles were incubated with varying amounts of $\mathrm{CuCl}_{2}$ up to th ratio $\mathrm{Cin}^{2} / \mathrm{pl}$ losphatidylserine of $20: 1$. Even when these incubations were carried out for severd hours, no change in coagulaion behaviour could be detected. At present, it is not clear why a perfect corratution is observed between the physical state of the bilayers before addition to the coagulation assay and not to the expected state when Ca ions are present. Recently, Barton and Findlay [36] suggested that prothrombin activation occurs most efficiently at the lateral interface between the gel state of an acidic phospholipid$\mathrm{Ca}^{2+2}$ complex (e.g. phosphatidylglycerol') and the liguid orystalline state of a neutral phospholipid (e.g:

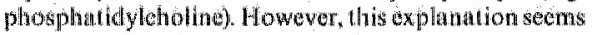
hardly applicable there as coagulation times are only slightly influched by the phosphatdylserine/phosphatidyloholine ratio, which should strongly intiluence the amount of laterat indertece. Morever, it apperars possible to correfat the lipid concentrations at which maximal coagutant netiwity is reached with the miscibility propertics of the naxtures, which indicstes that. anution should be exereised when only one lipid con-

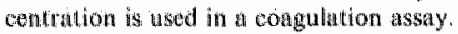

One of us (H. H. Zutphen) was sappored by the Foundation

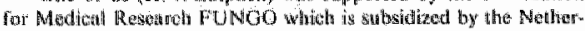

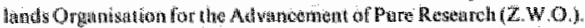

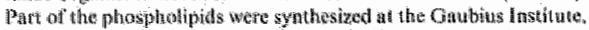

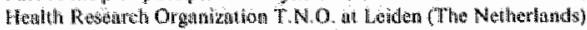
with the zussistance of M. L. M. win Hewetingern,

\section{REFERENCES}

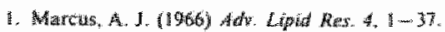

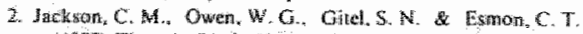

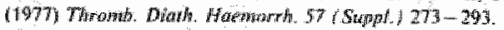

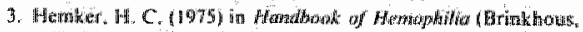

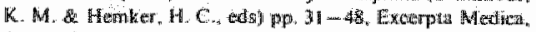
A.misteridistat.

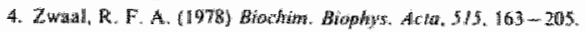

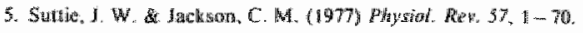

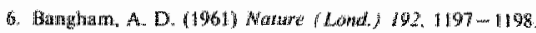

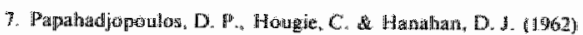

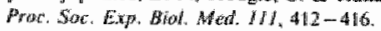

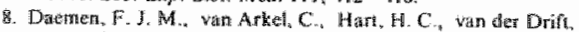

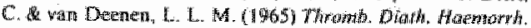
13. $194-217$.

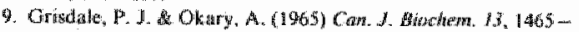
1470.

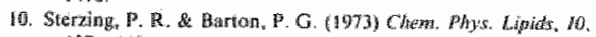
$137-148$.

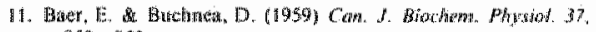
$953-959$

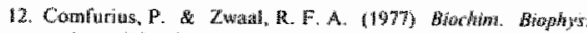
Acra, $488,36-42$.

13. Lindhoul, M, J. Kop-Klaassen. B. H. M. \& Hemer, H. C. (1078) Biodwin. Bophys. Acra, $333,342-344$.

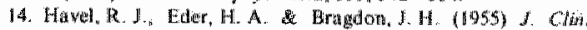
MFEs $34,1345-1351$.

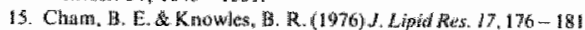

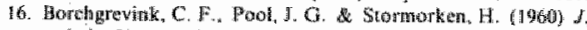

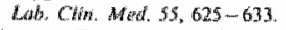

17. Wermeter, C., Soute, B. A. M. Femler, H. C. (1977) Thromb. Res. $10.495 \% 507$.

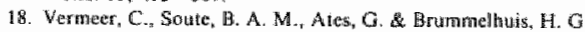
1. (1976) Fox. Sam $30,1-22$

19. Solvirman, S., Theodor, 1, a Rapapor, S. I. (1969) Biochenintmo, $s ; 130 \%-1495$

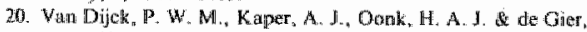

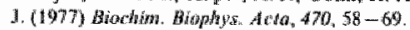

21. De Kruyp, B, Demel, R. A., Slontboom, Ah, J, vant Dexenen, L.

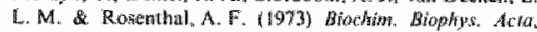
30) $1 .-1.9$.

22. Mc Donald, R. C. Simon, S. A. B Brer, E. (1976) Bochem istry, $15,8,85-89$, .

21. Ladbrooke, B. D. Comapman, D. (1969y chwe Phys Liptols. 3. $304-367$.

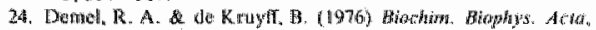
493,109 sis 132

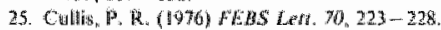

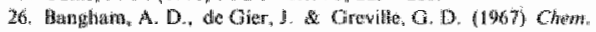
Phys. Linds, $1,22,-246$.

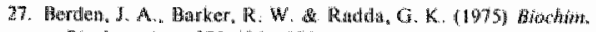
Bitophys . Ale:4a, 375, $186-208$.

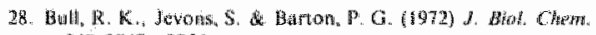
$247,2747-2754$

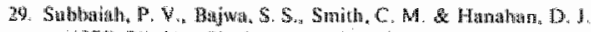

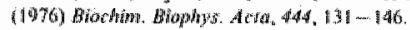

30. Towante, H. F. Ververgaeri, H. H. I. Th, Verklej. A. I. \& var Diener, L: L. M. (1014) Chem, Physe Liphats, 12, 201-219.

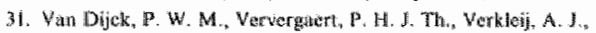

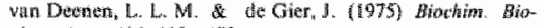

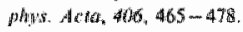

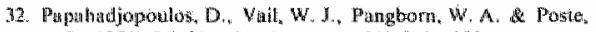

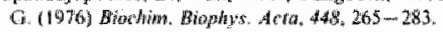

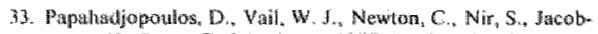

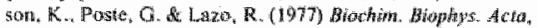
$465,579-598$. 


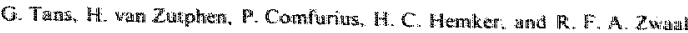

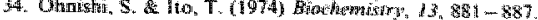

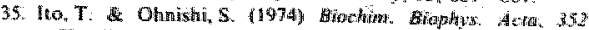
29 in- $3: \mathrm{T}^{\prime}$

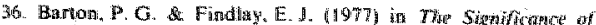

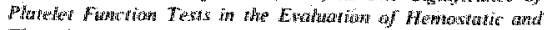

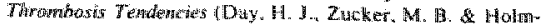

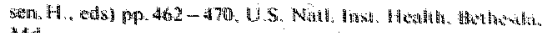
Nixti.

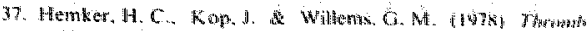

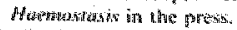

3. De K ra

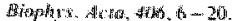

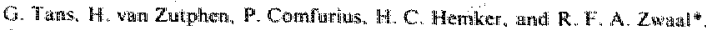

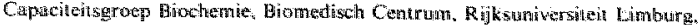

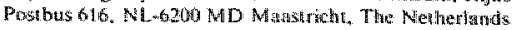

- To whom correspondenoe should be addressed 


\title{
The Role of Phospholipids and Factor Va in the Prothrombinase Complex*
}

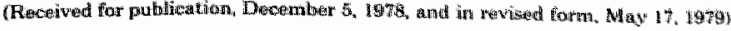

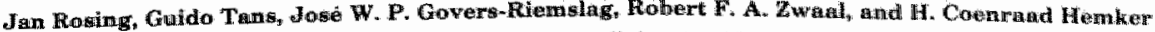

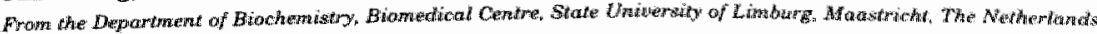

\begin{abstract}
The kinetic paraneters of the conversion of bovine prochrombin into thrombin by activated bovine blood prothing faction $\mathbf{X}\left(\mathrm{X}_{\mathrm{w}}\right)$ have been determined in. the atbsence and presence of $\mathrm{Ca}^{2+}$, activated hovine factor $\checkmark\left(V_{a}\right)$ and phospholipid (dioleoylphosphatidyleholine/ dioleoylphosphatidylserine, $1: 1 ; \mathrm{mol} / \mathrm{mol}$ ). In the absence of accessory components, the $K_{\text {oid }}$ for prothrombin is $131 \mu \mathrm{M}$, which is well above its concentration in bovine plinsma of about 1.5 pat. The $V_{\text {max }}$ of thrombin

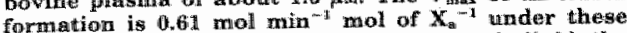
conditions. In the presence of 7.5 p phospholipid, the

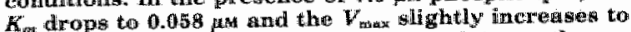
2.25 mol min ${ }^{-1}$ mol of $X_{\text {. }}$. For the complete prothronbizase complex $\left(X_{a}, V_{a,} C_{a^{2}}\right.$, and 7.5 yim phospholipid), a $K_{m}$ for prothrombin of 0.21 un and $W_{\text {byman }}$ of 1919 mol min ${ }^{-1}$ mol of $X_{a-1}^{-1}$ is found. The $V_{\text {max }}$ of thrombin formation slightly increases when more phospholipid to present in our experiments and there is comsider able increase of the $K_{\text {ir }}$ for prothrombin at higher phospholipid concentrations. Preliminary calculations whow that the prothrombin density at the phosspholipid surface at the $K_{\text {in }}$ is independent of the phosphindipid concentration. This indicates that the $K_{\text {mo }}$ meanumed in the presence of phospholipid has to be regardeoul an apparent $K_{e m}$ and the local prothrombin condentration determines the kinetice of activation.
\end{abstract}

Prothrondbin activation by prothrombinasie complexes of different composition was followed by gel electrophoresich in the presence of sodium dodecyl sulfate. Both in the alvance and preseste of phospholipid but without factore $V_{\text {wo }}$ prethrombin 2 is the main produet formed during the initial stages of steady state prothrombin activation. In the presence of factor $V_{n \text {, }}$ thrombirz is the main end product and minute anounts of prethrombin 2 are formed. This shift in the reaction pathway of prothrombin activation ceused by factor $V_{a}$ will contribute to the observed increase of the $V_{\text {wiun }}$ measured in the prescuse of factor $V_{a, a}$

One of the key rentetions in blood congugation and hemowtasis is the formation of thrombin thy linnited proteolysis of its

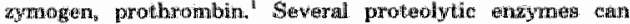
bring about this reaction, but under physiolonical conditions the serine protensta factor $\mathrm{X}_{\mathrm{A}}$ is the activatifing enzyme. In the

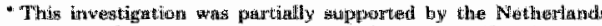

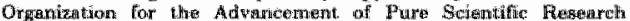

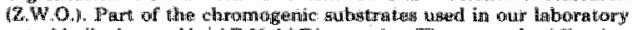

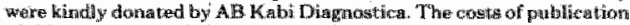

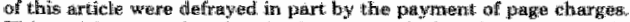

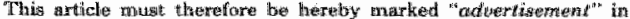

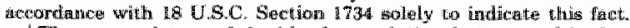

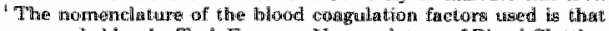

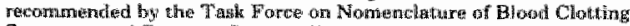

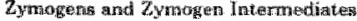

llasit 25 years many papers have sappared in the literature describing the detection and isolation of purtial protroblysis

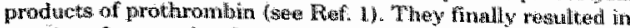
a series of papters by the group of Jackson of at $(2-7)$ which completed the clescription of the sites of peptide-bond splituring and ordicer of bond cleavage during prothrombin actervation. Papahadjopoulos and Hanahan (B) as well as several awtier authors (see Ref 1) have showra that additional carraponents

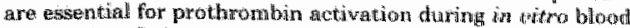
coagulation. It is now fentrally accepted that. $\mathrm{Ca}^{3+}$, a plogpholipid gurftace, and factor $V$ are arequared for prothrombin activation under physiollogical conditions. It has bean shown that the abowe mentioned clotting factoris have no le absordhed

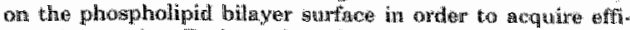

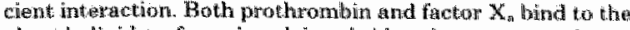
phospholipid surface vid alcium bridges bet waen $y$-cajboxy. glutarnic acids present in these protedus and polar head grow of the phosphotipial molecules $(9,10 \%$, while hyidrophobic interactions play an important rolle in the bincling of factor $V_{\text {a }}$

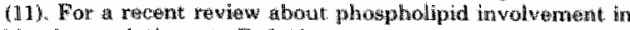
blood coagultion, see Ref. 12

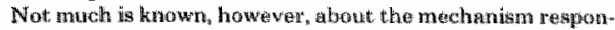
sible for the esmancemeat of the vate of prothrombin action tion by factor Vand phospholipids. Esmon and Jackson \5y did not the widence for a change of sites and ardurs of bond cheavage when the prothrombin molecule is activated by different combinations of the coniponenter of the prothrombinasse complex. The enhaneement of the rate of thrombir formation when phospholipid or factor" $W_{\text {an }}$ or both are adderd to a raixture of prothrombin, factor $\mathrm{X}_{\mathrm{n}}$ and $\mathrm{CaCl}_{3}$ as auch 17 . 13), does nat allow conclusions about the way they are in-

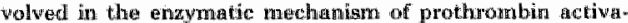
tion, since these experiments were carried out at single concentrations of the bomponents of the prothrombinase complax.

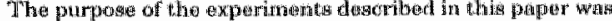

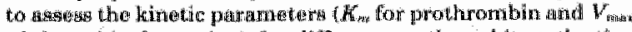

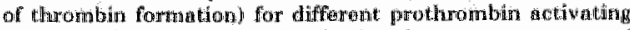
minctures ( $h$ e factor $X$ either in the absence or presence of

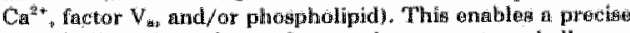

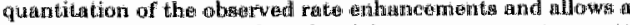
first attompt to explain the rote of the acedestry corngwrent in the mechanism of prothrombin actiwation.

Silwerberg et al. (14) have sepronted ar example of the offect af an acesisen componemt on the kindetice of a proteinats satalyzed activation of a clotiding, foctor. "They gtudied tho affect of thasue factor on the activation of factor $X$ by factor VII ${ }_{5}$, Tissue factar, a preparation which contains both phospholipids and protein compronents decteased the $K_{\mathrm{sm}}$ for freckor

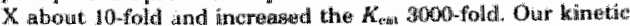

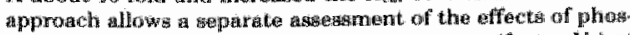
pholipid and the protein accessory component (factor $V_{4}$ ) of 
the prothrombinase complex on the kimetic parameters of prothrombin activation. The data presented in this paper likely have implications for the role of phosphtholipid and factor WII in the factor X-ractivating compllex (fiactor IX factor VIII, $\mathrm{Ca}^{2+}$, and phospholipid) of the intrimisic pathway of blood coegulatition.

\section{EXPERTEWTAL PROCEDURES}

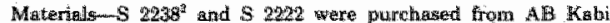
Diagnostica, Stockholm, Swreuen p-N PQCB was from Nutritional Bio-

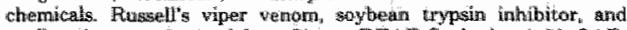

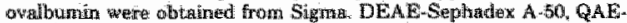

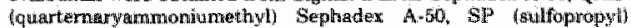
Sephadex $C-50$, Sephadex $6-100$, Sepharcese $4 \mathrm{~B}$ she $6 \mathrm{~B}$, and $\mathrm{CNBr}$.

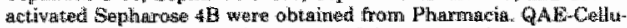

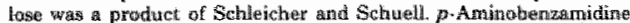
obtained fron Merch was wopled to Sepharose $4: B$ according to the procedure described by Di Scipio at al (1S). STI whe coupled to

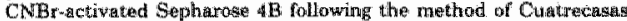
11.6\%. All reagenss used were of the bighest grade comamencially availabila.

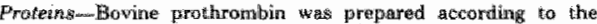
nethod of 0 wen al al. Before atorage at $-60^{\circ} \mathrm{C}$, whe prothorombing pireparations were passed through a collumn $0.9 \times 20 \mathrm{~cm}$ of $5 \mathrm{~s}$.

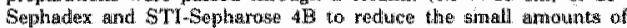
thrombin and factor $X_{n}$ which might the present in these proparntions. No thrombin and factor $X_{\text {a }}$ could be dewected in our fingl prothrombin preparations rusing an assay with the efmomogentic substrates $\$ 2238$

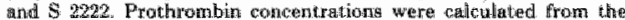

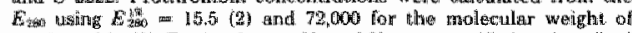

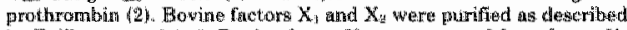

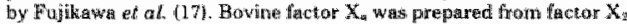

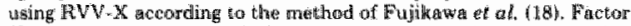
$X$ concentrationss were celculated after active site titration according to Smith (1)

Prothombin factor $X$ and factor $X$ preportanions were homoge.

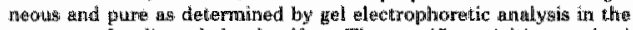
prosence of sodiun dodecyl sulfate. The specific antivitieg atiminten were equal to those peported in het. 2 (for prothrombin) and Rer. 17 for factor $X$ thend $x_{2}$ )

RVW.X was purified from the crade veam by the method af Swhiffman ef al (20). Factor W we puriffed acconding to the procedure gif Smith and Hamahan (23) witty mimor modifications. Who Gnal

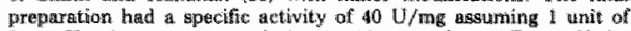
factor $V$ to be present per mil of normal bowine plasmye. Factor $V 10.4$ $\mathrm{maz} / \mathrm{mll}$ ) was activated at $37^{\circ} \mathrm{C}$ for $15 \mathrm{miru}$ in 200 and

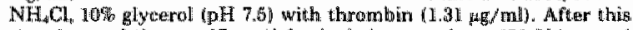

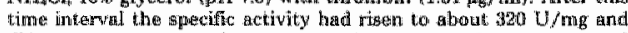

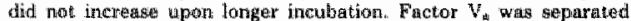
from thrombin on a benzamidine-Sepharose AB cobume which to our

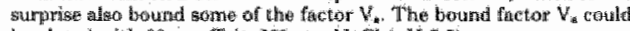

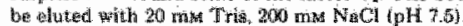

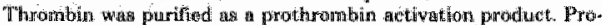

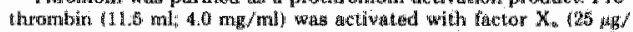

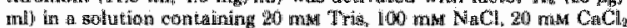

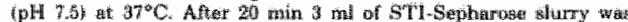

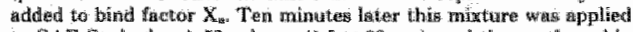
10 QAE-

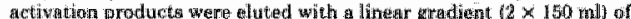

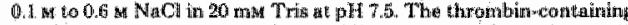

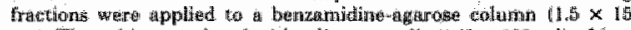

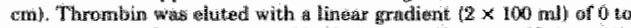

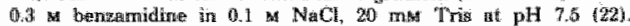

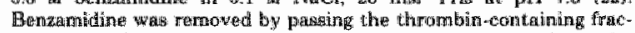

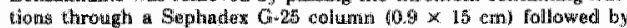

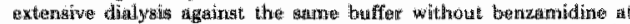
$g^{\circ} \mathrm{C}$. The thrombin concentration was determined by alctive mite utretion with $p$-NPOB according to chase and Shar $\$ 23$.

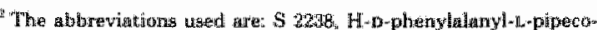

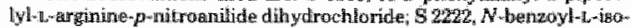

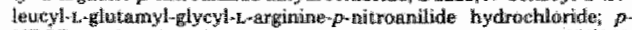

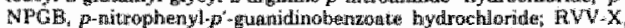

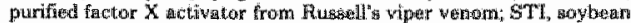
torypsirn inhibition.

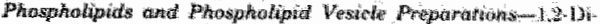

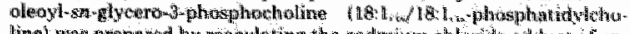

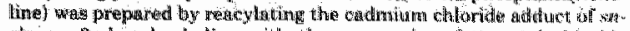

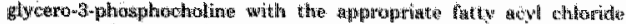

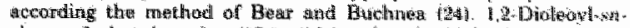

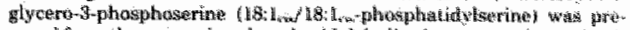

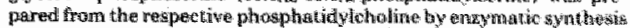

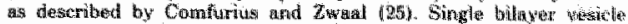

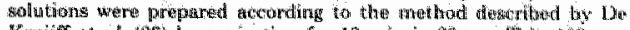

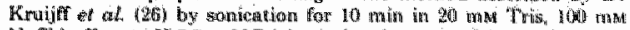

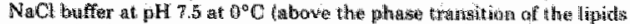

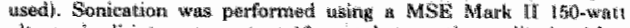

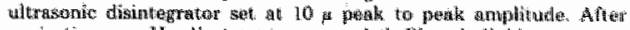

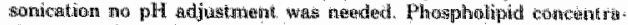
tions were determined by phosphate andyst ancording the method

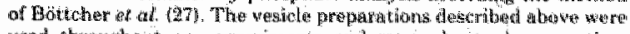

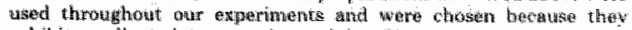

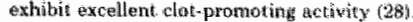

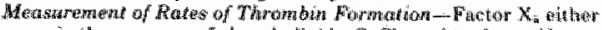

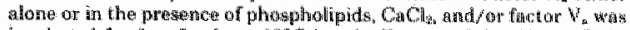

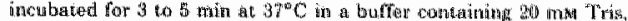

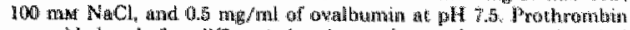
was added and atter difterent thme ingervgls sanplats were tathen and

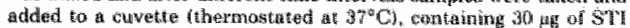

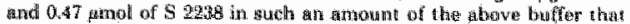

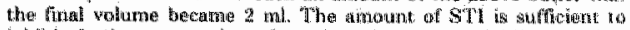
inhibit further conversion of prothrombin and to bribit the low

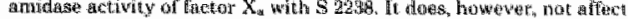

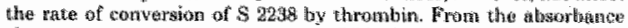

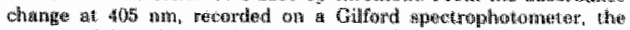

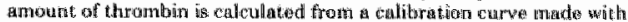

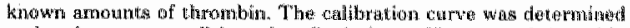

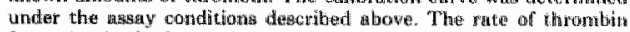

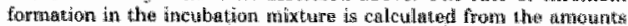

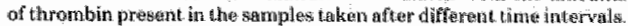

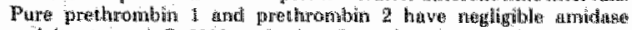

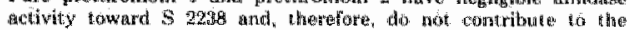

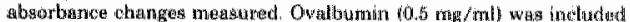
in all protein solutions and incubat thion of the protêtus.

For the congthuction of Linewerver . Burk plets the rute of thrombin

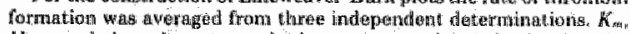

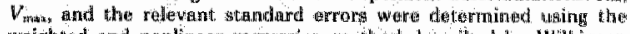

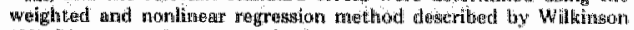
129). Dines were drawn accontingly.

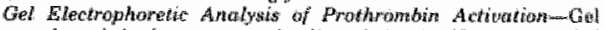

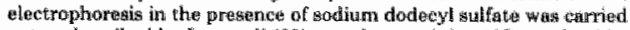

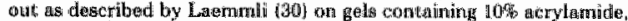

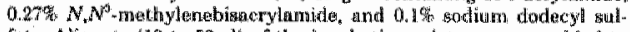

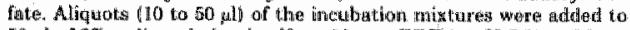

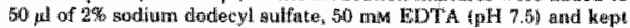

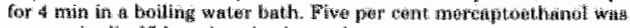

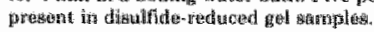

\section{HEULTH}

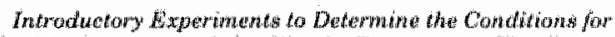
the Measurements of the Kinetic Parameders-"To lllow at kinetic approach it is neceseary in confirm that thas wethe of

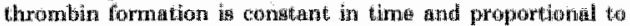
the amount of factor $X_{\text {a }}$ present for all different comprasitions of the prothrombin-actionating mixtures uswed. That this the

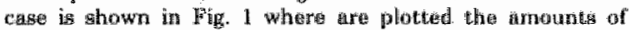
thrombin formed at different time intervale after starting the reaction with warying kaswon amounts of factor $X_{\mathrm{a}}$. Alliso when phospholipid wa factor $V_{n}$, or both, arte presant the rate of

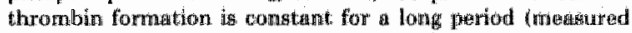
up to $\mathbb{2} 0$ miny and proportiongel to thic arrount of factor $X_{\text {. }}$ over the entire range of fractor $X_{a}$ cencentrations uad in the further experiments (datia not ahown). The latiter resiolit indi-

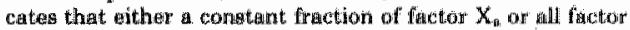

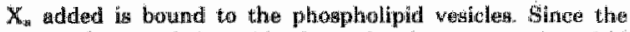
maximal rate of thrombin formation inereases only 4-fold when the phompholipid concentration is incresked form 2.6 $\mu \mathrm{M}$ bo $240 \mu \mathrm{M}$ (Fig, 11 , bo be discusised below) we conclude that at the low phospholipid concentrations 25 of of the added 


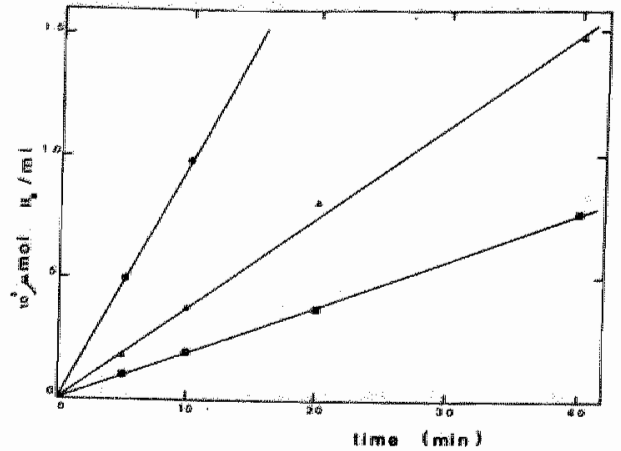

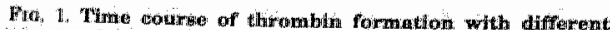

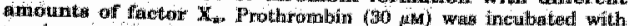

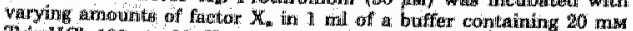

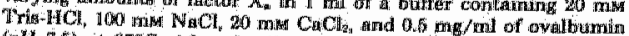

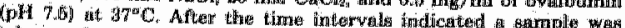

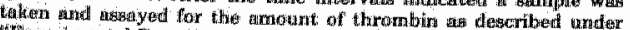

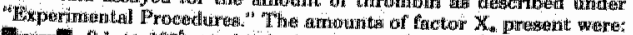

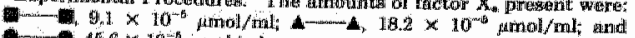

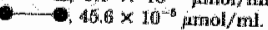

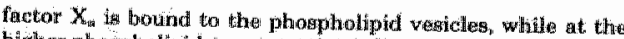
higher phoxpholipid concentriations almourt all ffactor $X_{\text {, added }}$ is bound. The linearity of thrombin formation with time was preserwad for all prothrombin concentrations used through
aut.

It ils well known that the rate of thrombin formation is influenced by the presence of factor $V_{\text {at and }} \mathrm{Ca}^{2 *}(7,13)$, In order to compare rates in the presence or absence of the accerasory compounds it is necessary that the experiments be carried out under optimal conditions with respect to the amounts of these components. This was accomplished by mesterinting thrombin formation at different factor $\mathrm{V}_{a}$ and $\mathrm{Ca}^{2}$ concentrmans at constant amounts of factor $X_{\text {and }}$ and thrombin. Mig. 2 ghows the $\mathrm{Ca}^{2}$ titation of thrombin formation when faetor $X_{\Delta}$ is converting prothrombin in solution in the presence and alinsence of factor $V_{\text {an }}$. The shapes of the titration curves and the optimal Cal concentrations ane independent of prothrombin, factor $\mathrm{X}_{\mathrm{a}}$ and factor $W_{n}$ in the concentration range used in our further oxperiments (not shown). The significant inhibition at $\mathrm{Ca}^{2+}$ concentrationg

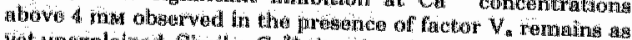

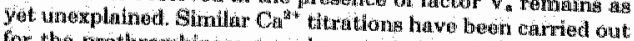
for the prothiromiloinase complex consistang of phosplioliphds

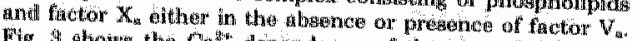
Fig. Stwows the cat dependence of the rate of thrombin

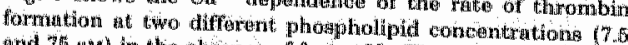

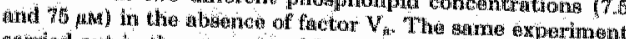
chirried out in the presesces of factor $V_{*}$ is shown th Fig. is interending to note that in the pressemes of factor $V$. It phospholipid the $\mathrm{C} \mathrm{a}^{2}$ tithation curves are aigmoidal.

Ther dieperidence of the thrombin formation rate on the anount of factor $W_{\text {a }}$ present was nessured at the optimal $\mathrm{Ca}^{2}$ conicentrationg determined in the abowe mentioned experi. ments. Whori factor $x^{2}$ converts prothrombin in exolution in the presenes of 3 mam Cach large amounts of factor $v$, have to be added in ordor to obtain the optimal rate of thrombin formation (Fig. 59 . "The true maximal rate cannot be obtamed experinentally, however; since thrombin formation is in. hibled at hight fuetor $V_{\text {is }}$ concentrations. Much, lower amourds of fantor $V_{n}$ and requirwd to obtain an optimal tate of thrombin

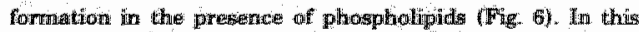
case no inlifibitory effect of factor $\mathrm{V}$, is found, so the ratere of thrombin formation in the presence of phosphinolispid and sat uratisig anownits of factuor $V_{n}$ can be regarded ans true optimal

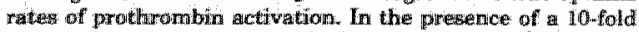
higher phospholipid concentration the fmount of factor $V_{\text {: }}$ needed to obtain half - saturation is increased about 5 times, and the optinnal rate attained is about 15\% lower which in cringed by a difference in the $K$ : for prothrombir low phrasphollipid concentrations (see liselow).

Dethermination of the Kinetic Constants of Prothrombin. Conversion with Differemt Prothrombin Activation Mix. twres-Rates of thrombin formation were measured at varying prothrombin concentrations with different octivation mixtores. When $\mathrm{Ca}^{2 *}$ or factor $\mathrm{V}_{\mathrm{a}}$ or both, are present, the datan

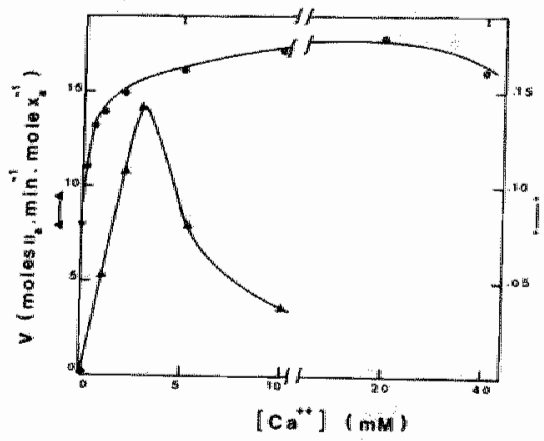

Fra. 2. The $\mathrm{Ca}^{\text {2** }}$ dependenee of thrombin formation in the

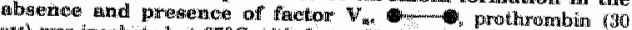

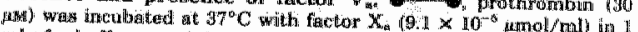

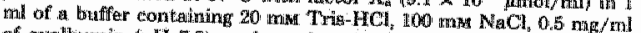
af ovallhwimin (pH 7.8), and warying amounts of $\mathrm{CaCl}_{2}$. "lhe itgte of thrombin formation was calculated from the amomis of thrombin present after 5 and 10 min of incutuation. pas) was incubated with factor $X_{0}\left(7.75 \times 10^{-7} \mu \mathrm{mol} / \mathrm{ml}\right)$ and factor $V_{0}$ (9.6 units/ml). Further experimental conditions as described above

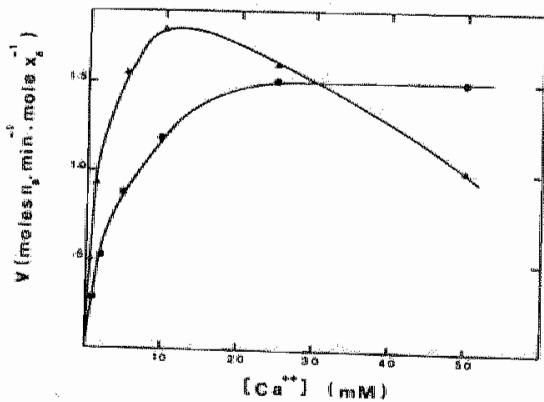

Fis. 3. The $\mathrm{Ca}^{\mathrm{a}-}$ dependence of the rate of thromibin forma-

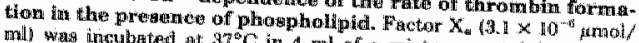

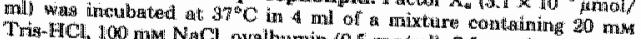

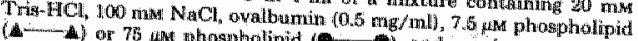

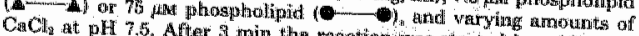

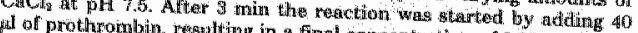

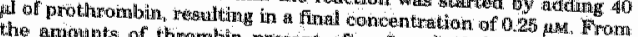

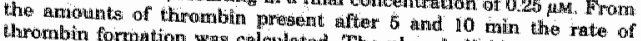

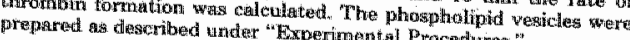




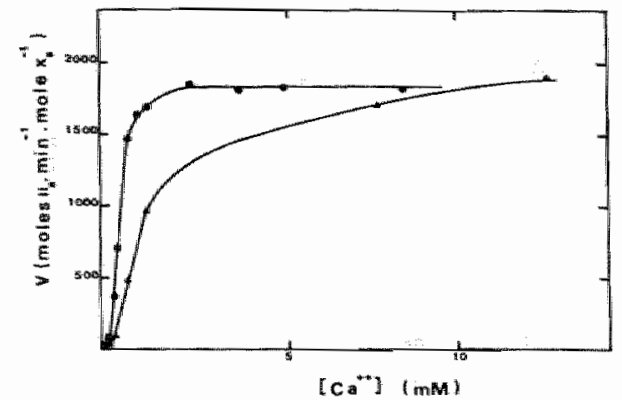

Fio. 4. The $\mathrm{Ca}^{2+}$ dependence of the rate of thrombin formatiroin in the presence of phospholipid and fater $V_{k}$. Factor $X_{\text {a }}$

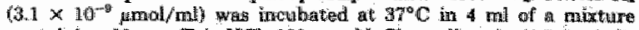
contailuing 20 ma Tris-HCl; $100 \mathrm{ma} \mathrm{NaCl}$, ovalbumis $(0.5 \mathrm{mg} / \mathrm{mal}$ );

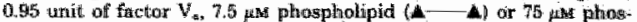
phetiphd (- - - ) and waryinge amounts of $\mathrm{CaCl}_{2}$ at pH 7.5. Aftar 3 min the reaction ow started by adding. 40 at of prothrombin giving a

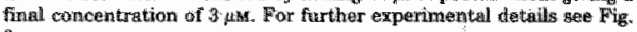
3.

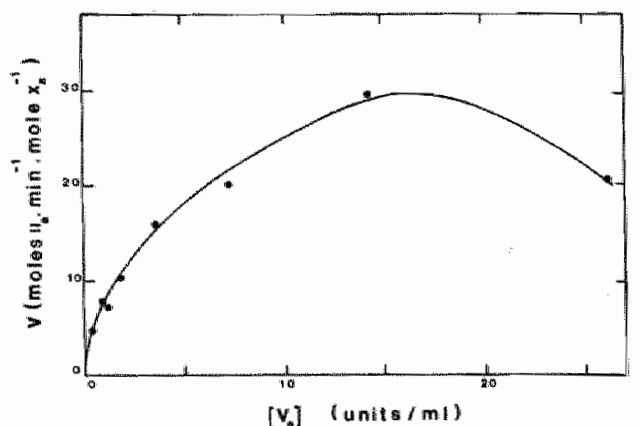

Fra. 5 . The factor $V_{\mathrm{s}}$ dependience of the rate of thrombin formation in solution. Factor $X_{m}\left(7.75 \times 10^{-7}\right.$ umol/mil) whes incubated at $37^{\circ} \mathrm{C}$ in $1 \mathrm{ml}$ of a mixhure containing $20 \mathrm{moM} T \mathrm{Tr}$ - $\mathrm{HCl}, 100$

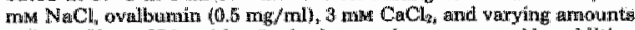

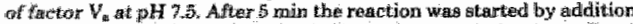

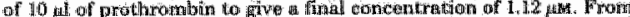

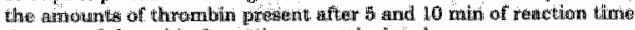
the rate of thrombing formation was collculated.

from $F$ igs. 2 to 6 have been wised to solect concentrations that givas as optimal rate of thrombin formation. In order to make a dirget compgrison of the different Lineweaver-Burk plots possible, rates of thrombin formation were exprested an moles of thinombin formed per min per wal of dector $X_{\text {a }}$ present. From the sinetic datu the $\mathscr{K}_{\mathrm{m}}$ for prothrombin (in $\mu$ ar) and the $W_{\text {max }}$ of thrombin formation (ir moles of thrombin per min per mol of $X_{\text {. }}$ ) were determined. Fig. 7 show the LinoweaverBurk plot of factor $X_{a}$ conversion of prothrombin into thrombin in the obsence of accessory components. From thiss plot

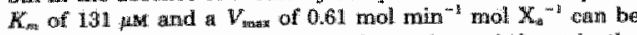
caloulated. When the sume experiment is carried out in the pressence of 20 mat $\mathrm{C}^{2}$ " there is a small decrime of the $K_{m}$ while the $W_{\max }$ is not affected. With o prothrombin activation

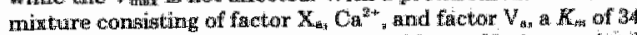
us is found (Fig. 8). In the presence of factor $V_{0}$ the ruaximal irate of thrombin formation is increased about 300 -fold to walue of $37 \mathrm{~mol}$ min ${ }^{-5}$ mal $\mathrm{X}_{\mathrm{*}}^{-7}$. Lineweaver-Burk plots of

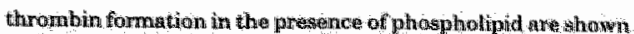

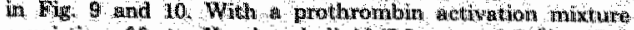

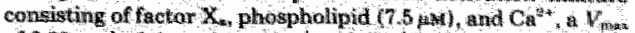

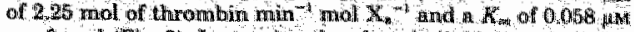
are found (fig 9). Increasing the phnspholipid coldentrituon

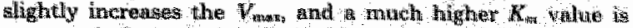

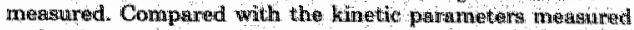
under the same conditions, bat in the abovice of phospholip ids, the considerable decresse of $h_{\text {nalues }}$ wost strilking Fig. 10 shows the Lineweaver-Burl plot of the complete prothrombinase complex (factor $\mathrm{X}_{\mathrm{ar}}$ phospholipad, $\mathrm{Ca}^{\mathrm{*}}{ }_{\mathrm{b}}$, arad

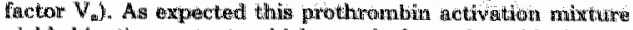

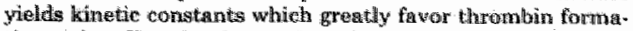
tion. A low $K_{\text {w }} v$ value for prothrombin, which is geinin dependent on the phosphotipid concentration and at hagh $W_{\min }$ of

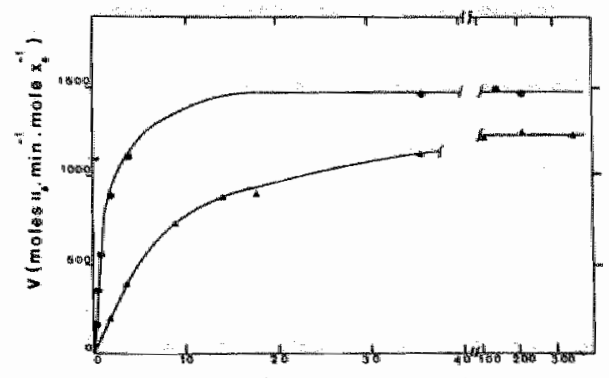

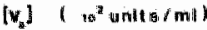

Fig. 6. The affect of factor $V_{a}$ on the nate of thrombin for

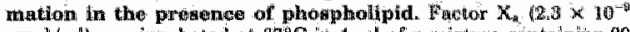

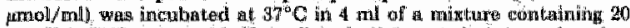

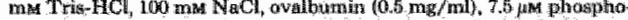

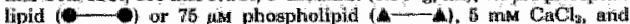

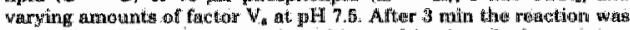
started by adding 60 pl of prothrombin resalting in a final conesentration of 0.95 and From the arnounts of thrombin present after 4 and is min of reaction time, the rate of thrombin formation was calculated.

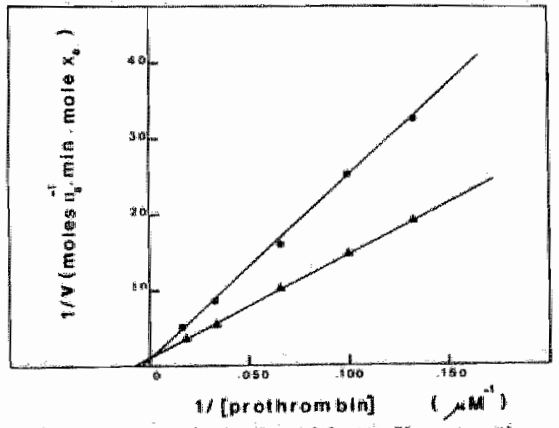

Fro. 7. Lineweriver-Burk plot of faetor $X_{\text {is }}$ converting pro-

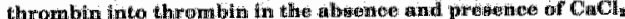

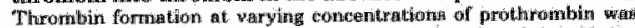

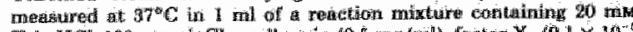

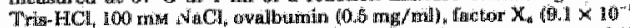

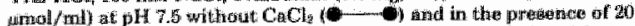

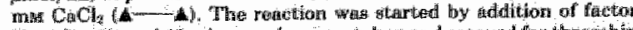

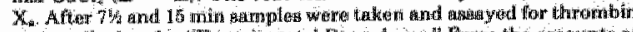

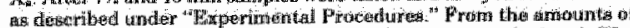

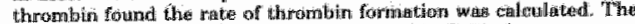

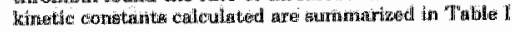


Mry

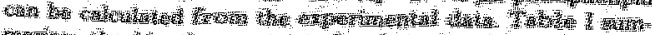
H

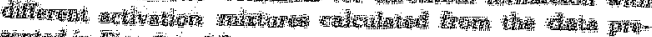

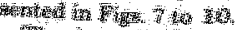

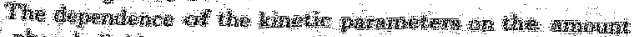

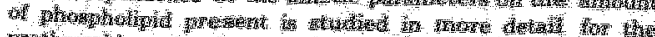

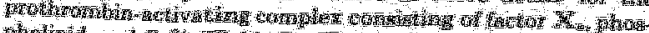

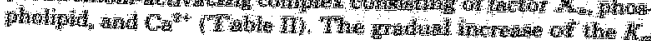

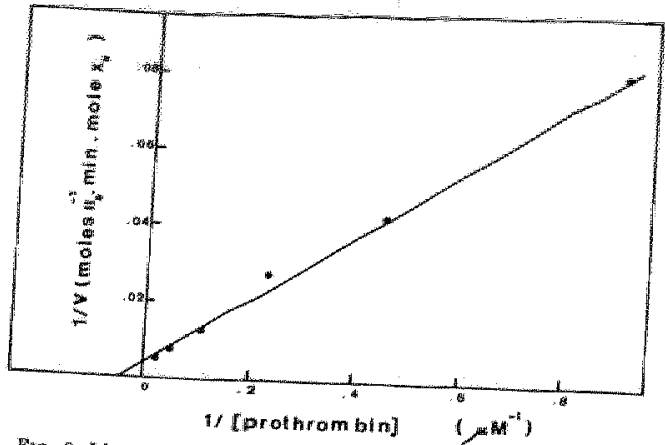

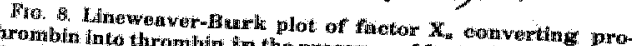

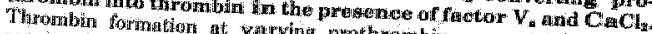

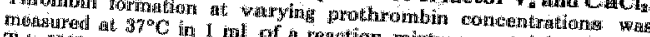

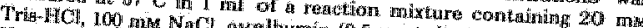

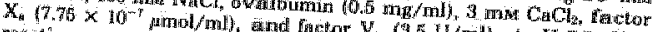

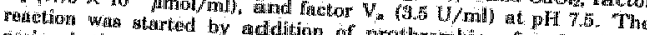

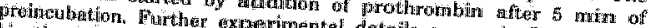

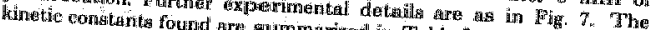

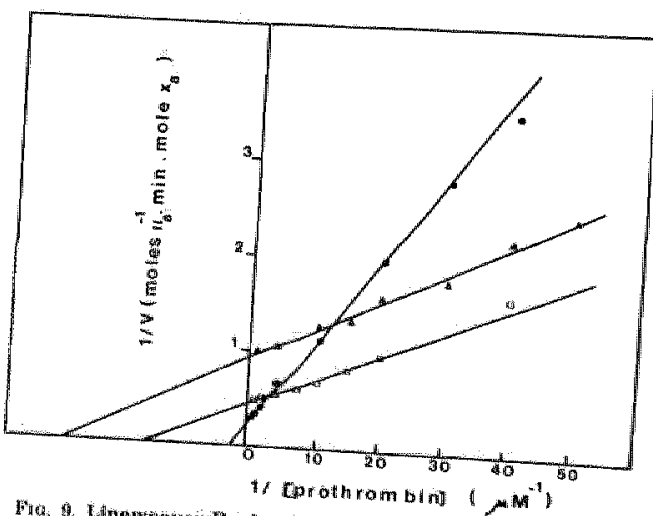

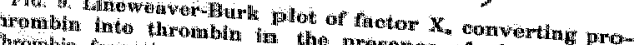

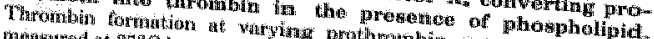

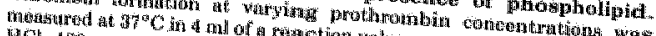

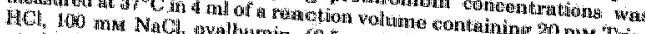
pribl/mit). of

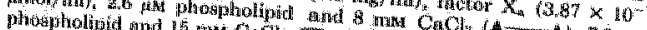

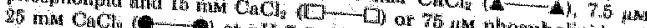

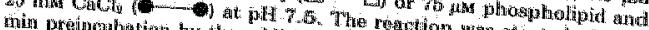

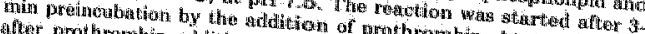

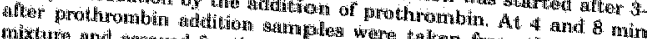

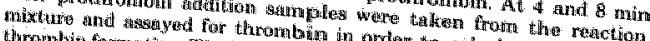

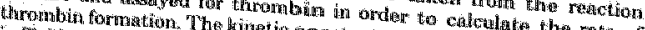

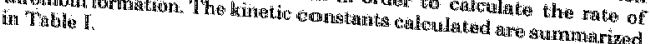

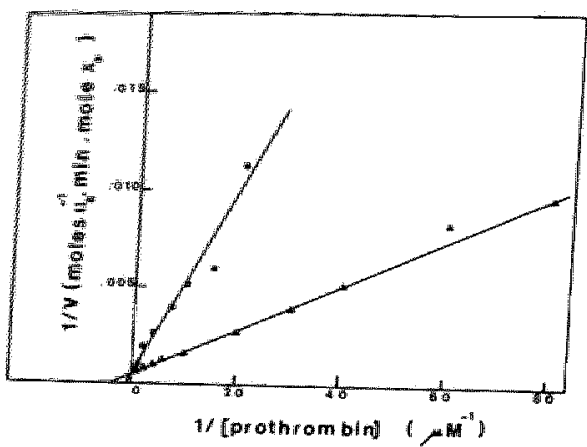

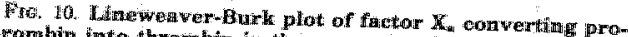
thrombin inte thrombin in the presente of phospholipilal and

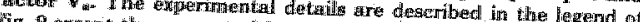

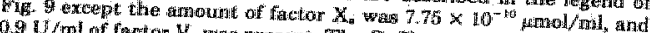

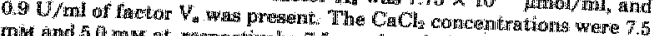

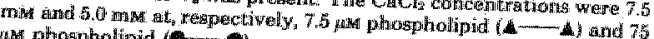
an phospholipion (1)

TARLE I

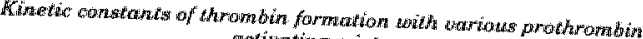
arctivating mutures:

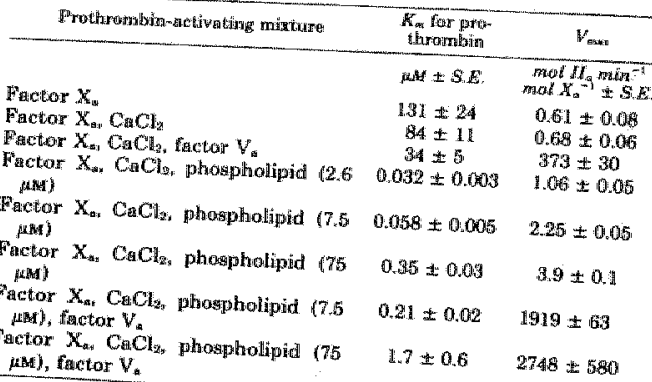

for parthrornbian with uncreasing phospholip id is obvilons "The increase of the $V$ " at higher amoun of phos the $V_{\text {raa }}$ of the thrombin formation This is likely due to the phoctipat is much less pronounced the amownt of fact or $X$. fact that the $V_{\text {mas }}$ is detwrimined by the different phompholipid com bound to the phosphollypid at

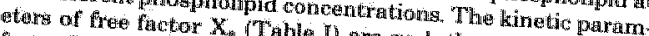

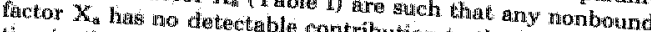
tion in the presence of phospholibution to thromibin forma with the phoswoholipid phospholipid. Thus variation of $V^{\prime}$

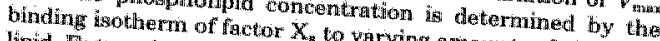
lipid. Exirapolation of a $X_{\text {a }}$ to warying amomats of phospho. 1/phospholipud] at constiant facto

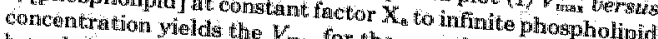

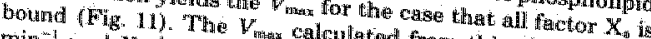
min'-1 moll $X_{a}{ }^{-1}$, which thow pholipid concentration shows that even at the lower phosthe added factor $\mathrm{X}$. in used in our experiments about $25 \%$

Teme Canse of prothom to the phospholipid vesicles. thrombin Actiontiom Minturan Activation by Different pro Sulfate Crel Electrophoresiog Visualized by Sodium Dodecti of Jackson (2-7) haphoresis-The experiments of the bin activation prodefets awm that different partial prothromthrombin with prodencts acelamulate clurin proithrom- 
FHBLE U

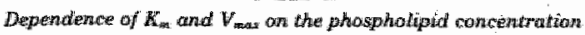

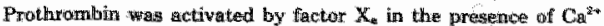
and phospholipid Remctions were charried out in mixtatre contrining $46 \times 10^{-7}$ funol of $\mathrm{X} / \mathrm{ml}, 100 \mathrm{~mm} \mathrm{NaCl}, 25$ ma Tris $0.5 \mathrm{mg}$ of

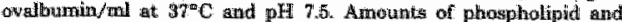

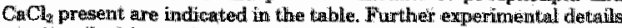

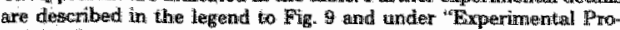
cediures."

\begin{tabular}{|c|c|c|c|}
\hline Phowphtolijofid & $\mathrm{CaCH}_{3}^{2}$ & $\bar{R}_{m}^{-}$ & $F_{\text {max }}$ \\
\hline 然㭗 & atist & $P M \pm \$ E$ & 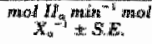 \\
\hline 2,6 & 8 & $0.0392=0.009$ & $1.06 \pm 0.05$ \\
\hline 4,0 & 8 & $0.062 \pm 0.005$ & $1.27 \pm 0.04$ \\
\hline 53 & 10 & $0.054=0.003$ & $1.54=0.09$ \\
\hline 7.5 & 10 & $0.058 \pm 0.005$ & $2.28 \pm 101.05$ \\
\hline 90 & 10 & $0,09=0.02$ & $2.04 \pm 0.20$ \\
\hline 10,5 & 10 & $0.068 \pm 0,008$ & $1.75 \pm 0.09$ \\
\hline 16,0 & 10 & $0.14 \pm 0.01$ & $2.35 \pm 0.48$ \\
\hline 26.3 & 15 & $0.164+0.006$ & $271 \pm 0.04$ \\
\hline 407.0 & 15 & $0.20 \pm 0.02$ & $3.12 \pm 0.10$ \\
\hline 536 & 25 & $0.25=0.01$ & $2.90+0.07$ \\
\hline 75 & 26 & $0.35 \pm 0.09$ & $3.90=0.10$ \\
\hline 80 & 25 & $0.46 \pm 0.097$ & $3,52 \pm 0,09$ \\
\hline 105 & 32 & 0.48 业 6.05 & $3,3=0.20$ \\
\hline 240 & 40 & $1.08 \pm 0.07$ & $4.10 \pm 0.20$ \\
\hline
\end{tabular}

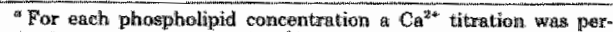
rormed to abtain the optimell $\mathrm{Ca}^{2+4}$ concentration.

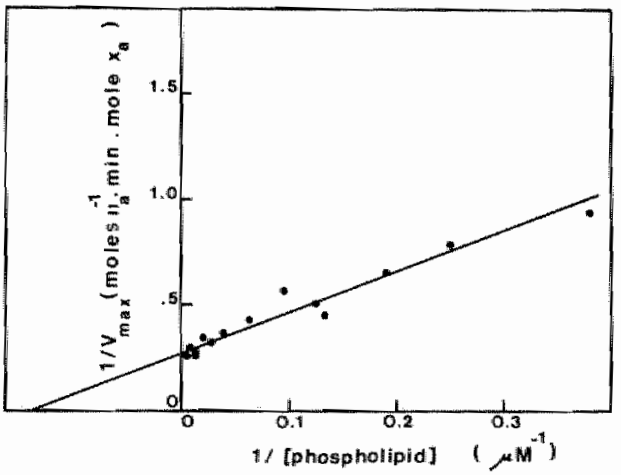

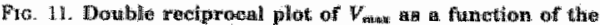

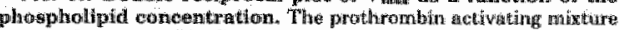

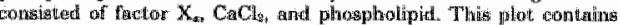
(itats summarizest in Table II.

that the kinetic parameters mearured in the experiments described abovia are in fact those for mixture of prothrombin and its parial activation products liberated diuring the time course of the reaction. However, get alpotrophoratic analysis of the produete formed during prothromingin activation undar the conditions of our experiments shows that only a neghigible amount of prothrombin is convertad into thitombin and othor partial activation products. Preliminaty experimentios on the kinetice of prethrombin 1 and prethrombin 2 point out that possibla conwersion of liborated activation products cannot contribute to thrombin formation in our experimants. "Iro investigate whather the changes of kinetic parrameters are accormpanied or earused by chariges in the reaction pathway of prothromibin activation it is necessery to devise experinentits in which suffucient activation products are formed, By incresto

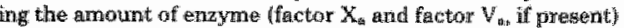

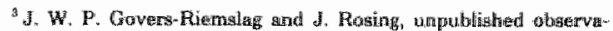
thong. it is possible to follow prothembirn ateivation by thiferemt

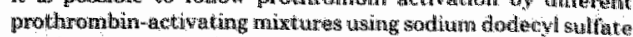
gel elloctropharesis (10ig. 12).

Prothrombin and ats actioston products ars ictentafied in the fignires. The relative migration distances and thaseyutence of prothrombin and activation products on the grel are cen sistent with earlier published gel data (2-6). In the absiace of factor $W_{A}$ (with or without phosphalipad) prethromtsin 2 is the main end preduct during the initial pinate of prothrombir

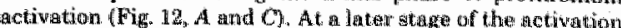
process suffieient thrombin is formed bo be detectable on the gels. With factor $V_{a}$ in the ahsence of phospholipid, thron num

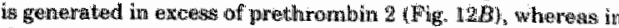
the presence of phospholipid and factor $V_{a}$ formation of prethrombin 2 cannot be detected (Fig. 12D). "These data point out that in the presence of factor $V_{a}$ a thift in the pathway of prothrombin activation oceurs (cose under "Disctusion"). For mation of prethrombin 1 during prothronabin activation will take place as a result of thrombin-catalytad proteolysis of prothrombin. lindesd prethrombin 1 is formed during the time course of prothrombin activation. In particaldar, it is foum in those experiments where considexalble amounts of thrombin are formed.

\section{DISCUSGION}

The atudies of Gsmon et a. (7) and wobin and Bsmout (13) have shown that both phospholipid and factor $V_{a}$ inereases the rate of convergion of prothrombin to thromition by factor $X_{\text {an. }}$ Since their experiments ware carried out at a singlie encen.

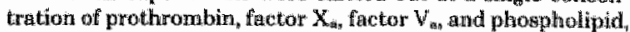
no insight in the mechanistic function of factor $V_{\text {in }}$ and phnospholipid in the prothrombinase complex could be obtained. Several explanations can be proposed for the rate enhancenents observed in the presence of tha accessory compononts of the prothrombingse complex (cf. Ref. 1) e.g.: 1. a change in the reaction pethwey of prothrombin activation; 2 an increase of the proteolytic capacity of factor $X_{6}$ upon interaction with

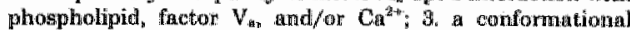
change of prothrombin apon binding to phospholipid, faetor $V_{t}$, and/or $\mathrm{Ca}^{2 *}$, making it a mores readily cleawidbla substivate: 4. an incriase of local prothrombin and favtor $X$ concentration after binding to phospholipid and/or factor $v_{\text {it }}$ prorrioting the formation of the prothrombin - prothrombinsss complex; 5. binding of prothrombin factor $V_{\text {ian }}$, and factor $\mathrm{X}_{\mathrm{w}}$ to phos-

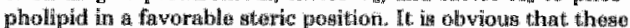

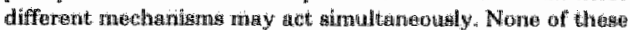

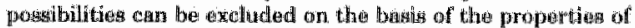

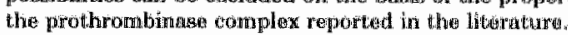

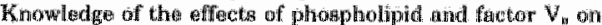

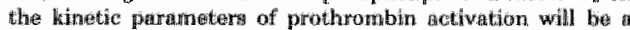

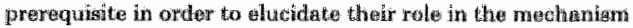
of the prothrombinese complex

The linetic partheters of different prothromiline activating

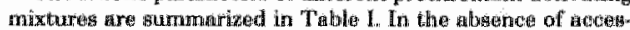
sory components prothermbin is a very poor gubstrake for

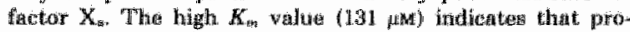
thrombin has a low affinity for factor $X_{\mathrm{s}}$ under thase condi-

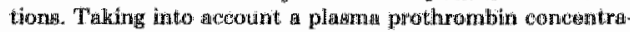
tion of abotit 1.5 Ma, which is far below the $K_{\text {min }}$ and the low

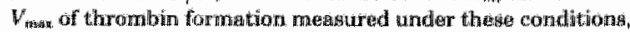

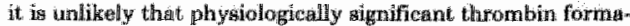
ton cals take in' ace whout inwolwernent of phospholiphid and factor $v$

The wanall decenese of the $K_{s n}$ for prothrombing arecurring

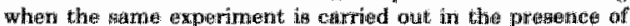

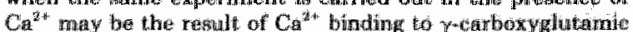
acid residues present in factor $X$ and prothrombirit. Since 
280

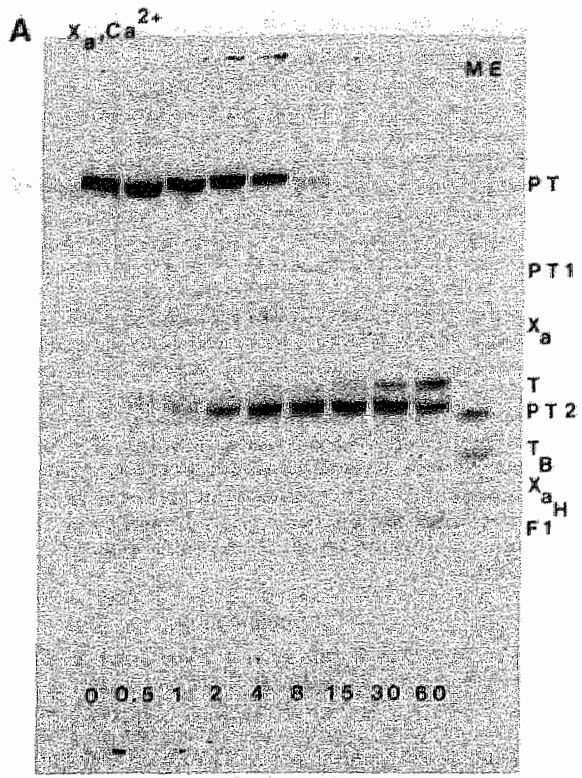

INCUEATION TIME (MIN)

C

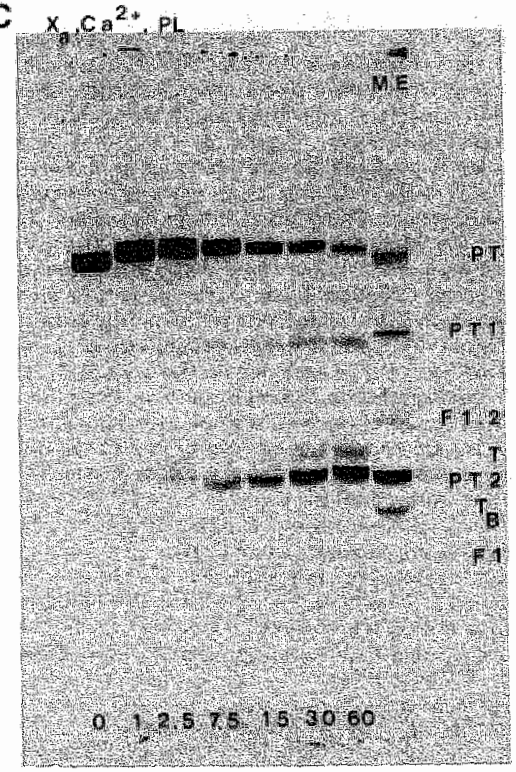

INCURATION TIME (TIN)

Fo. 12. "Winde controe of antivation of prothrombin with dif-

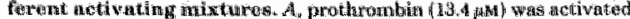

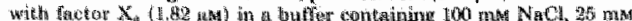

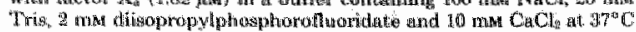

B

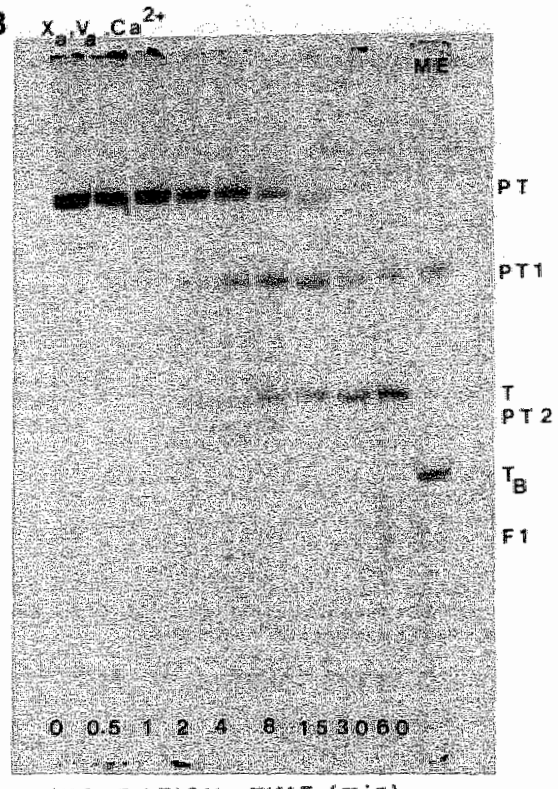

INCUBATION THAE (min)

D

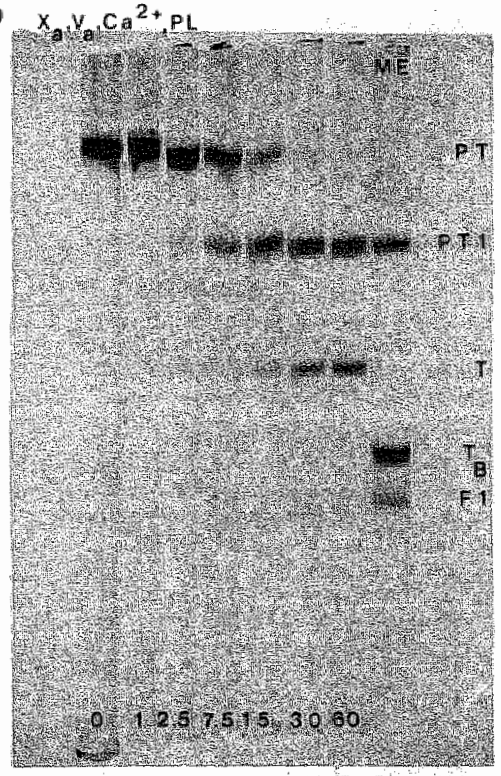

INICUBATION TINE (m)

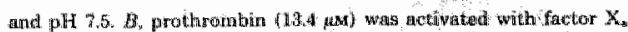

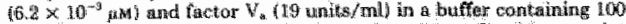

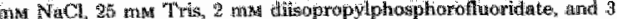

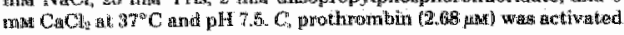


$\mathrm{Ca}^{3+}$ has no effect on the $V_{\text {max }}$ of thrombin formation wa

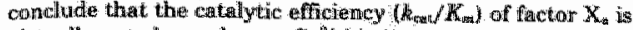
virtually not changed upon $\mathrm{Ca}^{3}$ binding.

Important changes of kinetic parameters taks place whem phospholipace or factor $V_{\text {s, }}$ or both, form part of the prothrom binmse complex. Phosphotipid causes a profound decrease of the $K_{m}$ for prothrombin. In the presenes of phospholipid the $K_{m a}$ decreases to walues bellow $1 \mu_{\mathrm{m}}$, which is lower than the plasma prothmombin concentration.

The $K_{n}$ for prothrombin is however, dependent on the amount of phosphohipid present (Table II). Highter $\mathbb{K}_{m: \text { values }}$ are measured at increasing phospholipid concentrations. The

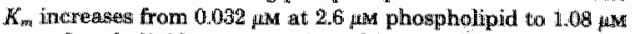
at: phospholipid concentration of $240 \mu \mathrm{m}$. Thwerefore, a $K_{\mathrm{m}}$ determined in the presenee of phospholipid has to be regarded as an apparent $K_{\text {an }}$. This is not surprising since the $K_{\text {te }}$ value is calculated using the concentrations of total added prothrombin. Howewer, the thrombin formed at the phospholipid surlace is in fact generated from bound prothirombin. "The prothrombin concentration at the $K_{m}$ should, therefore ${ }_{n}$ be expressed in terms of surface concentration in those experiments where $h_{n}^{\prime}$ values at different phospholipid concentrations are compared. To calculate the amount of bound pro. thrombin, binding parameters le,g available binding; sites and discociation constants) thave to be known for prothrombin binding to the phospholipid vesiches under our experimental conditions (temperature, $\mathrm{pH}$, ionic strength, and $\left[\mathrm{Ca}^{2+}\right]$ ). Although the appropriate binding data aro not avaliable, used as a finst approxim ation prothrombin binding parameters of Nelsestuen amd Broderius (31). For conditions approaching those of our experiments as close as possible $10.05 \mathrm{M}^{\mathrm{T}} \mathrm{Tris}_{\mathrm{y}}$ 0.1. $\mathrm{M} \mathrm{NaCl}, 5 \mathrm{~mm} \mathrm{CaCl}$ at $\mathrm{pH} 7 \mathrm{7} .5$ and $25^{\circ} \mathrm{C}$ ) they reported dissociation constant of $10^{-19} \mathrm{M}$ for the prothrombin.phospholipid complex and 17 umol of prothrombin binding sites per af of pospholipid for vesicles prepared from a $1 / 1$ (mol/ mol) mixture of bovire brain phosphatidylserine and egg yolk phosphatidylcholime. Using these binding data we calleulated the prothrombirn density at the phospholipid surface, expressed sis micromoles of prothrombin bound per $\mathrm{g}$ of phos. pholipid, at the $K_{r n}$ measured at different phospholipid ton. centrations (Table III). Although the apparent $K_{\text {nu }}$ increases when inereasing mounts of phospholipid are present, the prothrombin density at the phospholipid surface at the $K_{m}$ is independent of the phospholipid concentration. This means that it is the local prothrombin concentration at thes phospho hipid surfice which dotermines the kimetics in this case. Our experiment allow no conclusion as to what extent an in creased lockal prothrombin concentration explaing the Jarge decrease of tha $K_{\text {on }}$ observed in the presence of phospholiphid. This implies also that the possibility thet phospholipid brimgs prothrombin and fator $X_{0}$ together in a rave favorable crientation, the socalled juxtaposing effect, campot be evalu ated. Legitimate conehnsions in this conmection laswe to be based on a theoretical treatment of enzyrne kinetics in solution and hetarogeneous entyme centalyris taking place at the phos pholypid surface. This requires, for instance, knowiedge of diffusion conetants in solution and at the phospholipid surface.
TABLE

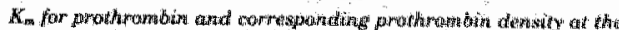

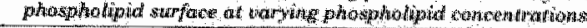

\begin{tabular}{|c|c|c|}
\hline 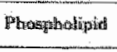 & $R^{\prime}$ & 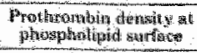 \\
\hline waty & WAst & amoly $z=5$ \\
\hline 2.6 & a.ase & 400.8 \\
\hline 40 & 0.0002 & $5.2+0.5$ \\
\hline 53 & 0.054 & $4.4 \geq 0.3$ \\
\hline 7.5 & 0.068 & 4.210 .4 \\
\hline 8.0 & 0.050 & 470 \\
\hline 10.5 & 0.068 & 4.210 .6 \\
\hline 16.0 & 0.14 & 6.920 .6 \\
\hline 26.3 & 0.164 & 50.2 \\
\hline 40.0 & 0.23 & 5. $7 \pm 0.6$ \\
\hline 52.6 & 0.25 & 40.3 \\
\hline 75 & 0.35 & $8=0$ \\
\hline 80 & 0.46 & $6.2 \pm 0.1$ \\
\hline 105 & 0.48 & $32 \pm 0.5$ \\
\hline 240 & 108 & $4 \pm 0.4$ \\
\hline
\end{tabular}

appropriate binding data, and arientation at the phospholipid surface of the proteins involved.

The role of factor $V_{n}$ in the complete prothrombinase com plex (factor $X_{a}$, factor $V_{\mathrm{a}=} \mathrm{Ca}^{2+}{ }^{2}$, and phosploblipid) is mainly restricted to an effect, on the $V_{\text {max }}$ of thrornbin formation. $A$ 700 -fold increase of $V_{\text {rian }}$ is observed in the presence of factor $V_{\text {a.. }}$

With resperet tos the mode of action of factor $V_{\alpha}$ in the prothrombinase complex one has to consider whether factor $V_{s}$ interacts with prothrombirs, changing its propertiass $a s$ subatrate or whether it forms complex with factor $X_{6}$ with a catalytic capacity different from free factor $X_{\text {. }}$. We exclude the possibility that factor $V_{n}$ exerts its stimulatory action, independent of factor $X_{\text {, or }}$ or prothrombin, by trapping potential inhibitury activation peptides relleased during prothrombin activation. Neicher fragment 1, fragment $2_{\text {o nor fragment }}$ 1.2. inhibit thrombin formation at concentrations generated during prothrombin activation in the time conume of our experiments. Since the factor $W$ concentration in our experiments is always much lower than the prothrom bin concentra tion a prothrombin. factor $V_{4}$ complex, if present, will be wh small fraction of the total amount of prothrombin added. "This combined with the fact that a turther increase of the amount

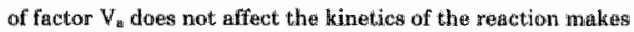
it very unlikely that a prothrombin - factor $V_{10}$ complex sats as

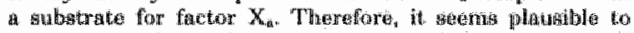

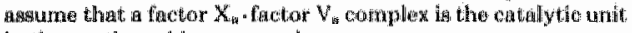
in the prothrombirnage compleis.

In solution factor $W_{8}$ also exhibits allimulating affect on thrembin formation. Hewever, from the oxperiment showith in

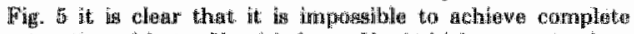

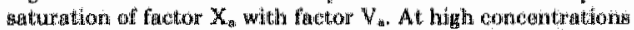
factor $V_{a}$ stren inhibitis thrombin formation. This phenomonon, for which we have no explanation yot, prevente addinge saturating amounts of factor $V$ a. This leaves open the aluestion whether phospholipid actustly has an additional affect on the

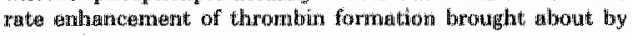
factor $V_{a}$.

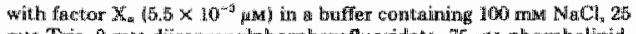

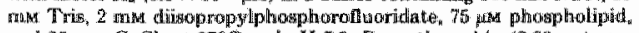

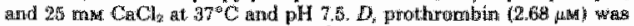

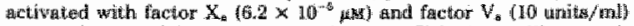

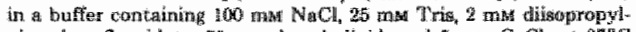

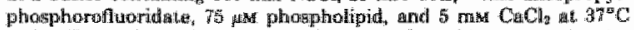

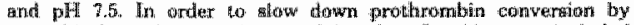

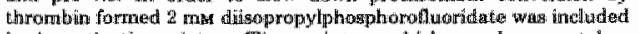
in the activation mixture. Thime points at which samples were taken and the identification of the band patern are indieg wed in the bigure.

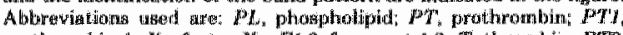

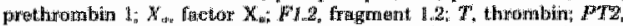

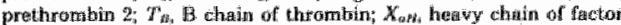

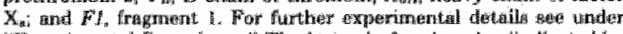

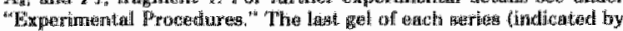

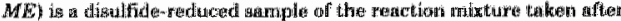

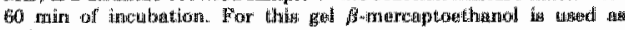
redueting agente. 


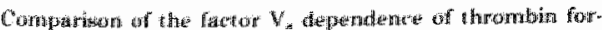

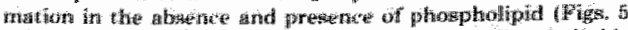

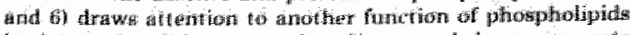

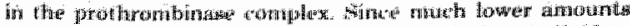

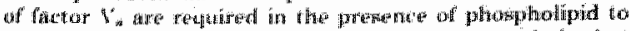

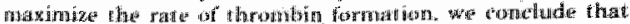

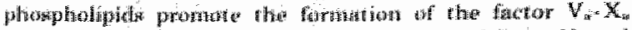

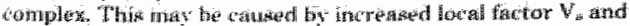

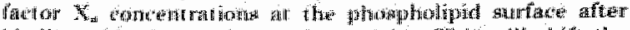

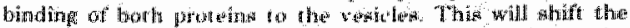

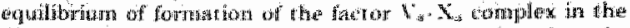

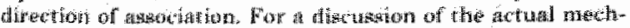

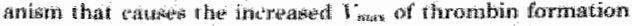

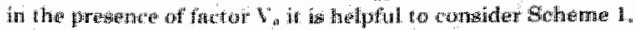

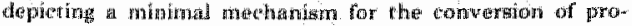

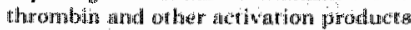

The different proteina alad complexes representhed in this

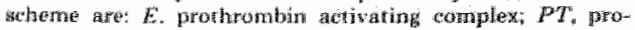
thrombira: $P T /$ prethernbin 1: PT2, prethrombin 2 , throm-

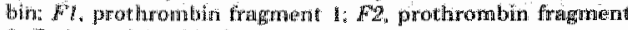
2. F.2. prothronbin fragment 1.2

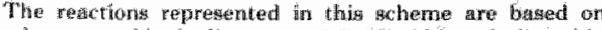
resulf res repored in the literature $(2-7,32)$. Although thrombin formation can take place with free prethrombin 1 or pretwrombin 2 as substrate (5), electrophoretic andlysüghow that in the courste of our kinetic experfiryents wuch gamull amounts of partisal activation products accumulate that conversion of intermediates released from the prothrombinase conplex or formed by the aetion of thrombin cannot contributhe the amount of thronbin formud. Therefore, thrombin is anerated in our kinetic experments wh the pathway fradichted by the solid werot's (Steps $1,2,3$, 赤

An wheriguing explasmation for the mechanism of rate enJancement by tactor $V_{\text {a }}$ can be put forward an the basis of the experiments ( $F$ ig. 12 ) in which the activation of prothrombin wit th different prothrombirnactivating mixtures is folllowed by soditum dodecyl sulfate gel eflectrophoresis. The experimental

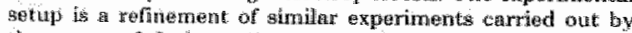
the graup of Jackson $(2,4,5,6)$. Our reaction conditions, prothombin eoncertumetion, and composition of activating mixtures are chosen on the basis of knowleche obtalned from our kinetic axperiments. When factor $X_{n}$ converts prothrom. bin in the absence and pressence of phospholipad, bart in the absende of factor $V_{\text {th }}$ mainly prethrombin 2 is formed, whil with tha complete prothrombinase complex (factor $X_{\text {an }}$ factor

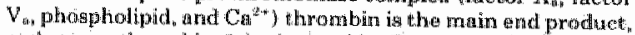

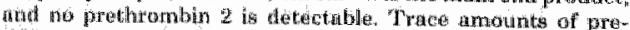

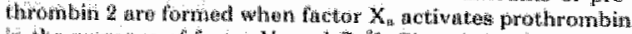

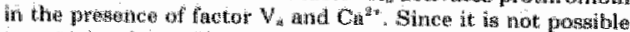

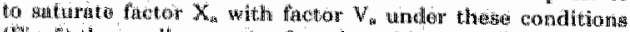

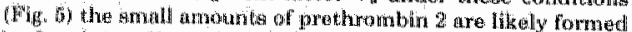

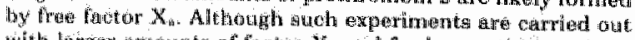

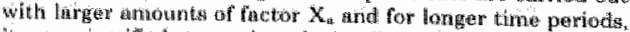

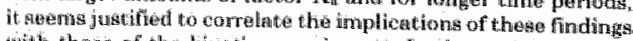
with those of the kinetic experimenta. Iri that case we make the followng proposal for the modle of factor Vaction. The main pathway occurring during puth hrombin activation in the

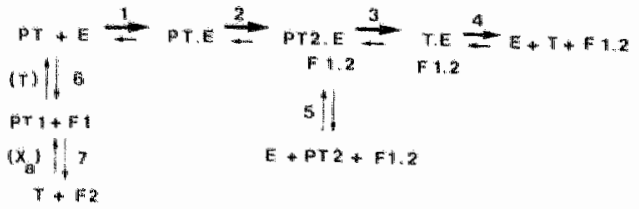

Scat nit absume of factor $v_{\text {an }}$ either in the absence ar presence of

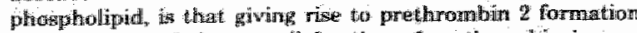

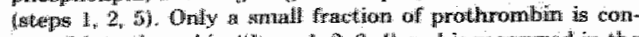

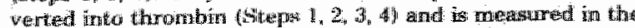

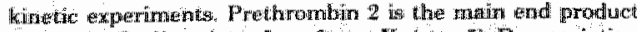

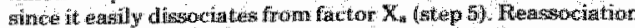

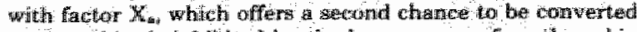

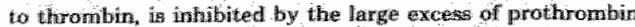

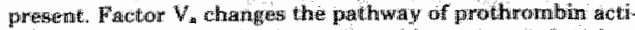

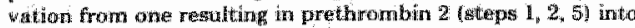

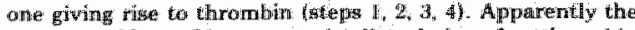

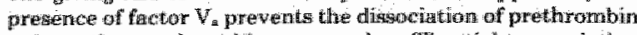

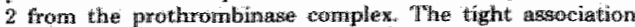
between fragment 1.2 and both prethrombin 2 and factor (5) can explain why prethrombin 2 does not dissocia from the prothrombinase complex. Disiselation of prethrombin 2 cam, however, alsw be prewerted whon factor $V_{x}$ increases Jirmitug rate constant owcurring in the reaction schicme ofter formation of the PT2. E conplex. This will detronse the stealy

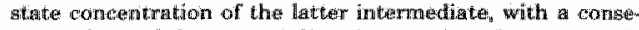
querut drop of the rate of dussociation of pretturombin 2 lit must: be empthasied that more complex mechanisms may be devised to accommodate abu observatons. However, the proposed explanation tow the observed shiff in the penthway

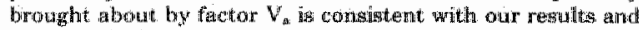
data wailwble in the literature. A study on the kingetics of activation of pertial prothrombin activation products with warious activating mixtures and the effects of prothrombir fragrmonts theareor, in progress in our labaratory, will liead to a more detailed deseription of the mechanisun of protinrombin activation.

Our fondings may gave important implications for the mechanism of other ghospholipix - protein complaxes thent participate in blocod coagulation. "The role of factor VIII wind phospholiph in the factor X-netiwatirg complex consisting of fiator

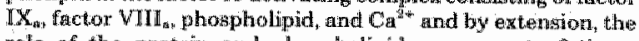
role of the proteun arud phospholipid component of tisisue

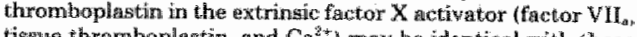
tisstue thromboplagtin, and $\mathrm{Ca} \mathrm{a}^{2+}$ ) may be identical with those of phospholipid and factor $V_{\text {an }}$ in the prothirombinasie compllex. Indewd Silverberg ot al. (14) reporked that tissue factor increases the $k_{\text {zas }}$ of factor $X$ activation by factor $W I_{n}$ abont $2900-f o l d$ and decreased the $R_{m}$ for factor $X$ 10-folkt. Since thssue factor contains thoth the phosphohipid and protein accessory comporment "y is not possible to sepertat their effect

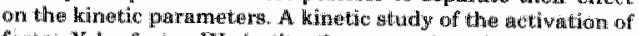

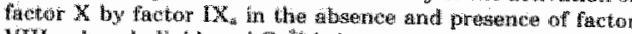

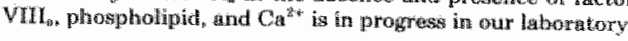

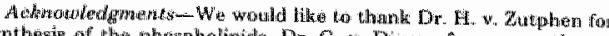

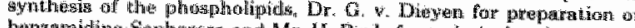

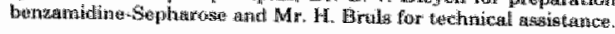

\section{REFERERCHS}

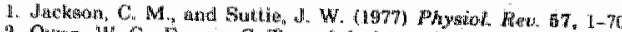

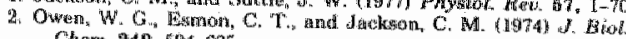
Chem, $249,594-60 \%$

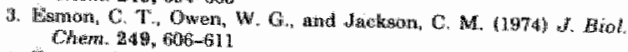

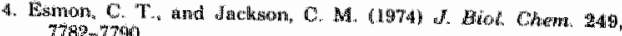
$7782-770$

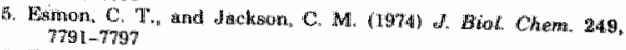

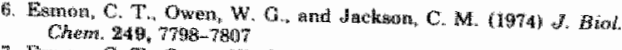

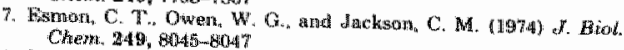

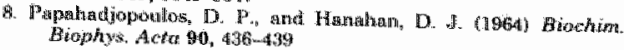




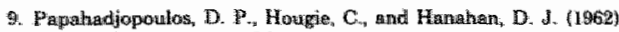

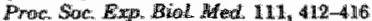

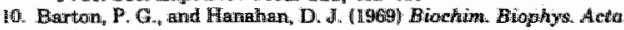
$187,319=327$

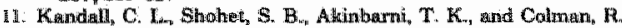

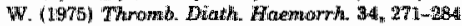

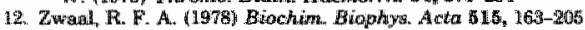

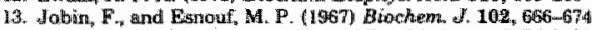

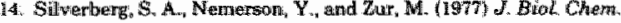
2512, $8401-18498$

15. Di Scipio, the $G_{4,}$ Hermodson, M. A, Yates, $S_{2} G_{3}$, and Davie

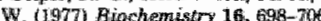

16. Cuatrecasas, P. (1970) s. Bapd, Chem, 245, 3059-3065

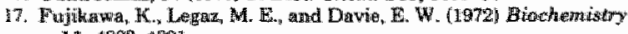
$11,4882-4991$

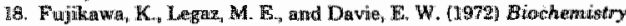
11. $4892-4849$

19. Smith, R L (1973) J Biot chert, 248, 2419-2424

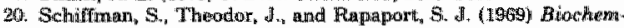
witry $8,1397-140 \%$

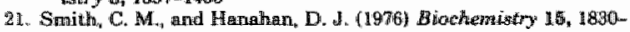

1888

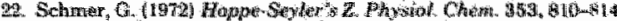

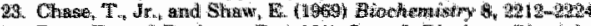

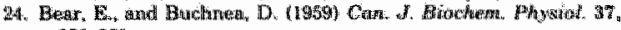
950 - 0

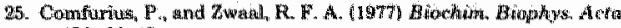
488, $36-42$

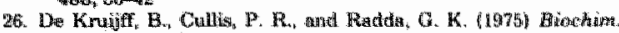
Brophira Acta w0, $6-30$

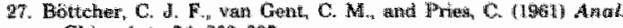

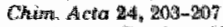

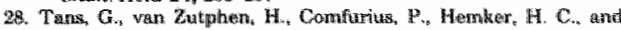

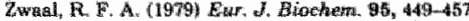

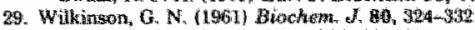

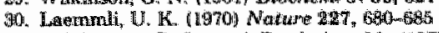

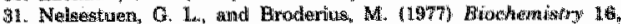
$4172-417 \%$

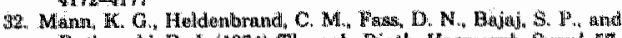

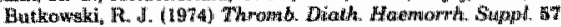
$179-196$ 
CHAPTER 5

THE ROLE OF PHOSPROLIPID AND FACTOR VIII TI THE ACTIVATON OF BOVINE RACTOR $X$

Gerbrand van Dieifen, Gutdo Tans, Jan Rasing and H. Coenrad Hemker

\section{SUMMARY}

The kinetic parameters of bovine factor $x$ activation by bovine factor $\mathrm{IX}_{\mathrm{a}}$ have been determined in the absence and presence of $\mathrm{Ca}^{2+}$ " thrombin activated bovine factor VIII (VIII ${ }_{a}$ ) and phospholipla (dLoleoylphosphatidylcholine/dioleoylphosphatidylserine, 75/25, mole/mole). Factor $\mathrm{IX}_{\mathrm{a}}$ in the absence of $\mathrm{Ca}^{2+}$, factor VIII and phospholipid $1 \mathrm{~s}$ able to catalyse factor $X$ activation. The $K_{m}$ for factor X Is 299 WM which is well above 1 ts concentration in bovine plasma of about 0.2 HM. The $V_{\max }$ of factor $x_{a}$ formation 1 is 0.0022 mole $x_{a} \cdot m^{-1}$. mole $I X_{a}^{-1}$ under these conditions. Adaltion of $\mathrm{Ca}^{2}+$ has 1 ittle effect on the kinetic constants of factor $\mathrm{X}$ activation by factor $I x_{a}$. In the presence of $10 \mathrm{mM} \mathrm{CaCl}_{2}$ the $\mathbb{R}_{\mathrm{m}}$ for

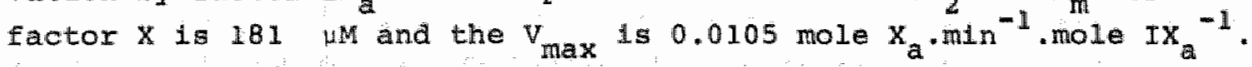
The presence of $10 \mathrm{\mu M}$ phosphollpld dramatically decreases the $\mathrm{K}_{\mathrm{m}}$ for factor $x$ to $0.058 \mu \mathrm{H}$ and the $\mathrm{V}_{\max }$ becomes 0.0025 mole $\mathrm{X}_{\mathrm{a}} \cdot \mathrm{min}^{-1}$. mole $\mathrm{Ix}_{\mathrm{a}}^{-1}$. The $\mathrm{V}_{\max }$ of factor $\mathrm{x}_{\mathrm{a}}$ formation silghtly increases when more phospholipia is present in our experlments and there is a conslderable increase of the $\mathrm{k}_{\mathrm{m}}$ for factor $\mathrm{x}$ at higher phospholipid concentrations. Therefore, the $\mathbb{K}_{\mathrm{m}}$ measured in the presence of phosphollpld has to be regaraed as an apparent $\mathrm{K}_{\mathrm{m}}$. The possible explanations for thit phenomemon are alscused.

For the complete factor $X$ actlvating complex (1.e. factor $X_{a}$, factor VIII $\mathrm{Ca}^{2+}$ and $10 \mathrm{wM}$ phospholipld), the $\mathbb{K}_{\mathrm{m}}$ for factor $\mathrm{X} 1 \mathrm{~d}$ $0.0063 \mu \mathrm{M}$ and the $v_{\max }$ is ralsed 200,000 fold to 500 mole $x_{\text {e. }} \mathrm{min}^{-1}$. mole $\mathrm{Ix}_{a}^{-1}$. In orcer to exert 1 ts stumlating effect on factor $x$ activation, factor VIII has to be activated with thrombln. Our results show that factor $I x_{a}$ is an enzyme which can activate factor $x$ at a very low rate. The stimulating effect of phosphollpld in factor $X$ activation $1 \mathrm{~s}$ malnly due to an ffect on the $\mathrm{K}_{\mathrm{m}}$ for factor $x$, bringing it within the range of the plasm concentration. The stimulatory effect of factor VIII 1 s explained by its 50,000 fold increase of the $v_{\max }$ of factor $x_{a}$ formation. 


\section{IHTRODUCRION}

Blood coagulation factor $x$ is a plasma glycoprotein that, during the clotting process, is converted into the serine protease factor $x_{a}$ through proteolytic cleavage of a single peptide bona $(1,2)$. Factor $x_{a}$ is the enzyme that, during the coagulation process, activates prothrombin to thrombin in a reaction accelerated by factor $v_{a}$, calcium ions and phospholipid.

Undex physlological conditions, the activation of factor $x$ can be accomplished in both the extrinslc and intxinsic pathways of blood coagulation. In the extrinsic pathway, factor $x$ is activated by a complex of factor VIT, tissue factor and calcium lons for a review, see ref. 3), whereas the activation of factor $x$ via the intrinsic pathway inwolves the interaction of factox IX, factor VIII, calcium ions and phospholipid.

It is now generally accepted that factor $\mathrm{IX}_{a}$, factor VIII, phospho1.pid and calclum lons form a complex (1, 8-11) in which factor Ix likely is the enzyme responsible for factor $x$ activation, since it 1. highly homologous to other serine proteases involved in blood coagulation $(12,13)$, and factor VIII, phospholipid and calcium ions function as cofactors (14). Thus it is tempting to speculate that the roles of the components of the intrinsic factor $x$ activator are analogous to those of factors $x_{a}, v_{a}$, phospholipid and calcium ions in the prothrombin activating complex $(7,8,9,1,14)$.

Since the activity of factor VIII is considerably enhanced by preincubation with small amounts of thrombin, it is likely that factor VIII participates in the factor $x$ activating complex in ar activated form (15). Davie et al. (16, 18$)$ reported that factor VIII can also be activated with factor $x_{\text {a }}$. Of interest is the finding of vehar and Davie $(17,18)$ that thrombin activated factor VIII is inhibited by disopropylphosphoroflworidate and antithrombin II which may have consequences for the way in which Eactor VIII functions in factor $x$ activation.

In addition to the proteins factor $\mathrm{XX}_{a}$ and factor VIII, the factor $x$ activating complex requdres negatively charged phospholipid and calcium lons. It has been shown that the proteins have to be adsorbed to the phospholipld bllayer surface during the activation reation $(6-11,14)$. Both vitamin $K$ dependent clotting factors $I X$ and $X$ bind to the phospholipia surface via calcium bridges between the $\gamma$-carboxyglutamic acld containing domains of the proteins and 
Whe polar head groups of the phospholipid (for a recent review on he role of phospholipid in blood coagulation, see ref. 19).

Whe purpose of the experiments described in this chapter is to examine the role of the various components of the intrinsic factor $x$ activating complex by an analysis of the kinetics of factor $x$ activation. In the past, a direct study of this reaction has been difficult for a number of reasons. Methods for purification af the protelns involved were not avaliable and factor $x$ activation could only be followed by a coagulation assay. Such an assay is, however, only possible in the presence of other coagulation factors and may be influenced by a number of feedback reactions.

A more detailed study of the activation reaction is now possible because methods are avaliable to purify the proteins involved and factor $\mathrm{x}_{\mathrm{a}}$ formation can be measured directly either with the chromogenic substrate $s 222 *(20)$ or through the release of an acia soluble radiolabelled activation peptide (21). Fujikawa et a1. (1) have shown that the activation of factor $x$ is the result of the cleavage of the same arginyl-isoleucine peptide bond in the heavy chain of factor $X$ both with factor IX and factor VIXI or tissue factor and factor VII as activator. Suomela and Blombäck (20) and Hultin and Nemexson (22) have shown that factor $X$ is activated at a very low rate by factor IX $\mathrm{I}_{2}$ in the presence of phosphollpld and calcium ions. Addition of thrombin-actlvated factor virl increased the rate of factor $x_{a}$ formation more than $1500-f o l d(22)$.

Brown et al. (23) reported a $k_{m}$ for factor $x$ of about 0.2 when factor $x$ is activated by human factor IXa and bovine factor VIII in the presence of calcium ions and phospholipid. No activation of factor $x$ by factor $I x_{a}$ in the absence of accessory components has been reported in the literature yet.

In this chapter we present experiments designed to sudy the kinetics of intrinsic factor $x$ activation. The approach $i s$ simflar to that in chapter 4. Using purified clotting factors and an assay for factor $x_{a}$ with chromogenic substrate, we are able to show factor $x$ activation by factor Ixa alone and derive kinetic parameters $\left(K_{m}\right.$ For factor $X$ and $V_{\max }$ for factor $x_{a}$ formation) for this reaction. We determined the effects of phosphollpid and factor VIII on these kinetic parameters. The results of this study lilow a first attempt to explain the role of phospholipid and factor vIII in the mechanism of factor $x$ activation and appreciating the contribution of the 
intrimbic pathway to thrombin formation in vivo.

\section{EXPERTAWHAL PROCEDURES}

\section{MATERIALS}

$S 2222$ and $s 230$ were purchased from $\mathrm{AB}$ Kabi Diagnostica, stockholm, weden. P-NeGB was from tutrtional Biochemicals. Russeli"s viper venom, heparin sodium salt (grade $T, 170$ USP units/mg), STI and ovalbunin oberined from Slgma. DEA-Sephadex A-50, Sephadex G-100 and G-25, Sepharose $4 B$ and $6 B$ and CNBI-activated sepharose $4 B$ were from pharmacla. AcA 44 was purchased from $\mathrm{LKB}$, Stockholm, Sweden. Trasylol was from Bayer, Leverkusen, Germany. Kaolin light was from BDH chemicals Jud. STI was coupled to CNBr-activated Sepharose $4 B$ followling the method of Cuatrecasas (24). Heparin was coupled to sepharose $4 \mathrm{~B}$ according to the method of cuatrecasas (24) as described by Fujikawa et al. (25). All reagents used were of the highest grade commercially avallable.

METHODS

\section{Proteina}

Bowlne factor $I X$ was purifted as described by Fujikawa et al. (25). Bovine factor $x_{1}$ and $x_{2}$ were preparea according to Fujikawat et $a$ (26). The factor $I X_{,} x_{1}$ and $x_{2}$ preparatlons were homogeneous and pure as determined by gel electrophoresis in the presence of sodium dodecyl sulfate. The specific activities of these pxeparations, as determined with a clotting assay, were equal to those reported $(25,26)$.

Partilly purifled contact pxoduct was prepared according to Nossel (27) and furthex purified by heparin-agaxose affindty chromatography a suggested by ostertad et al. (2B). Contact product was applied to the hepartm-agrarose colum $(1.5 \times 15 \mathrm{~cm}$ in a buter containing $0.05 \mathrm{M}$ sodium acet te and $0.3 \mathrm{M}$ NaCl at pH 5.5 ard was eluted with 1.rear gradient of 0.3 to $1.0 \mathrm{M}$ NaCl in $0.05 \mathrm{M}$ sodiumacetate at pel 5.5 .

RVV-X was purified from the crude venom as described by Schiffman at. $(29)$.

Bovine factor $x_{a}$ was prepared rom bovine factor $x_{2}$ using AVV-X acoording to the method of Fujikawa et al. (30).

Bovine factor $1 x_{a}$ was prepared by incubating factor IX $(2 \mathrm{mg} / \mathrm{mI})$ at $37^{\circ} \mathrm{C}$ with the purified contact product $(38 \mathrm{Hg} / \mathrm{ml}$ in a buffer contalning $50 \mathrm{mM}$ Tris-HCl, $50 \mathrm{mM} \mathrm{NaCl}$ at $\mathrm{pH} 8.5 \mathrm{in}$ the presence 
of $10 \mathrm{mM} \mathrm{CaCl}_{2}$ (31). After $60 \mathrm{~min}$ incubation EDTA and benzamidine wer added to result in final concentrations of $15 \mathrm{~m}$ and $20 \mathrm{~mm}$, res actively. The reaction mixture was then applied to a colum of DEA -Sephadex A-50 (1.5 x $30 \mathrm{~cm})$ in $50 \mathrm{mM}$ Tris-HCI. 50 mM NaCL and 20 Mu benzamidine at $\mathrm{pH} 7.9$. Factor $\mathrm{Ix}_{\mathrm{a}}$ was eluted with a Inear gradient of $50 \mathrm{mM}$ to $400 \mathrm{mM} \mathrm{NaCl}(2 \times 250 \mathrm{ml})$ in $50 \mathrm{mM} \mathrm{Tr} i \mathrm{~s}-\mathrm{HCl}$, 20 benzamidine at $\mathrm{pH} 7.9$.

Bov $y$ ne Bactor $x$ was prepared from factor $x_{2}$ by incubation of factor $x_{2}(3 \mathrm{mg} / \mathrm{ml})$ with factor $x_{a}(36 \mu g / m i)$ in the presence of $100 \mu$ phospholipid vesicles (for preparation see below in a buffer containing $175 \mathrm{mM} \mathrm{NaCl}, 10 \mathrm{mM} \mathrm{CaCl}_{2}$ and $50 \mathrm{mM} \mathrm{Tris-HCl}$ at $\mathrm{pH} 7.9$ at $37^{\circ} \mathrm{C}$ (cf. ref. 32 ). Gel electrophoresis in the presence of sodium dodecyl sulfate showed that after $90 \mathrm{~min}$ incubation all factor $x_{2}$ present was converted into Bfactor $X$ and a small amount of Bfactor $x_{a}$. So after 90 min incubation EDTA was added to a final concentration of $15 \mathrm{mM}$ and the reaction intxture was applied to an AcA 44 column $(2.5 \times 90 \mathrm{~cm})$ in $0.1 \mathrm{M}$ sodiumcitrate at $\mathrm{pH} 6.0$. Factor $\mathrm{X}$ was eluted with 0.1.M sodium citrate pH 6.0. After pooling, the bfactor $x$ preparation was dialysed against $175 \mathrm{mM} \mathrm{NaCl}, 50 \mathrm{mM}$ Tris-HCl buffer at pH 7.9 and chromatographed on a STI-Sepharose column $(1.5 \times 10 \mathrm{~cm})$ to remove factor $\mathrm{x}_{\mathrm{a}}$. BFactor $\mathrm{x}$ preparations were homogeneous and pure as determined by gel electrophorests in the presence of sodium dodecyl sulfate:

Thrombin was purified as a prothrombin activation product as described in chapter 4.

For the preparation of factor VIII, 9 litres of blood were collected in plastic contalners containing 1 litre 0.1 M oxalate, 100 m benzamidine, 20,000 units of heparin and 100,000 KIE units of tratol. Plasma was obtained by centrifugation of the blood at $0^{\circ} \mathrm{C}$ for 25 min at $2000 \times \mathrm{g}$ in a MSE Mistral $6 \mathrm{I}$ centrifuge. Baso, $(100 \mathrm{mg} / \mathrm{mI}$ ) was addea to the plasma and the suspension was stirred for 20 min at $4^{\circ} \mathrm{C}$. me $\mathrm{BaSO}_{4}$ was removed by centrifugation at $0^{\circ} \mathrm{C}$ for $20 \mathrm{~min}$ at $2000 \times 9$. $\mathrm{BaSO}_{4}$ treated plasma was stored at $-70^{\circ} \mathrm{C}$ ir 3 litre plastic ontalners before further use. After thawing and ethanol precipitation as described by schmer et al. (33), the suspension was centrifuged for 20 min at $2000 \times 9$ at $-2^{\circ} \mathrm{C}$ in a MSE Mistral $6 \mathrm{~L}$ centrifuge. The precipitate containing factor VIII was dissolved in a buffer of $0.017 \mathrm{M}$ parbituric acid, $0.125 \mathrm{M}$ NaCl, $0.05 \mathrm{M}$ 6-aminohexanoic acid at pH 7.0 at room temperature. This was then applied to two coupled sepharose 
6e columing $(5 \times 100 \mathrm{~cm})(34)$

Factor VIII was eluted at room temperature with the same barbituric acid buffer containhng $0.02 \mathrm{NaN}_{3}$ at pH 7.0 . After about $950 \mathrm{ml}$ of luate factor VII activity appeared well separated from a large protein peak contalning fibrinoger. The front of the peak $160 \mathrm{ml})$ was pooled and the pooled eluate was centrifuged at $190,000 \times \mathrm{g}$ for 21 in in a MSE superspeed 65 ultracentrifuge at $4{ }^{\circ} \mathrm{C}$. The pellet (factor VIII) was dissolved in $50 \mathrm{mM}$ Tris-HCl, $1.75 \mathrm{mM} \mathrm{NaCl}$ at pH 7.9 to a concentration of $40 \mathrm{U} / \mathrm{m}$. Following this procedure the total tecovery of factor VIII is about $2 \%$. The specific activity of this preparation, measured with a clotting assay, is about $25 \mathrm{u} / \mathrm{mg}$. The activity is raised 15-fold upon incubation with thrombin. The specific activity of purified factor VIII, measured with a clotting assay is a minlmun value, since it 1 sis dependent on the dilution of the factor VIII preparation. Higher values were obtained when higher dilutions were tersted.

Factor VIII activities were measured in a one-stage coagulation assay in factor VIII deficlent plasma prepared according to chantarangkul et al. (35). 50 wl buffer containing $0.029 \mathrm{M}$ sodium barbiturate, $0.029 \mathrm{M}$ sodiumacetate, $0.116 \mathrm{M} \mathrm{NaCl}$ (pH 7.4), $0.25 \mathrm{mg} / \mathrm{ml}$ inosithine and $0.5 \mathrm{mg} / \mathrm{ml}$ kaolin $1 . \mathrm{ght}$ were incubated for $6 \mathrm{~min}$ at $37^{\circ} \mathrm{C}$ with 50 WI of the factor VIII reagent. 50 wl of a factor VIII containing sample was added followed by the addition of 50 , 1 of $0.033 \mathrm{M} \mathrm{CaCl}_{2}$ and the clotting time was measured. Activities of factor VIII were expressed in $\mathrm{U} / \mathrm{ml}$ assuming $1 \mathrm{U} / \mathrm{ml}$ present in normal bovine plasma. Ali protein preparations were stored at $-70^{\circ} \mathrm{C}$ after dialysis against $50 \mathrm{mM}$ Tris-HCI, $175 \mathrm{mM} \mathrm{NaCl}$ at $\mathrm{PH} 7.9$. Before storage at $-70^{\circ} \mathrm{C}$, the Factor $X_{1}, X_{2}, B X$ and $I X$ preparations were passed through a column of StI-Sepharose $10.9 \times 20 \mathrm{~cm}$ to reduee the small amounts of factor $x_{a}$ that mlght be present in these preparations. No thrombin and factor $x_{a}$ could be detected in our protein preparations as determined with the chromogenic substrate $S 2238$ and $\$ 2222$.

Protein concewtiotions

Factor $x_{a}$ concentrations were determined by active site titration with p-NPGB acoording to smith (36). Factor Ix concentrations were also determined by active site titration with p-NPGB (see chapter 6). Factor $x_{1}, x_{2}$, and $\beta x$ concentrations were determined after complete activation with RVW-X followed by active site titration with p-NPGB. When protein concentrations are expressed in $\mathrm{mg} / \mathrm{ml}$, 
they were calculated from the $A_{280}$ using an $A_{280}$ of 14.9 and 14.3 for factors $I X$ and $I X_{a}(31)$ and of 12.4 for factors $x_{1}, x_{2}(37)$ and $B \mathrm{X}$.

phospholipids ard phosphotipid vesicte preparations

1,2-Dioleoyl-sn-glycero-3-phosphocholine $\left(18: 1_{\mathrm{cis}} / 18: 1 \mathrm{cis}\right.$-phosphatidylcholinel was prepared by reacylating the cadmium chloride adduct of sn-glycero-3-phosphocholine with the appropriatc fatty acyl chloride according to the method of Bear and Buchnea (38). 1,2-Dioleoy 1-sn-glycero-3-phosphoserine $118: 1 \mathrm{cis} / 18: 1 \mathrm{cis}$-phosphatidylserine) was prepared from the respective phosphatidylchollne by enzymatic synthesis according to the method of comfurius and zwal. (39).

Single bilayer vesicle solutions were prepared according to the method described by De Kruljff et al. (40) by sonication for 10 min in $50 \mathrm{mM}$ Tris-HCl, $175 \mathrm{mM} \mathrm{NaCl}$ buffer at $\mathrm{pH} 7.9$ at $0^{\circ} \mathrm{C}$ (above the phase transition of the lipids used). Sonication was performed using a MSE Mark II 150-Watt ultrasonic disintegrator set at 10 p peak to peak amplitude. After sonication no $\mathrm{pL}$ adjustment was needed. Phospholipid concentrations were determined by phosphate analysis according to Bötcher et al. (41). Vesicle preparations were made of a mixture of $25 / 75$ (mole/mole) of the phosphatidyluholine preparations described above.

Masumement of the rates of factor $x_{a}$ formation Activation of factor $X$ by factor $I x_{a}$ at $37^{\circ} \mathrm{C}$ elther in the presence or absence of phospholipid, $\mathrm{CaCl}_{2}$ and/or factor VIII (for further experimental conditions, see legends to the figures) was followed by transferring small aliquots of the reaction mixture after aifferent time intervals to a cuvet (themostated at $37^{\circ} \mathrm{C}$ ) contalining a buffer of $50 \mathrm{mM}$ Tris-HCl, $175 \mathrm{mM} \mathrm{NaCl}, 0.5 \mathrm{mg} / \mathrm{ml}$ ovalbumin and $10 \mathrm{mM} E D+A$ at $\mathrm{pH} 7.9$ in such amounts that the final vollume became $2 \mathrm{ml}$. In the cuvet also $192 \mu \mathrm{M}$ of the factor $\mathrm{x}_{\mathrm{a}}$ spectic chromogenic substrate $s 2222$ is present. Further reaction of factor $I X_{\text {a }}$ with factor $x$ in the cuvet is prevented by dilution and the presence of EDTA. Since factor IXa has no amiase activity towaras $s 2222$, the absorbance change recorded at $405-500$ m on an Aminco DW2 spectrophotometer (set in the dual wavelength mode), is a measure for the amount of factor $x_{a}$ present in the aliquot. From a calibration curve made with known amounts of active site 
titrated factor $x^{\text {a }}$ " determined under the same assay conditions as described above, the amount of factor $x_{a}$ present in the aliquot can

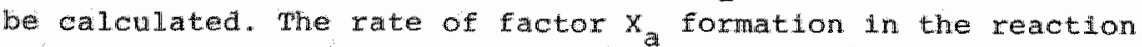
mixture is calculated from the amounts of factor $x_{a}$ present in the samples taken at alfferent time intervals.

The mount of factor IX present in the incubation mixture was chosen such that less than 2 of the factor $\mathrm{x}$ added is converted auring the experiment. Rates of factor $x_{a}$ formation are expressed as mole factor $x_{a}$ formed per minute per mole factor $I X_{a}$ present as determined by active site titration.

For the construction of Lineweaver-Burk plats the rates of factor $x_{a}$ formation were averaged from three independent determinations at each factor $X$ concentration. $\mathrm{K}_{\mathrm{m}}$ and $\mathrm{V}_{\max }$ were determined by statistloal analysis of the data as described by Eisenthal and Corntsh-Bowden (42) and Iines were drawn accordingly.

Gel eteotropharesta

Gel electrophoresis in the presence of sodium dodecyl sulfate was carried out as described by Laemil (43) on gels containing $10 \%$ acrylamide, $0.278 \mathrm{~N}_{1} \mathrm{~N}^{3}$-methylbisacrylamide and 0.18 sodium dodecyl sulfate. Before application to the gels, aliquots. (10 to 50 wl) of the protein preparations or incubation mixtures were added to 50 H. of 2 sodium dodecyl sulfate, $50 \mathrm{mM}$ EDTA (pH 7.9 ) and kept for $4 \mathrm{~min}$ in a boiling water bath. Five percent mercaptoethanol was present in aisulfide reduced samples.

RESULTS

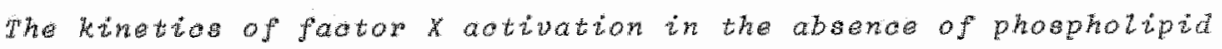
and factor vitr

Although there are no reports in literature which demonstrate that factor $\mathrm{IX}_{a}$ alone $\mathbb{H}$ able to activate factor $\mathrm{X}$, our kinetic experiments on prothrombin activation in solution (see chapter 4), which showed a high $\mathrm{K}_{\mathrm{m}}$ for the substrate prothrombin and a low vmax" made clear that it might be possible to activate factor $X$ in solution at high factor $X$ and factor $I X$ concentrations. Fig. 1 shows that factor $I X$ a $1 s$ indeed able to activate factor $X$ in the absence of calcium ions, factor VIII and phospholipid. Callium ions stimulate the activation about 7 -fold and there is a rather broad optimum around $10 \mathrm{mM} \mathrm{Ca}{ }^{24}$. The $\mathrm{Ca}^{2+}$-titration curves are independent of the amounts of factor $I_{a}$ and $X$ present. Pretreatment of factor IX 
with $10 \mathrm{mM}$ disopropylphosphorofluoridate for 1 hour followed by dialysis aid not affect the rate of activation. since factor ix. Is probably the only serine protease involved in blood coagulation that is not sensitive to disopropylphosphorofluoridate (5, 44). it is unlikely that factor $x$ activation in the above experiment is accomplished by traces of other serine proteases contaminating our factor IX preparations.

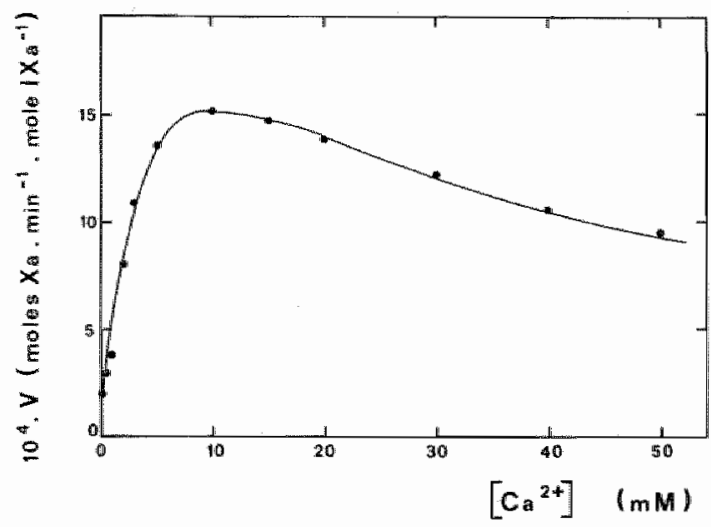

Fig. 1. The $c a^{2+}$-dependence of Eactar $x$ activation by factor IXa in solution

$\mathrm{F}_{2} \mathrm{x}_{2}(31.4$ wM) was incubated at $37^{\circ} \mathrm{C}$ with $\operatorname{IXa}\left(1.1 \times 10^{-3}\right.$ umoles/ml) in 200 Hi of th buter containing 50 mM Tris-Red, 175 $\mathrm{mm}$ acl, $0.5 \mathrm{mg} / \mathrm{mi}$ ovalbumin at pH 7.9 in the presence off varying amounts of $\mathrm{CaCl}_{2}$. Varying amounts of extra NaCl were present to compensate for the changes in lonic strength due to the variation of the $\mathrm{CaCl}_{2}$ concentration. When no $\mathrm{CaCl}_{2}$ was added, the presence of $5 \mathrm{mM}$ EDTA did not influence the rate of $\mathrm{x}_{\mathrm{a}}$ formation. The rate of $f x_{a}$ formation was calculated from the amounts of $f x_{\text {a }}$ present afex 7.5 and 15 min of 1 inewbation.

To allow a kinetic analysis of the reaction, it is necessary to demonstrate that the rate of factor $x_{a}$ formation 1 constant in time and increases IInearly with the amount of factor IX present. That this is the case is shown in Fig. 2. We also obtained constant rates of factor $x_{a}$ formation, proportional to the amount of factor $\mathrm{IX}_{\mathrm{a}}$ at higher factor $\mathrm{X}$ concentrations and in the absence of calclum lons (data not shown).

The rate of factor $x_{a}$ formation at various factor $x$ concentrations was determined in the absence of calcium ions and in the presence of $10 \mathrm{mM} \mathrm{CaCl}{ }_{2}$. The data are presented in the form of Lineweaver- 


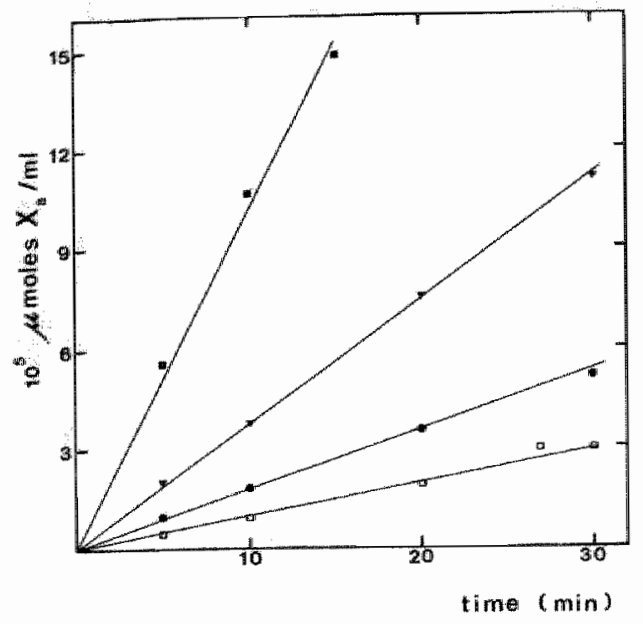

1.9. 2. The course of factor $x$ activation with different amounts af factor Ix a

$\mathrm{F}_{2}(31.4 \mu \mathrm{m})$ was incubated at $37^{\circ} \mathrm{C}$ with varying amounts of Ix $1 \mathrm{n} 200$ H1 of a buffer containing $50 \mathrm{mM}$ Txis-hCl. $175 \mathrm{mM}$ NaCl. $10 \mathrm{~min}$ cacli 2 and $0.5 \mathrm{mg} / \mathrm{ml}$ ovalbum in (pH 7.9 ). After the time intervals indicated, a sample was taken and assayed for $f x_{a}$ as aescribed under "Experimental procedures". The amounts of Ix a present were:
$\square-0 \times 0.55 \times 10^{-3}$
$\Delta * 2.2 \times 10^{-3}$
pmoles/mi ;
- $1.1 \times 10^{-3^{a}}$ moles/mil;
umoles/mi;
a- $6.6 \times 10^{-3}$ umoles/ml.

Burk plots (Fig. 3A, B). In the absence of calcium lons the $\mathbb{R}_{\mathrm{m}}$ for factor $X$ is $299 \mu M$ and the $V_{\text {max }}$ of factor $X_{a}$ formation is $2.2 \times 10^{-3}$ mole $x_{a} \cdot m^{-1}$.mole $I x_{a}^{-1}$. In the presence of $10 \mathrm{mM}$ $\mathrm{CaCl}_{2}$ the $\mathrm{K}_{\mathrm{m}} 181$ in and the $\mathrm{v}_{\max }$ is $10.5 \times 10^{-3}$ mole $\mathrm{x}_{\mathrm{a}} \cdot \mathrm{min}^{-1}$. nole $\mathrm{Ix}_{\mathrm{a}}{ }^{-1}$. "The factor $\mathrm{X}$ used in these experiments was factor $\mathrm{x}_{2}$. Hence all subseguent experiments reported in this paper are carried out with factor $\mathrm{x}_{2}$ as substrate.

The knthies of faotor $x$ activation in whe preance of phosphotipid and galetwm tone

The time course of factor $X$ activation by factor IX in the presence of calcium lons and varying factor $x$ and phospholipld concentrations is shown th Fig. 4. To obtain a linear time course of factor $x$ activation, it is essential to preincubate the phospholipid vesicles for $10 \mathrm{~min}$ at $37^{\circ} \mathrm{C}$ in the presence of $50 \mathrm{mM} \mathrm{CaCl}{ }_{2}$. As can be seen, the rate of factor $x$ activation is linear at factor $x$ concentrations 
A

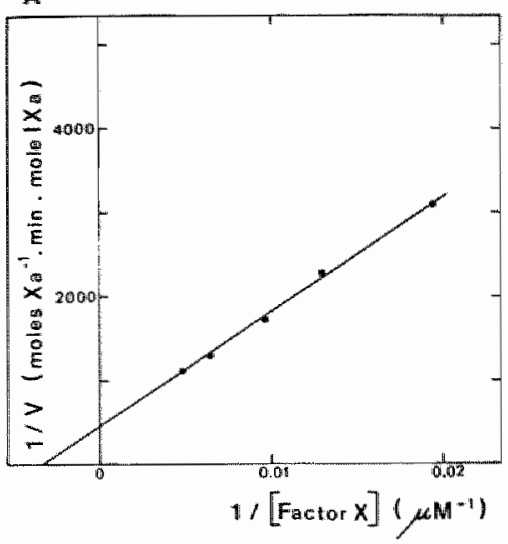

B

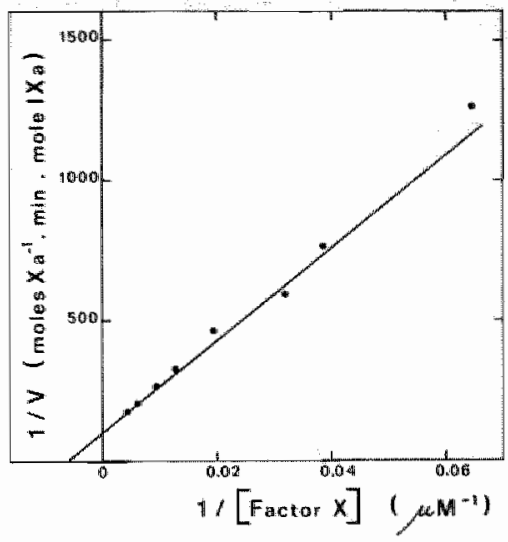

Fig. 3. Lineweaver-Burk plots of factor $x$ activation by factor ix in the presence and absence of $\mathrm{Cacl}_{2}$

$F x_{a}$ formation at varying concentrations of $f x_{2}$ was measurea at $\mathrm{pH} 7.9$ at $37^{\circ} \mathrm{C}$ in 200 ul of a reaction mixture containing $50 \mathrm{~mm}$ Tris-HCl, $175 \mathrm{mM} \mathrm{NaCl}$, ovalbumin $(0.5 \mathrm{mg} / \mathrm{ml})$, $\mathrm{f} \mathrm{IX}$ a $\left(1.1 \times 10^{-3}\right.$ «moles/mly.

: in the presence of 5 rm EDTA and $B$ : in the presence of $10 \mathrm{mM}$ $\operatorname{Cacl}_{2}$. The reaction was started by the addition of $F x_{a}$. After 7.5 and 15 min samples were taken and assayed for $f x_{a}$ as described undex "Experimental procedures". From the amounts of $f x_{a}$ found, the rate af $x_{a}$ formation was calculated. The kinetic constants calculated are sumarized in Table IrI.

well below and above the $\mathrm{K}_{\mathrm{m}}$ determined at the respective phospholipid concentrations (see below).

Jesty et aJ. (32, 45) and Fujikawa et al. (46) have shown that factor $x_{a}$ is able to catalyse a number of feedback reactions on the substrate factor $x$, espectally in the presence of phospholipta and calciun ions. Factor $x_{a}$ can cleave a small glycopeptide from the carboxyterminal end of the heavy chain of factor $x$, giving rise to so-called pfactor $X$. Factor $X$ is also able to convert both factor $x$ and $B$ factor $x_{a}$ by hydrolysing a specific peptide bond in the aminoterminal region of the heavy chain. Especialiy, this second feedback reaction may interfere with the rate determination of factor $x$ activation by factor IX $\mathrm{a}$. It is possible, however, to select experimentad conditions such that the feedback factor $X$ 


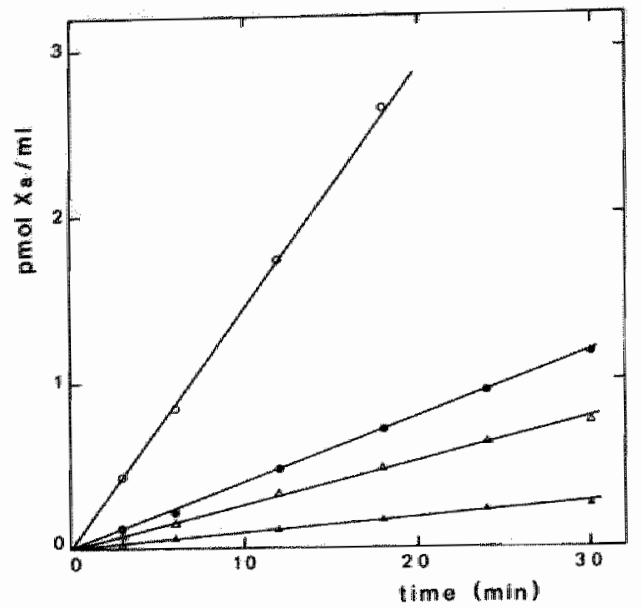

Fig. 4. rime course of factor $x$ activation by factor Ix in the presence of phospholipla and Cacl.

PL vesieleg were lmoubated $10 \mathrm{~min}$ at $37^{\circ} \mathrm{C}$ in a bufer containing

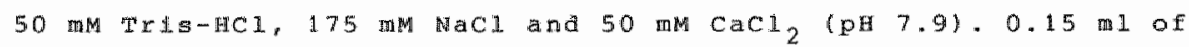
this Plo suspension was added to 1.2 mi of a reaction mixture containing $50 \mathrm{~mm}$ Tris-HCl, $175 \mathrm{mM}$ NaCl, $0.5 \mathrm{mg}$ ovalbumin/mi and $x$ (amounts indicated below) at pH 7.9 and $37^{\circ} \mathrm{C}$. Ateer 3 min, Ex activation was started by the adation of $0.15 \mathrm{mi}$ IX 10.067 M $(0)$ The final reation mixture contained: 50 mM Tris-HCl, 175 mMacl, $10 \mathrm{~mm} \mathrm{CaCl}, 0.45 \mathrm{mg} / \mathrm{ml}$ ovalbumin, $6.7 \times 10^{-6}$ Hmoles/mi. E IX and

$\Delta-\Delta, 10 \mu M$ PL, 0.02 HME $\mathrm{E}$;
$\Delta-\Delta, 10 \mu \mathrm{M}$ PL, 0.1

After the thine interval indicated in the figures, samples were

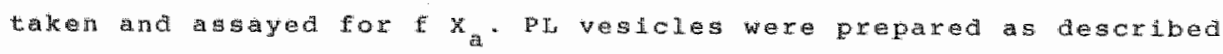
in the "ropeximertal procedures"

activation by factor $x_{a}$ are negligible compared to the contribution by factor $I x_{a}$. The low amounts of factor $x_{a}$ formed in our experiments $10.05-2$ pmol $/ \mathrm{ml}$ ) can easily be detected on the Aminco DW2 spectrophotometer. When these amounts of factor $x_{a}$ are incubated with calcium ions, phospholipid and factor $x$ at the conditions employed in our kinetic experiments, no extra factor $x_{a}$ formation is detectable. As an extra control an aliquot of the reaction mixture (see legend 
to Fig. 4) taken after $30 \mathrm{~min}$ was analysed by polyacrylamide gel electrophoresis in the presence of sodium dodecyl sulfate. The only protein that could be seen on the gel was factor $X$ (data rot shown) and no sfactor $x$ or factor $x_{a}$ is detectable. From these control. experiments we conclude that the factor $\mathrm{x}_{\mathrm{a}}$ formation we measure in our experiments results from the action of factor $I X$ on actor $x$.

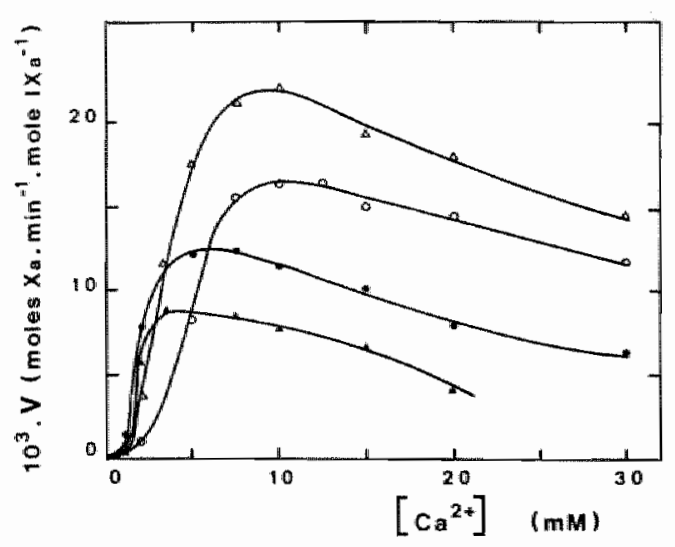

Fig. 5. The ca $\mathrm{a}^{2+}$-dependence of factor $x$ activation by factor IX ${ }_{a}$ in the presence of phosphoilpid

$\mathbb{P L}$ wesicles wexe incubated at $37^{\circ} \mathrm{C}$ in 0.3 m 1 af a buffex containing 50 mats-HCl. (pH 7.9), $100 \mathrm{mM} \mathrm{NaCl}, 0.5 \mathrm{mg} / \mathrm{mal}$ ovalbumin and vaying amounts of $\mathrm{CaCl}_{2}$. The iontc strength was kept constant by the addition of extra Nacl. After 10 min. $0.95 \mathrm{ml} \times(2.0 \mathrm{HM})$ wa added and 4 min later, $f x$ activatiom

was started by the adition of $0.25 \mathrm{ml}$ f IX $(0.09$ HM). Both proteins were dissolved in a buffer contalning $50 \mathrm{~mm}$ Tris-GCl (pH 7.9), 100 mM Nacl and $0.5 \mathrm{mg} / \mathrm{ml}$ ovalbumin. The final reaction mixture contained

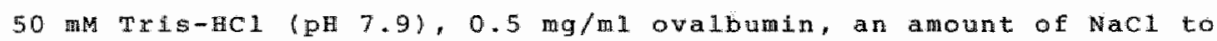
bring the ionic strength at $0.21, \mathrm{CaCl}_{2}$ as indicated in the figure, $1.27 \mu \mathrm{M} X \mathrm{x}, 1.5 \times 10^{-5} \mu \mathrm{moles} / \mathrm{mI}$. F IX and

$$
\begin{aligned}
& 4-25 \mu M P L ;-4,50 \mu M P L ; \\
& 0-0,400 \mu M P L .
\end{aligned}
$$

The rates of $x x_{a}$ formation we calculated from the anount of $f x_{a}$ present in the reaction mixture after 7.5 and $15 \mathrm{~min}$. PL vesicies were prepared as described in the "Expeximental procecuxes".

The $\mathrm{Ca}^{2+}$-dependence of the rate of factor $x_{a}$ formation at vartous phospholipid concentrations is shown in Fig. 5. The titration curves are sigmoldal and the optimal $\mathrm{Ca}^{2+}$ concentration slightly increases with increasing phospholipid concentrations. The $\mathrm{Ca}^{2+}$ optimum is. however, independent of the amounts of factor $\mathbb{I X}_{a}$ and factor $X$ present.

When the factor $I x_{a}$ concentration is varied at a constant amount of 
factor $X$, calclum lons and phospholipid, the rate of factor $X$ activation observed is directly proportional to the factor $I X$ concentration (F1g. 6).

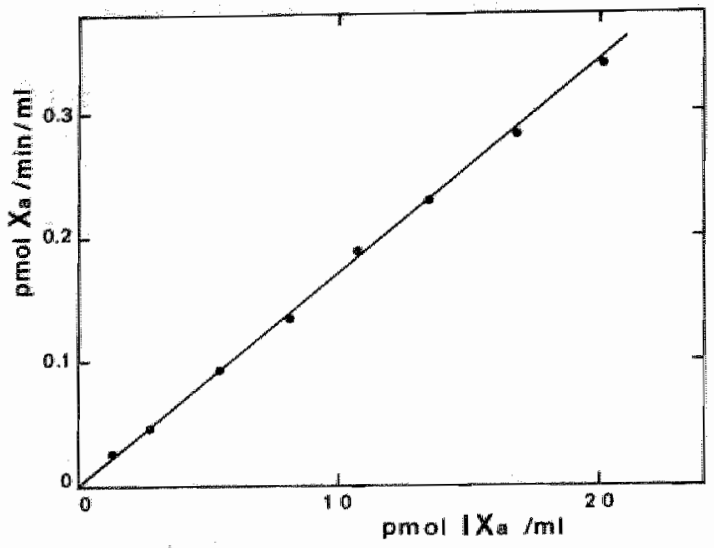

Fig. 6. The effect of factor IX an the rate of factox $x$ activation in the presence of phospholipid

pi vesicles were preincubated at $37^{\circ} \mathrm{C}$ in $50 \mathrm{~mm}$ Tris-HCl, $175 \mathrm{~mm}$ Naci, $50 \mathrm{mg} \mathrm{Cacl} 2$ at $\mathrm{pH} 7.9$. After $10 \mathrm{~min}, 50$ pl of this suspension was transerred to 300 yl of a buffer containing 50 mm Tris-HCl, $175 \mathrm{mM} \mathrm{NaCl}, 0.5 \mathrm{mg} / \mathrm{mL}$ ovalbumin and 0.833 M $F \mathrm{X}$ at $\mathrm{pH} 7.9$. After 4 min incubation at $37^{\circ} \mathrm{C}$, f $x$ activation was started by the addition of 150 ul 50 mM Tris HCl (pt 7.9), 175 mM Nacl buffer contalning $0.5 \mathrm{mg} / \mathrm{ml}$ ovalbumin and vaxious amounts f Ix " The final reaction mixture contalned 50 ma Tis-HCl (pH 7.9), 175 mM NaCl,

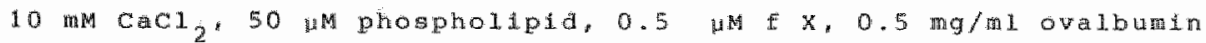
arid amounts off $f x_{\text {a }}$ ind cated in the figure. The rate of $x$ activation was calculated from the amounts of $f$ x present in the reaction mixture after 5 and $10 \mathrm{~min}$. The PL vesicles were prepared as deseribed in the "Experimental procedures".

The dependence of the rate of factor $\mathrm{x}_{\mathrm{a}}$ formation on the factor $\mathrm{x}$ concentration is determined at $10 \mathrm{mM} \mathrm{CaCl}_{2}$ and various phospholipid concentrations. A set of Lineweaver-Burk plots is obtained, two of which are shown in Fig. 7. An interesting feature of the lineweaverBurk plots shown in Fig. 7 is the hockey-stick shape of the plot. Above a certaln factor $x$ concentration, no further increase of the 
rate of factor $x_{a}$ formation is observed. The factor $x$ concentration at which the Iineweaver-Burk plot levels off increases with the phosphollpid concentration. A number of explanations is possible for this phenomenon. Since they depend on the model for the mode of action of phospholipid in the factor $\mathrm{X}$ activating complex, the explanations will be treated in the discussion. For calculation of the kinetic parameters $k_{m}$ and $v_{\text {max }}$, we only used the experimental points where the rate of factor $x$ activation is still dependent on the amount of factor $x$ present.

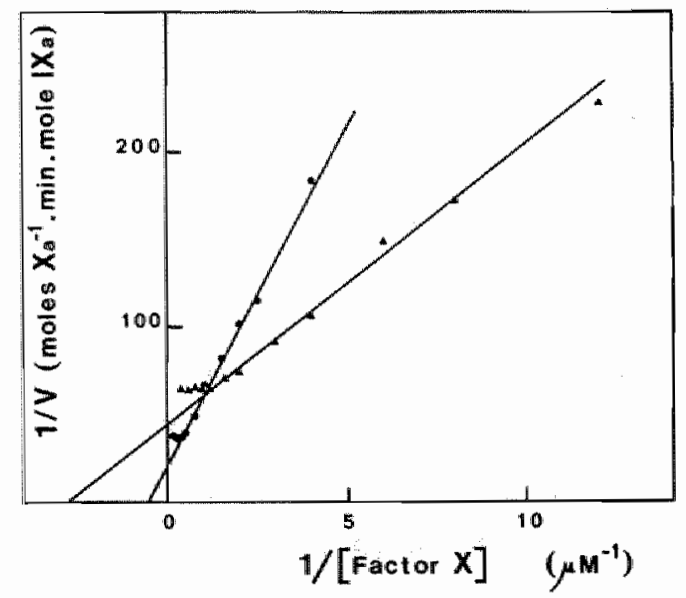

Fig. 7. Lineweaver-Burk plots of factor $x$ activation by factor $x_{\text {a }}$ in the presence of phospholjpid

PU vesicles were preincubated at $37^{\circ} \mathrm{C}$ in a buffer containing 50 im Tris-BCl, $175 \mathrm{mM} \mathrm{NaCl}$ and $50 \mathrm{~mm} \mathrm{Cacl} 2$ at pH 7.9 . After $10 \mathrm{~mm}, 0.1$ m af the pL mixture was transferrea to $0.35 \mathrm{~m}$ of a buffer containing $50 \mathrm{mM}$ Tris (pH 7.9), $175 \mathrm{mM} \mathrm{NaCl}, 0.5 \mathrm{mg} / \mathrm{m} 1$ oralbumin and varying amounts of $x$. Four min latex, $x$ activation was started by the adaition of 0.05 m 1 IX $10.11 \mathrm{MM})$. The final reaction mixture contained: $50 \mathrm{~mm}$ Tris-HCl, $\mathrm{pH} 7.9 ; 175 \mathrm{~mm} \mathrm{NaCl} ; 10 \mathrm{mM} \mathrm{CaCl} ; 0.4$ mg/ mi ovalbumin; $1.09 \times 10^{-5}$ woles/ml $\mathrm{IX}_{a}$, varylng amounts $\mathrm{f} x$ and -4. 50 M PL; - 200 M PL. The rate of $\mathrm{X}_{a}$ formation was calculated from the amount of $x_{a}$ present in the reaction mixture after 7.5 and 15 min. PL vesicles were prepared as described lin the "Experimental Procedures". The kinetic parameters calculated are summarised in Table $I$. 
At 20 Wh phospolipid the $K_{\text {mat }}$ for factor $X$ is 0.14 uM and the $\mathrm{M}$ max of factor $x_{a}$ formation $15.8 \times 10^{-3}$ mole $x_{a} m^{-1}$. mole $I X_{a}^{-1}$. The rates are expressed pex mole of factor Ix $_{a}$ added.

Compared with the results obtained in solution, it is seen that phospholipld lowers the $K_{\mathrm{m}}$ for factor $\mathrm{X}$ about $2000-\mathrm{fold}$ with onil little effect on the $v_{\text {max }}$ of factor $x_{a}$ formation.

The kinetic constants determined at different phospholipid concentrations are sumarized in Table $I$. There is a gradual increase of the $\mathbb{R}_{m}$ for factor $x$ when the phospholipid concentration is raised. Iabie $x$. Wfect of phospholipia on kinetic parameters of factor $x$ activation

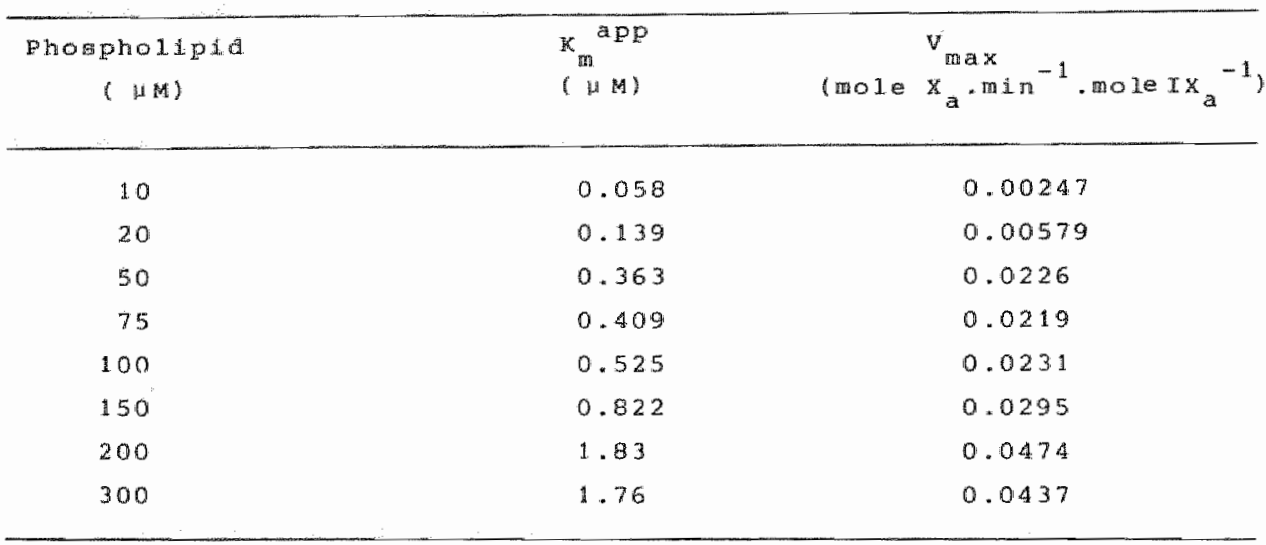

The $v_{\max }$ of factor $\mathrm{x}_{\mathrm{a}}$ formation also increases with the phospholipid concentration. The variation of $V_{\max }$ may be due to the fact that the Wix 1 calculated from the amount of factor $r x_{a}$ added, while it is actually the amount of factor Ix bound to the phospholipid surface at each phospholipla concentration that determines the rate of factor $x$ activation. The $k$ inetic parameters of factor $x$ activation in solution are such that free factor Ix does rot contribute to factor $x_{a}$ formation. Therefore, a variation of the amount of factor $\mathrm{IX}_{\mathrm{a}}$ bound due to the variation of the phospholipia concentration will then be reflected in the observed value of $\mathrm{v}_{\max }$. In that case extrapolation of a double reciprocal plot (1/v max versus 1/ [phospholipid]) at constant factor IX to infinite phospholipid concentration $y i$ ids the $V_{\max }$ for bound factor $\mathrm{Ix}_{\mathrm{a}}\left(\mathrm{F} 1 \mathrm{~g}\right.$. 8). The $\mathrm{V}_{\max }$ calculated from this plot $1 \mathrm{~s} 0.08$ mole $\mathrm{x}_{\mathrm{a}} \cdot \mathrm{min}^{-1}$. mole $\mathrm{Ix}_{\mathrm{a}}^{-1}$ bound. 


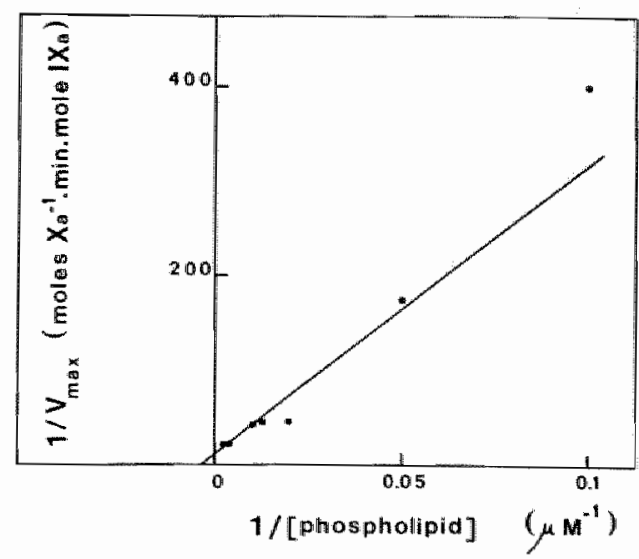

Fig. B. Double reciprocal plot of $v_{\max }$ as a function of the phospholipid concentration

The $F \mathrm{X}$ activating mixture consisted of $f X_{\mathrm{A}}, \operatorname{cacl}_{2}$ and pL. This plot contains data sumarised in rable $I$.

The kinetica of factor $X$ activation in the presence of phospholipid and factor VIII

From many reports in the literature, it is obvious that factor VIII participates in the factor $X$ activating complex in an activated form (15, 18, 22). The activity of factor VIII in the intrinsic factor $X$ activation is considerably enhanced by prior incubation with trace amounts of thrombin. The effect of thrombin on the activity of factor VII is evaluated in general with a clotting assay. Feedback reactions by thrombin and other serine proteases accumlating during clotting hamper a study of the quantitative aspect of this activation. Therefore, we aimed to set up a system in which the activation of factor VIII by thrombin can be followed directly by measuring its effect on factor $x$ activation.

The experimental set-up is as follows. Factor VIII is incubated with varying amounts of thrombin and the time course of activation is followed by transferring after alferent time intervals aliquots of this activation mixture to a reaction mixture containing a small. amount of factor Ix $(2000 \times$ lower than in the experiments of the previous section, factor $\mathrm{X}, \mathrm{CaCl}_{2}$ and phospholipid. From the amount of factor $x_{a}$ formed after 2,3 , and $4 \mathrm{~min}$ in this mixture, the rate of factor $x_{a}$ formation is calculated. This rate is taken as a measure for the amount of factor VIII present in the aliquot. The time course of factor VIII activation by various amounts of thrombin was neasured with this assay and is shown in Fig. 9. 


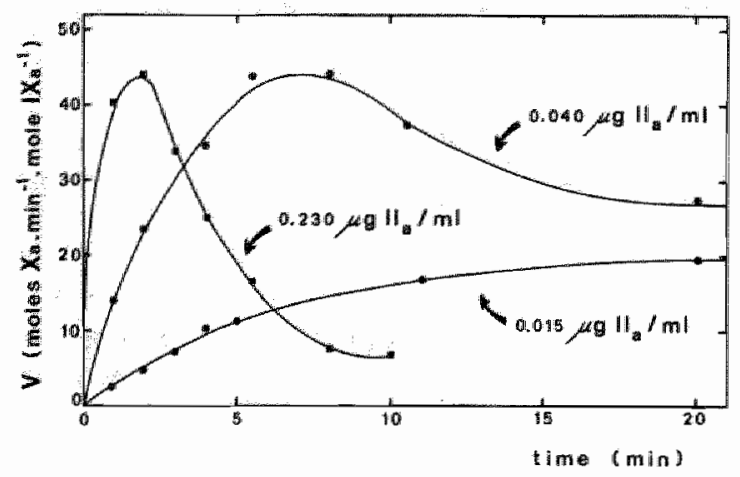

Fig. 9. The course of activation of factox VIII with various amounts of thrombin

F VII $(10 \mathrm{~d} / \mathrm{m} \mathrm{l})$ was incubated at $37^{\circ} \mathrm{C}$ with various amounts of thrombin in a buffer containing $50 \mathrm{mM}$ Tris-HCl, $175 \mathrm{mM}$ NaCl at pil 7.9. The amounts of thrombin present are indicated in the figure. After the tine intervals indicated, 0.1 mil of this incubation mixture was trinsfexred to 0.9 ml of a reaction mixture containing all futher components required fox f $x$ activation. The final concontrations in the reaction mixture ( $1 \mathrm{mi})$ were: 50 mM Tris-HCI (pH 7.9); $175 \mathrm{~mm} \mathrm{NaCl} ; 10 \mathrm{mM} \mathrm{CaCl}, 0.5 \mathrm{mg} / \mathrm{ml}$ ovalbumin; f Ix $10.34 \times 10^{-8}$ Hmoles/m1); $0.015 \mu \mathrm{m} \times$ and 12.5 HM PL. The PL vesicles were preincubated for 10 min at $37^{\circ} \mathrm{C}$ in a buffer containing $50 \mathrm{~mm}$ Txis-HCl, $175 \mathrm{mM} \mathrm{NaCl}$ and $50 \mathrm{mM} \mathrm{CaCl}_{2}$ before adition to the reaction mixture. Two, three and four min after the addition of $f$ VIII. aliquots from the reaction mixture were assayed for $f x_{a}$. The rate of $x_{\text {a formation }}$ wat calculated from the amounts af $f x_{a}$ present In these aldquote. PL volicles were prepared described under "Expextmental procedureg".

Incubation of factor VIII with thrombin results in a rapid increase of factor VrII activity followed by a decrease. Both the rates of activation and inactivation increase with the thrombin concentration. When elther factor VIII or thrombin is omitted from the activation mixture no factor $x_{\text {, }}$ is formed in the reaction mixture. This experiment stresses again that factor VIII has to be activated before it can exert its stimulating effect on the activation of factor $x$ by Eactor $\mathrm{IX}_{\mathrm{a}}$.

We were unable to show actlvation of factor VIII by factor $x_{a}$ 
neither in the presence nor in the absence of phospholipid and calcium lons. This is in contrast with earliex reported findings $(16,18)$ that factor $\mathrm{x}_{\mathrm{a}}$ can activate factor VIII. We have to emphasize, however, that the amount of factor $x_{a}$ is limited to $0.5 \mathrm{~kg} / \mathrm{ml}$ since higher amounts of factor $x_{a}$ cause autocatalytic factor $x$ activation in the assay system. In our further experiments, factor VIII is activated by incubation with 0.04 wg thrombin/ml for 5 min at $37^{\circ} \mathrm{C}$.

The time course of factor $X$ activation lin the presence of factor VII $\mathrm{A}^{\text {, }}$ calcium ions and 5,10 , or 25 ;M phospholipid was determined at a low and a high factor X concentration (Fig. 10). Factor VIII a activated as described above, was added to a mixture of phospholipid (pretreated with $\mathrm{CaCl}_{2}$, $\mathrm{CaCl}_{2}$, factor $\mathrm{IX}_{\mathrm{a}}$ and factor $\mathrm{X}$ preincubated 3 min at $37^{\circ} \mathrm{C}$. A typical time course of factor $x$ activation shows a lag period of $1-2$ min, a four minute perlod with an apparent constant rate of factor $x_{a}$ formation followed by a decrease of the activation rate. We have been unable to shorten the lag perlod by changing the preincubation conditions or the order of addition of the components of the factor $x$ activating miluture. The time course of factor $\mathrm{x}_{a}$ formation did not change when extra factor $\mathrm{x}_{\mathrm{a}}$ (up to amounts formed in the above experiment) was included in the reaction mixture. At the moment we have no explanation for the observed lag period. The decrease of the rate of factor $x_{a}$ formation after flve minutes is probably caused by inactivation of factor VIIIa, since addition of extra factor VIII to the reaction mixture restores the ability to activate factor $X$ (data not shown).

In all subsequent experiments, we calculated the rate of factor $x_{a}$ formation in the presence of factor VIII over the four minute time interval during which the rate was constant.

The $\mathrm{Ca}^{2+}$-titration curve of factor $\mathrm{x}$ activation by factor $\mathrm{Ix}_{\mathrm{a}}$ in the presence of 5 and 25 wh phosphollpid and factor VIII is shown In Fig. 11. The curves are sigmoidal. and the optimal ca ${ }^{2+}$ concentration under these conditions is about $7.5 \mathrm{mM}$ at both phospholipid concentrations.

When the factor IX concentration is varied at a constant amount of factor $\mathrm{X}_{,} \mathrm{CaCl}_{2}$, phosphollpld and factor VIII, the rate of factor $X$ activation observed 1 s directly propoxtional to the factor IX concentration (Fig. 12). 

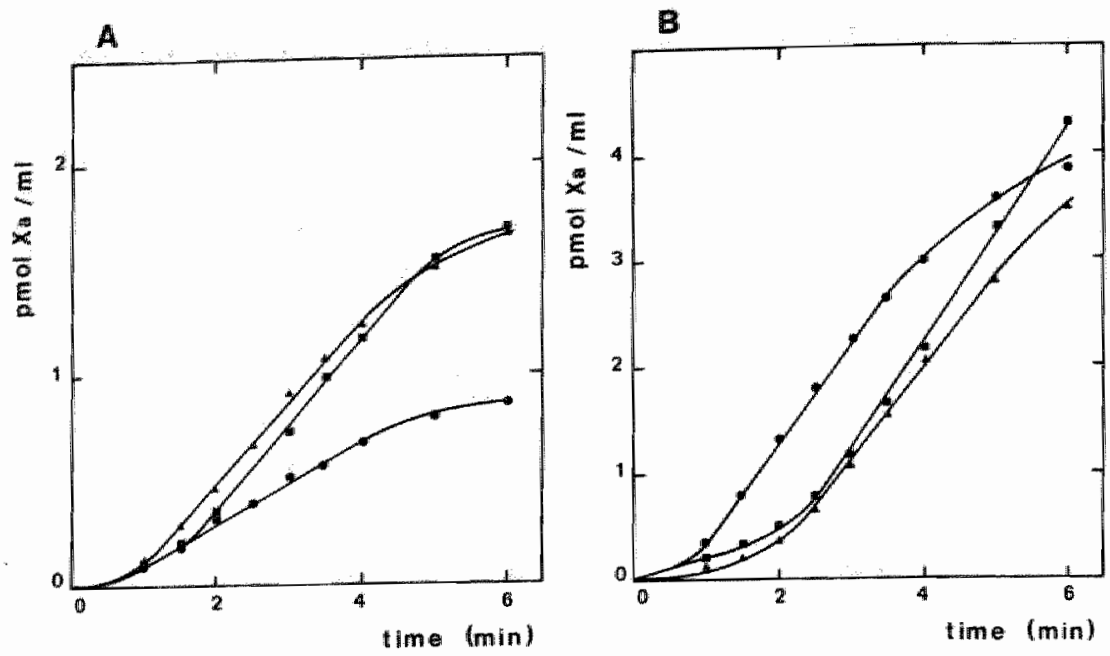

Fig. $20 \mathrm{~A}, \mathrm{~B}$. Time course of factor $\mathrm{X}$ activation by factor $\mathrm{IX}_{\mathrm{a}}$ in the presence of phospholipld, factor VIII and CaCl 2

Frti $(20 \mathrm{u} / \mathrm{mi})$ was activated at $37^{\circ} \mathrm{C}$ with $0.04 \mathrm{wg} / \mathrm{ml}$ thrombin. After

$5 \mathrm{~min} 0.5 \mathrm{ml}$ of the activation mixture was added to $0.5 \mathrm{ml}$ of a reactiom mixture contalning $5.0 \mathrm{mM}$ Tris-HCl (pH 7.9); $175 \mathrm{mM} \mathrm{NaCd,} 10 \mathrm{mM}$ $\mathrm{CaCl}_{2}$, $1 \mathrm{mg} / \mathrm{ml}$ ovalbumln, $0.68 \times 10^{-8}$ unoles/ml $\bar{f}$ Ixa and varlous amounts of $P L$ and $f x$ at $37^{\circ} \mathrm{C}$. Before use, $P L$ vesicles wexe incubated $10 \mathrm{~min}$ at $37^{\circ} \mathrm{C}$ in a buffer containing $50 \mathrm{mM}$ Tris, $175 \mathrm{mM} \mathrm{Nacl}$ and $50 \mathrm{~mm}$ $\mathrm{CaCl}_{2}$ at pH 7.9. After the time intervals indicated in the figure, aliquots from thls activation mixture were taken and assayed for

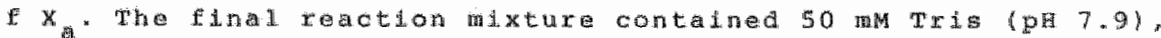
175 inM NaCl. $5 \mathrm{mM} \mathrm{CaCl}, 0.5 \mathrm{mg} / \mathrm{ml}$ ovalbumin, $0.34 \times 10^{-8}$ moles $/ \mathrm{ml}$

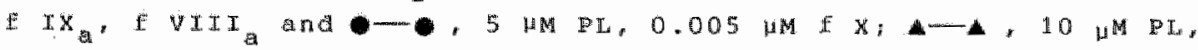

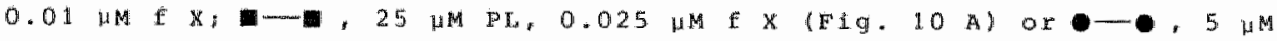

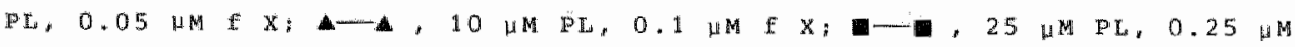
f $\mathrm{x}(\mathrm{H} 1 \mathrm{~g} \cdot 10 \mathrm{~B})$. PL vesicles we prepared as aescribed in "Experimental procedurea".

Hiving established the best experimental conditions for measurement of factor $X$ activation with the complate factor $X$ activating complex, Lineweaver-Burk plots were made at 10 wM phospholipid with various amounts of factor VIIT present (FIg. 13). The kinetic parameters that are obtained from these plots are sumnarised in Table II. At high factor VIII concentrations the $\mathrm{k}_{\mathrm{m}}$ for factor $\mathrm{X}$ is $0.063 \mathrm{uM}$ 


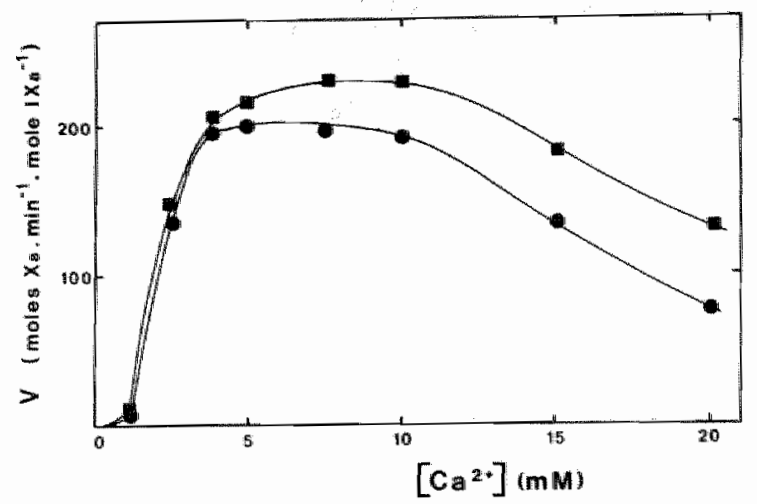

Fig. 11 . The $\mathrm{Ca}^{2+}$-dependence of factor $\mathrm{x}$ activation by factor $1 x_{\text {a }}$ in the presence of phospholipid and factor VIII

F VIII $(20 \mathrm{U} / \mathrm{ml})$ was activated with $0.04 \quad \mu g / m \mathbb{L}$ thrombin in a bufEer containing 50 mM Tris-HCl (pH 7.9 ) and 175 m Nacl.

After $5 \mathrm{~min}, 0.5 \mathrm{ml}$ of the activation mixture was adade to $0.5 \mathrm{ml}$

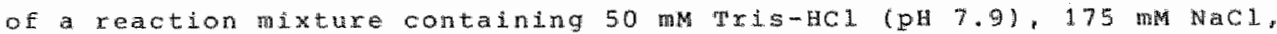
$1 \mathrm{mg} / \mathrm{ml}$ ovalbumin, 10 or $50 \mu \mathrm{MP}, 0.68 \times 10^{-8} \mu \mathrm{moles} / \mathrm{mi}$ Ix, 0.04 or $0.2 \mu M \& X$ and varying mounts of $\mathrm{CaCl}_{2}$. The ionic strength in the reaction mixture was kept constant by the adition of Naci. Before use the RI vesicles ( $1 \mathrm{~mm}$ ) were preincubated for lo min at $37^{\circ} \mathrm{C}$ in $50 \mathrm{mM}$ Tris-HCl, $175 \mathrm{mM} \mathrm{NaCl}, 50 \mathrm{mM} \mathrm{CaCl}_{2}$ at pH 7.9 . The incubation mixture with $0 \mathrm{mM} \mathrm{CaCl} 2$ contained 5 mM EDT. Each minute of the incubation, a sample was taken from the reaction mixture and assayed for $f x_{a}$. The rate of $f x_{a}$ formation was calculated from the linear part of the time course of fi $x_{a}$ formation. The Elnal. reaction misture contained Cacl 2 as indicated, 50 mM Tris-HCl

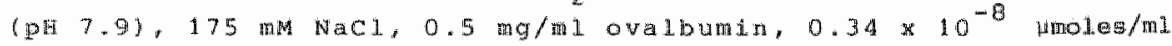

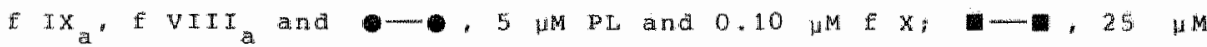
Pí, $0.10 \mu \mathrm{K} X$. PL vesioleg were prepared as described under "Experimental procedures".

and the $V_{\max }$ is 500 mole $x_{\text {and }}{ }^{-1}$. mole $\mathrm{Ix}_{\mathrm{a}}^{-1}$. Wher the same experiment was carried ont in the absence of factor VIII $a^{\prime}$ the $\mathrm{K}_{\mathrm{m}}$ was 0.058 M and the $V_{\max } 0.0025$ mole $x_{a} \cdot m^{-1}$ imole $I x_{a}^{-1}$ isee Table I). It is obvious that the presence of factor VIII hardy affects the $\mathrm{K}_{\mathrm{m}}$ for factor $\mathrm{X}$ but increaseg the $\mathrm{V}_{\mathrm{max}}$ of factor $\mathrm{x}_{\mathrm{a}}$ formation about 200,000 fold. 


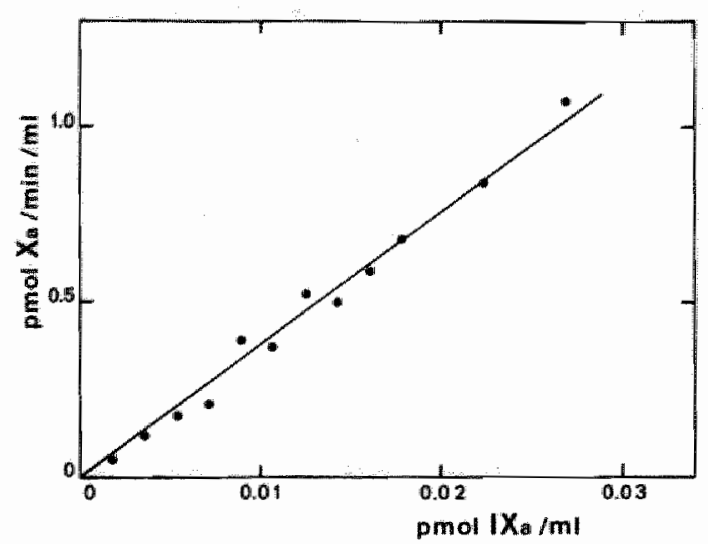

Fig: 12. The efect of factor IX on the rate of factor $x$ activation 1 the presune of fator vII and phospholipid

FIII (10 v/mI) was activated at $37^{\circ} \mathrm{c}$ with $0.04 \mathrm{~kg} / \mathrm{ml}$ thrombin

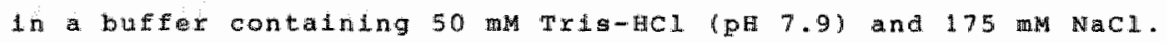
After $5 \mathrm{~min}, 0.1 \mathrm{~m}$ of the activation mixture was added to 0.9 m 1 a maction mixture. The final concentrations in the reaction mixture were: $50 \mathrm{mM}$ Tris-HCl (pF 7.9), $175 \mathrm{~mm}$ Nac1, $10 \mathrm{mM} \mathrm{CaCl}_{2}$ "

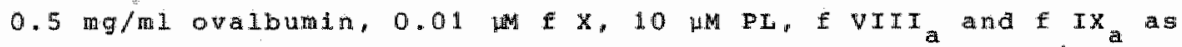
indicated. Before use, the pL vesicles fere preincubated fot 10 min at $37^{\circ} \mathrm{C} 1 \mathrm{n} 50 \mathrm{mM} \mathrm{Txis-HCI}, 175 \mathrm{mM} \mathrm{NaCl}, 50 \mathrm{mM} \mathrm{CaCl}$ at pH $7.9 . \mathrm{Atter}$ 2. 3. and 4 min, aliguots were taken from the reaction mixtures and wexe assayed for $f x_{\text {. The rate of }} x_{\text {a }}$ formation was calculated from the amount of $f x_{a}$ present in these aliquots. PL vesicles were pre-

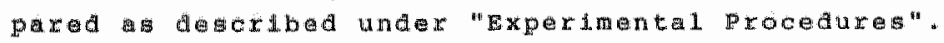

Whe $V_{\text {max }}$ lriceases with the amount of factor VIII added (Table II). At high concentrations of factor VIII, the rate of activation is not Further licreases, undicating that it is possible to add saturating amourtes of factor VIII *

In model dn which factor VIII 1 the cofactor of the enzyme factor IX this means that at this point factor IX is saturated with factor VII and an optimal concentration of factor IX - factor VIII complex is formed. It $1 \mathrm{~s}$ a queston, nowever, whether the model is as simple as that, since the amount of factor VIII present also lnfluences the $\mathrm{K}_{\mathrm{m}}$ for factor $\mathrm{x}$ that is measured (Table $\mathrm{II}$ ). Eor this phenomenon we have no obvious explanation yet. 


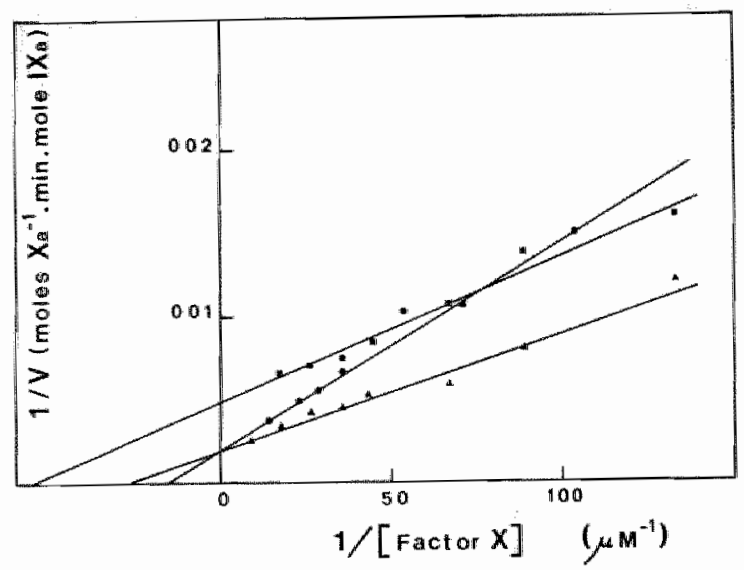

Elg. 13. Lineweaver-Burk plots of actox $x_{a}$ formation by factor IX in the presence of phospholipld and wary ing amountes of factor VIrI FVIII $(20 \mathrm{~d} / \mathrm{mL})$ was activated at $37^{\circ} \mathrm{C}$ with $0.04 \mathrm{Hg} /$ ml thrombin in a buefer containing $50 \mathrm{~mm}$ Txis-Hed and $175 \mathrm{~mm} \mathrm{NaCl}$ at pH 7.9 . After 5 min incubation vary-

ing amounts of this incubation mixture were aded to a reaction mixture containing the further components for $f x$ activation in such amounts that the final concentrations in the reaction mixture ( $1 \mathrm{~m}$ ) becama

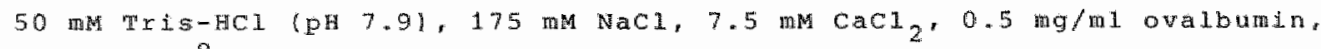
$0.34 \times 10^{-8} \mu$ moles/mI $f$ IX $\mathrm{a}^{-1} 10$ uM phospholipid, varying amounts of

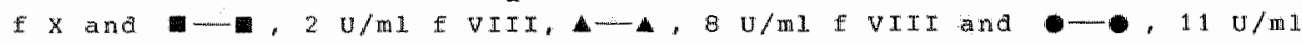
F VIII. At 2, 3, and min atter addition of f VII to the reaction mixture, aliquots wexe taken and assayed for $f x_{a}$. The rate of $x_{a}$ formation was calculated from the amounts of $f x_{a}$ present in these aliquots. The PL vesicles present in the reaction mixture were prepared as described under "Experimental Procedures" and wexe incubated for $10 \mathrm{~min}$ at $37^{\circ} \mathrm{C}$ in $50 \mathrm{mM}$ Tris-HCl ( $\mathrm{pH} 7.9$ ) and 175 mM Macl before addition to the reaction mixture. The kinetic parameters calculated aresumarised in Table II.

Lineweaver-Burk plots in the presence of factor VIIIa $\left.(8 \mathrm{o} / \mathrm{m})_{1}\right)$ were made at three different phospholipid concentrations (Fig. I4). The kinetic constants obtained from these plots are also sumbisid in Table II. The $\mathrm{K}_{\mathrm{m}}$ for factor $\mathrm{X}$ appears to be dependent on the phospholipid concentration to the same extent as observed in the experiments carried out in the absence of factor VIII (ef. Table I). Kinetios of activation of factor $x_{2}$ and Bfacter $x$

since all experiments reported in this paper were carried out with factor $x_{2}$, we were interested whether factor $x_{1}$ and $\beta$ factor $x$ behave kinetically ldentical. Therefore, a number of experiments was re- 
Table II. Effect of factor VIII, and phospholipid on the kinetic parameterg of factor $\%$ activation

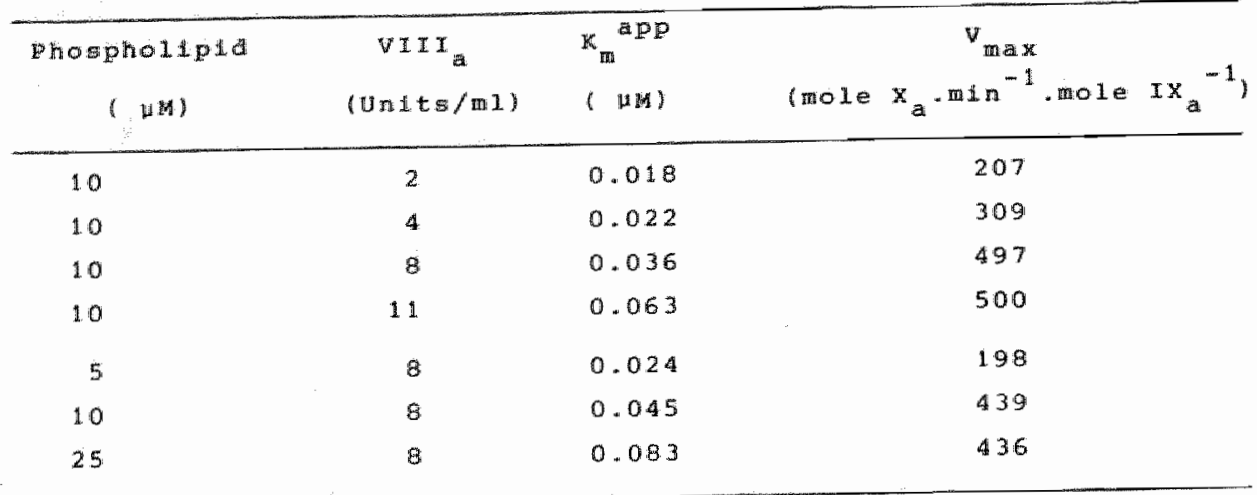

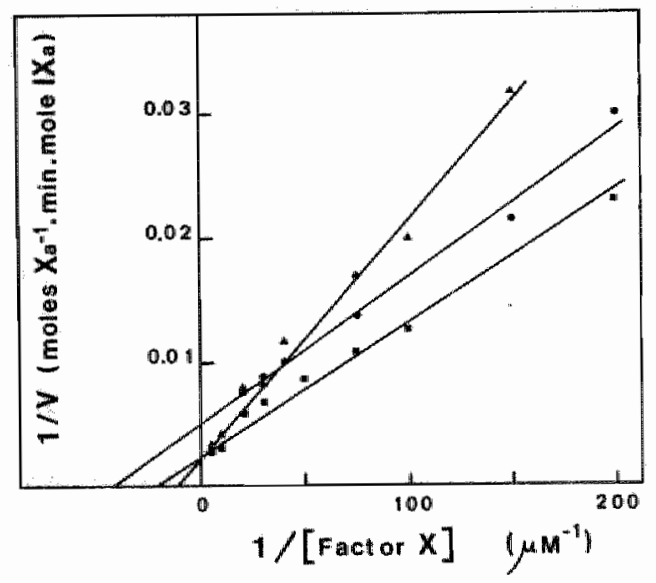

Fig. 14. Linewear-Burk plots of factor $x$ formation by factor IXa In the presence of factor VIII and yarying amounts of phosplyoleda

The rate of $x_{a}$ formation at vaxious $f x$ concentrations was measurea

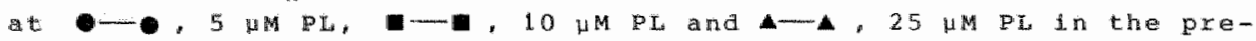
sence of activated f VIII $(B \mathrm{u} / \mathrm{m} 1)$ and $\mathrm{CaCl}_{2}(7.5 \mathrm{~m})$. For experimental detalis, see legend to plg. 13. 
peated using factor $x_{1}$ and factor $x$ as substrate. Both factor $x_{1}$ and $B X$ showed the same kinetics of activation as factor $\mathrm{X}_{2}$ *

\section{DISCUSSIOH}

Previous studies on the intrinsic activation of factor $x$ suggest that the activator is a complex composed of factor IXa, factor VIIIa" phospholipid and calcium ions $(8-11,22,23)$. Several properties of factor Ix $\mathrm{I}_{\mathrm{a}}$ indicate that it is a serine protease and hence will be the enzyme that actually activates factor X. Factor IX is highly homologous to othex serine proteases involved in blood coagulation (i3) and has an esterase activity towards synthetic arginine esters (47). Its enzymatic activity is also inhibited by well-known serine protease inhibitors like antithrombin III $(47,48)$ and hirudin $(49)$. When it is accepted that factor $I x_{a}$ is the enzyme in the factor Xactivating complex it is plausible to assume that factor VIIT, phospholipid and calcium ions act as cofactors to factor Ixa. In this concept the roles of factor $I_{a}$, factor VIIT and phosphollpid are analogous to those of respectively fiactor $x_{a}$, factor $v_{a}$ and phospholipid in the prothrombin-activating complex.

If this model is correct one would expect that factor IX can activate factor $X$ in the absence of accessory components. Although no activation of factor $X$ by factor $I X$ in solution has been reported yet, Hultin and Nemerson (22) have shown that factor $I X_{a}$ in the presence of phospholipid and calcium ions, but without factor VIII, slowly activates factor $x$. The rate of factor $X$ activation was substantially increased when thrombin-activated factor VIII was included in the reaction nixture. A rate enhancement caused by factox vIII has been reported in several other papers $(1,20,22,23)$. These findings extend the and logy wh the prothrombin-activating complex. The accessory components phospholipld and factor VIII stimulate factor X activation by factor IX $a$ " like phospholipid and factor $v$ increase the rate of conversion of prothrombin to thrombin by factor $x_{a}(50,51)$.

In this chapter it is shown that factor $I x_{a}$ in solution, in the absence of accessory components, is able to catalyse the activation of factor $x$. This finding supports the concept that factor $I X_{a}$ is the enzyme in the intrinsic factor $x$ activating complex. It appeared to be possible to carry out a kinetic study and obtain the kinetlo parameters $\left(K_{m}\right.$ and $\left.V_{\text {max }}\right)$ for the activation reaction in solution. we determined a $k_{m}$ for factor $x$ of 299 u and a $y_{\text {max }}$ of 
2.2 $210^{-3}$ mole $x_{a} \cdot m^{-1}$. mole $I x_{a}^{-1}$. The presence of calcium ions has ilttle effect on the kinetic parameters (Table III).

iable IXI. Effect ot the acessory components on kinetic parametexs ot iactor x actiotion

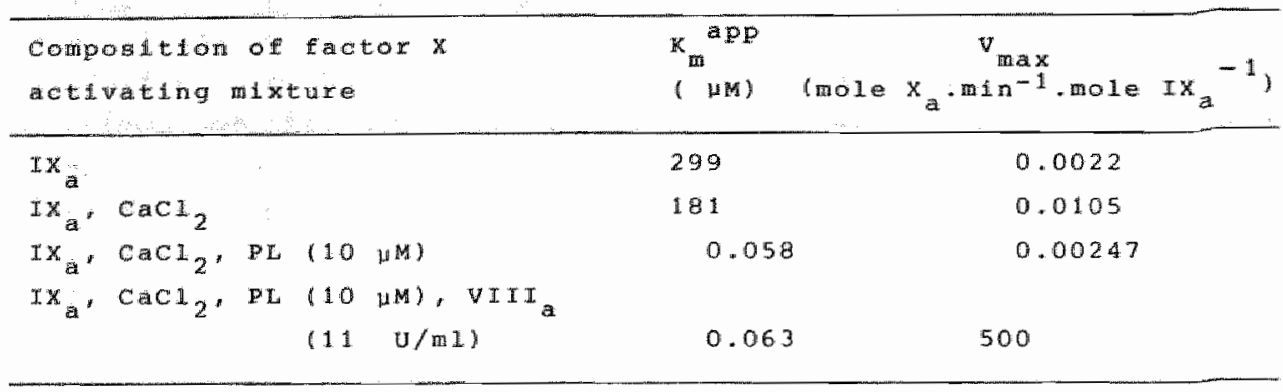

The fact that we were able to study the kinetics of the reaction in solution made it possible to determine the effect of phosphoilpid and factor VIII on the kinetic parameters of factor $x$ activation. such a kinetic analysis offers the possibility to gain insight in the role of phospholipid and factor VIII in the nechanism of factor $x$ activation. Knowledge of the kinetic parameters is also essentlal to evaluate the contribution of intrinsic factor $x$ activation to factor $x_{a}$ formation at physiological conditions.

The kinetic parameters for different factor $x$ activating mixtures are summaxised in Table III. Both phospholipid and factor VIII a cause important changes of the kinetio parameters of factor $x$ activation. In the presence of $10 \mu \mathrm{M}$ phospholipid, the $\mathrm{K}_{\mathrm{m}}$ drops from 181 HM to $0.058 \mu M$, whle there is 11ttle change of the $v_{\max }$. whe effect of factor VIII is mainly restrloted to the $V_{\max }$. In the presence of factor VIII the $V_{\text {max }}$ increases about 200,000 fold. The data in Table III explain why to this day no factor $x$ activation was found by factor IX in the absence of accessory components. The kinetic parameters in solution are such that factor $x_{\text {a }}$ formation can only be measured at very high factor $X$ and factor $I X_{a}$ concentrations and in addition a sensitive assay for factor $x_{a}$ is requiled. Factor $X$ activation by factor $I X_{a}$ in the presence of phospholipid and calcium ions is easter to detect. The $k_{m}$ for factor $x$ arops to a value in the molar range or lower. This explairs the findings of Hultin and Nemerson (22) who measured 
factor $X$ activation under these conditions. They carried out their experiment at 1.25 W factor $\mathrm{X}$. With the complete factor $\mathrm{X}$ activating complex (factor $\mathrm{IX}_{\mathrm{a}}$, factor VIII a, phospholipid and calcium ions) factor $x_{a}$ formation is most readily detectable since both kinetic parameters favour factor $\mathrm{x}$ activation.

The data presented in this chapter have important implications for the mode of action of phospholipid in the mechanism of intrinsic factor $x$ activation. Phospholipid has little effect on the catalytic activity of factor $I x_{a}$. For free factor IX a $V_{\max }$ of 0.01 mole $x_{a} \cdot m^{-1}{ }^{-1}$. mole IX $_{a}^{-1}$ is measured (Table III) and for phospholipid bound factor IX $x_{a}$ the $v_{\max }$ is 0.03 mole $x_{a} \cdot m_{i n}^{-1}$.mole $\operatorname{Ix}_{a}^{-1}\left(\mathrm{Fr}_{\mathrm{g}}\right.$. 8). The $\mathrm{K}_{\mathrm{m}}$ for factor $x$ is dramaticaliy decreased in the presence of phospholipid. There is, however, a considerable increase of the $\mathrm{k}_{\mathrm{m}}$ at higher phosm pholipid concentrations, so a $\mathrm{K}_{\mathrm{m}}$ measured in the presence of phospholipid has to be regarded as an apparent $k_{m}$. In chapter 4 we have showh that in the prothrombinase complex phospholipid causes a marked decrease of the $\mathrm{K}_{\mathrm{m}}$ for prothrombin, and the $\mathrm{K}_{\mathrm{m}}$ is also raised at increasing phospholipid concentrations. Hence it seems plausible that the mechanistic basis for the mode of action of phospholipid in both complexes is lidentical. Two models have been proposed to explain the role of phospholipid in prothrombin activation. Because of the similarlty between prothrombin and factor $X$ activation with respect to phospholipid involvement, these madels are also applicable to factor $x$ activation. In previous papers (chapter 4 , ref. 52) we suggested that the enzyme and substrate are bound to the phospholipid surface and that the amount of bound substrate determines the rate of activation. An increased local substrate concentration at or in the vicinity of the phospholipid surface (cf. ref. 53) can explain the large decrease of the $\mathrm{k}_{\mathrm{m}}$ observed in the presence of phospholipid. The $K_{m}$ measured, expressed in terms of added subtrate, $1 \mathrm{~s}$ an apparent $\mathrm{K}_{\mathrm{m}}$ which increases when increasing amounts of phospholipid are present since at higher phosplioliptd concentrations more substrate has to be added to attain the local concentration at which the enzyme bound to the surface works at $1 / 2 \mathrm{~V}_{\text {max }}$. A different model is proposed by Nelsestuen (54). He suggests that the enzyme bound at the phosphalipid surtace is active on the soluble substrate. Phospholipla causes a decrease of the apparent $k_{m}$ by altering the binding affintty of the acture site of the enzyme for its substrate. Although Nelsestuen does not mention in his paper the increase of the apparent $\mathrm{K}_{\mathrm{m}}$ at highex 
phospholipld concentration, this can also be explained in this nodel. Binding of the substrate reduces the concentration in solution. At a higher phospholipid concentration more substrate is bound and hence nore substrate has to be added to reach a substrate level in solution at which the enzyme functions at $1 / 2 \mathrm{~V}_{\text {max }}$. It will be obvious that bot models can qualdtatively explain the effect of phospholipid on the $\mathrm{K} \mathrm{m}$. For factor $\mathrm{x}$ of the intringid factor $\mathrm{x}$ activator reported in this paper. The flattring of the Lineweaver-Burk plots observed at high factor $x$ concentrations is most easily explained in the model where bound factor $x$ is the substrate. At high factor $x$ concentrations the binding sites for factor $x$ at the phospholipid vesicles become saturated. The addtion of extra factor $x$ cannot further increase the bound factox $x$ concentration and consequently there lis no further increase in the rate of activation. At higher phospholipid concentration more factor $x$ is required to saturate the binding sites, hence the leveling off ocours at a higher factor $x$ concentration. It is Anteresting to notice that the break point in the Lineweaver-Burk plots 1 s observed at factor $X$ concentrations about equal to the concentration of binding sites for factor $x$ present on the kind of phosphollpid vesicles used in our expeximents $10.011 \mathrm{\mu m}$ binding sites/ M phospholipid; ref. 55). A qualitative explanation of the above phenomenon in the model where soluble factor $X$ is the substrate is not readily avaliable. In order to determine which of the two models is valid, the exact binding parameters of factor $x$ binding to the phospholipid vesicles under the conditions of our kinetic experiments have to be known. In that case the amounts of bound and Exee factor $x$ at each individual point of the Lineweaver-Burk plot can be calculated and $\mathrm{it}$ can be werified whethex the reaction obeys Michaelis-Menter kinetics wh bound or soluble substrate.

At the moment expertments are under way in our laboratory in which binding- and kinetlc parameters for varlous phospholipid mixtures axe determined at ldentical conditions wh the aim to discriminate between the two models (cf. chapter 7 and 8 ).

Factor VIII a enormousiy stimulates the $v_{\text {max }}$ of factor $x$ activation. No activation of factor $x$ can be detected by factor VIII alone. Since factor IX, even In the absence of accessory components, can catalyse the formation of factor $x_{a}$, we conclude that factor VIII acts as a cofactor which accelerates an enzymatic reaction which already occurs in its absence. Factor VIII has to be activated with thrombin to accomplish 1 ts stimulatory effect on the $v_{\max }$. When 
factor VIII is replaced by factor VIII in an experiment carried out at a saturating factor VIII concentration, the rate of factor $\mathrm{X}$ activation is below 1 of that measured with factor VIIIa. The remaining activity cannot be explained by the action of factor IX alone. Since our unactivated factor VIII preparation may contain small amounts of factor VIII, we camot determine whether native factor VIII can support factor $x$ activation. The $V_{\max }$ raises when increasing amounts of factor VIII are present. At high concentrations of factor VIII $I_{a}$ the $V_{\text {max }}$ is not further increased, which in the cofactor model for factor VIII would mean that factor $I X_{a}$ becomes saturated with co-factor. Under these conditions factor $I X_{a}$ has a proteolytic activity comparable to factor $\mathrm{x}_{\mathrm{a}}$ in the prothrombin activating complex (chapter 4, ret: 56). and to factor VII in the extrinsic factor $x$ activating complex (21) determined in the presence of saturating amounts of their respective co-factors factor $v_{a}$ and tissue factor. For the increase of $\mathbb{K}_{\mathrm{m}}$ for factor $\mathrm{X}$ observed at increasing factor VIII concentrations we have no interpretation yet. A mare extensive kinetic analysis will be required to explain this phenomenon. The time course of factor $x$ actlvation in the presence of factor VIIT showed a lag period of $1-2 \mathrm{~min}$ and a leveling of after about $6 \mathrm{~min}$. Such a time course of activation has been reported earliex $(22,23)$. The reason for the lag period is unclear. It is not due to an extra activation of factor VITI by factor IX or factor $x_{a}$ during the time course of the reaction. Preincubation of thrombin-activated factor wiI with factor $I_{a}$ or factor $x_{a}$ in the presence of calcium ions and phospholipid did not cause disappearance of the lag. The slowing down of the reaction after 6 min is likely due to inactivation of factor VIII since addition of extra factor VIII restores factor $X$ activation. The high molecular weight form of factor VIII is used in the expertments described in this paper. This preparation, generally referred to as factor VIII/von Willebrand factor (factor VIII/WWI) is a complex of low molecular welght factor VIII coagulant activity and high molecular weight won willebrand platelet aggregating activity. Recently, vehar and Davie (18) succeeded in obtalning a highly purified factor VIII coagulant activity. It will be interesting to compare the effects of the factor VIII coagulant activity and factor VIII/WWF on the kinetics of factor $X$ activation.

The physiological significance of the alteration of kinetic parameters will be obvlous. Intrinsic Eactor $\mathrm{X}$ activation requires 
phospholipia because it lowers the $K_{\text {m }}$ for the substrate to within the sange of the plasma concentration 10.2 H). At high phospholipid concentrations the $k_{m}$ rlses, however, above the plasma factor $x$ concen tration. It is possible that this phenomenon plays a role in the phystologic regulation of factor $x_{\mathrm{a}}$ formation. Factor VIII via its effect on $v_{\text {max }}$ increases the rate of factor $X$ activation to a level where sufficlent factor $x_{a}$ is formed to control haemostasis. It is interesting to compare the kinetic parameters that we found for the Intrinsic factor $x$ activator with those of the extrinsic factor $x$ activator determined by silverberg et al. $(21)$. They found a $\mathbb{k}_{m}$ for factor $x$ of $0.34 \mu \mathrm{M}$ and a $v_{\max }$ of 1900 mole $x_{a} \cdot$ min ${ }^{-1}$.mole $V_{I}{ }^{-1}$. Thus the catalytic efficlency, $v_{m a x} / \mathrm{K}_{\mathrm{m}}$ " for both activator systems is about equal. These data will have to be taken into consicleration in a discussion about the contribution of the intrinsic and extrinsic factor $x$ activation to factor $x_{a}$ formation in vivo.

\section{FOOTNOTES}

14) The nomenclature of the blood coagulation factors used is that recommended by the Task Force on Nomenclature of Blood clotting zymogens and zymogen Intermediates.

*) The abbreviations used are:

S 2222, N-benzoy1-L-isoleucy 1-L-glutamy1-glycyl-L-arginine-p-nitroaniltade hydrochlortae; S 2238, E-D-phenylalanyl-L-plpecoly1-Larginine-p-nitroan111de dihyarochloride; p-NPGB, p-nitrophenyl$\mathrm{p}$ "-guandainobenzoate hydrochloride; RVV-X, purlfied factor $\mathrm{X}$ activator from Russell's Viper venon; STr, soybean trypsin inhibitor; PL, phosphaliptd; $f x$, factor $X ; f x_{a}$, factor $x_{a} ; \mathbb{I X}$,

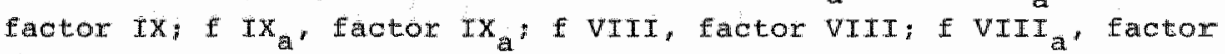
VIII a

\section{ACKNONLEDQEMENTS}

We would I.1ke to thank Mr.J.H.L.Franssen for the preparation of factor VII, Mrs.G. Wanssen-claessen for excellent technical assistance, Dr. $Y$. Nemerson for kindly providing the computer program for calculation of the kinetic constants, Mrs.J.W.P.Gowers-Rlemslag for adaptation of the program, and Prof.Dr.R.F.A. Zwaal for stimulating atscussions.

REEERENCES

1. Fujikawa, K., Coan, M.H., Legaz, M.E. and Davie, E.W. (1974) Btoohemiaty $13,5290-5299$ 
2. Jesty, J. and Nemerson, Y. (1974) J.B2ol.Chem.249, 509-515

3. Davie, E.W. and Fujikawa, K. (1975) Afw.Rev. Btochem.44,799-829

4. MacFarlane, R.G., Biggs, R., Ash, B.J. and Denson, K.W.E. (1964) Br.J.Hasmatol. 10, $530-541$

5. Lundblad, R.L. and Davie, E.W. (1964) Btochemisty 3,1720-1725

6. Schiffman, S., Rapaport, S.I. and Chong, M.M.Y. (1966) Proe.Soc. Exp.Biol. Med, 123,736-744

7. Hougie, C., Denson, K.W.E. and Biggs, R. (1967) Thrombos. Drathes. haemorn. 18, 211-222

8. Barton, P.G. (1967) Nature 215, 1508-1509

9. Hemker,H.C.and Kahn, M.J.P. (1967) Nature 215, 1201-1202

10. Dsterud, B. and Rapaport, S.I. (1970) Biochemistry 9, 1844-1861

11. Varadi, K. and Henker, H.C. (1976)Thrombos.fos. 8, 303-317

12. Bucher, $\mathbb{K}$, Nebelin, E., Thomsen, J. and stenflo, J. (1976) WEBS Letcexs $68,293-296$

13. Katayama, K., Ericsson, L.H., Enfield, D.L., Walsh, K.A., Neurath, H., Davie, E.W. and Titani, K. (1979) Proc.Natt.Acad.Sol. USA $79,4990-4994$

14. Hemker, H.C., Kahn, M.J.P. and Devilee, P.P. (1970) rhrombos. Diathes. haemorrh. 24, 214-223

15. Gsterud, B., Rapaport, S.I., Schiffman, S. and Chong, M.M.Y. (1971) Br. J.Haematol.21, 643-660

16. Davie, E.W. Fujikawa, K., Legaz, M.E. and Kato, H. (1975) cota Spring Habox Conference on Cell Proliferation 2, 65-72

17. Vehar, G.A. and Davie, E.W. (1977) seience 197, 374-376

18. Vehar, G.A. and Davie, B.W. (1980) Biochemistry 19,401-41,0

19. Zwaal, R.F.A. (1978) Biochim.Biophys.Aata 515, 163-205

20. Suomela, H. and Blombäck, B. (1977) Thrombos.teg. 1, 267-281

21. Silverberg, S.A., Nemerson, Y.and Zur, M. $(1977)$ J.Biol.Chem. $252,8481-8488$

22. Hultin, M.B. and Nemerson, Y. (1978) Blood 52, 928-940

23. Brown, J.E., Baugh, R.F. and Hougie, C. (1978) thrombou.Rea. 13. $893-900$

24. Cuatrecasas, P. (1970) J.Btol. Ghem.245, 3059-3065

25. Fujikawa, R., Thompson, A.R., Legaz, M.E., Meyer, R.G. and Davie, E.W. (1973) Biochemistry 12, 4938-4945

26. Fujikawa, K., Legaz, M. E. and Davie, E.W. (1972) Bzoohemiatry $11,4882-4891$

27. Nosse1, H.L. (1964) The contact phase of blood coagulation (Blackwell scientific publication, oxford) 
28. Dsterud, B. and Rapaport, S.I. (1977) Proc. NatL.Acad.Sei. WSA $74,5260-5264$

29. Schiffman, S., Theodor, I. and Rapaport, S.I. (1969) Biochemistry 8, $1397-1405$

30. Fujlkawa, K., Legaz, M.E. and Davie, E.W. (1972) Biachemiatry $11,4892-4899$

31. Fujikma, K., Legaz, M.E., Kato, H. and Davie, E.W. (1974) Bipohemistry $13,4508-4516$

32. Jesty, J., Spencer, A.K. and Nemerson, Y. (1974) J.BiaZ.Chem. $249,5614-5622$

33. Schmer, G., Kirby, E.P., Teller, D.C. and Dawie, E.W. (1972)

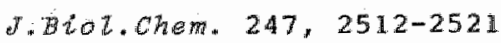

34. Van Mour1k, J.A. and Mochtar, I.A. (1970) Biochim.Biophys.Acta $221,677-679$

35. Chantarangkul, V., Ingram, G.I.C., Thorn, M.B. and Darby. S.C. (1978) Br.d. Hamatol. 40, 471-488

36. Smith; R.L. (1973) J.Biol. Chem.248, 2418-2423

37. Jackson, C.M., Johnson, T.F. and Hanahan, D.J. (1968) Bioehemistry $7,4492-4505$

38. Bear, E. and Buchnea, D. (1959) Can. J. Biochem. Physiot. $37,953-959$

39. Comfurius, P. and zwaal, R.F.A. (1977) Biochim.Biophys.Acta $488,36-42$

40. De Kruljff, B., Cullis, P.R. and Radda, G.K. (1975) Biochim.Btophys. Aata $406,6-20$

41. Böttcher, C.J.F., van Gent, C.M. and Pries, C. (1961) Anal. Chint Aota 24, 203-207

42. E1sentha1, R, and Corntsh-Bowden, A. (1974) Bzochen.J. 139, $715-720$

43. Laemi1, U.K. (1970) Nature 227,680-685

44. Aronson, D.L. (1974) Thrombos. Diathes.haemorah. 559, 11-26

45. Jesty, J., spencer, A.K. and Nemerson, Y, (1974) J.Biol. Chem. $249.5614-5622$

46. Fujlkawa, K., Titani, K. and Davie, E.W. (1975) Proc. Natz.Acad. Sot. USA 72, 3359-3363

47. Kuxachi, K., Fujikawa, K., schmer, G. and Davie, E.W. (1976)

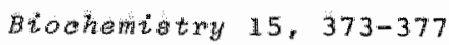

48. Rosenberg, J.S., McKenna, P.W. and Rosenberg, R.D. (1975) J.BLOL.Cham. 250, $8883-8888$ 
49. Dawie, E.W., Fujikawa, K., Kurachi, K. and Kisiel, W. (1979) Adv.in Enzymot. 48, 277-318

50. Jobin, F. and Esnouf, M.P. (1967) Biochem.J. 102,666-674

51. Esmon, C.T., Owen, W.G. and Jackson, C.M. (1974) J.Biot. Chem. $249,8045-8047$

52. Zwaal, R.F.A., Rosing, J., Tans, G. "Bevers, E.M. and Hernker, H.C. (1980) In The Regulation of Coagulation (Mann, K.G. and Taylor. F.B. Eds.) pp. 95-112; Elsevier North Holland Inc, New York

53. Nemerson, Y., Zur, M., Bach, R. and Gentry, R. ibid, pp.193-202

54. Nelsestuen, G.L. ibid, pp. 31-41

55. Nelsestuen, G.L. and Broderius, M. (1977) Biochemista $16,4172-$ 4177

56. Nesheim, M.E., Taswe11, J.B. and Mann, K.G. (1979) J.Bzal. Chom* 254, $10952-10962$. 
CHAPTER 6

THE ACTIVATIOW OE FACTOR IX BY EACTOR XI

Active site titration and development of a spectrophotometrie cisay

Factor $I X$ is the zymogen form of factor $I X a$, a clotting factor that participates in the activation of factor $x$ via the intrinsic pathway. The heavy chain of factor IX $x_{a}$ shows considerable homology with trypsin, trombin and factor $x_{a}$ which suggests that factor $I_{a}$ is a serine esterase which active site is located in the heavy chain (1). Since factor $\mathrm{IX}_{\mathrm{a}}$ is capable of activating factor $\mathrm{X}$ in the absence of $\mathrm{Ca}^{2+}$, phospholipid and factor VIII, it is likely the enzyme responsible for factor $X$ activation via the intrinsto pathway (see also chapter 5).

In order to be able to quantitate reaction rates of factor $\mathrm{x}$ activation by factor IX on a molar basis it is necessary to quantitate the amounts of factor $\mathbb{I X}_{a}$ present in the reaction mixture. An active site titration is the most direct method to determine the concentration of active enzymes participating in a given reaction (2). In this chapter it is shown that active site titration of factor $I_{\text {a }}$ is indeed possible using $\mathrm{p}^{\mathrm{NPGB}}{ }^{*}$ as a titrant *

Factor IX can be activated by factor XI and by RVV-X (4, is; see also chapter 2). Activation by factor XI accurs via an intermediate which has no coagulant activity and no esterase activity towards synthetic axginine esters, whereas activated factor IX shows both activities $(4,5)$. Activation of factor $I X$ bY RVV-X results in an activited factor IX molecule of the same molecular weight as the zymogen. This socalled melizofactor $\mathrm{IX}_{\mathrm{a}}$ has a coagulant and an esterase activity amounting to only half that of the factor Ixa molecule which results from the activation of factor $I X$ by factor $X_{a}$ (4).

In this chapter we report experiments in which the time course of activation of factor IX by factor $x I_{a}$ is monitored in three ways:

1) by measurement of biological activity to which end a spectrophotometric assay was developed using the natural substrate for factor $I X$ a (i.e. factor $X$ ). Activation of factor $X$ by factor $I X_{a}$ was monitored using the chromogenic substrate $s 222$;

2) by active site titration of the active sites generated

3) by gelelectrophoretic analysis in the presence of sodium dodecyl 
sulfate.

It w11 be show that the intermedate occurring during activation of factor $X X$ by factor $X I$ does not interact with $p-N P G B$, indicating that the active gite is not avaliable.

Theopy of titition

When arine eaterage is active ate titrated with $p$-NPGB, a rapla burst of $\mathrm{p}-\mathrm{n}$ trophenol $1 \mathrm{~s}$ observed followed by a very slow or negliglble teady tate production of p-nitrophenol. Bender et al. $(2,6)$ have derived kinetic equations for this proceas according to a three-gtep mechandsm.

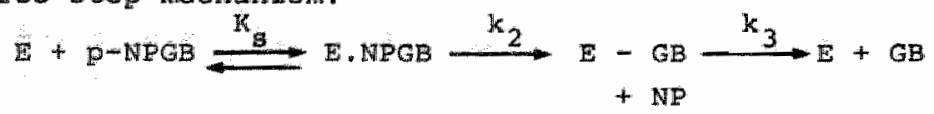

Here $\mathrm{E}$ 10 the enzyme, p-NPGB $1 \mathrm{~s}$ the substrate, E.NPGB is the adsorptive enzyme-substrate complex, E-GB is the guaniainobenzoyl enzyme that westes from the atolchiometric reaction of enzyme with substrate 1 lberating 1 eq of $p-n i t r o p h e n o l$ (NP) and $G B$ is the free p-guanlidinobenzoate that result from the deacylation of the E-GB complex. when $[\mathrm{s}] \mathrm{o}^{>} \mid \mathrm{E} 1 \mathrm{o}$ the following equation describes the production of p-jitrophenol in time:

$$
[\mathrm{NP}]_{t}=\mathrm{A} \cdot \mathrm{t}+\pi\left(1-\mathrm{e}^{-\mathrm{bt}}\right\}
$$

This can be recognilsed to consist of a steady state part (A.t) and of a presteady state part $\left(\pi \cdot\left(1-\mathrm{e}^{-b t}\right)\right)$. The rate with which the exponential term dropg to zero 1 s determined by the operational flrat order rate constant (b) of the presteady state reaction. The burst of p-nitrophenol production 1 s proportional to the concentration of the enzyme [ $\mathrm{E}]$ and is given by:

$$
\left.\pi=\|\mathrm{E}\|_{0} \cdot \frac{\mathrm{k}_{2} /\left(\mathrm{k}_{2}+\mathrm{k}_{3}\right)}{1+\mathrm{K}_{\mathrm{m}} \mathrm{app} /[\mathrm{s}]_{0}}\right\}^{2}
$$

Here $\mathrm{K}_{\mathrm{m} \text { app }}=\mathrm{K}^{\mathrm{n}} \mathrm{k}_{3} /\left(\mathrm{k}_{2}+\mathrm{k}_{3}\right)$

Equation II can be rearranged to glve:

$$
1 / / \pi=\frac{k_{2}+k_{3}}{k_{2} \sqrt{[E]_{0}}}+\frac{\left(k_{2}+k_{3}\right) \cdot k_{m} \operatorname{app}}{\left.k_{2} \cdot \sqrt{[\mathrm{I}}\right]_{0}} \cdot \frac{1}{[\mathrm{~S}]_{0}}
$$


When $\pi$ is measured at different substrate concentrations, a plot of $1 / \sqrt{\pi}$ vs $1 /[\mathrm{S}]_{0}$ gives a straight ine which intercept at the $1 / \| S]_{0}=0$ axis is $\left(k_{2}+k_{3}\right) \cdot k_{2}{ }^{-1} \cdot \mid E l_{0}$. However, in order to be of practical use, it is desirable that titration of the enzyme can be carried out at one substrate concentration which gives airectly $[E]_{0}$. As can be seen from eq. II, $\left.=\mid E\right]_{0}$ only when $k_{2}>k_{3}$ and $[s]_{0} \gg k_{m}$ app" Therefore, $k_{2}, k_{3}$ and $k_{m}$ app have to be determined. In practice, $\mathrm{k}_{\mathrm{m}}$ app is very low and cannot be accurately determined from the $1 / \sqrt{\pi}$ vs $1 /[S]_{0}$ plot and $i t$ is therefore calculated from the values of $\mathrm{k}_{2}, \mathrm{k}_{3}$ and $\mathrm{k}_{\mathrm{s}}$ using eq. III.

$k_{3}$ can be determined after isolation of the acylenzyme intermediate by following the first order dissociation. A plot of the logarithm of the fraction of enzyme remaining acylated at time $t$ vs time gives a straight line with slope $-k_{3}$.

From the presteady state part of the reaction $\left(k_{2}+k_{3}\right)$ and $\mathbb{K}_{s}$ may be determined. As cam be seen from eq. I, the first order rate constant b from the presteady state reaction can be obtained from a plot of the logarithm of the extrapolated steady state line (A.t + m) minus the actual amount of p-nitrophenol produced at time $t$ vs time. The equation for $b$ as a function of substrate concentration is ${ }_{0}$ is given by

$$
b=\frac{\left(k_{2}+k_{3}\right) \cdot[s]_{0}+k_{3} \cdot k_{s}}{k_{s}+[s]_{0}}
$$

When $k_{3} \cdot k_{5} \ll\left(k_{2}+k_{3}\right)$, a condition usually met, this can be rearranged to

$$
1 / b=\frac{1}{k_{2}+k_{3}} * \frac{k_{s}}{k_{2}+k_{3}} \cdot \frac{1}{[s]_{0}}
$$

Thus a plot of $1 / \mathrm{b}$ vs $\mathbb{1} /\|\mathrm{S}\|_{0}$ gives $\left(k_{2}+\mathrm{k}_{3}\right)$ and $\mathrm{k}_{\mathrm{g}}$.

\section{EXPERTMEHTAL PROCEDURES}

\section{Materials}

S 2222 was purchased from $A B$ Kabi Dlagnostica, Stockholm, Sweden. p-NPGB was from Nutritional Biochemicals. Russeli's viper venom, heparin sodium salt (grade I, 170 USP units/mg), STI, egg-yolk phosphatidylcholine and ovalbumin were obtained from sigma. 
DEA -Sephadex A-50, Sephadex $G-25$ and $G-100$ were products of Pharmacia. Agarose (Blogel A-15 M) was obtalned from Blo-Rad. All reagents used were of the highest grade commerclally awailable.

MEPHODS

\section{Proteins}

Purlfied contact product, RVV-X, bovine factor $I X$, bowine factor $X_{2}$ " bovine factor $I x_{a}$ and bovine factor $x_{a}$ were prepared as described in chapter 5 . Before storage at $-70^{\circ} \mathrm{C}$, the protein preparations were dialysed against a buffer containing $50 \mathrm{mM}$ Tris-HCI, $175 \mathrm{mM}$ NaCI at $\mathrm{pH} 7.9$.

protein ooncentration

Protein concentrations were determined as described in chapter 5 . Phospholipids and phoopholipid pesiale preparation

Brain phosphatidylserine was prepared as described by sanders (7). single bilayer vestale solutions of a mixture of brain phosphatidylserine and egg-yolk phosphatidylcholine $(25 / 75 \mathrm{w} / \mathrm{w})$ were prepared according to de Kruijff et al. (8) by sonication for $10 \mathrm{~min}$ in $50 \mathrm{mM}$ Tris-HCl, $175 \mathrm{mM} \mathrm{NaCl}$ at pH 7.9. Sonication was performed usling a MSE Mark II 150 watt ultrasonic disintegrator set at $10 \mu$ peak to peak amplitude. After sonication no pll adjustment was needed.

Titration of activated factor IX

Titration experiments were conducted at $37^{\circ} \mathrm{C}$ in thermostated cuvets in an Amlnco DW-2 spectrophotometer set in the split beam mode at $405 \mathrm{~nm}$. In a typical experiment the sample cuvet contained 40 factor IX in 800 ul 0.05 M sodium veronal buffer (pH 8.3 ) In the presence of $20 \mathrm{mM} \mathrm{CaCl} 2$. The reference cuvet contained $800 \mathrm{HI}$ $0.05 \mathrm{M}$ sodum veronal buffer and $20 \mathrm{mM} \mathrm{CaCl} \mathrm{CH}_{2}$. After an appropriate time to allow for temperature equilibration $5 \mu 1$ of a $0.02 \mathrm{M}$ solution of $\mathrm{p}-\mathrm{NPGB}$ in dimethylformamide was simultaneously added to the sample and the reference cuvet using matched micropipettes. onder these conditions the presteady state part of the reaction 1 is completed in about 6 minutes.

When factor IX at comparable concentrations is allowed to react with p-NPGB no burst of p-nitrophenol production is observed. However, factor IX glives a low steady state production of p-nitrophenol. 
Deterination of thetio constants

$k_{3}$ was determined as described by chase and shaw $(9)$. 5 , of 0.1 N P-NPGB in dimethylformamide was adaed to $1 \mathrm{mI} 0.05 \mathrm{M}$ sodium veronm buffer at pH 8.3 containing $350 \mathrm{Hg}$ factor Ixa and $20 \mathrm{mM} \mathrm{CaCl}_{2}$. After 30 minutes incubation at $37^{\circ} \mathrm{C}$ the reaction mixture was applied to a Sephadex G-25 column $(1.5 \times 10 \mathrm{~cm})$ in $0.05 \mathrm{M}$ sodium veronal, $0.02 \mathrm{M}$ $\mathrm{CaCl}_{2}$ at pH 8.3. After 3 mi of eluate 2.5 m l, containing factor IX was collected and incubated at $37^{\circ} \mathrm{C}$. After different time intervals samples were taken and assayed for free factor IX as described under assay for activated factor IX. The wime at which the reaction mixture had sunk into the column was taken as time zero. The concentration of potentially active enzyme [E]。 was determined by measuring the protein concentration in the eluate according to Lowry et al. and according to Bradford $(10,11)$. Thus the fraction of enzyme remaining acylated can be calculated and a plot of the logarithm of this fraction versus time yields $\mathrm{k}_{3}$.

$k_{2}$ and $k_{5}$ were determined by analysis of the presteady state part of the reaction at different $p-N P G B$ concentrations. The amount of enzyme not yet acylated $\left(\left[E \|_{0}-|E-G B|_{t}\right)\right.$ at various time intervals was determined fxom the difference between the steady state line of p-mitrophenol production lextrapolated back to time zerol and the amount of p-nitrophenol actually produced at time $t$. From a semilogarithmic plot of the amount of enzyme not yet acylated versus time the operational first order rake constant b of the presteady state reaction is obtained. A plot of $1 / \mathrm{b}$ versus $1 /$ [p-NPGB] o yields then $\left(k_{2}+k_{3}\right)$ and $\mathrm{K}_{\mathrm{s}}$.

$\mathrm{K}_{\mathrm{m}}$ app can then be calculated from the obtained values of $\mathrm{k}_{2} \cdot \mathrm{k}_{3}$ and $\mathrm{K}_{\mathrm{s}}$.

Asody for activated footor ix

Since factor $x_{a}$ formation by factor $I x_{a}$ in the presence of phospholipid and $\mathrm{CaCl}_{2}$ is linear in time and proportional to the amount of factor $I x_{a}$ added (see results and chapter 5 ), this provides an excellent method for measuring the factor $I x_{a}$ concentration in samples which contain an unknown amount of factor $I X_{a}$.

Phospholipid vesicles $(250 \mathrm{M})$ were incubated in the presence of $50 \mathrm{mM} \mathrm{CaCl}_{2}$ in a buffer containing $50 \mathrm{~mm} \mathrm{Tris}-\mathrm{HCl}, 175 \mathrm{mM}$ $\mathrm{NaCl}$ at $\mathrm{pH} 7.9$ at $37^{\circ} \mathrm{C}$. 100 w. was then transferred to $375 \mu 1$ of a reaction mixture containing $0.1 \times 10^{-9}$ mole factor $x_{2}$ 
In the same buffex at $37^{\circ} \mathrm{C}$. After 4 milnutes incubation factor $x$ activation was statted with the addition of 25 w of a solution of unknown factor Ix concentration. After 5 minutes 400 w 1 of the reaction moture sas subsmoled to a curet (themostated at $37^{\circ} \mathrm{Cl}$ contanding 1600 w of the same buffer. In the cuvet 192 w $\mathrm{S} 2222$ was present as well as 15 m EDT to block further reaction. Factor IX has no amiase activity towards $\$ 2222$. Therefore, the absoxbance change recorded at 405 - 500 nm on an Aminco bw-2 spectrophotometer (set in the dual wavelength mode) is a measure of the amount of factox $x_{\text {a }}$ present in the reaction mixture. From a calibration curve made wth known amounts of active site titrated factor $x$ " determined under the same assay conditions as described above, the amount of factor $x_{\text {a }}$ present in the reaction mixture can be calculated. The rate of factor $x_{a}$ formation obtained with known amowns of active site titrated factor IX a deterined also under the same conditions as described above, was used to construct a calibration curve for the amount of factor $I x_{a}$ present in the reaction mixture.

Ged eteotrophometio watygis of factor IX activation

Gel electrophoresis in the presence of sodium dodecyl sulphate was carrted out as described by taemili (12) with gels containing 10 acrylamide, 0.27 w, $\mathrm{N}^{3}$-methy 1 bisacrylamide and 0.18 sodium dodecyl sulphate. Allquots of the activation mixture (10 $\mu 1$ ) were diluted 30-fold In 2 sodium dodecyl sulphate and were kept for $3 \mathrm{~min}$ in a bolling water bath. $5 \%$ Mercaptoethanol was present in disulfide reduced samples. Finally, 50 wI was brought on the gels. In order to get an estimate of the factox IX formed and of the factor 1 still present in the reaction mixture, gels with know amounts of factor IX and factor IX (both in the presence and absence of mercaptoethanoly were run simultaneously. Aftex staining and destaining of the gels according to falrbanks et al. (13) , the geds were scanned on Gilford Model 250 spectrophotometer.

RESULTS

Asat for arizated factor ix

In general, factor IX is assayed with a clotting assay in factor IX deflcient plasma. However, factor IX deficient plasma is expensive and not readly avallable. Moreover, although sensitive for factor $I x_{a}$, guantitation of factor IX in a clotting assay essentially is a 
bioassay based on a dose-response curwe between the amount of factor IX added and the clotting times neasured, with all the inherent inaccuracies of such an assay. Therefore, we aimed to devise an assay for factor IX in a purisied system. Earliex work in our laboratory (cf. chapter: 5) suggested that factor IX can be quantitated adequateIy via its ability to activate factor $\mathrm{X}$.

The rate of factor $x_{a}$ formation by factor $x_{a}$ in the presence of 0.2 $\mu \mathrm{M}$ factor $\mathrm{x}_{2}, 25 \mu \mathrm{M}$ phospholipid and $10 \mathrm{mM} \mathrm{CaCl} \mathrm{Can}_{2}$ be easily measured, is linear in time (CF. chapter 5) and is directly proportional to the amount of factor IX present (Fig. 1). The calibration curve for factor IX gives a straight line up to concentrations of 1 wg/m.

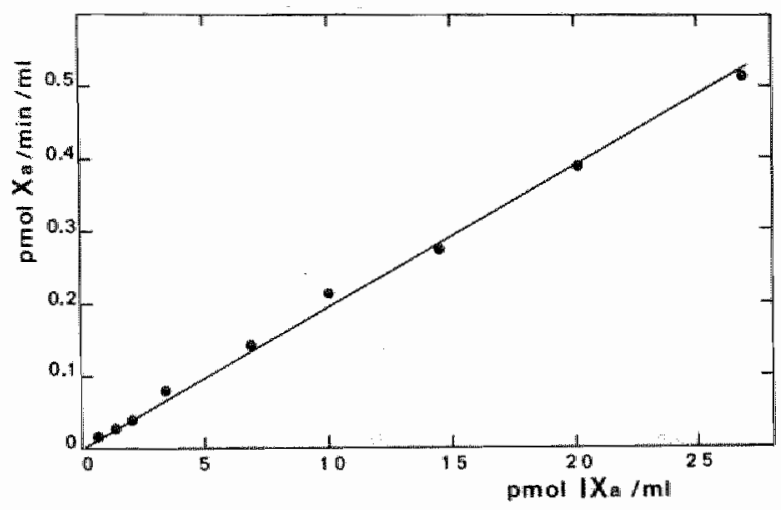

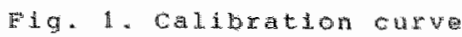
otit the rate of factor $\mathrm{x}$ formation with varying amounts of Eactor $I_{\mathrm{X}}$

Phospholipid vegicles (125 y) were preincubated

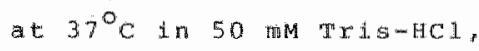
$175 \mathrm{~mm} N \mathrm{NCl}, 50 \mathrm{mM} \mathrm{CaCl}$ at pH 7.9. After 10 min. 100 ni of this susponsion was transferred to 375 li of a bufer containing

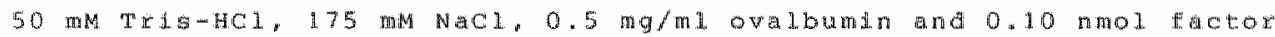

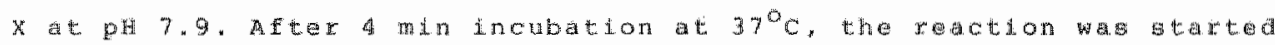

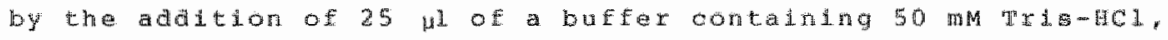
$175 \mathrm{mMNaCl}, 0.5 \mathrm{mg} / \mathrm{ml}$ owalbumin and varying amountg of factor. IX.

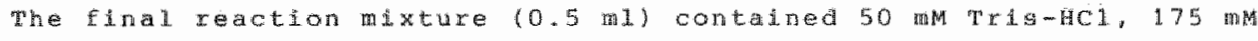

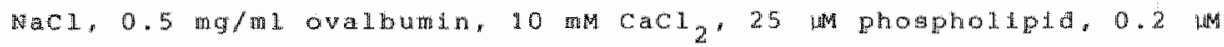
factor $x$ and amounts of factor IX as indictred in the figure. The rate of Factor $x$ activation was calculated from the amounts ot factor xa presert in the ceaction mixture attet 5 min. The phosphoIlpda vesicles were prepared as described under "Experimental procedures:

Factor IX has no activity in the assay for factor IX a " Furified contact product has a very low anidase activity towards $s 222$ conly detectable when amounts of contact product of $0.5-1 \mathrm{mg} / \mathrm{ml}$ 
are present in the cuvet) and gives no additional factor $x_{\text {form }}$ ation in the assay. However, the amounts of contact product, present In some experiments on factor IX activation (see below) were such that they did not alsturb the measurement of factor $x_{a}$ formation by factor $\mathbb{1} X_{\text {al }}$ *

Determination of Rinetic contants of factor IX for p-NPGB

When factor $I x_{a}$ is active site titrated with $\mathrm{p}-\mathrm{NPGB}$ at $37^{\circ} \mathrm{C}$ in $50 \mathrm{mM}$ veronal at pH 8,3 , a burst of p-nitrophenol production is observed followed by a slow steady state p-nitrophenol production (Fig. 2 ).

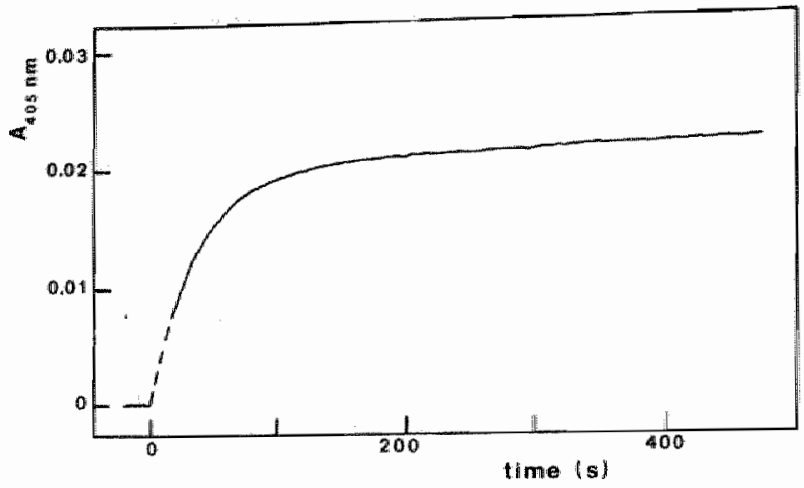

Fig. 2. Tituation of 0.8 m 1 of a solution of factor Jx at $37^{\circ} \mathrm{C}$ Factor $\mathrm{rx}$ was therated with p-NPG at $37^{\circ} \mathrm{C}$ in 50 mM sodinn vexonal, $20 \mathrm{mM} \mathrm{Cacl}_{2}$ at pH 8.3 as described under "Ixperimental Procedures". The A 405 (i) was determined by extapolation of the steady state

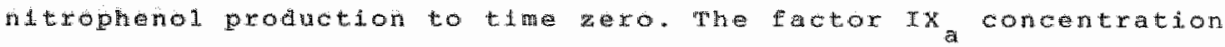

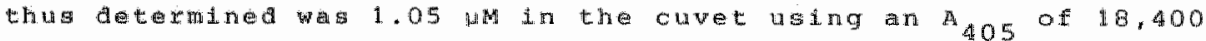
tox atrophed.

The dependence of this burst on p-NPGB concentration is shown in H. 3. At $0.1 \mathrm{mM} \mathrm{p}-\mathrm{NPGB}$ the observed burst is 98 of the maximal attalnable burst. Therefore, p-NPGB meets the criterium that active sute titration of the enzyme must be possible at one titrant concentition.

From the 1inearity of $1 / \mathrm{b} k \mathrm{~s} 1 /[\mathrm{p}-\mathrm{NPGB}]_{0}$ (Fig. 4 ) it is concluded that the reaction of factor IX with p-NPGB can be describea in terms of the three step mechanism described by Bender et al. 12,6$)$. From this plot values of 187 w for $\mathrm{K}_{\mathrm{s}}$ and $0.056 \mathrm{~s}^{-1}$ for $\mathrm{k}_{2}+\mathrm{k}_{3}$ axe caloulated. 


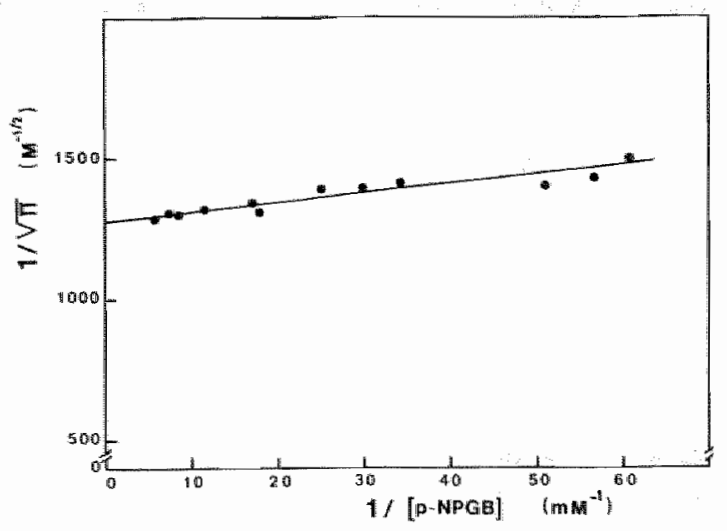

Eig. 3. Depenaence of the burst $\pi$ on $\mathrm{p}^{-\mathrm{NPG}}$ concentration

Factor Ix as titrated at $37^{\circ} \mathrm{C}$ with warying amounts of P-NPGB in $50 \mathrm{~mm}$ sodium weronal. $20 \mathrm{mM} \mathrm{Cacl} 2$ at pH 8.3 as described under "Experimental procedures" " "The burst m was determined by extrapolation of the steady state nitrophenol production to time zero

and factor IX concentration was calculated asing an A 405 of 18.400 for nitrophenol. Factor Ix concontration was $0.62 \mu$.

Fig. 4. Depenaence of the operational fitst oxdex rate constant (b) of the acylation of factor IX on p-MPGB concentsation

Factor IX was titrated at $37^{\circ} \mathrm{C}$ with varying amounts of p-NFGi in 50 mM sodjum veronal, $20 \mathrm{mM} \mathrm{CaCl}$ at pH 3 . 3 described under "Experimenta 1 pocedures". The operational irst

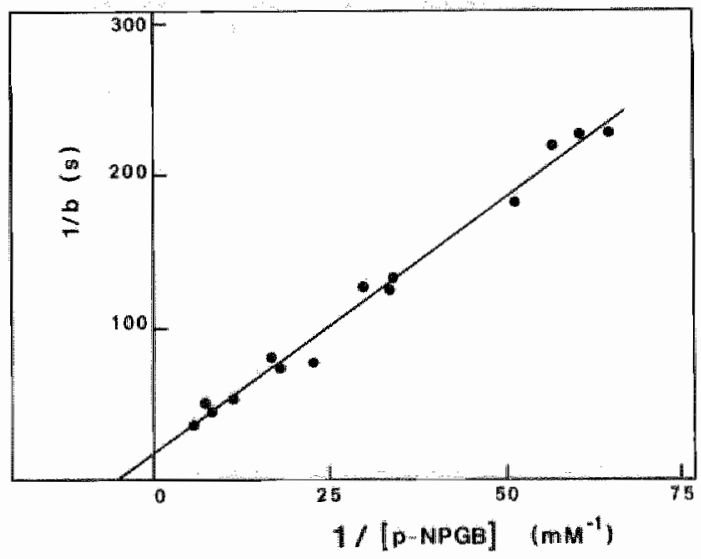

order rate constant b was deternined a described under "Experimental Procedures". "We kinetio constants calculated from this plot are sumarised fin rable $I$.

Fig. 5 shows that deacylation of the E-GB complex is first order with respect to $\mathrm{E}-\mathrm{GB}$. A Iinear plot for the logarithm of the fraction of the enzyme remaining acylated at time tys time is obtained ard from the slope of this plot a $k_{3}$ of $3 \times 10^{-5} \mathrm{~s}^{-1}$ is calculated. 
The kinetic constants determined are sumarised in Table $I$. These data axe in agreement with the data from Byrne et al. 13; see also Table I).

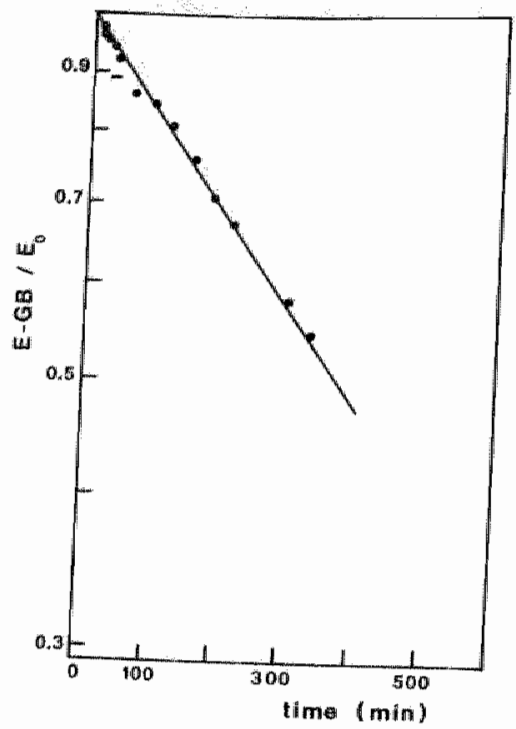

Fig. 5. Deacylation of the factor Ix guaniainobenzoate complex

The acyletizye complex (E-GB) was prepared and 1 solated as described under "Experinental Procedures". Deacylation of the E-GE complex at $37^{\circ} \mathrm{C}$ was monitored by measuring the amount of free f $\mathbb{I X}$ as descrlbed under "Experimental Procedures". k was determined as the slope of the 1ine by lineat regression. The

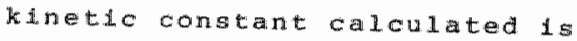
summarised in Table $I$. $p-N$ PGB

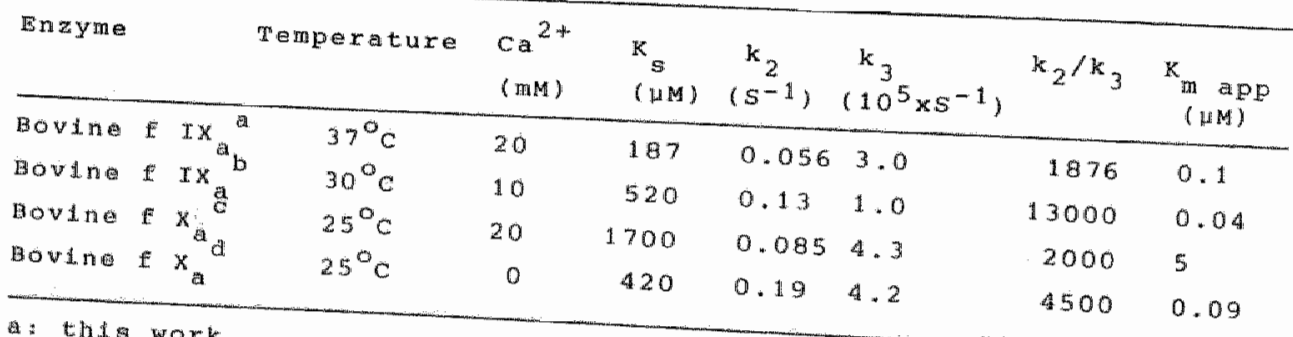

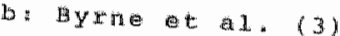

o: sinth $(15)$

a: linanout t a (16).

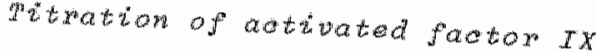

When afferent preparations of bovine factor IX axe active site 
on a protein determination using two different methods $(10,11)$ using a MW of 46,500 (4) and assuming one active site per molecule of factor IX . Activation of factor IX with purified contact product of RVV-x yields 95 - 100 of the active sites expected, based on protein determination, using a mof 55,400 (14) for the zymogen and assuming the presence of one active slte per molecule. mis confirms the notion that activation of factor $I X$ by factor $X I$ ax by RVV-X generates one active site per molecule of zymogen.

Activation of factom IX

During the activation of factor IX by factor XI two peptide bonds are cleaved and an activation peptide of $9,000 \mathrm{MW}$ is liberated (5). After cleavage of the fixst peptide bond an intermediate is formed which has mo coaqulant activity and no esterase activity (4,5). coagulant and esterase activity appear after the cleavage of the second bond. Therefore, we investigated whether the appearance of the active site, as determined by titration with p-NPGB colncided with the cleavage of the second bond. Fig. 6 shows the time course of activation of factor IX as followed by gel electrophoresis, by active site titration and by the activity in the assay for factor Ixa. It can be seen that the appearance of the active sites does not correlate with the disappearance of factor IX. After 10 minutes incubation, 13 of the zymogen is left but only 448 of the active sites has appeared. Therefore, it is concluded that the active stte cones free when the second bond is cleaved in the intermediate.

Activation of factor IX by RVV-X results in the formation of socalled metzofactor IXa. This molecule has the same molecular weight as the zymogen. Melzofactor IX was reported to have hall of the specific activity of the normal factor $I X_{a}$ molecule both in a clotting assay and in an esterase assay with tosyl-L-arginine methyl estex (4). This can be due to a difference in kinetic parameters for the substrate of the two different forms of factor $I X_{a}$ or $\mathbb{I t}$ can be aue to the fact that RVV-X activated factor IX results in the appearance of only half the maximil attalnable sites.

Activation of factor IX by RV $\mathrm{x}$ results in the same number of active sites as is the case when factor IX is activated by contact product (3). Moreover, when contact product was added after activation with RVV-X, meizofactor IX was completely converted into nomal factor $I X_{a}$ and there occurred no change in the number of active sites present (data not shown). Therefore, it is concluded that activation 


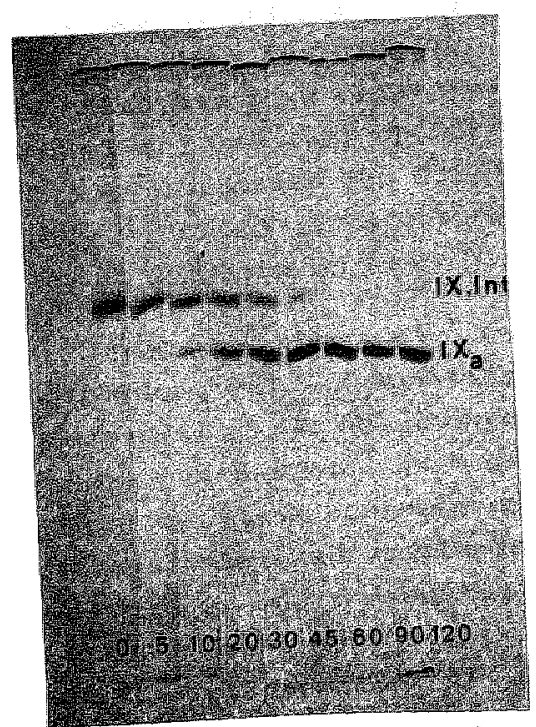

incubation time ( $\mathrm{min}$ )

C

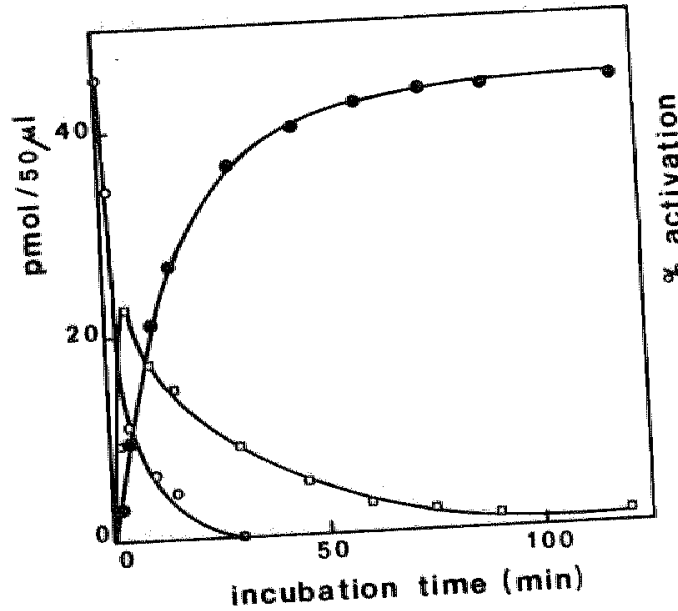

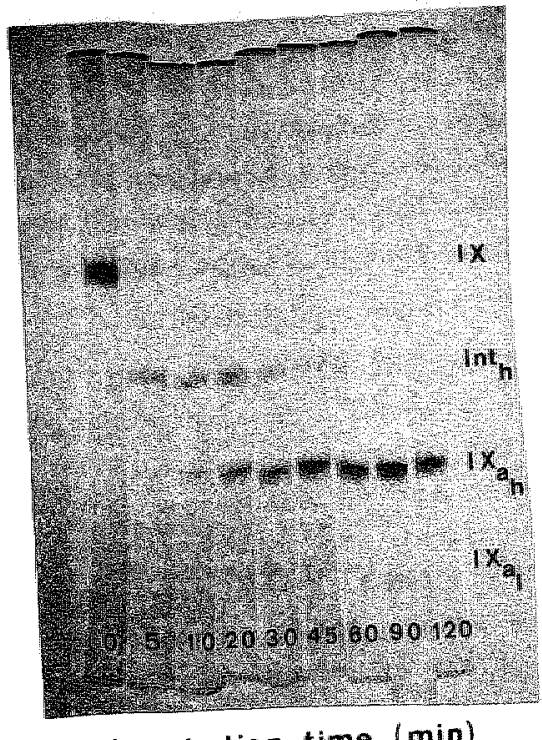

incubation time (min)

D

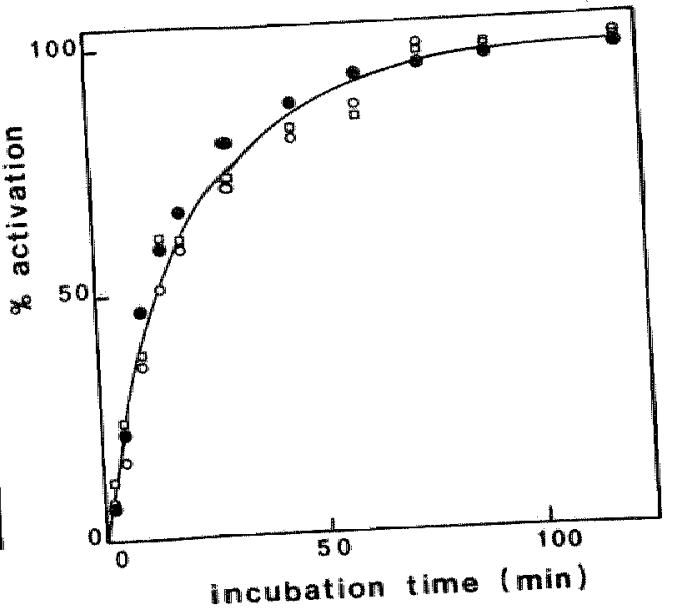




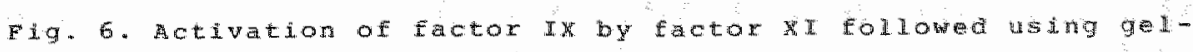
electrophoresis, active site titracion and by mesurement of factor IX in the spectrophotometric assy

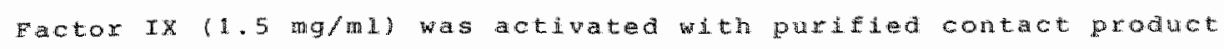

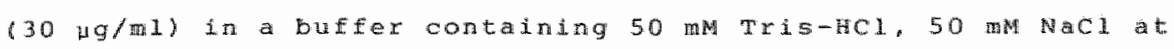
pal 8.5 at $37^{\circ} \mathrm{C}$. After the time intervals naicated sables wex taken and active site titrated, assayed for factor rxa and bought on the gels as described under "Experimental rocedures". simultan eousiy. gels were run with samples contaning known anounts ot factor IX (xeduced and unxeduced) and factor Ix (unxeduced. After staining and aestaining, the gels were scanded on a Gilfoxd Model 250 spectrophotometer.

From scanning of the gels contalning the known amonts of factor Ix a (ureduced) a calibiation curve was constructed in oxder to calculate the amounts of factor Ix present in the urrecuced samples From the reaction mixture.

From scanning of the gels contaling the known amounts of factor Ix (xeduced), a calibxation curve was corstructed in order to calculate the amount of factor IX present in the sample (reduced) from the reaction mixture.

Assuming that factor IX and the intermediate give the same intensity of staining in the unreduced samples, the anount of factox IX + intermediate present in these samples can be calculated using the calibration curve obtained from ginning of the gels with the known amounts of factor Ix (unreduced). Thus the amount of intermedite in the sample can be calculated.

G: Ael pattern of activation (urreduced gmples)

6 B: Gel pattern at activetion (reduced sambles)

$6 \mathrm{c}:$ Data obtained from gel scaning: In the sample: $0-0$, amount of $f$ Ix pregent in the sample 口- - a , amount of intermediate present in the sample

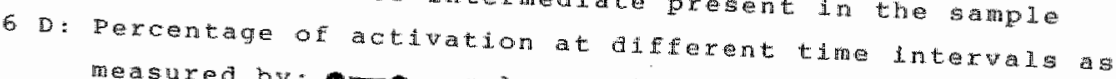
me suxed by:

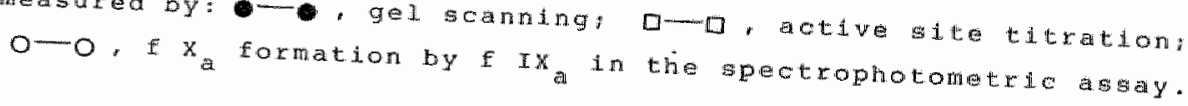


of factor IX by FVV-X results in an activated factor IX molecule wit its active site free, which has less favourable kinetic parameters for factor $x$ activation and for esterase activity towards tosy $1-L-$ arglnine methyl ester.

\section{DISCUSSTOH}

In this chapter it is shown that quantitation of factor IX on a molar basls $1 \mathrm{~s}$ readily posslble by active site titration of the enzyme with $\mathrm{p}$-NPGB. In Table I the kinetic constants of the reactior of factor $\mathrm{IX}_{\mathrm{a}}$ with $\mathrm{p}$-NPGB are summarised together with the constants for the reaction of factor $x_{a}$ with $p-N P G B$. As can be seen from Table I, the kinetic constants reported here are comparable to those reported by Byrne et all. (3), who determined the kinetic constants in the presence of $10 \mathrm{mM} \mathrm{CaCl} 2$ at $30^{\circ} \mathrm{C}$. The $k_{3}$ that we measure is hligher which may be due to the fact that we determined $k_{3}$ at $37^{\circ} \mathrm{C}$. The $k_{2}$ determined by Byrne et al. in the absence of $\mathrm{Ca}^{2+}$ is $0.11 \mathrm{~s}^{-1}$ whereas $\mathrm{k}_{3}$ and $\mathrm{K}_{\mathrm{s}}$ remain the same. Therefore, it appears that the aifferences $i_{n} k_{2}$ and $k_{5}$ compared with those determined by Byrne et $a l$. are not due to the alfference in Ca ${ }^{2+}$ concentration. From the data taken from smith (15) and from Lindhout et al. (16) for the reaction of factor $x_{a}$ with $p-N P G B$ it is clear, however, that differences in $\mathrm{Ca}^{2+}$ concentrations may result in considerable changes in $\mathrm{k}_{2}$ and $\mathrm{k}_{\mathrm{s}}$.

The rate of factor $x_{a}$ formation in the spectrophotometric assay for factor $I X_{a}$ is proportional to the amount of active sites present. Different factor IX preparations which contain an equal anount of active site give the same rate of factor $x_{a}$ formation. Factor $x_{a}$ formation by factor $\mathbb{I x}_{\mathrm{a}}$ is completely blocked by the presence of $\mathrm{p}-\mathrm{NPGB}$ and reappears upon deacylation (see Fig. 5). From these observations we conclude that the site that reacts with p-NPGB is the same site or close to the site which is responsible for the activation of factor $x$.

The experiments on the activation of factor IX with purffied contact product or $R V V-X$ show that both factor $I X$ and meizofactor IX have the same number of active sites. This is in agreement with the data of Byrne et al. (3). Factor $\mathrm{IX}_{\mathrm{a}}$ and meizofactor $\mathrm{IX}_{\mathrm{a}}$ were reported to exhibit different specific clotting and esterase activities (4). Since the number of active sites is the same, the kinetic parameters of these two enzymes for the substrate should differ. Byrne et al. showed this indeed to be the case for the 
Kinetic parameters for benzoy $1-\mathbb{L}$-arginine ethyl ester in the absence of $\mathrm{Ca}^{2+}$. However, in the presence of $10 \mathrm{mM} \mathrm{Ca}{ }^{2+}$ the $\mathrm{kinetic}$ parameters of the two enzymes are about the same. It 111 be interesting to compare the kinetic parameters of factor $\mathrm{Ix}_{\mathrm{a}}$ and melizofactor IX for factor $\mathrm{X}$ activation to see whether they show any difference.

The intermediate which occurs during the activation of factor Ix with contact product has neither coagulant activity nor esterase activity (4). It is shown here that there is neither reaction wit p-NPGB. This indicates that the active site is not yet free 1 this intermediate. This might be due to the fact that the $9,000 \mathrm{MW}$ activation peptide stili present in the intermediate prevents the formation of a productive Michaelis complex. However, cleavage of the second bond in the zymogen by $\mathrm{RVV}-\mathrm{X}$ does result in the formation of an active site pocket which is comparable to that of the normal Ix molecule in its esterase activity (3). Thus the presence of the $9,000 \mathrm{MW}$ activation peptide in meizofactor IX does not seem to be of consequence. Therefore, it is tempting to speculate that the cleavage of the second bond in the factor IX molecule is a prerequisite for the formation of a proper active site pocket. Whe proof of this, however, will have to awalt $x$-ray crystallographic analysis of the molecules involved.

ACKNOHLEDCEMENTS

Part of the chronogenic substrate $\$ 2222$ was kindly donated by $A B$ Kabi Diagnostica, Stockholm, Sweden.

FOOTMOTES

Abbreviations used are:

P-NPGB, P-nitrophenyi-p'-guanidinobenzoate; 52222 , N-benzoylL-isoleucy $1-I-g 1$ tatamyl-glycy $1-L-a r g i n i n e-p-n i t r o a n d$ id de hydrochloride; RVV-X, purifled factor $X$ activator from Rugsell "s viper verom; STI, soybean trypsin inhibitox.

\section{REFERENCES}

1. Katayama, K., Ericsson, L.H., Enfleld, D.I., Walsh, K.A., Neurath, H., Davie, E.W. and Titani, K. (2979) Proo. Natt.Aodd. Soz. USA 76, 4990-4994

2. Bender, M.L., Begue-Canton, M.L., Blakeley, R.L., Brubacher, L.J., Feder, J., Gunter, C.R., Kezdy, F.J., Killheffer, J.V., Thomas, H.M., Millex, C.G., Roeske, R.W. and Stoops, J.K. (1966) 
J.Am.Chem. Sod. $88: 24,5890-5913$

3. Byrne, R., Link, R. R. and Castelino, E.J. (1980) J.Biot.Chem. $255,5336-5341$

4. Lindquist, P.A., Eujikawa, K. and Davie, E.W. (1978) d.Etol.Cham. 253, $1902-1909$

5. Fujlkawa, K., Legaz, M.E., Kato, H. and Davie, E.W. (1974) Butoohemuty $13,4508-4516$

6. Bender, M.L., Kezdy, F.J. and Wedler, E.G. (1967) J.Ghem. Edwation 4., $84-88$

7. Sanders, H. (1967) Brochim.Btophye. Alta 144,485-487

8. De Krudjef, E., Cull1s, P.R. and Radda, G.K. (1975) Biochim.Biophys. Acta $406,6-20$

9. Chase Jr, W, and shaw, E. (1969) Biochemitry 8, 2212-2224

10. Lowry, O.H., Rosebrough, N.V., Farr, R.J. and Randa11, R.J. (1951) d. Biot. Chem. 193, 265-268

11. Bradtord, M.M. (1976) Anal. BLoohem.72, 248-252

12. Laemi1, O.K. (1970) Nature 227, 680-685

13. Falrbanks, G., Stech, I.L. and Wa11ach, D.F.H. (1971) Biochamiatry 10, $2606-2617$

14. Fujlkawa, K., Thompson, A.R., Legaz, M.R., Meyer, R.G. and Davie, E.W. (1973) Bioohemistry 12, 4938-4945

15. Smith, R.L. (1973) J.Biol.Chem, 248, 2418-2423

16. Lilnahout, M.J., Kop-Klaassen, B.H.M. and Hemker, H.C. (1978)

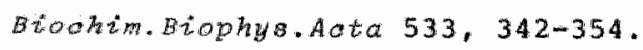




\section{CHAPTER 7}

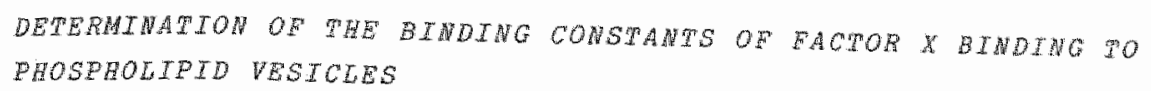

\section{INRODUCRON}

Lipld-protein interactions play an important role in blood coagulation (for a review see ref.1). Factor $x$ activation both via the antrinstc and extrinsic pathway as well as prothrombin activation take place on a phospholipid surface (ct. chapter 2). In ordex to be able to describe the reactions taking place on the phospholipid surface it is essential to know the binding parametexs of the interaction between the phospholipld bilayer and the proteins involved.

A number of methods have been used for the detemination of the binding parametexs of clotting factors to phospholipid bilayers. Nelsestuen et al. $(2,3)$ carried out an extensive study of factor $x$ and prothrombin binding to phospholipid vesicles of different composition using a light scattexing techrique. Bloom et al. (4) used the same technigue to determine the binding of factox $x$, factor $V_{a}$ and prothromin to vesicles of a mixture of phosphatidylserine and phosphatidylcholine (25/75;w/w). Since phospholipid vesicles with a mole fraction of phosphatidylserine higher than 30-40\% are known to aggregate in the presence of $\mathrm{Ca}^{2+}$-jons $(5,6)$ the 1 ight scattering methods are restricted to measurement of binaing at low $\mathrm{CaCl}_{2}$ concentrationg (1ess then 5 mu) and to vesicles containing a low mole fraction of phosphat dyliserine. This is a serious disadvantage since the optinal ca" ${ }^{2+}$ concentration for factor $x$ and prothrombin activation in the presence of phospholipla is about lomu tot chapters 4 and 5 ). Dombrose at al. (7) used the method of Humel and Dryer (a) to determine the binding parameters of prothrombin fragment 1 to vesicles of a inixture of phosphatidylglyeerol and phosphatidylcholine. This latter method which is also applicable for prothrombin and factor $x$ binding is, however, labotious and requires large amounts of protein.

Nesheim et al. (9) inferred the binding parameters for the components of the prothrombinase complex from the rates of prothrombin activation. This method is, however, subject to the 
assumption that the rates of prothrombin activation found are a Eunction of the binding of the aifferent components to the bilayer. It is, however, this latter assumption which one would like to prove. Moreover, the binding constants thus determined wil be apparent binding constant dependent on the amount of phospholipid present.

We report here a simple and rapid method for the determination of the binaing constants of factor $x$ binding to phospholipid vesicles. This method 1 s based on the finding that RVV- $\mathrm{X}^{*}$ ) is unable to activate factor $x$ that is bound to phospholipid vesicles, but rapidiy activates free factor $X$. In this chapter it is shown that from the observed rates of factor $x_{a}$ formation in the presence of phospholipid vestcles the amounts of Eree and bound factor $x$ can be calculated. This enables determination of the binding parameters of factor $x$ binding to the phospholipla vesicles present in the reaction mixture.

The great advantage of this technique is that the binaing of factor $x$ to the vesicles can be measured at the same conditions as used in the kinetic experiments of factor $x$ activation lof. chapter 5). This is needed in order to be able to interpret the observed kinetics of factor $x$ activation in a model in which factor $X$ bound to the phospholipid surface is the substrate for the enzyme factor Ix ${ }_{a}$.

since the method is based on the specific interaction between factor $X$ and RVV-X it is not applicable to othex coagulation factors.

\section{WXERTMEUTAL PROCEOURES}

\section{MATERALS}

S 2222 was purchased from AB Kabi Dlagnostlca, Stockholm, Sweden. p-NPGB was from Nutritional Blochemicals. DEAE-Sephadex A-50, Sephadex G-100 and G-200 were products of Pharmacia. STI, ovalbumin and Russel's viper venom were obtained from sigma. All reagents used were of the highest grade commercially available. 


\section{METHODS}

\section{Proteins}

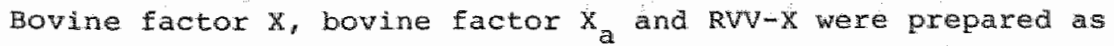
described in chapter 5 . No phospholipase $A_{2}$ activity could be detected in the RVV-X preparations. Before storage at - $70^{\circ} \mathrm{C}$ the protein preparations were dialysed against a buffer containing $50 \mathrm{mM}$ Tris-HCl, $175 \mathrm{mM} \mathrm{NaCl}$ at $\mathrm{pH} 7.9$.

Proteth eancentrations

Concentrations of factor $x$ and factor $x_{a}$ were determined as described in chapter 5. RVV-X concentrations were held constant in the experiments at $2.9 \mathrm{ng} / \mathrm{ml}$ reaction mixture. The concentration of RVV-X was calculated from the $A_{280}$ assuming an $A_{280}^{1}$ of 10.0 .

Phospholipid and phosphotipid vesicte proparations were prepared as described in chapter 5 . Determination of the rate of factor $x_{a}$ formation by $P W-X$ Factor $x$ was preincubated at $37{ }^{\circ} \mathrm{C}$ in $450 \mu 1$ of a buffer containing $50 \mathrm{mM}$ Tris-HCl, $175 \mathrm{mM} \mathrm{NaCl}, 0.5 \mathrm{mg} / \mathrm{ml}$ ovalbumin and $11.1 \mathrm{mMCac} \mathbb{H}_{2}$ at $\mathrm{pH} 7.9$. After 4 minutes, the reaction was started with the addition of $50 \mu \mathrm{l}$ RVV-X (1.45 ng) in the same buffer. After different time intervals aliquots of the reaction mixture were sampled to a cuvet. The final volume in the cuvet was $2 \mathrm{ml}$ of a buffex containing $50 \mathrm{mM}$ Tris-ECl, $175 \mathrm{mM} \mathrm{NaCl}$, $0.5 \mathrm{mg} / \mathrm{ml}$ ovalbumin, $15 \mathrm{mM}$ EDTA and $192 \mathrm{WM} \mathrm{s} 2222$. The EDTA is present to block further reaction. Since $k V V-X$ has no detectable amidase activity towards 52222 , the rate of change in absorbance at 405-500 nm measured on an Aminco DW2 spectrophotometer is a measure for the amount of factor $x_{a}$ present in the sample. The amount of factor $x_{a}$ present 1 in the sample was calculated from the measured absorbance change at 405-500 nim using a calibration curve made with known anounts of active site tritated factor $x_{a}$ under the same conditions as described above. Rates of factor $x_{a}$ formation are expressed in pmol $x_{a}$ min $^{-1}$ ml $^{-1}$. When phospholipid vesicles were present these were preincubated for $10 \mathrm{~min}$ at $37^{\circ} \mathrm{C}$ in a buffer containing $50 \mathrm{mM}$ Tris-HCl, $175 \mathrm{mM} \mathrm{NaCl}$ and $50 \mathrm{mM} \mathrm{CaCl}_{2}$ at $\mathrm{pH} 7.9$. 
The kinetic constants of factor $x$ activation by RVV- $X$ in the absence of phospholipla were obtalned from the construction of a ulneweaver-Burk plot using the statistical analysis of the ata as described by Eisenthal and Cornish-Bowden (10). For the construction of the wineweaver-Burk plot the rate of factor $X_{\text {a }}$ formation was averaged from three independent determinations.

\section{RESULTS}

The basis of the method to be described is that in a mixture containing free factor $x$ and factor $x$ bound to phospholipid, only free factor $x$ ls activated by RVV-X. In order to determine the binding parameters of factor $x$ binding from the rates of factor $x_{a}$ formation by RWV-X it is necessary to know the kinetics of factor $X$ activation by RVv-X first.

Kinetied of faotor $X$ aotivation $B y$ RVV-X in the absence of photphotipid

The reaction of $\mathrm{kVV}-\mathrm{X}$ with factor $\mathrm{X}$ requires $\mathrm{CaCI}_{2}$ (11). Fig. 1 shows the $\mathrm{Ca}^{2+}$-dependence of the reaction at 1 and $0.1 \mathrm{H}$ factor $\mathrm{X}$.

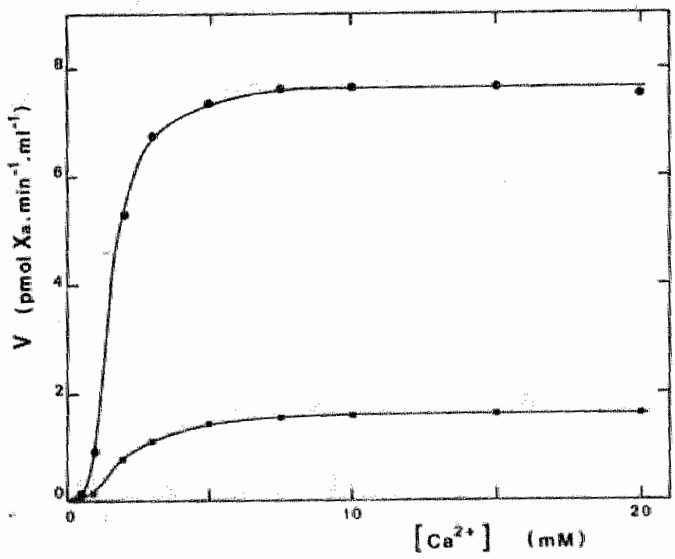

19. 1. $\mathrm{Ca}^{2+}$ - dependence

of $x_{\text {a formation }}$

by RVV-X at differet

f x concentrations

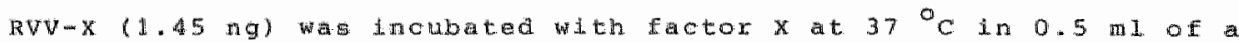

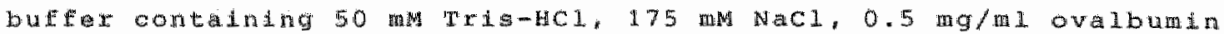

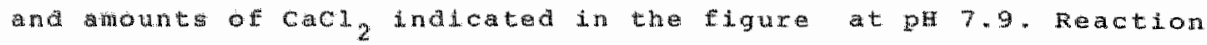

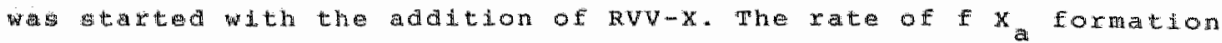

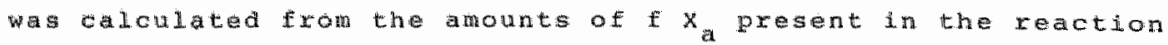
mature aftex 2.5 ard 5 min the f x concentrations present were $0-0,1$ HW 


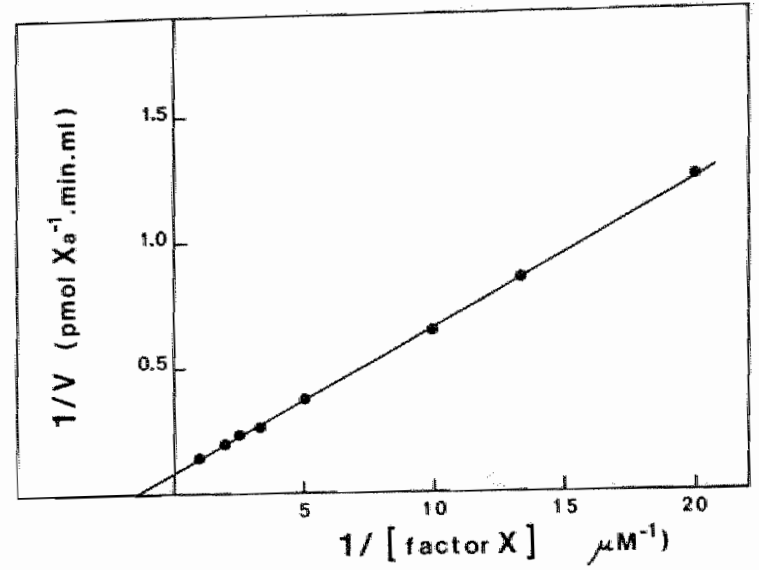

Fig. 2, flneweatorBurk plot of $x_{\text {a }}$ fior mation by RWV - $\mathrm{X}$

F $x_{\text {a formation by }}$ fVV-x at varying $F$ concentrations wis measurec

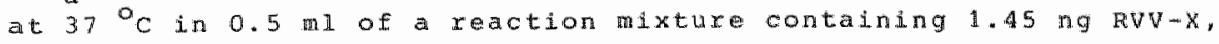
$50 \mathrm{mM}$ Tris-HCl, $175 \mathrm{mM} \mathrm{NaCl}, 0.5 \mathrm{mg} / \mathrm{ml}$ ovalbumin, $10 \mathrm{mM} \mathrm{CaCl}_{2}$ and varying amounts of $x_{\text {. }}$. The tate of $\hat{x} x$ formation wa calculated from the amounts of $t$ a present in the reaction mixture after 2. 5 and $5 \mathrm{~min}$. The kinetic constants determinea axe 0.71 w fox

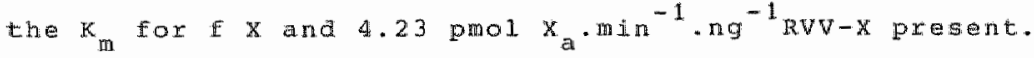

These concentrations are well above and below the $\mathrm{K}_{\mathrm{m}}$ for factor $\mathrm{x}$ (see below). The sigmoidal shape of the curve is due to the presence of the $\gamma$-carboxy glutamic acid residues in the factor $x$ molecule (12). Since the rates of factor $x_{\text {a }}$ formation at both factor $x$ concentrations are constant in the range of $5-20$ m CaCl, we conclude that the kinetic parameters of factor $x_{a}$ formation are constant in this range of $\mathrm{Ca}^{2-}$-concentrations. The steady state velocity of the reaction is constant in time and proportional to the amount of enzyme present (data not shown). The rates of factor $x_{\text {a }}$ formation at varying factor $x$ concentrations were measured at $10 \mathrm{mM} \mathrm{CaCl}_{2}$ and a Ineweaver-Burk plot was constructed (ig. 2). The kinetio constants determined from this plot axe 0.71 for the $K_{m}$ for factor $X$ and a $V_{\max }$ of 4.23 pmol $x_{a}$. min $n^{-1} \cdot n g^{-1}$ RV $x$ present. These values are in reasonable aggreenent with the kinetic parameters reported by kosow at al. (11). Provided that the amount of RVV-x present in a reaction mixture is 
known, knowledge of the kinetic parameters of factor $\mathrm{X}$ activation enables the determination of an unknown amount of factor $x$ present in the reaction mixture from the observed rate of factor $x_{a}$ formation using the following equation:

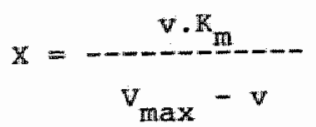

Here $x$ is the unknown concentration of factor $x$ present in the reaction mixture, $V_{\text {max }}$ and $\mathrm{K}_{\mathrm{m}}$ are the kinetic parameters of factor $X$ activation by $R V V-X$ and $V$ is the observed rate of factor $X_{a}$ formation.

Thibition of factor $x_{a}$ formation by $R V V-X$ in the presence of phophotipid

Fig. 3 shows the time course of factor $x$ activation by RVV-X in the absence and presence of phospholipid vesicles. The steady state veloolty of the reaction is markedly decreased by the presence of phospholipia.

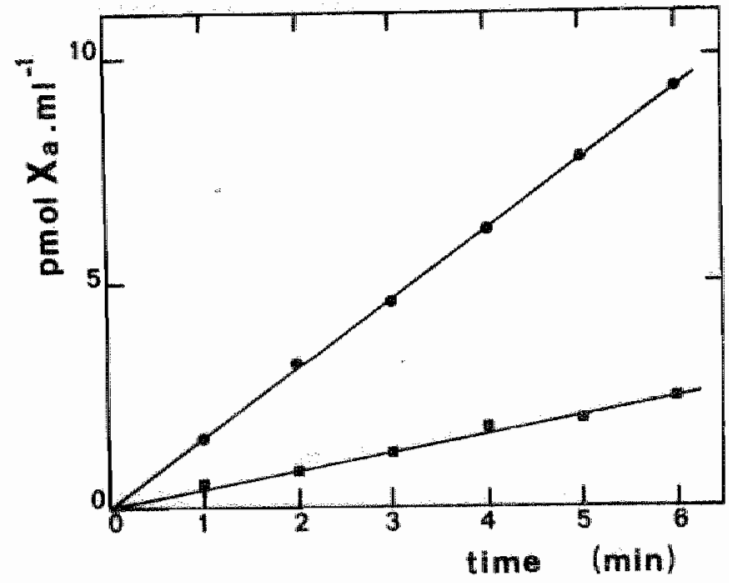

Fig. 3. Time course of \& activation by $\mathrm{RVV}-\mathrm{X}$ in the presence and $a b \operatorname{sence}$ of phospholipid

E⿱ $x$ activation by RVV-X was measured at $37^{\circ} \mathrm{C}$ in 1 m of a reaction mixtuxe containing 50

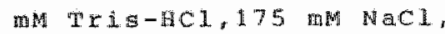
$0.5 \mathrm{mg} / \mathrm{ml}$ ovalbumin, 10 $\mathrm{mMCaC1}, 0.1$, $\mathrm{C}$, $2.90 \mathrm{nG}$ RVV $-X$;

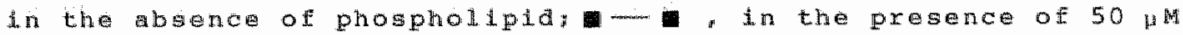
phompholipld wesiches of a axture of diolobylphosphatidylserine and aldeylphosphatidylcholine (1/1; mole/mole). Reaction was started wih the adition of RVV-X. Phospholipid vesicles were preincubated for 10 min at $37^{\circ} \mathrm{C}$ in 50 m $\mathrm{mris}-\mathrm{HCl}$, $175 \mathrm{mM}$ Nacl and 50 ma cacl. at pH 7 . 9. Mfter the time intervels indicated samplesere taken and ssayed for $f$ w as aescribed under "Experimental Procedures". 


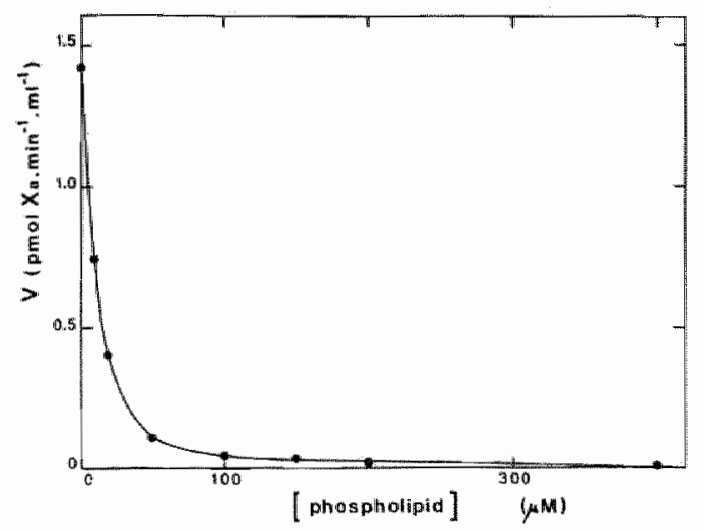

Fig. 4. Efect or phosphollpid on the rate of f $x_{a}$ formation by $R V Q-X$

$F$ X activation by RVv-X was measured at $37^{\circ} \mathrm{C}$ in 0.5 in 1 of a reaction mixture containing $50 \mathrm{mM}$ Tris-FCl, $175 \mathrm{mM} \mathrm{NaCl}, 0.5 \mathrm{mg} / \mathrm{ml}$ ovalbumin, $10 \mathrm{~mm} \mathrm{CaCl}, 0.1$ HM $f x, 1.45 \mathrm{ng} R V V-x$ and amounts w of phospholipid as indicated in the figure. Reaction was started with the acition of RVV-X. Phospholipid vesicles were preincubated for $10 \mathrm{~min}$ at $37^{\circ} \mathrm{C}$ in $50 \mathrm{mM}$ Tris-HCl, $175 \mathrm{mM} \mathrm{NaCl}$ and 50 m $\mathrm{CaCl}_{2}$ at pel 7.9. The rate of $x_{a}$ formation was calculated from the amounts of $f x_{a}$ present in the reaction mixture after 2.5 ant 5 min.

Fig. 4. shows the dependence of the steady state velocity on the phospholipid concentration. At 400 wM phospholipid the remaining rate of factor $x_{a}$ formation 1 is less then 18 of the rate measured in the absence of phospholipid. This inhibition by phospholipld can be explained assuming that either RVV- $X$ binds to the phosphoipld vesicles and becomes inactive or that RVV-X is not able to actlvate factor $x$ molecules bound to the phosphollpld bilayer. Factor $x_{a}$ bound to phospholipid has the same activity towards S 2222. Therefore, this explanation can be ruled out.

To distinguish between these two possibilities the following experiment was carried out. Four centrifugation tubes were filled with mixtures of varying composition of RVV-X, factor $X$ and liposomes of a mixture of dioleoylphosphatidylserine and dioleoylphosphatidylcholine (50/50; mole/mole) in a buffer containing $50 \mathrm{mM}$ Tris-HCl, $175 \mathrm{mM} \mathrm{CaCl}, 0.5 \mathrm{mg} / \mathrm{ml}$ ovalbumin and 
Iable $i$. Effect of f $x$ binding to 1 iposomes on the rate of factor $x$ formation by $\mathrm{R} W \mathrm{x}-\mathrm{x}$

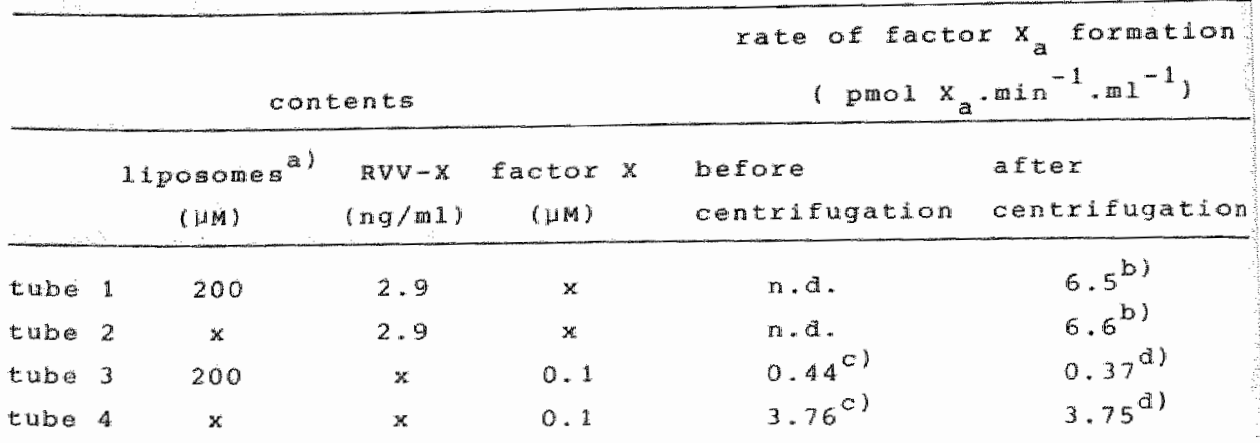

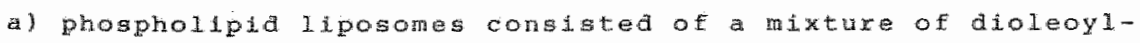

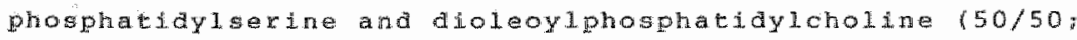
moledmole)

b) rate of $x_{a}$ sormation was measured after addition of f $x$ to the supernatant to result in a conocntration of 4.2 lim

c) rate of $x_{\text {a }}$ foxmation was reasured after adition of RVV-X ( $2.9 \mathrm{ng} / \mathrm{min})$

a) rate of $x$ a formetion was measured after addition of rvv (2.9 ng/mi) to the supernatint.

$10 \mathrm{~m}^{\mathrm{CaCl}} 2$. The composition of the mixtures $1 \mathrm{~s}$ indicated in Table I. After centrifugation at $50,000 \times g$ for 45 min of tube I and tube 2 , tube 1 contained a pellet of the phospholipid 1 iposomes. Factor $X$ was added to both supernatants to a final concentration of $4.2 \mathrm{MM}$ and the rate of factor $x$ formation was measured. Since the rates of factor $x_{a}$ formation are the same in both supernatants. We conclude that equal amounts of $R V V-X$ are present and that RVV-X does not bind to the liposomes. Before centrifugation samples $(0.6 \mathrm{ml})$ were taken from tube 3 and tube 4 , RVV-X was added and the rate of factor $x_{\text {a }}$ formation was measured. Due to the presence of the liposomes the rate of factor $x_{a}$ formation was markedly decteased for the sample taken from tube 3. After centrifugation RVV-X was added to $0.6 \mathrm{ml}$ of the supernatant of tube 3 and to $0.6 \mathrm{mi}$ of tube 4 and the rate of factor $x_{a}$ formation was measured. 
Since the rates of factor $x_{a}$ romation before and after centrifugation are the same it is concluded that it is indeed the amount of free factor $x$ which determines the rate of factor $x_{a}$ formation by RVV-X. Thus RVV-X can be used to measure the amount of free factor $X$ in reaction mixtures with phospholipid present and this can be used to determine the bunding parameters af factor $x$ binding to phospholipid vesicles.

Determination of the paraneters of factor $x$ binding to phosphoLipid vestetes

Since RVV-X is only able to activate factor $X$ molecules not bound to the phospholipid bilayer the observed rates of factor $\mathrm{x}_{\mathrm{a}}$ formation in the presence of phospholipid can be used to calculate the concentration of free factor $X$ using equatiom $I$. From the calculated amount of factor $x_{\text {free }}$ and the known amount of factor $x$ added the amount of factor $x_{\text {bound }}$ can be calculated. When the binding of factor $X$ is measured in this way, care has to be taken that the amount of factor $X$ converted does not influence the binding equilibrium. Therefore, the reaction with RVV-X was allowed to proceed for only 1 minute before a sample was witharawn from the reaction mixture and was assayed for factor $x_{a}$. From the amounts of factor $x_{a}$ found the rate of factor $x_{a}$ formation was calculated. The amounts of factor $x$ converted were never more than $2 \%$ of the amount of free factor $x$ measured. This can be calculated from the amount of factor $x_{a}$ found in the sample and the amount of free factor $x$ calculated.

It has been shown that factor $x_{a}$ can autocatalytically convert factor $x$ to factor $x_{a}$ in the presence of Cacl ${ }_{2}$ and phospholipid (13, 14). However, the smali amounts of factor $x_{\text {a }}$ formed duxing the activation by RVV-X were such that no autocatalytical factor $x_{a}$ formation could be measured. Moreover, gelelectrophoretic analysis of a sample in which these small amounts of factor $x_{\text {a }}$ were formed also showed that no $B$ factor $X$ was formed (data not shown).

The binding of factor $x$ to phospholipid vesicles composed of a $1 / 1$ (mole/mole) mixture of dioleoylphosphatidylserine and dioleoylphosphatidylcholine at three different phospholipid concentrations was determined. 

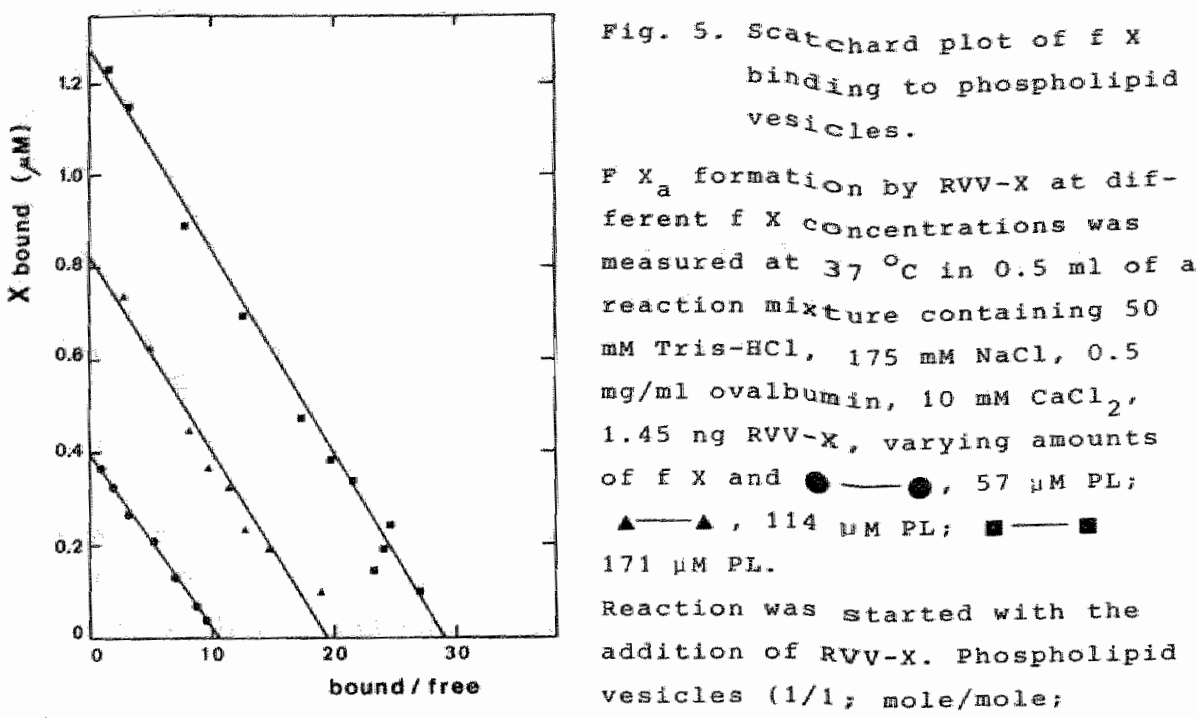

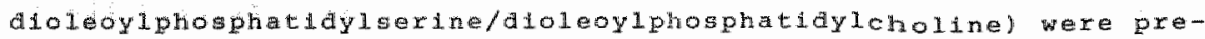

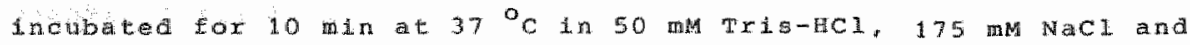
$50 \mathrm{mac} \mathrm{Cl}_{2}$

The rate of $f$ x formation was calculated from tha amount of $f x_{a}$ presert in the reaction 1 xture aftex 1 min. From the observed $x a t e$ of $x_{a}$ formation the amount of f $x_{\text {fre }}$ was calculated (sectegutes sotion).

Fig. S shows the Scatchard plots obtained. The binding constants determined are sumarised in Table II.

As can be seen the $\mathrm{K}_{\mathrm{d}}$ is constant $(0.04 \mathrm{MM})$ and the amount of binding sites found lis proportional to the amount of phospholipia present $(0.73$ um binding sites per $100 \mu \mathrm{M}$ phospholipid).

The bindung parametes of factor $x$ binding prere strongly dependent on the anount of phosphatidylserine present in the vesicles. ag. 6 show the dependence of $\mathrm{K}_{\mathrm{d}}$ and sites tper $100 \mathrm{H}$ phospholipla) on the molle fraction of phosphatidylserine present. The binding constants are also summarised in rable II. The $\mathrm{K}_{\mathrm{d}}$ and the number of sites depend almost linear on the fraction of phosphatidylserine in the range of $0-30$ moles phosphatidylserine. The $K_{\mathrm{d}}$ decreases from 0.18 uM for vesicles containing 6 moles phosphatidylserine to $0.03 \mathrm{HM}$ for vesicles containing 37 moles phosphatidylserine whereas the amount of sites increases from 
TABLE II Binding constants fox phospholipid vesicles composed of a miture of doleoyphosphatidylserine and dioleoylphosphatidylcholine

\begin{tabular}{|c|c|c|c|}
\hline $\begin{array}{l}\text { Total phospholipid } \\
\text { concentration }\end{array}$ & $\begin{array}{l}\text { wole fraction } \\
\text { phosphatidylsexine }\end{array}$ & $\mathrm{k}_{\mathrm{a}}$ & sites \\
\hline$\left(\begin{array}{ll}n \\
n\end{array}\right)$ & (x) & $(\mu \mathrm{N})$ & $(\mu \mathrm{M})$ \\
\hline 57 & 50 & 0.038 & 0.40 \\
\hline 114 & 50 & 0.043 & 0.83 \\
\hline 171 & 50 & 0.04 .4 & 1.29 \\
\hline 100 & 6 & 0.176 & 0.21 \\
\hline 100 & 12.7 & 0.152 & 0.42 \\
\hline 100 & 17.3 & 0.084 & 0.67 \\
\hline 100 & 23 & 0.065 & 0.78 \\
\hline 100 & 37.3 & 0.032 & 0.85 \\
\hline 100 & 44 & 0.030 & 0.83 \\
\hline 100 & 50 & 0.017 & 0.80 \\
\hline 100 & 54 & 0.019 & 0.63 \\
\hline 100 & 70 & 0.048 & 0.54 \\
\hline 100 & 85 & 0.046 & 0.43 \\
\hline 100 & 100 & 0.07 & 0.22 \\
\hline 100 & $70^{a)}$ & 0.035 & 0.58 \\
\hline 100 & $85^{a !}$ & 0.046 & 0.43 \\
\hline 100 & $100^{a)}$ & 0.0 .5 & 0.27 \\
\hline 100 & $25^{b)}$ & 0.049 & 0.65 \\
\hline 100 & $100^{b)}$ & 0.202 & 0.29 \\
\hline
\end{tabular}

a) the vesicles used were treated with $10 \mathrm{~mm} \mathrm{Cacl} 2$ and subsequenty 15 ram EDira was adad. After this treatment Cacl 2 was added to result in a final concentration of $10 \mathrm{mu}$;

b) the vesicles used were prepared accoraing to Gerrltsen et al (15). For Eurthex experimental details see legends to figures 5 and 6.

0.2 to 0.85 iM respectively.

When the mole fraction of phosphatidylserine is raised the amount of sites is not further increased, in aggreement with the findings of Nelsestuen and Broderius (3). However, the amount of sttes present 

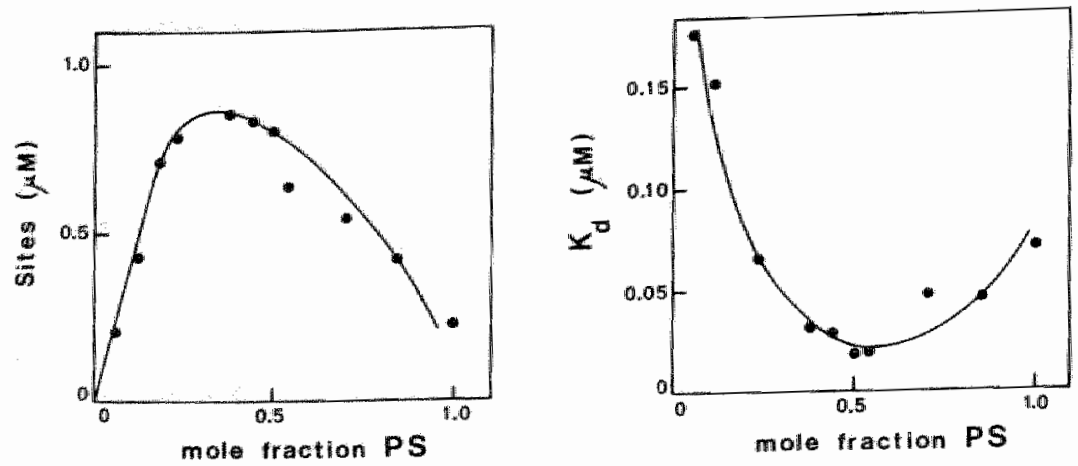

Fil. 6. Efect of the mole fraction of phosphatidylserine present 1.n the wesicles on the parameters of $x$ binding.

scatchard plats of $x$ binding to phospolipla vesicles contalning a warying mole fraction phosphatiaylsexine were obtainea by measuring the rate of $f x_{a}$ formation by $R V V-X$ at varying $f$ concentrations Ln the presence of 100 HM pu. For further experimental details see lagend to fig. 5. The binding constants determined are sumarised in Table I.

arastically decreases for vestcles contalning more than 60 phosphatidylserine. For vesicles of pure phosphatidylserine only 0.22 uM sites remain and the $\mathrm{K}_{\mathrm{d}}$ has increased to $0.07 \mu \mathrm{M}$.

From literature it is known that vesicles composed of brain phosphatidylserine aggregate in the presence of CaCl 2 and form structures known as scrolls (5). This can explain the observed decrease in stees since much less surface is then avaliable for the binding of factor $x$. Adaltion of EDTA to these scrolls results in the formation of laxge single bllayer vesides (5). Therefore, the vesicles we used were first treated with $10 \mu \mathrm{M} \mathrm{CaCl} 2$ and were then treated with 10 mW EDTA. The opague white suspension becomes clear apor the addition of EDTA. When this process is monitored by measuring the optical density of the phospholipid vesicle solutions at $400 \mathrm{~nm}$ it is seen that the large increase in optical density caused by $\mathrm{CaCl}_{2}$ is counteracted by subsequent addition of EDTA. Since the vesicles are now larger the optlcal density resulting is still higher than that of the sonicated vesicle solution. Subsequent addition of $\mathrm{CaCl}_{2}$, 
however, again increases the optical density to the same lewel as before the addition of EDTA. It was therefore not surprising that treatment of the vesicles in this way did not result in a signilicant change in the amount of sites present on the phospholipid surface (see table II).

Vesicle solutions of large single bilayer vesicles prepared according to Gerritsen et al. (15) also gave a high increase in optical. density upon addition of $10 \mathrm{mM} \mathrm{CaCl}_{2}$ and in this case also the amount of sites found did not significantly change (see table II).

\section{DTSCUSSTON}

To determine binding parameters for factor $x$ binding to phospohlipid vesicles it is necessary to measure either the concentration of free factor $x$ or bound factor $x$ or both. When both the amount of free and bound ligand can be measured accurately over a wide range of concentrations there is almost no limitation as to which $\mathbb{K}_{\mathrm{d}}$ can be measured. When only one component $\mathbb{1}$ s measured there may be limitations as to which $\mathrm{K}_{\mathrm{d}}$ 's can be measured.

When the concentration of bound ligand is monitored it is in general. difficult to determine low $K_{d}$ 's. When $\mathrm{k}_{\mathrm{d}}$ is too low the amount of bound ligand is much greater than the amount of free ligand. ThereFore, small errors in the measured concentration of bound ligand will produce large errors in the calculated concentration of free $\mathbb{1 i g a n d}$.

When the concentration of free ligand is monitored it is difflcult to measure high $\mathrm{K}_{\mathrm{d}}$ 's. In this case almost all of the litgand will be free and small errors in the determined concentration of free Ilgand will cause large exrors in the calculated concentration of bound ligand.

Unfortunately, the kinetics of factor $X$ activation by RVV-X set a strict limit to the highest $K_{d}$ which can be measured. To allow accurate measurement of $\mathrm{x}_{\text {free }}$ the highest concentration of $\mathrm{x}_{\text {free }}$ used (about 4 orders of magnitude above the $\mathrm{K}_{\mathrm{d}}$ which has to be aetermined) must not exceed the $\mathrm{k}_{\mathrm{m}}$ for factor $\mathrm{X}$ too much. ThereFore, since the $K_{m}$ is $0.71 \mu M$ the $h i g h e s t K_{a}$ which can be measured $1 \mathrm{is}$ at most 1 HM. The lower limit for the $k_{\text {a }}$ we can determine 1 experimentally determined by the lowest concentration of factor $x_{a}$ we can still accurately measure. On the Andnco DW-2 spectrophotometer this is $0.005 \mathrm{nM}$ Factor $\mathrm{x}_{a}$. This concentration should 
represent about 18 of the amount of the lowest $x_{\text {free }}$ concentration measured. Since this $x_{\text {free }}$ concentration will be about $\frac{3}{4} . K_{a}$ the lowest $\mathbb{K}_{a}$ which can be measured is about $\mathbb{l}-2 \mathrm{nM}$.

The binding parameters obtained for vesicles composed of a mixture of dioleoylphosphatidylserine and doleoylphosphatidylcholine at varying ratios are sumarlsed in Table II. The $\mathrm{K}_{\mathrm{d}}$ ana sites we determined at 25 moles phosphatidylserine are lower than the values reported by Nelsestuen and Broderius (3) and by Bloom et al. (4). These values are sumarised in Table III. The experimental condithons we used are, however, significantly different. The lower value of $K_{a}$ is probably due to the higher $\mathrm{CaCl}_{2}$ concentration since it was reported that $K_{d}$ is dependent on the amount of $\mathrm{CaCl}_{2}$ present (3). For the alfference in sites we have no explanation.

Table Ir einding constant for phospholipid vesioleg containing 25 mole phosphatidy sertat

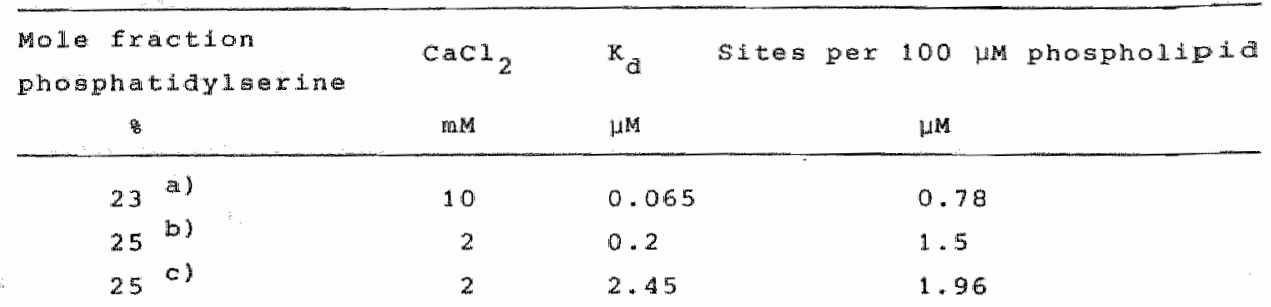
a) this work
b) calculated from Nelsestuen and Broderlus (3)

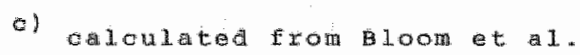

It was observed that the amount of sites present was arastically decreased for vesicles with a high mole fraction of phosphatidylserine. This is probably due to the aggregation of the vesieles at $10 \mathrm{mM} \mathrm{CaCl}_{2}$. The use of larger vesicles did not result in a significant increase of the sites present.

It has been reported that the addition of $\mathrm{CaCl}_{2}$ to small vesicles composed of pure phosphatidylserine results in the formation of structures known as scrolls (5). These have an apparent diameter of $2300 \AA$ as determined by $90^{\circ}$ light scattering (6). When EDTA is added large vesicles remain with a diameter of $2400 \&(6)$. Measurement of the changes in optical density in the presence of 
$\mathrm{CaCl}_{2}$ showed that the optical density for these large vesicles increased to the same level than the optical density for solutions of small vesicles. Therefore, it appears that these large vesicles again form scrolls.

The use of RVW-X for the measurement of binding parameters of factor $x$ binding offers an advantage over other methods published thus far. It is easier than the method of Humnel Dryer (8) and requires much less protein. The light scattering technique cannot be used at high $\mathrm{CaCl}_{2}$ concentrations when vesicles with a high phosphatidylserine content are present. When RVW-X is used this offers no problem. It is then possible to determine the binding parameters of factor $x$ at exactly the same conditions as are used in the kinetic experiments of factor $X$ activation by factor $I X a$ in the presence of CaCl${ }_{2}$ and phospholipid (cf. chapter 5 ). In that case it is no longer of any significance whether the vesicles are single bilayer or not since $\mathrm{k}_{\mathrm{d}}$ and the amount of sites can be determined using the same conditions.

For the inference of the binding parameters for factor $x$ binding From the observed kinetics of factor $x$ activation by factor $I x_{a}$ in the presence of phospholipid and $\mathrm{CaCl}_{2}$ (analous to ref.9) one needs the assumption that rates of factor $x_{a}$ formation observed are a reflection of binding of the proteins to the phospholipid vesicles. However, it is of great advantage that an independent technique for the measurement of binding parameters can now be used to test this assumption.

\section{ACRNOWLEDGEMENIS}

Part of the chromogenic substrate 52222 was kindly donated by AB Rabil. We thank Dr. E.M. Bevers, Mr. P. Confurtus and prof.Dr. R.F.A. Zwal for stimulating aiscussions.

\section{FOOTMOTES}

*) Abbreviations used are: RVV-X, purified factor $x$ activator from Russel"s wiper venom; $S 2222$, N-benzoyl-I-isoleucyl-L-gllutamyl-

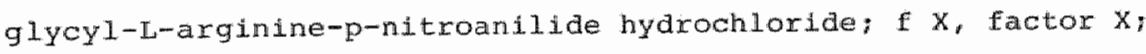
I $x_{a}$, factor $x_{a}$ * 


\section{RETERENCES}

1. Zwaal, R.F.A. (1978) Biochim.Biophy.Aota 515, 163-205

2. Nelsestuen, G.K. and Lim, T. K. (1977) Biochemitry 16, 4164-4171

3. Melsestuen, G.K. and Broderius, $M$ (1977) Biochemistry 16 , $4172-4181$

4. Bloom, J.W., Nesheim, M.E. and Mann, K.G. (1979) Bioonemistry 18, $4419-4425$

5. Rapahadjopoulos, D., Vail, W.J., Jacobson, K. and Poste, G. (1975) Broonim. Btophya. Acta 394, 483-491

6. Day, E.P., Ho, J.T., Kunze Jr, R.R. and Sun, S.T. (1977) Broohtm. Biophys. Acta 470, 503-508

7. Dombrose, F.A., Gitel, S.M., Zawalich, K. and Jackson, C.M. (1979) J.BLOZ.Chem. 254,5027-5040

8. Humiel, J.P. and Dreyer, W.J. (1962) Eiochim.Biophys.Acta 63, $530-532$

9. Nestre1m, M.E., Taswe11, J.B. and Mann, K.G. (1979) J.BqoZ.Chem. $254,10952-10962$

10. Elsenthal, R. and Cornish-Bowden, A. (1974) Biochem. o. 139, $715-720$

11. Kosow, D.P., Furle, B. and Forastieri, H. (1974) Thromb.Rea. 4, 219-227

12. Lindhout, M.J., Kop-KIaassen, B.H.M. and Hemker H.C. (1978) Biochim. Biophye.Acta 533, 327-341

13. Jesty, J., Spencer, H.K. and Nemerson, Y (1974) J.Bioz.Chem. $249,561,4-5622$

14. Fujtkawa, K., Tttant, K. and Davie, E.W. (1975) Proo.Natz. Aodd. Soz.USA $72,3359-3363$

15. Gerritsen, W.J., Verkley, A.J., Zwaal, R.F.A. and van Deenen, I.L.M. (1978) Eur.d.Btoonem. 85, 255-261 


\section{CHAPTER 8}

\section{GEMERAD DISCUSSION}

The activation of factor $x$, both via the extrusic and intrinstc pathway, and prothrombin are very similar.

The enzye responsible for prothrombin activation in wivo is the serine protease factor $x_{a}$. Serine proteases are in general powerful

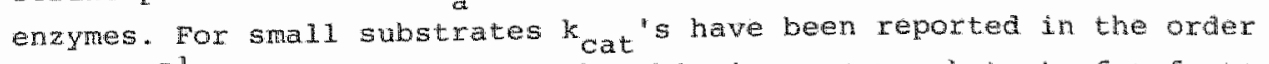
of $100 \mathrm{~s}^{-1}(1-3)$. However, prothrombin is a paor substrate for faotor $x_{a}$. The $\mathrm{K}_{\mathrm{m}}$ for prothrombin is well above the plasma concentration and the $k$ cat of the reaction is low (see rable I). Therefore, it is not surprising that under phystological conditions accessory components are required to increase the rates af prothrombin activation to a level sufficient to control hamostasis. Jobin and Esnouf (4) and Esmon et al. (5) showed that the relative rates of prothrombin activation are enormously enhanced by the presence of phospholipid, $\mathrm{Cacl}_{2}$ and a protein co-factor (factor $v_{a}$ ).

Factor $x$ activation via the intrinsic and extrinsic pathway is accomplished by respectively the serine proteases factor IX and factor VII " Factor $x$ activation by factor $\mathrm{IX}_{\mathrm{X}}$ is markedly enhanced by the presence of phospholipid, $\mathrm{CaCl}_{2}$ and factor VIII whereas the relative rate of factor $X$ activation by factor VII is stimulated by the presence of $\mathrm{CaCl}_{2}$ and tissue thromboplastin $(6,7)$. Tissue thromboplastin is a complex of phospholipid and one or more protein co-factors (7).

The enhancement of the relative rates of activation of prothrombin and factor $X$ in the presence of accessory components will be caused by a change of the kinetic parameters of these reactions. In wable I the kiretic data presented in this thesis on prothrombin and factor $x$ activation are summarized together with recent data from literature. The changes of the kinetic parameters of prothrombin and factor $x$ activation measured in the presence of accessory components explain the alsove mentioned rate enhancements. The protein co-factors factor Va, factor VIII and the protein component of thromboplastin have similar effects on the kinetio paxameters. They cause a aramatic increase of the $k_{c a t}$ of theix respective reactions. The effect of phospholipid in the three complexes is also similar. The presence of phospholipid causes a marked decrease of the $\mathrm{k}_{\mathrm{m}}$ for prothrombin $1 \mathrm{n}$ the prothrombinase complex and of the $K_{m}$ for factor $x$ in both the intrinsic and extrinstc factor $x$ activating complex. 
Table I winetic constantio orothrombin and factor $x$ activation

\begin{tabular}{|c|c|c|c|c|c|}
\hline Enzyme & substrate & Accescory components & $\begin{array}{r}\mathrm{K}_{\mathrm{m}} \\
(\mu \mathbb{N}) \\
\end{array}$ & $\begin{array}{l}\left.{ }^{k} \operatorname{cat}^{t}\right) \\
\left(s^{-1}\right)\end{array}$ & Source \\
\hline$x_{a t}$ & prothrombin & $\mathrm{ca}^{2+}$ & 84 & 0.011 & 1 \\
\hline$x_{a}$ & 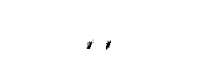 & $\mathrm{Ce}^{2+}, \mathrm{PL}(7.5 \mu \mathrm{M})$ & 0.05 & 0.038 & 1 \\
\hline$x$ & 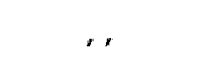 & $\mathrm{Ca}^{2+}, \mathrm{PL}(7.5 \mathrm{MM}), \mathrm{v}_{\mathrm{a}}$ & 0.2 & 32.0 & 1 \\
\hline $\mathrm{x}_{\text {俩 }}$ & +1 & $\mathrm{C}^{2+}, \mathrm{PL}(63 \mu \mathrm{M})$ & 0.63 & & 2 \\
\hline$x_{\text {a }}$ & $m$ & $\mathrm{Ca}^{2+}, \mathrm{PL}(11.5 \mu \mathrm{M}), \mathrm{V}_{\mathrm{a}}$ & 1.03 & 35.0 & 3 \\
\hline $\mathbb{I X}_{a}$ & factox $x$ & & 181 & $1.75 \times 10^{-4}$ & A \\
\hline $\mathbb{1} x_{a}$ & .' & $\mathrm{Ca}^{2+} \cdot \mathrm{PL}(10 \mathrm{MM})$ & 0.058 & $4.11 \times 10^{-3}$ & 5 \\
\hline$I x_{a}$ & 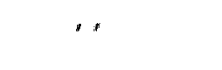 & $\mathrm{Ca}^{2+}, \mathrm{PL}(10 \mu \mathrm{M}), \mathrm{VIII}$ & 0.063 & 8.33 & 4 \\
\hline $\operatorname{vII}{ }_{a}$ & 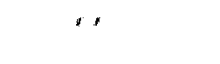 & $\mathrm{Ca}^{2+}, \mathrm{PL}$ & 4.87 & $3.95 \times 10^{-4}$ & 5 \\
\hline VII & $"$, & $\mathrm{Ca}^{24}, \mathrm{PL}$, tissue factor & 0.45 & 1.15 & 5 \\
\hline
\end{tabular}

1. Chapter of this thesis.

2. pL vesicles were composed af a mixture of egg phosphatiayethanolamine and posphatidylserine (Folch fraction III) in a ratio of $2 / 1$; molermale. Taken rom ref. 22 .

3. PL vesicles were composed of a mixture of phosphatidylgerine (Folah Exaction III) and soybean phosphatidylcholime $125 / 75$; mole/mole). Taken from ret. 19 .

4. Chapter 5 of this thesis.

5. PIj concentration was $0.75 \mathrm{mg} / \mathrm{ml}$ of a suspension of rabbit brain

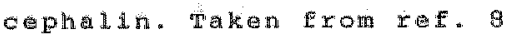

The physiologteal signiflcance of the changes of the kinetic parameters observed in the presence of accessory components is clear. Phospholipld is required to bring the $\mathbb{K}_{\mathrm{m}}$ for prothrombin and factor $X$ in the range of their respective plasma concentrations while the accessory protein components are required to increase the $k$ cat of the reactions to a level where suffloient activated clotting factors are formed to control hamosiasis.

Whe mole of fators $V_{a}$ and VIII in respootively prothrombin and factor $x$ activation

In chapter it was shown that factor $v$ a has little influence on the $\mathbb{K}_{m}$ for prothrombin but increases the $k_{\text {cat }}$ of thrombin formation 
SER
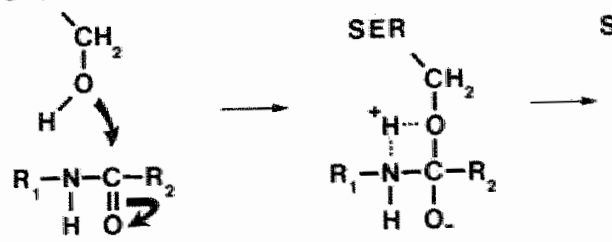

SER<smiles>[R]C(=O)OCC</smiles>

SER

* R, $\mathrm{NH}_{2}$<smiles>CCO</smiles>

Michaelis

complex

\section{Tetrahedral}

complex

\section{Acylenzyme}

$+P_{1}$<smiles>C[Pb](=O)O</smiles>

Enzyme

$+P_{2}$

Eig. 1. Molecular mechanism of peptide bond splitting by setine proteases

In the first step the Michaelis complex is formed between the enzye and the substrate through non-covalent interactions. In this conplex the substrate is located fin the actue site pocket in such a way that the nucleophyjic attack of the active site serine of the enzye on the carbonyl group of the peptide bond to be spit in the substrate 15 facilitated. Atter going through the tetrahedral intexmedate the first product (P1) and the acylenyme result. Upon hydrolisation of the acyleryye the second product (P2) is liberated and the active site comes iree again.

dramatically. In chapter $5 \mathrm{it}$ was shown that factor VIIT has the same effect in factor $x$ activation by factor $I x$. Howevex, from this change in $k_{c a t}$ no conclusions can be aram about the mode of aotion of these proteins in the mechanism of prothrombin and factor $\%$ activation. In order to be able to draw such conclusions more information about the molecular mechanism of the respective reactions $1 \mathrm{~s}$ required.

Factor $x_{a}$ and factor $I_{\mathrm{A}}$ are highly homologous to the sertne proteases trypsin and chymotrypsin. Therefore, it is likely that the mechanism of peptide bond cleavage in prothrombin and factor $x$ wil be similar to the general mechanism of peptide bond cleavage by sarine proteases. The mechanism wia which trypsin and chymotrypsin act upon their substrates is quite weil understood (see ref. 9).

Fig. I shows the molecular changes occuring upon interaction of a serine protease with its substrate. The first step is the formation of a complex between the enzyme and the substrate via non-covalent 
Interactions (the so-called Michaelis complex). In all serine proteases of which the three-dimensional structure is known it has been found that the active site sexine residue is hydrogen bonded to a histidine residue which in turn is hydrogen bonded to an aspartic acid residue. Thig line-up of SER-FIS-ASP, called the charge-relay system, is thought to greatly facliltate the next step occuring in the mechanism, 1.e. the formation of a covalent intermediate (tetrahedral intermediate) through nucleophylic attack of the active site serine on the carbonyl group of the peptide bond to be split. The tetrahedral intermediate rapidy dissociates into the acyl-enzyme and the first product (PI) is liberated. The final step is the hydrolysis of the acyl-enzyme intermediate in which the second product (P2) is 1 iberated and the active site comes Eree again.

From the work of the groups of Davie (7) and Nemerson (10) it can be concluded that the acyl-enzyme in factor $x$ activation by factor $I x a$ is a covalent complex of factor $I X_{a}$ and the activation peptide of factor $X$, 1.e. the N-terminal part of the heavy chain up to and including the ARG 51 residue. Thus a reaction scheme for factor $\mathrm{x}$ activation by factor $\mathrm{IX}_{\mathrm{a}}$ can be deplicted as follows:

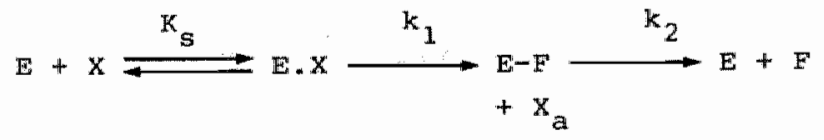

Here $\mathrm{E}$ is the enzyme factor $\mathrm{IX}_{\mathrm{a}}, \mathrm{F}$ is the activation peptide and $x_{a}$ is the product of the reaction.

The $k_{\text {cat }}$ of an enzymatic reaction cannot be greater than any first order rte constant in the forward reaction pathway. Therefore, an increase in $\mathrm{V}_{\max }$ can come about by inoreasing one or more of these forwaxd rate constants or by the removal of an inhibitory reaction product. Since factor $X$ activation in the absence of factor vIII is Ilnear in time and proportional to the amount of enzyme present, it Is unlikely that inhibition by reaction products occurs. We conclude that factor VIII a increases the $V_{\text {max }}$ of factor $x_{a}$ formation by increasing one or more of the forward rate constants in the reaction pathway.

In prothrombin activation two peptide bonds have to be split by the enzyme factor $x_{a}$ (ef. chapter 2). Although the order of peptide bond aplitting is not known it is generally assumed that first prethrombin 2 1. formed (11berating the activation peptide fragment 1.2 ) and that 
subsequently prethrombin 2 is cleaved to produce thrombin. the general reaction scheme can be depicted as follows:

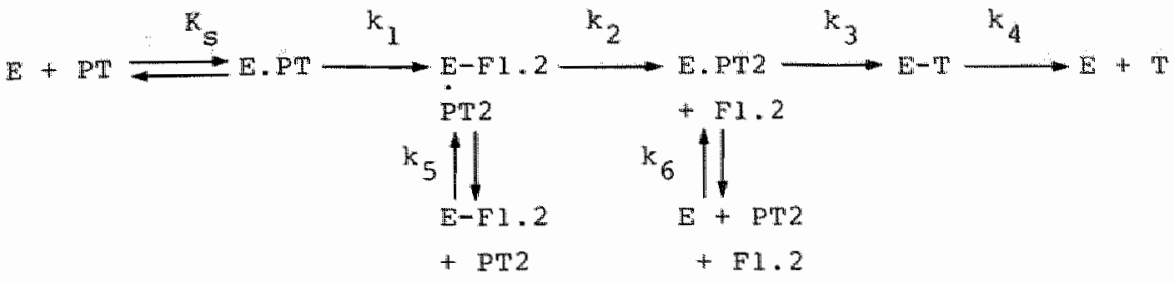

Prothrombin (PT) binds to factor $x_{a}$ (E) and after going through the Michaelis complex and tetrahedral intermediate, the acyl-enzyme consisting of the activation peptide fragment 1.2 (F1.2) and factor $x_{a}$ is formed. Before the next bond can be split the acylenzyme has to be hydrolised. The activation peptide dissociates from the enzyme and a new Michaelis complex between factor $x_{a}$ and prethrombin 2 (pT2) can be formed whereupon thrombin is formed. This mechanism leaves ample possibility for the prethrombin 2 molecule to dissociate from the enzyme. Reassociation, which would offer a second chance to be converted to thrombin, is prevented by the excess amount of prothrombin competing for the same enzyme. Therefore, in this mechanism thrombin formation can be very slow compared to prethrombin 2 formation. In chapter 4 it was shom that in the absence of factor $v_{a}$ the main end product of the reaction is not thrombin but prethrombin 2. Only smal amounts of prethrombin 2 siip through and are converted to thrombin which is measured in the kinetic experiments. When factor $V_{a} 1 \mathrm{~s}$ present the pathway of activation shyts from one resulting in prethrombin 2 into one resulting in thrombin. We conclude that the presence of factor $v_{a}$ prevents dissociation of prethrombin 2 from the enzyme. This can be achieved in two wass. Either the dissociation of prethrombin 2 is prevented directy by lowering the dissociation constant or indirecty by lowexing the steady state concentration of the enzym-prethrombin 2 complex, by increasing a limiting forward rate constant $\left(k_{2}{ }^{-k_{4}}\right.$ in the reaction scheme). Direct prevention of dissociation of prethrombin 2 by factor $v_{a}$ is not unlikely because it has beeri shown that factor $v_{a}$ binds to the fragment 2 region of the prothrombin molecule and tight non-covalent interaction between fragment 1.2 and prethrombin 2 has been reported $(\mathbb{1})$. We do no think that this can be the only mechanism involved. Since the kat in the presence of factor $v_{a}$ is about $50 \mathrm{~s}^{-1}$ each forward rate constant must be at least $50 \mathrm{~s}^{-1}$. 
Eble Ir Etimation of the rete of pethrombin 2 and thrombin forma tor by factor $x_{\text {a }}$ in the presence of Cacl 2 and phospholipid

\begin{tabular}{|c|c|c|c|}
\hline Incubation & Thxom & in Eormed & Prethrombin 2 \\
\hline mintes & 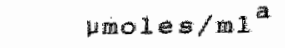 & $\mu_{0} 1 \mathrm{~s} / \mathrm{m} \mathrm{I}^{\mathrm{b}}$ & Hole \\
\hline 2 & $0.065 \times 10^{-4}$ & - & $0.7 \times 10^{-4}$ \\
\hline 5 & $0.16 \times 10^{-4}$ & $0.2 \times 10^{-4}$ & $1.9 \times 10^{-4}$ \\
\hline 10 & $0.34 \times 10^{-4}$ & $0.5 \times 10^{-4}$ & $3.1 \times 10^{-4}$ \\
\hline 20 & $0.66 \times 10^{-4}$ & $0.88 \times 10^{-4}$ & $5.3 \times 10^{-4}$ \\
\hline 30 & $0.78 \times 10^{-4}$ & $0.86 \times 10^{-4}$ & $6.2 \times 10^{-4}$ \\
\hline
\end{tabular}

25 stmated cat of thrombin formetion $0.05 \mathrm{~s}^{-1} \mathrm{a}^{-1} 0.075 \mathrm{~s}^{-1} \mathrm{~b}$

kat of prethrombin 2 formation $0.45 \mathrm{~s}^{-1} \mathrm{c}$

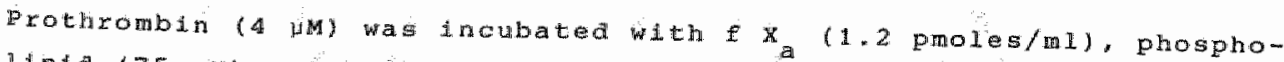

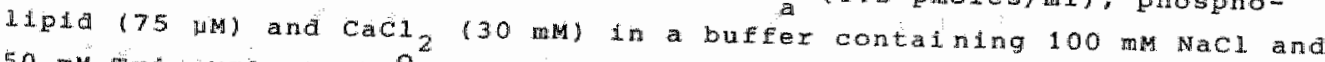
$50 \mathrm{mM}$ Tri-HCl at $37^{\circ} \mathrm{C}$ at pH 7.5 . AEter different time intervals amples wre taken ana asayed for thrombin ustrig $52238^{2}$. In arder to get an estimate of the rate of prethrombin 2 formation, samples were taken and run on sos-gels. Together with these gels, gels with known amouts of prethrombin 2 and active site titrated thrombin wexe peparea. After stalining and desteinimg of the gels, they were scannad on a ailford Model 250 spectrophotometer. The bands on the gels with known anounts of thrombin and prethrombin 2 were 1 itegratea and from caldbration curve the amounte of thromblnb and prethrombin 2 e present in the activaton muture could be calculated.

If factor $v_{\text {a }}$ ondy decheses the dssochation rate corstant of prothrombin 2 and woula not infuence a forwar rate constant these rate constants in the absence of factor $v$ a $1 \mathrm{so}$ have to be at least $50 \mathrm{~s}$. In

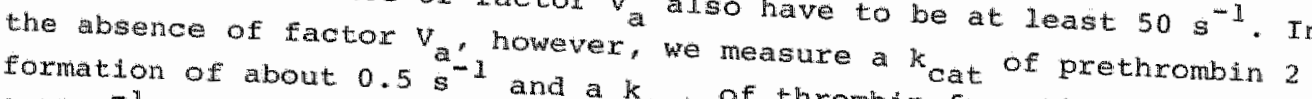

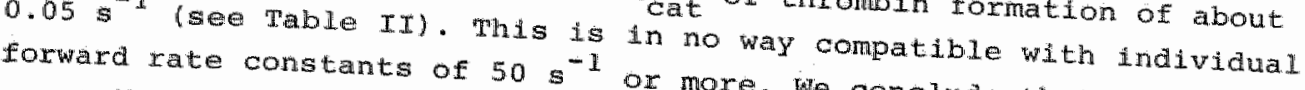
possible role lr lowering the prethromin or more. We conclude that apart from ther must be at least one rate prethrombin 2 association constant activation pathway that is ratsed limiting Eorwara rate constart in the agrement with the fact that factor vit is a

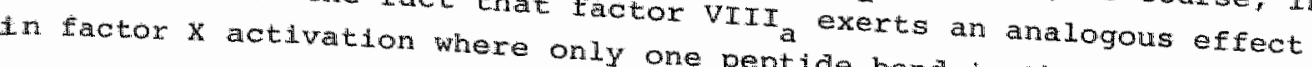


has to be cleaved. The experimental evidence obtained with both complexes thus far allows no speculations on the localisation of this rate Iimiting step. A thorough kinetic study of the appearance and aisappearance of intermediates and reaction products will be required to solve this question.

The role of phostholipid in prothrombin and factor $x$ activation It is gererally accepted that the phospholipid bilayer exerts its coagulant activity when it is able to bind the proteins irvolved. Phospholipid bilayers stimulate coagulation only when they possess a net negative charge. Factors $I X_{a}, X_{a}, x$ and prothrombin are thought to bind to the phospholipid bilayer via ca ${ }^{2+}$-briges between the $\gamma$-carboxyglutanic acid residues of these proteins and the negatively charged phospholipid head groups. The factors $v_{a}$ and VIIr presumably bind via more hydrophobic interaction (cf. chapter 2).

It is thought that under physiological conditions the blood platelet membrane providesthe phospholipid surface required for factor $x$ and prothrombin activation. This procoagulant activity of the platelet has been referred to as platelet factor $3(P F-3)$ activity. However, platelets have no significant amount of negatively charged phospholipids in the outer layer of the plasma membrane. To stimulate coagulation. the negatively charged phospholipids which are present inside the platelet must become exposed.

Until a few years ago the postulated appearance of negatively charged phospholipids has been assumed to be identical to $\mathbb{P F}-3$ activity. In recent years doubt has growm whether $P F-3$ is indeed identical to phospholipld. It has been reported that factor $x$ binds with a high affinity to a specific receptor present on the platelet surface. It was demonstrated that this receptor is factor $v_{a}$ bound to the outside of the platelet membrane $(12-16)$. The binding site for factor $v_{a}$ on the platelet is thought to be a specific receptor which, apart from possible role of phospholipid, probably requires a protelin component. Thus it is thought that the ariving force bringing factor $v_{a}$ and factor $x_{a}$ together on the platelet surface is the interaction of factor $\mathrm{V}_{\mathrm{a}}$ with a specific receptor (probably a protein) and of factor $x_{a}$ with bound factor $v_{a}$. The receptor theory 4 supported by the findings of the group of Mann. They found that factor $\mathrm{v}$ binds more tightiy to platelets than to vesicles composed of a mixture of phosphatidylserine (Folch fraction III) and soy-bean phosphatidyloholine $(25 / 75 ; w / w)(17,18)$ and that factor $x_{a}$ binas more tigktiy to phospho- 
1.jia vesicles when factor $v_{a}$ is present (19).

The factor $x_{a}$ thus bound to intact or released platelets via bound factor $v_{a}$ can convert prothrombin at the same rate as factor $x_{a}$ bound to a phospholipla surface of a miture of phosphatidylserine and phosphatidylcholine in the presence of sacurating amounts of factor $v_{a}$.

The question which rematns is: Where do phospholipids come into this plcture re in adition to the receptors for factor $\mathrm{V}$ and factor $X_{a}$ nesatuviy charged phosholipids required for prothrombin and factor $x$ activation under physological conditions? we think the answer to this guestion 1 y yes.

Fixst, the platelet surface should play a role in factor $X$ activation. However, it has not been reported that factor VII and factor IX bind to the platelet surface via spectic receptor. Second, it is not sufficient that factor $V_{a}$ and factor $x_{a}$ bind to the platelet surface. Interaction with prothrombin as well has to be taken into accoint. Thus far no evidence has been reported that prothrombin would bind better to platelets or phospholipid in the presence of factor $v_{a}$ and factor $x_{a}$. Third, in the papers in which prothrombin activation by factor $x_{a}$ bound to intact ox released platelets was reported no corrections were made for platelet $1 y s i s(12-16)$. Thus small anounts of platelets may have been disrupted and this may have resulted in small amounts of negatively charged phospholipids to become available for prothrombin activation. Moreover, to control haemostasis PE-3 activity showld become available. The total amount of thrombin produced with intact ox thrombin activated platelets is low. When 1008 PF-3 is avallable the rate of thrombin production is increased about a 100-fold. Therefore, lis lysis coula explain the reported prothiombin activation with intact or released platelets. Fourth, phosphtidylserine is demonstrable in the outer layer of the plasm membrane when platelets axe stimulated by the combined action of thrombin and collager $(20,21)$. Since this was demanstrated to occur without distuption of the platelets this is presumably caused by a translocation of phosphatidy lserine over the platelet membrane. Concomittant with the occurence of phosphatidylserime in the outer layer of the plasma membrane pr-3 activity appeared. It is unilkely that this occurs as a result of the platelet release reaction since it was shown that upon the separate action of collagen or thrombin, though stimlating the platelet release reaction, a small amount of $\mathrm{PF}-3$ activity appeared which could be attributed completely to a small amount 
of Iysed platelets. Thus, prothrombin activation occurs ondy when phosphatidylserine appears in the outer layer of the plasma membran. Therefore, although it is probable that platelets possess a specific receptor for factor $v_{a}$ and that this bound factor $v_{a}$ represents a specific receptor for factor $\mathrm{x}_{a}$, we still think that negatively charged phospholipids are required to promote factor $x$ and prothromin activation.

Investigation of the kinetics of prothrombin and factor $x$ activation in the absence and presence of phospholipld allows a first attempt to evaluate the role of phospholipid in these reactions.

kosow and orther (22) carried out a kinetic study of prothrombin activation by factor $x_{a}$ in the presence of $\mathrm{CaCl}_{2}$ and phospholipid vestcles composed of a mixture of egg-yolk phosphatidylethanolame and brain phosphatidylserine (2/1;mole/mole). They reported a $\mathrm{k}_{\mathrm{m}}$ for prom thrombin of $0.05 \mathrm{\mu M}$ at $63 \mathrm{HM}$ phospholipid and $10 \mathrm{mM} \mathrm{CaCl}$. This is $1 \mathrm{~m}$ reasonable aggreement with our results. The conclusions they arrived at fot the mode of action of phospholipid are, however, in confliet with oux results. They did not recognise that the $k_{\text {mi }}$ is dependent on the amount of phospholipid present and. from the small increase in max with increasing phospholipld concentrations, they conoluded that the effect of phospholipid in prothrombin activation is aue to an

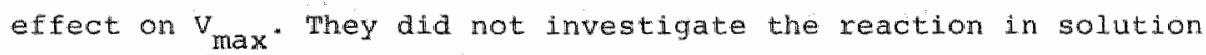
though. When the kinetics of thrombin and factor $x$ activation in the presence and absence of phospholipid are compared to the kinetics of the reaction in solution (see Table II) it is clear that the presence of phospholipid enhances the relative rates of thromin and factor $x_{\text {a }}$ formation by causing a aramatic decrease in the $K_{m}$ whereas the $V_{m a x}$ is only slightiy affected.

Two models car be put forward to qualitatively explain the eftect of phospholipid in prothrombin and Eactor $x$ activation. We will make a differentiation as strict as possible between these two in arder to avold unnecessary confusion.

The first model (model 1) is based on the assumption that it is the substrate bound to the phaspholipla bilayer that is converted by the bound enzyme and that the free substrate does not participate in the reaction. The driving force bringing the substrate and enzyme together is the binding of the proteins to the phospholipid bidayer. The second model (model 2) is a model in which the bound enzyme acts upon the substrate not bound to the phospholipid bilayer. 
Both modelig can qualitatively explain the observed effect of phospholipid on the kinetics of prothrombin and factor $x$ activation. In model 1 in which it is assumed that the substrate bound to the bilayer is converted by the bound enzyme it is not necessary to assume that the kinetic parameters of the reaction change upon binding of the proteins to the phospholipid bilayer "Even fif the kinetic parameters remain equal to those in solution a considerable decrease in $k_{m}$ will be measured since the local substrate concentration is much higher than the Bulk concentratton. When the concentration of phospholipid is increased the density of the bound substrate decreases and more substrate has to be added to reach the same density on the phospholipid surface. "Therefore, $K_{m}$ apparent increases. In model 2 (free substrate converted by bound enzyme) the large decrease in apparent $K_{m}$ can be explained when 1t is assumed that the binding affinity of the substrate for the catalytic site of the enzyme is changed as a result of the binding of the enzyme to the phospholipid bilayer. In that case the substrate binding sites of the phospholipid surface compete with the enzyme for the free substrate. When more phosphollpid is added more substrate will be bound and more substrate has to be added to obtain the same level of free substrate. Therefore, $\mathrm{K}_{\mathrm{m}}$ apparent increases.

The findings of the groups of Jackson and Majerus on factor $x_{a}$ binding to platelets discussed above led Nelsestuen to propose yet another model for the role of phospholipid in prothrombin activation (23). Nelsestuen postulates that both factor $x_{a}$ and prothrombin bind to an "active site" on the phospholipid surface, this active site being factor $V_{a}$ bound to the bllayer. He states that the affinity of this actlve site $\left(V_{1}-P L\right)$ for prothrombin "WAll be a composite of prothrombinphospholipid and prothrombln-factor $V_{\text {a }}$ interactions. This should represent a tlghter binding than the wimple prothrombin-membrane binding. ' In wew ok the work presented in this thesis it is clear that this model camnot hold. The $k_{\text {m }}$ for prothrombin in the presence of phospholipid either in the presence or in the absence of factor $v$ is about the same. Therefore, the decrease in $\mathrm{K}_{\mathrm{m}}$ by phospholipid cannot be caused by a specific phospholipid-factor $v_{a}$-prothrombin interaction. In order to be able to explain the effect of phospholipid in prothrombin and factor $x$ activation on a quantitative basis it is necessary to know the binding parameters of the substrate-phospholipld binding under the same conditions as are used in the kinetic experiments. It is then possible to convert the ineweaver-Burk plots in which $1 /$ ltotal substratel was plotted against $1 / v$ into Lineweaver-Burk plots of 


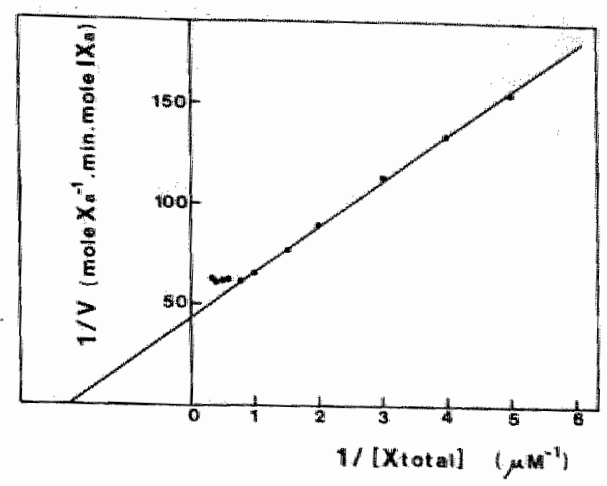

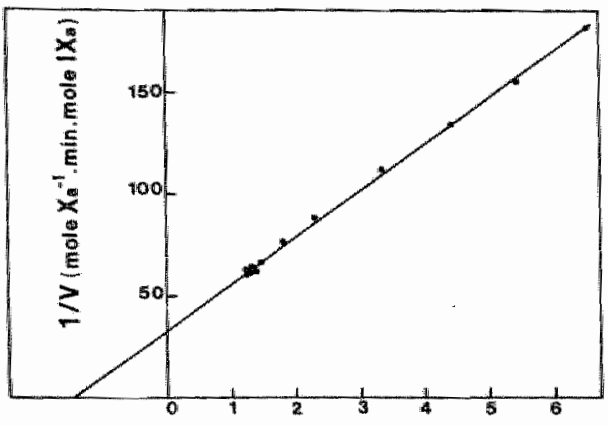

$1 /[$ Xtround $] \quad\left(\mu M^{-1}\right)$

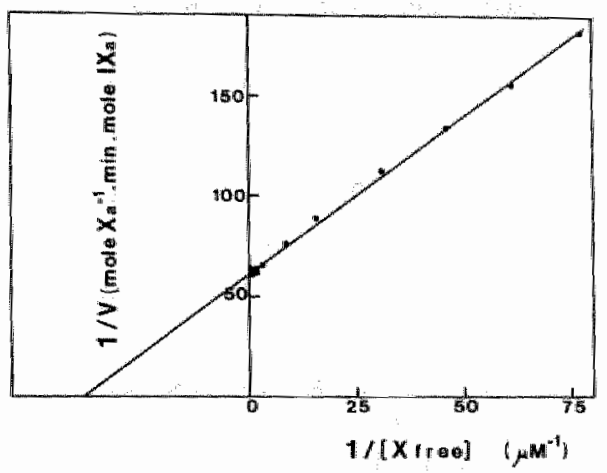

Fig. 2. Evaluation of the kinetics of factor $\mathrm{x}_{\mathrm{a}}$ formation by factor Ixa in the presence of $100 \mathrm{HM}$ phospholipid and $10 \mathrm{mM} C a \mathrm{~L}_{2}$ in the two proposed models

Fig. 2A shows the tineweaver-Burk plot in milon $1 /$ (total substrate) is

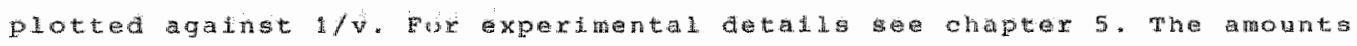
of bound and free factor for each potnt in the Linewerver-auk plot were calculated using the binding paxmeters rox factow obtanded in chapter 7. In neweaver-burk plots wer conteructed in which $1 /$ (bound substrate) (B) and 1/(free substrate) (C) were plotted agatnet 1/w. The

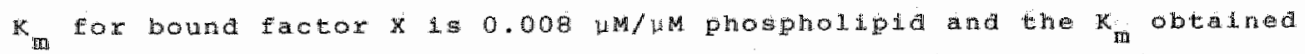
fox free factor $X$ as substrate 150.03 un lsee also table III.

$1 /$ (bound substrate) and $1 /$ (Eree substrate) vs $1 / v$ and to see whether the reaction obeys Michaelis-Menten kinetics with bound or with free substrate.

For factor $x$ the binding parameters axe known for the kind of vesieles usea in the kinetic experiments described in chapter 5 (cf. chapter 7 ). 


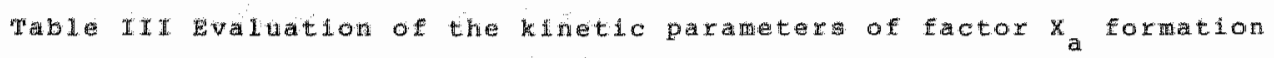

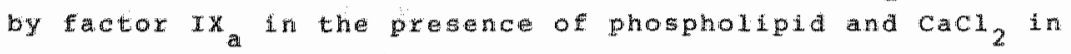
the tro proposed models

\begin{tabular}{|c|c|c|c|c|c|c|}
\hline \multirow{2}{*}{$\begin{array}{l}\text { Phospholipid } \\
\text { concerteration } \\
\text { (WM) }\end{array}$} & \multicolumn{2}{|c|}{ 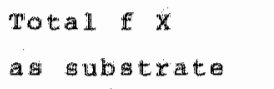 } & \multicolumn{2}{|c|}{$\begin{array}{l}\text { yeef } x \\
\text { as substrate }\end{array}$} & \multicolumn{2}{|c|}{$\begin{array}{l}\text { Bound } f x \\
\text { as substrate }\end{array}$} \\
\hline & $v_{\max }$ & $\mathbb{R}_{\mathrm{min}}$ & $v_{\text {ma } x}{ }^{a}$ & $\begin{array}{c}K_{m} \\
(w M)\end{array}$ & $v_{\text {max }}$ & $x_{\mathrm{min}}$ \\
\hline 10 & 0.0025 & 0.058 & 0.0021 & 0.021 & 0.0032 & 0.046 \\
\hline 20 & 0.0058 & 0.139 & 0.0042 & 0.027 & 0.0079 & 0.144 \\
\hline 50 & 0.0226 & 0.363 & 0.0161 & 0.035 & 0.0413 & 0.641 \\
\hline 75 & 0.0219 & 0.409 & 0.0160 & 0.027 & 0.0302 & 0.549 \\
\hline 100 & 0.0231 & 0.525 & 0.0164 & 0.026 & 0.0309 & 0.705 \\
\hline 150 & 0.0295 & 0.822 & 0.0206 & 0.027 & 0.0400 & 1.140 \\
\hline 200 & 0.474 & 1.830 & 0.0268 & 0.042 & 0.0631 & 2.485 \\
\hline 300 & 0.0437 & 1.760 & 0.0300 & 0.032 & 0.0558 & 2.252 \\
\hline
\end{tabular}

a. $v_{\text {max }} 1 s$ expresised as mole $x_{a} \cdot m^{-1}$. mole $\operatorname{Ix}_{a}^{-1}$

The $x_{\text {rn }}$ calculated for free factor $x$ as substrate is 0.03 phand the $x_{\text {m }}$ calculated for bound factor $x$ as susbtrate is 0.008 w/HM phospholipld.

Therefore, 1 to wossible to calculate the amount of bound and free factor $X$ for each point of the original Limeweaver-Burk plot (see chapter 5). In fig. 2 the different plots are shown. In both models the reaction appears to obey Michaelis-Menten kineticis. It will be clear that in both models the $\mathrm{k}_{\mathrm{m}}$ expressed in bound or free substrate has to be independent of the phospholipid concentration. That this is the case is shown in rable III were the results of the calculations fox the kinetic parameters at diferent phospholipid concentations in both models are given. In the nodel in which bound factor $X$ is the substrate a $\mathrm{K}_{\mathrm{m}}$ of $0.008 \mu \mathrm{M} / \mathrm{M}$ phospholipid present is measured. In the model in which free factor $X$ is the substrate the $\mathbb{K}_{\mathrm{m}}$ is very low 0.025 HM.

The kinetio data obtained thus far allow no conclusions as to which of the two models 1 s actually describing the real situation. However, 
from the analysis of the data obtained thus far, predictions can be made for what to expect when phosphollpid vesicles are used with a higher $\mathrm{K}_{\mathrm{d}}$ than the vesicles used thus far. It will be expected that less substrate is bound by the phospholipid surface and therefore the free factor $X$ concentrations will be higher. It will be easier to saturate the enzyme with substrate if free factor $x$ is the substrate. On the other hand if bound factor $x$ is the substrate $i t$ will require more factor $X$ to saturate the binding sites. Thus it is expected that $K_{\mathrm{m}}$ apparent will increase if bound factor $\mathrm{X}$ is the substrate and that $\mathrm{K}_{\mathrm{m}}$ apparent will decrease if free factor $\mathrm{x}$ is the substrate. Therefore, we are confident that in the near future it will be possible to determine which of the two models is valid.

REEERENCES

1. Zerner, B., Bond, R.P.M. and Bender, M.L. (1964) d. Am. Chem. Soe. $86,3674-3683$

2. Berezin, I.V., Kazanskaya, N.F, and Klyosov, A.A. (1971) kBBS Zetetexs $15,121-127$

3. Tans, G.. Rosing, J., v. Dleijen, G.V. and Hemker, H.C. (1980) In The Regulation of Coagulation (Mann, K.G. and Taylor, F".B. Eds.) Pp. $173-185$

4. Jobin, F. and Esnouf, M.P. (1967) Biochem. of, 102, 666-674

5. Esmon, C.T., Owen, W.G. and Jackson, C.M. (1974) d. Biot. Chem. 249, $8045-8047$

6. Hultin, M.B. and Nemerson, Y. (19.87) B200d 52, 928-940

7. Fujikawa, K., Coan, M.H., Legaz, M.E. and Davie, E.W. (1974) Btochemistry 13, 5290-5299

8. Silverberg, S.A., Nemerson, $X$. and zur, M. (1977) d. Bhol. Chem. $252,8481-8488$

9. Rersht, A.R. (1977) Enzyme structure and Mechanism, W.H. Freman and Company, Reading and San Fransisco

10.Jesty, J., Spencer, A.K. , Nakashima, Y."Nemerson, Y. and Koniggberg, W. (1975) I. Biol. Chem. 250, 4497-4504

11.Esmon, C.T. and Jackson, C.M. (1974) J. Biol. Chem. 249, 7791-7797

12. Miletich, J.P., Jackson, C.M. and Majerus, P.W. (1977) Proo. Mati. Acad. Sei. USA 74, 4033-4036

13.Milletich, J.P., Majerus, D.W. and Majerus, P.W. (1978) y. CLth. Inv. $62,824-831$

14.Miletich, J.P., Jackson, C.M. and Majerus, P.W. (1978) J. Büol. chem. $253,6908-6916$ 
15.Mileteh, J.P., Rane, W.H., Hofmann, S.L., Stanford, N. and Majexus, P.W. (1979) B20od 54, 1015-1022

16. Kane, W.H., Iindhout, M.J., Jackson, C.M. and Majerus, P.W. (1980) A. Btol. Chem. 255, $1170-1174$

17.B10om, J.W., Mesheim, M.E. and Mann, K.G. 1979y Eiochemistry 18, $4.19-4424$

18.Tracy, P.B., Peterson, J.M., Negheim, M.E., McDuffie, F.C. and Mann, K.G. (1979) J. Biol. Chem. 254,10354-10353

19. Neshedm, M. E. Taswe11, J.B. and Mann, K.G. (1979) f. Diot. Chem. $254,10952-10962$

20.zwaal, R.F.A., Rosing, J., Tans, G., Bevers, E.M. and Hemker, H.C. (1980) In The Regulation of Coagulation (Mannn, K.G. and Taylor, F".B. Eds.) pp. 95-112; Elsevier North Holland Inc, New York

21. Bevers, E.M., Comfurius, P., V. Rijn, J., Hemker, H.C. and zwaal, R.F.A. (1980) submitted for publication

22. Kosow, D.P. and Oxthner, C.L. (1979) J. Biol. Chem. 254, 9448-9452

23. Melsestuen, G.I. (1980) In The Regulation of Coagulation (Mann, K.G. and Taylor, F.B. Eds.) Elsevier North Holland Inc. New York. 


\section{SUMHARY}

In this thesis work is presented which concerns the role of proteinphospholipid interactions in coagulation. During coagulation a complicated chain of biochemical reactions occurs in which specific zymogens (clotting factors) are activated and which ultimately leads to the formation of thrombin. Thrombin converts fibrinogen into fibrin and the fibrin network, necessary for the arrest of bleeding from a wound, is formed.

In three reactions occuring in the so-called coagulation cascade phospholipid is thought to play a role. These reactioms are factor $x$ activation, both via the intrinsic and extrinsic pathway of coagulation, and prothrombin activation.

Phospholipld molecules spontaneously form lameliar structures when dispersed in an aqueous environment. These structures are known as bilayers. In these bilayers the phospholipid molecules are oriented with their chains towards each other and their head groups interact with the aqueous environment. Phospholipid bilayers show a peculiar feature. Above a certain temperature (transition temperature) the molecules in the bilayer can move freely in the plane of the bilayer. This is the so-called liquid crystaline state. Below the transition temperature diffusion of the molecules in the bllayer is hindered considerably. In chapter 3 it is shown that phospholipid bilayers in the liquid crystalline state promote coagulation much better than phospholipid bilayers in the solid gel state.

It was know already a long time that prothrombin activation by the enzyme factor $x_{a}$ was stimulated enormously by the presence of caci. phospholipid and a protein co-factor, factor $V_{a}$. In chapter 4 it is shown that this stimulation is caused by limpartant changes tri the kinetic parameters of prothrombin activation. Phospholdpids stimulate the reaction by bringing the $\mathbb{K}_{\mathrm{m}}$ for the substrate prothrombin to a level which is about equal to the plasma concentration of prothrombin whereas factor $v_{a}$ dramatically increases the $k_{c a t}$ of thrombin formation. Phospholipld and factor VIII exert the same effect in factor $x$ activation by factor $I_{a}$ as 1 s shown by phospholipid and factor $V_{a}$ in prothrombin activation (chapter 5).

In order to be able to express observed velocities in an enzynatic reaction in turnover rates of the enzyme it is necessary that the enzyme can be quantitated on a molecular basis. In chapter 6 it $1 \mathrm{~s}$ 
show that factor IX can be quantitated via active site titration of the enzyme with pinitrophenyl-p'-guanidinobenzoate.

The reactons Linvestigated in this thesis are thought to take place on the phospholipla surface. Therefore, to appreciate the process going on on this surface it is essential that the parameters for the binding of the different proteins to the phospholipid bilayer are known. Chapter 7 describes a new method for the determination of the binding constant of factor $x$ to phospholipid vesicles. The great advantage of this technique is that the binding parameters can be determined at exactly the same conditions as are used in the kinetic 3tudies on factor $X$ activation descxibed in chapter 5. An additional advantage $2 \mathrm{~s}$ that the method is relatively easy to perform. In chapter a the flndings presented $1 n$ this thesis are discussed. 


\section{SAMENWATTING}

In dit proefschrift worden de resultaten beschreven wan onderzoek aan eiwit-lipide interakties in de bloedstolling. Stolling is $0 . a$. het gevolg van een ingewikkelde reeks opeenwolgende biochemische reakties warin eiwitten (stolfaktoren) die vrij in het bloed circuleren geaktiveerd worden. Deze reeks reakties leidt uiteindelijk tot de vorming van thrombine. Thrombine zet fubrinogeen om in fibrine en het fibrine netwerk, noodzakelijk voor bloedstelping, wordt gevorma.

Deze reeks opeenvolgende reakties wordt de stolcascade genoend. In drie van deze reakties spelen fosfolipiden een rol. Dit $z i j n$ faktor $x$ aktivering, langs de intrinsieke en extrinsieke weg, en prothrombine aktivering.

Wanneer fosfolipide molekulen in water opgenomen worden vormen ze spontaan lamellaire strukturen. Deze strukturen worden bilagen genoemd. De fosfolipide molekulen zijn in de bilaag met hun vetzuur staarten naar elkar toe georienteerd. De kopgroepen vertonen interaktie met het water. Fosfolipide bilagen vertonen een speciale eigenschap. Boven een bepaalde temperatuur (overgangstemperatuur) kummen de molekulen vrij bewegen in het vlak van de bilaag. De bilaag bevindt zich dan in de zgn. Vloeibaar kristallijne fase. Beneden de overgangstemperatuur is de diffusie van fosfolipide molekulen in het vlak van de bilaag sterk gehinderd. In hoofdstuk 3 wordt aangetoond dat fosfolipide bilagen die zich in de wloeibaar kristallijne fase bevinden de stolling veel beter bevorderen dan billagen die $z$ ich in de zgn. vaste fase bevinden.

Prothrombine wordt geaktiveerd door het enzym faktor $x_{a}$. Reeds lang was bekend dat deze reaktie enorm gestimuleerd wordt door CaCl $2^{\text {" fos- }}$ folipiden en een eiwit co-faktor. faktor $V_{a}$. In hoofdstik a worden experimenten beschreven die aantonen dat deze stimulering veroorzakt wordt door belangrijke verandertngen in de kinetische parameters van prothrombline aktivering. Fosfollpiden stimulexen de reaktie doordat de $\mathrm{K}_{\mathrm{m}}$ voor het substrat prothrombine verlaagd wordt tot een niveau dat ongeveer gelijk is aan de plasma concentratie van prothrombine. Faktor $v_{\text {a }}$ stimuleert de reaktie door een sterke verhoging van de $k_{c a t}$ van thrombine vorming. In hoofdstuk 5 wordt aangetoond dat fosfolipiden en faktor VII a eenzelfde effekt hebben op de aktivering van faktor $X$ door faktor $I X_{a}$.

Wanneex men de snelheden van substraatomizetting wil uitarukken in 
hoeveelheden substraat ongezet per enzym is het noodzakelijk de hoeveelheden enzym anwezig in het reaktievolume te kwantiteren. In hoofdstuk 6 wordt beschreven dat faktor IX concentraties geneten kurnen worden door het enzym te titreren met p-nitrophenyl-p"-guanidinobenzoat.

De reaktiem welke onderzocht zijn worden geacht plats te vinden op het fosfoliplde oppervlak. Om dit proces op het oppervlak te kunnen beschrjuven en begrijpen is het noodzakelijk dat de bindingskonstanten van de elwiten voor de binding aan de fosfollpide bliag bekend zijn. In hoofdstuk 7 wordt een nleuwe methode geintroduceerd voor het meter van de binding van faktor $X$ aan fosfolipide vesicles. Het voordeel van deze methode is dat ze relatlef eenvoudig is en dat de bindingskonstanten gemeten kunnen worden onder dezelfde omstandigheden als gebruikt werder in de kinetische experimenten beschreven in hoofdstuk 5 . In hoofdstuk 8 wordt een algemene kritische beschouwing gegeven van de resultater die in dit proefschrift gepresenteerd worden. 


\section{CURRCBLUM VITAE}

De schrijver van dit proefschrift werd op 2 januari 1952 geboren te Mastricht. Na het doorlopen wan de lagere school en de H.B.S.-B werd in 1969 een aanvang gemakt met de studie scheikunde aan de rijksuniwersiteit te Groningen. Het kandidaatsexamen werd in 1973 afgelega. Het doctoraalsexamen werd in 1976 afgelegd in de studierichting Fysische chemie met als bijuak Informatietheorie.

Varaf 1 mei 1977 is de schrijver werkzaam aan de Rijksuniversiteit Limburg te Mastricht bij de capaciteitsgroep Biochemie. 